\title{
MiNisialen:
}

2.4

\section{HNSTMUTION PTOLOUE}

行 
\% 


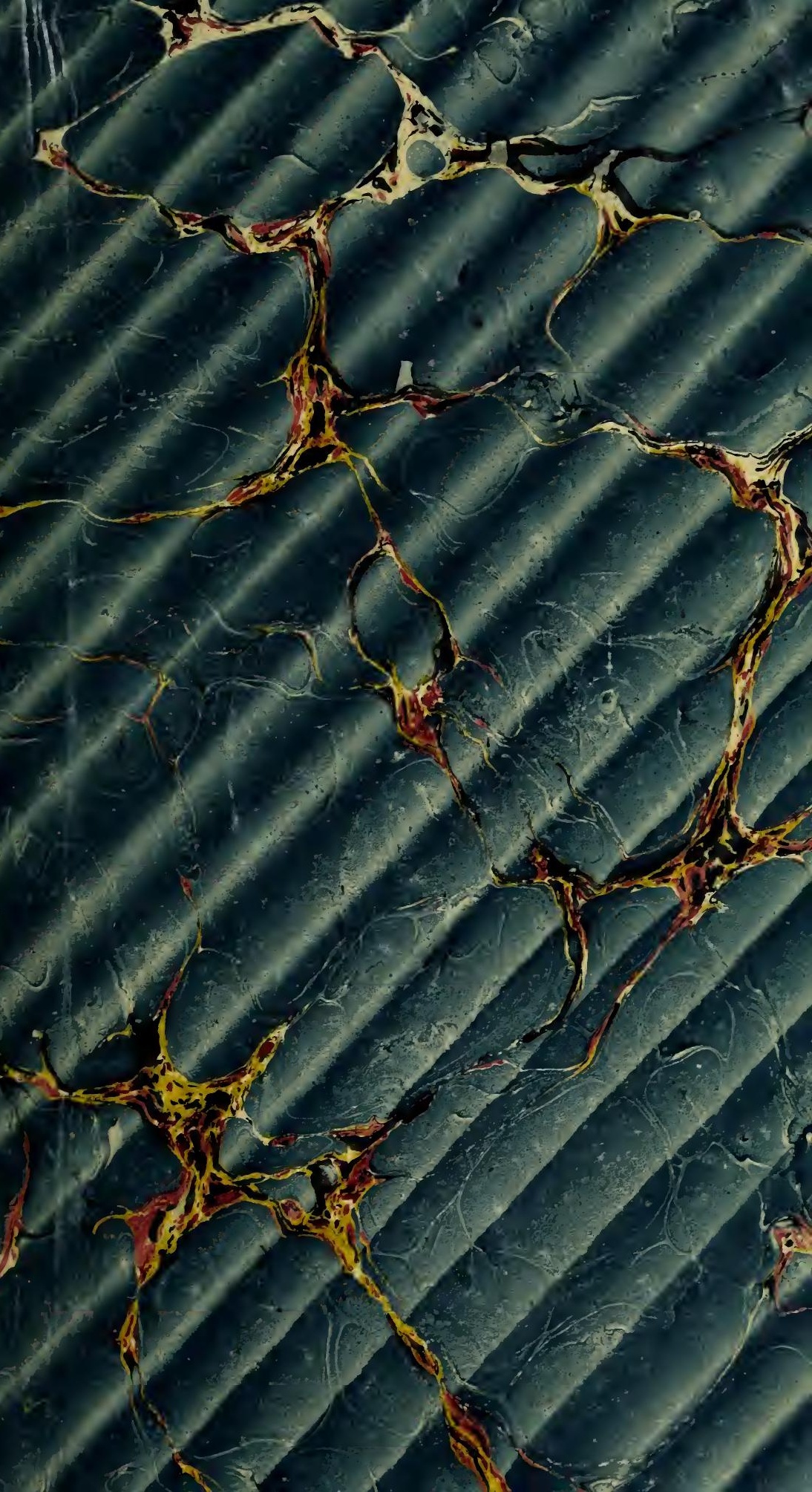





\section{LES INSECTES}

C OXSI DÉ liÉs

COMME NUISIBLES A L'AGRICULTURE 
$5 B 93$ $M 4$ 


\section{ERNEST MENAULT}

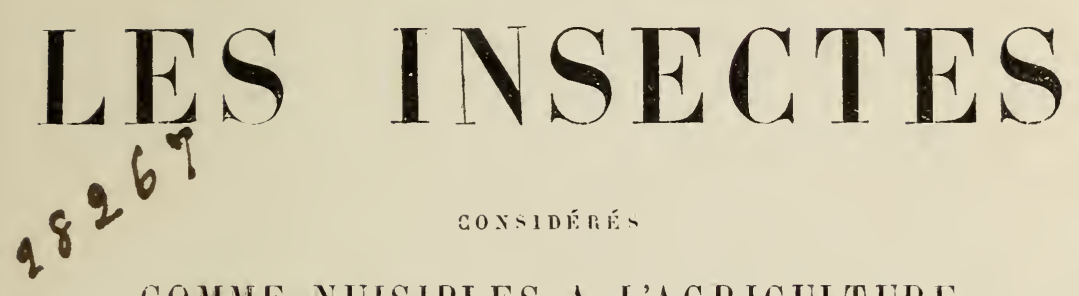

COMUE NUISIBLES A LAGRICULTURE

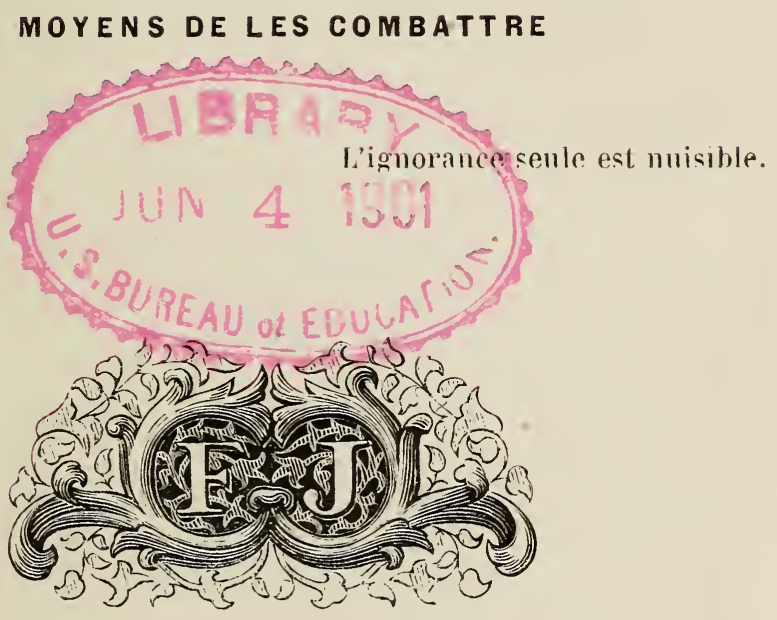

PARIS

FIRYE, JOIVET ET CIE, ÉDITEURS RTE S IIST-INDRE-DES-IRT<, \& 


\section{By Tranafer \\ iv 16 iy 25}

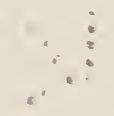




\section{MONSIEUR JANNAIRE}

PROPRIÉTAIRE-CULTIVATELR A BALCHERY

(SEINF-FT-VARME)

Hor mage de respect et d'affection,

ERYEST IEXALT. 



\section{IVIDT-PROPOS}

Plusieurs ourrages sur les Insectes nuisibles à l'agriculture ont été publiés dans ces derniers temps. Nous citerons d'abord celui de II. Goureau, qui est un bon livre fait avec une grande conscience, et dans lequel l'auteur a consigné des observations originales pleines d'intérêt, mais dont les descriptions sont peut-être trop scientifiques. Le petit traité de M. Isabeau s'adresse aux enfants. L'Entomologie ayricole de M. Gobin est une causerie spirituelle. Ces ouvrages ne sont pas spécialement consacrés aux Insectes nuisibles à l'agriculture, ils ont le grand inconvénient de ne pas domner l'image des insectes dont il est question. Convaincu que la vue d un insecte reste plus dans la mémoire que la meilleure description qu'on en puisse faire, nous avons cru qu'il y avail 
une lacune à combler dans l'enseignement de l'entomologie agricole. Nous avons, dans notre ouvrage, représenté les insectes que nous avons décrits. De plus, M. Vasseur, préparateur-naturaliste, rue de l'École-de-Médecine à Paris, a bien voulu former des collections pour les personnes qui désireraient avoir ces insectes en nalure. Puissions-nous avec ces moyens et les efforts que nous avons faits pour réunir lous les matériaux relatifs à nolre sujet avoir réussi à donner aux cultivateurs un livre utile et avoir un peu mérité les encouragements que nous ont valu quelques articles sur ce sujet publiés dans le Moniteur du soir. Nous devons à ces encouragements lidée de notre petit ouvrage qui n'a d'autre prétention que de présenter un résumé des excellents mémoires de MM. Blanchard, Guérin, Meneviile, Herpin, Huzard, etc.

Angerville, mai 1866. 


\section{DESGRIPTION SOMIIAIRE D' UN INSEGTE}

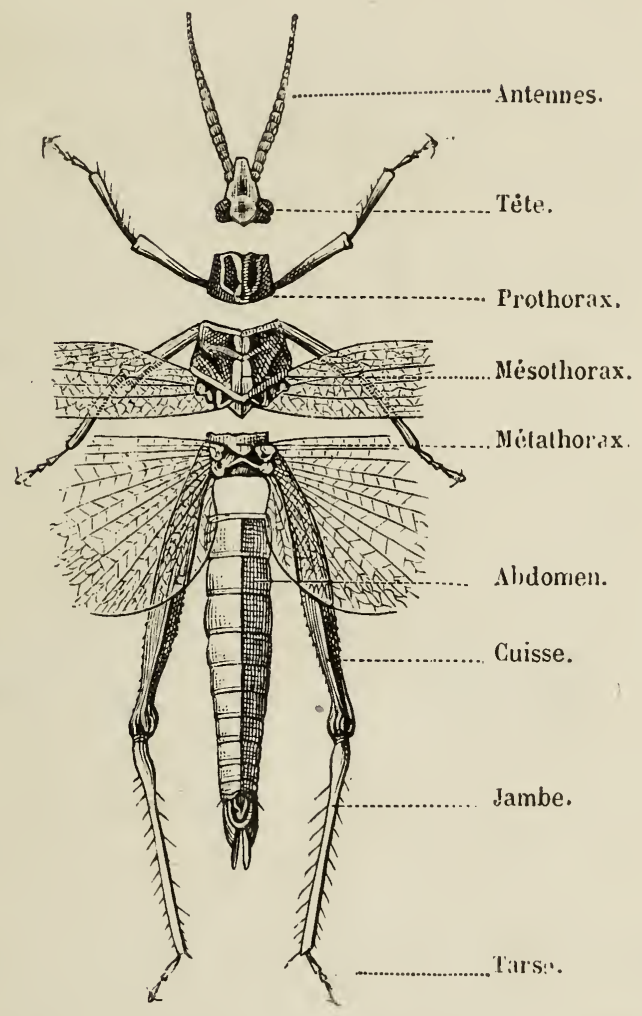

Fig. 1. - Description d'un insecte

La tète est une des parties les plus compliquées d'un insecte. On y remarque les antemnes, les yeux et la bouche; cette dernière se compose de six pièces principales :

$1^{\circ}$ Quatre latérales disposées par paires et se mouvant 
transversalement. Les deux supérieures se nomment mandibules, et les deux inférieures mâchoires ; on trouve sur chacune de ces màchoires un ou deux petits filets articulés : ce sont les palpes ou antennules.

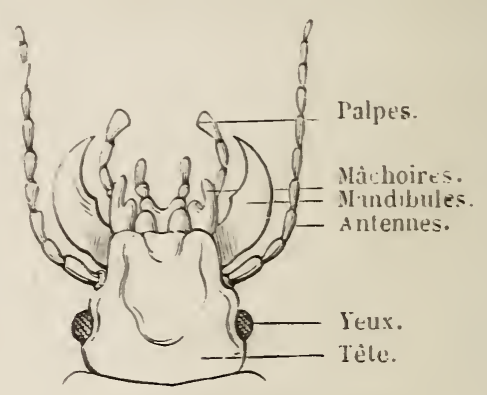

Fig. 2.

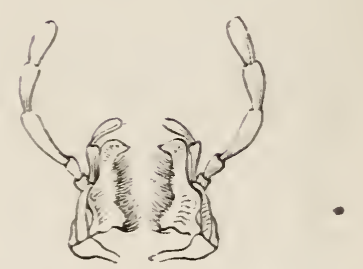

Fig. 5. - Màchoires portant ses palpes.

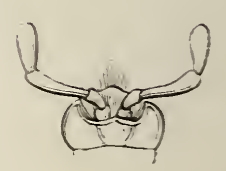

Fị̆. 4. - Lèvre inférieure avec ses palpes.

20 Deux autres pièces transiersales, opposées et pla. cées, l'une au-dessus des deux mandibules qu'on appelle labre ou lèrre supérieure; l'autre, au-dessous des màchoires, c’est la levre inférieure, composée de deux parties bien distinctes : le menton et la languette.

Les ailes des insectes méritent aussi d'ètre étudiées. Quelquefois elles sont au nombre de deux, et, dans ce cas, 
elles sont toujours membraneuses, comme, par exemple, celles d'une mouche; les insectes qui n'en ont que deux se nomment diptères. Au-dessous des ailes, près de l'insertion, on remarque un petit filet mobile, terminé en massue, auquel on a donné le nom de balancier; au-dessus est une petite écaille membraneuse, formée de deux pièces réunies par un de leurs bords et représentant assez bien les deux valves d'une coquille. Cette pièce se nomme le cucilleron ou l'aileron : beaucoup d'insectes ont quatre ailes. Chez les uns, elles sont toutes quatre membraneuses, comme dans les demoiselles; chez d'autres, par exemple les papillons, elles sont recouvertes d'une poussière farineuse, toujours colorée des plus brillantes teintes. Cette poussière, vue à la loupe, n'est rien autre chose qu'un nombre prodigieux de petites écailles de formes rariées, toujours régulières et placées en recouvrement, avec beaucoup de symétrie, sur la membrane transparente de l'aile. D'autres insectes, comme le hanneton ou le cerf-rolant, ont aussi quatre ailes, mais de consistance tout à fait différente; celles de dessus sont formées d'une substance ferme ou mème dure, plus ou moins cornée, opaque; elles ont, quand elles sont fermées, la forme d'un demi-étui dans lequel la moitić supérieure du corps de l'animal serait enchâssée : ce sont les élytres, et l'insecte qui en est pourvu porte le nom de coléoptère. Sous ces élytres sont cachées des ailes membraneuses repliées transver'salement pendant le repos.

II arrive quelquefois que ces ailes supérieures ne sonlt de substance ferme et écailleuse que dans la moitié supé= 
rieure de leur longueur, et que le reste est membraneux, dans ce cas, elles prennent le nom de demi-étui on hemélytre.

\section{INDICATION}

\section{DES CARACTERES DES PRINCIPAUX ORDRES D INSEGTES}

Les insectes que nous allons étudier appartiennent aux ordres suivants : coléoptères, hémiptères, hỵménoptères, diptères, orthoptères et lépidoptères.

\section{COLÉOPTÈRES}

Le mot coléoptère, tirẻ du grec, veut dire littéralement : ailes renfermées dans un étui. Les caractères des insectes de cet ordre sont : ailes antérieures ou supérieures crustacées, ne se croisant jamais; ailes postérieures ou inférieures, membraneuses, offrant des nervures rameuses et se repliant sous les premières (élyttres); bouche munie de mandibules, màchoires et lévres libres, propres à triturer les corps solides. Le Carabe, le Hanneton, le Charançon sont des coléoptères.

\section{HÉMIPTĖRES}

Le mot hémiptère veut dire : ailes demi-coriaces et demi-membraneuses; les antérieures sont, en effet, souvent cornées dans leur moitie antérieure; bouche composée de pièces soudées entre elles de manière à constituer un su- 
coir; les mandibules, les mâchoires, la lèvre inférieure qui leur sert de gaine, et la lèrre supérieure qui la protége en dessus, ayant la forme de soies grêles.

Exemple: les Pucerons, les Thrips.

\section{HYMÉNOPTĖRES}

On appelle hyménoptères rles insectes qui ont des ailes membraneuses. Leurs caractères sont :

Ailes croisées horizontalement sur le corps, entièrement membraneuses, et pourvues de nervures sans réticulations; trois ocelles ou yeux ronds sur le front; bouche composée de deux mandibules cornées, de mâchoires et de lèvres phıs ou moins allongées et propres à sucer.

Exemples : l'Abeille, l'Ichneumon.

\section{DIPTÈRES}

Les diptères sont des insectes qui n'ont que deux ailes. Leurs caractères sont :

Ailes antérieures grandes, veinées; les postérieures, très-rudimentaires, réduites à la forme de simples petits balanciers ; bouche composée de pièces soudées entre elles, constituant un bec.

Exemple : la Mouche.

\section{- ORTHOPTÉRES}

Les orthoptères constituent un ordre d'insectes comprenant ceux dont les ailes sont pliées longitudinalement. 
Leurs caractères sont :

Ailes antérieures semi-cornées, croisées ordinairement l'une sur l'autre; les postérieures, membraneuses, trèsveinées et pliées longitudinalement en éventail pendant le repos; bouche composée de pièces libres, comme dans les coléoptères.

Exemple : la Sauterelle.

\section{LÉPIDOPTÈRES}

Les lépidoptères sont des insectes dont les ailes membraneuses sont courertes de petites écailles, semblables à une fine poussière; bouche composée de màchoires et de lères allongées et soudées ensemble, de manière à constituer une trompe; les mandibules très-rudimentaires.

Exeniple: les Papillons.

\section{MÉTAMORPHOSES DES INSECTES}

Parmi les insectes, lorsque le mâle a fécondé sa femelle par l'accouplement, il meurt, et celle-ci après aroir pondu ses œufs dans le lieu le plus favorable à l'éducation des petits êtres qui en sortiront, ne tarde pas non plus à périr. L'œuf éclot, mais le pelit qui en sort n'a aucune ressemblance, aucume analogie de forme avec ses parents, c'est un rer mou, allongé, sans ailes, que l'on nomme chenille, quand ses parents sont des Papillons, et larve pour tous les atres insectes. L'insecte passe dans ce premier état la plus grande partie de sa vie, et c'est alors seulement qu'il prend de l'accroissement; il change plusieurs 
fois de peau, puis, dans un lieu retiré qu'il se choisit à l'abri de tout danger, il quitte sa forme de larve ou de chenille et se métamorphose en chrysalide, s'il doit être Papillon, ou en nymphe s'il appartient à une autre classe. Cette nymphe est de forme oblongue, sans membres distincts, souvent enveloppée dans une coque de soie ou de terre, sans aucun mouvement, et ayant toute l'apparence de la mort et du desséchement. Après un temps plus ou moins long, la nymphe ou la chrysalide se fend et il en sort un insecte parfait, capable au bout de quelques heures de reproduire son espèce.

Quelques insectes cependant, mais en très-petit nombre, font exception à cette loi de métamorphose, et sortent de l'œuf tels qu'ils seront toujours; chez d'autres, la nymphe ne diffère de l'ètat parfait que par l'absence de quelques parties et notamment des ailes dont elle n'a que les rudiments. 



\section{COLÉOPTĖRES}

\section{CHARANCSON DU BLE}

(Sitophilus granarius, curculio).

Synonymie : Ruyxcépiluhe. - Porte-bec. - Calandre cosson ou goussox.

...Populatque ingertem farris acervum Curculio... Georg., lib. I.

Le Charancon ravage un vaste tas de blé.

Le Charançon est un coléoptère de la famille des curculioniens. Ces insectes se reconnaissent aisément à leur tête prolongée en museau ou en trompe, à leur bouche toute rudimentaire, à leurs antennes souvent coudées après le premier article.

Les curculioniens ont reçu le nom vulgaire de charançons et celui de ryncéphores à raison de la conformation particulière de leur tête. Si l'on en croit Varron, l'agriculteur romain, le nom latin curculio du charancon s'écrivait d'abord gurgulio et signifiait grand gosier ou grand mangeur. 
Les curculioniens vivent exclusivement de matières végétales; leurs larres sont privées de pattes, re consistance charnue, et plus épaisses antérieurement que ver's l'extrémité, arec une tête très-petite; elles vivent dans l'intérieur des régétaux, soit dans les tiges, les troncs ou dans les graines.

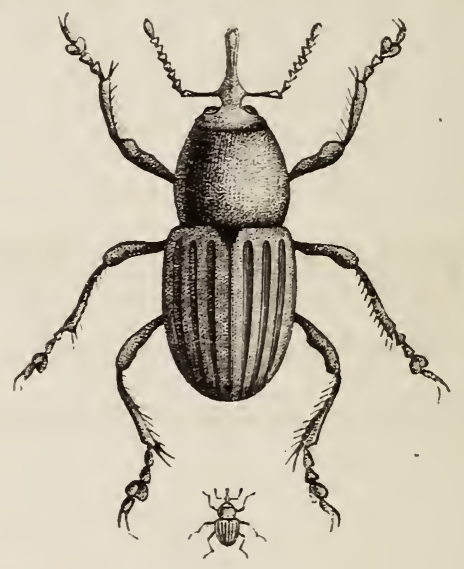

5. - Charançon du hlé, grossi et de grandeur naturelle.

II. Émile Blanchard classe le charançon du blé dans le groupe des calandrites, insectes dont les antennes n'ont pas plus de six articles avant la massue. Les caractères spéciaux qui font distinguer le Charançon sont d'abord: l'abdomen dont l'extrémité est à découvert, puis les antennes courlées qui sont armées d'une massue plus ou moins comprimée.

Lorsqu'on regarde un Charançon, on voit un petit insecte d'un brun plus ou moins foncé qui arec sa trompe, a troịs millịmètres de longueur, son corselet a la même 
étendue que les élytres et forme à peu près la moitié du corps.

Les élytres ne sont guère plus larges que le corselet, un peu arrondies à leur extrémité et présentant des rainures longitudinales dans toute leur étendue.

Les Charançons causent de grands rarages dans les greniers. Nais ne croyez pas qu'on les y rencontre à toutes les époques de l'année. En hiver, vous avez beau les chercher, vous ne les trouverez pas. C'est vers la fin d'avril qu au commencement de mai, dès les premières chaleurs du printemps, qu'on les roit apparaitre sur les sacs de blé ou qu'on les trouve dans les fentes du plancher. Alors commence la fécondlation qui n'aurait pas lieu s'il faisait plus froid, si, par exemple, la température était abaissée de 8 ou 9 degrés du thermomètre de Réaumur. La femelle, après aroir été fécondée, entre dans un tas de blé, y pénètre à 5 ou 6 centimètres de profondeur pour y ètre tranquille, puis elle choisit le grain dans lequel elle veut pondre son œuf, et, à l'aide de sa trompe et de ses dents, elle y fait un petit trou, ordinairement dans le sillon où l'enveloppe est le plus tendre. Lit, comme si elle voulait mieux cacher l'endroit où elle ra déposer son œuf, elle dirige ce petit conduit obliquement et le bouche avec un enduit de la couleur même de la semence attaquée, de sorte que l'œil le plus exercé n'en saurait décourrir le trou.

Elle attaque ainsi une quantıté de grains ègale à la quantité d'œufs qu'elle doit pondre.

L'œuf déposé dans le grain ne tarde poịnt à éclore : il en provient une petite larre, blanche, allongée, molle, ayant 
le corps formé de neuf anneaux, avec une tête arrondie de consistance cornée, munie de deux fortes mandibules, au moyen desquelles elle agrandit chaque jour sa demeure, en se nourrissant de la substance farineuse dont est composé son berceau. Parvenue au terme de son accroissement, elle est alors longue de $\mathbf{3}$ millimètres environ, elle se métamorphose en nymphe, sommeille dans cet état durant huit ou dix jours, et se transforme enfin en une nouvelle calandre, capable de perpétuer la race destructrice, après avoir brisé l'enveloppe qui la tenait enfermée, comme le poulet brise la coque de l'œuf où s'organise sa vivante machine. La durée des métamorphoses de la calandre est subordonnée au degré de la température atmosphérique, la chaleur l'accélérant et le froid la retardant beaucoup; en terme moyen à compter du dépôt de l'œuf jusqu'à l'émancipation de la calandre, on l'évalue de quarante à quarante-cinq jours. Bory de Saint-Vincent dit que, selon le calcul de Déjeer, une seule mère peut, dans le cours d'une année, produire 23,600 individus, résultat effrayant; d'autres naturalistes restreignent cette fécondité à 6000 environ. Ce dernier chiffre suffit à lui seul pour justifier les craintes du cultivateur à l'égard de cet insecte.

Le grain rongé à l'intérieur par la larve du Charançon n'est nullement altéré dans sa forme ni dans sa couleur, il est même impossible de le distinguer du grain non attaqué; mais si on le jette dans l'eau, il surnage, tandis que le blé sain se précipite au fond du liquide.

Les Charançons mâles rivent à peine quelques jours après la fécondation. La femelle prolonge son existence jusqu'à la fin de la ponte, et, comme elle a beaucoup 
d'œufs à pondre, elle vit plus longtemps. Quand le grain lui manque pour pondre, elle tombe dans un état d'engourdissement qui n'est pas la mort et qu'elle préroit sans doute, car elle choisit une retraite pour s'engourdir. Le voisinage du grain, dont l'odorat l'avertit probablement, la réveille; elle pond, puis elle meurt.

C'est donc surtout à l'état de larve que le Charançon cause le plus de dégàts ; à l'état parfait ne rongent le blè que ceux qui n'ont pas accompli l'acte de la fécondation qui a lieu pendant toute la belle saison, jusqu'à ce que le froid ôte à l'insecte l'activité nécessaire à la propagation de son espèce. Alors, il quitte les tas de blé et va chercher un gite soit dans les trous de murs ou les fentes du plancher, où il est difficile de le trouver; et, dès les premières chaleurs du printemps, il apparait, s'accouple, se reproduit et meurt.

ll y a un instinct merveilleux dans cet insecte qui doit mourir immédiatement après avoir produit, et qui ne dépose ses œufs que dans l'endroit où les larves pourront se nourrir. Cette prévoyance de la postérité est remarquable chez les coléoptères. Le IIanneton, qui ne mange que des feuilles et des semences d'orme, ne pourrait vivre de racines; sa femelle enterre ses œufs pour qu'au moment de leur naissance les larves soient à portée des racines dont elles se nourrissent. D'autres femelles de coléoptères entassent des provisions autour de leurs oufs pour l'usage d'une postérité qu'elles ne comnaitront pas, car elles meurent avant la naissance de leurs larves. L'instinct dit à la femelle de l'insecte où elle doit pondre et comment elle doit assurer l'existence desa postérité, sans qu'on 
puisse dire si elle se souvient de ce qu'elle a mangé étant elle-mème à l'état de larve.

\section{MOYENS DE DESTRUCTION}

Après aroir signalé les dommages causés par les Charançons, nous sommes naturellement conduit à indiquer les moyens employés contre ces insectes nuisibles. Ils sont de plusieurs sortes : les uns, les premiers que nous domnerons, sont tirés du règne végètal; certaines plantes, telles que la fleur du houblon, celle du sureau, l'absinthẹ, la rue, l'aurone, lâ sarriette, la fougère, la lavande, la nielle et la coriandre, en un mot presque toutes les plantes à odeur pénẹtrante, ont, dit-on, la proprièté sinon de toujours faire mourir les Charançons, au moins de les èloigner. La décoction de ces plantes, comme aussi celle du lierre, du buis, du pied d'alouette, répandue dans les greniers, produit le mème effet.

La Gazette d'agriculture a vanté autrefois la recette suivante : On remplit un grand chaudron de feuilles de persicaire, on met sur les feuilles une livre et demie de sel marin, deux ou trois gousses d'ail et environ un bon seau d'eau. On fait bouillir le tout ensemble et on arrose avec cette décoction le plancher du grenier, les murs et les tas de blé, sans les remuer; cette aspersion, dit-on, est à peine faite que le Charancon quitte arec précipitation les tas de blé, et lorsqu'il passe sur les endroits arrosés, il périt en devenant rouge comme une écrevisse cuite, 
La Gazette d'agriculture conseillait aussi autrefois de faire bouillir une certaine quantité de cornes de mulets et de vieux souliers pour empester les insectes. Jans le Midi on emploie les bergeromettes pour détruire les charancons. Vingt bergeronmettes enfermées dans un grenier suffisent, dit-on, pour sauver la récolte.

Le Journal de la nature considérée, année 1778, rapporte que le domestique de M. de Brosses, premier président du parlement de Dijon, sauva les récoltes de son maître en jetant sur le blé des écrevisses vivantes. Les Charançons se mirent à fuir presque aussitôt et se retirèrent en masse sur les murs, où il fut facile de les exterminer.

Au lieu d'ècrevisses, qui peuvent être employées plus utilement, on peut, quand les greniers sont vides, y rípandre des Fourmis; ces insectes livrent des batailles terribles aux Charancons, qu'ils dètruisent et dévorent entièrement.

On peut encore prendre les Charancons par la gourmandise. Vers la fin de septembre, à l'époque où les noix sont mûres, on dépose une grande quantité d'écorece de ces fruits dans les greniers; les Charançons ne tardent pas à quitter le blé, pour venir se jeter dessus, où ils meurent empoisommés.

Si l'on en croit Valmont de Bomare, tous ces meyens sont insuffisants ou impraticables. L'expérience faite par fluhamel de renfermer du blé attaqué par les Charancons dans une caisse vernissée d'huile de térébenthine, où les Charançons ont très-bien vécu, donne lieu, dit-il, de se méfier de cesprétendus moyens de les faire périr ou de les chasser arec des décoctions d'ail ou d'autres plantes d'une odemr 
forte et désagréable. Selon ce naturaliste, la seule vapenr de soufre les fait périr, mais communique au blé une odeur désagréable.

L'usage ordinaire, qui ne fait, dit-il, que diminuer le mal sans le détruire dans ses sources, est de remuer le blé fréquemment, de le cribler et de le passer sur un grillage de fil de fer en plan incliné, dont les fils sont assez serrés pour que le bon grain ne fasse que glisser dessus, tandis que le grain rermoulu et les Charançons passant entre les fils, sont reçus dans une poche de peau, et se trouvent ainsi séparés d'arec les bons grains.

Dans quelques provinces, on mêle des grains de millet arec les blés, parce qu'on a remarqué que les Charançons s'atlachent de préférence à ces grains. Au bout d'un certain temps, on prend un crible fait exprès, à travers lequel passent la poussière et le millet.

Les bons effets de la méthode du pelletage, qui est encore aujourd'hui la plus employeee, reposent sur ce fait que les insectes aiment la tranquillité. Dès le moindre bruit. ils percent les grains où ils ont pris naissance, et s'en ront chercher domicile ailleurs; ennemis de la lumière, ils aiment cependant la chaleur, et préfèrent habiter au midi, mais dans l'endroit du grenier le plus abrité, le plus reculé, le plus obscur. C'est pourquoi les Charançons se plaisent dans le blé, pour y faire leur ponte et s'en nourrir. La petitesse des grains constitue entre eux un rapprochement très-serré qui forme un obstacle impénétrable à la lumière.

Le savant agronome Duhamel du Ionceau avait imaginé une sorte de machine qu il appelait un grenier de conser- 
vation, qui a pour but de renfermer une très-grande quantité de froment dans le plus petit espace possible, afin d'empêcher qu'il ne fermente, qu'il ne s'y échauffe, et qu'il n'y contracte de mauvais goût; de le garantir des rats, des souris, des oiseaux, sans l'exposer à être endommagé par les chats; de le préserver aussi des Mites, des Teignes, des Charançons et de toute espèce d'insectes, et de le conserver indéfiniment sans frais et sans embarras. Le lecteur qui voudra avoir des renseignements complets sur le système de Duhamel devra lire son traité de la Conservation des grains. Voici en résumé en quoi il consiste : on a une double caisse dont le fond est en crin, le couvercle percé. Au fond de la caisse extérieure s'adaptent des soufflets; l'air, poussé vivement dans l'espace qui se trouve entre les deux fonds, traverse rapidement le grain, se charge de l'humidité, et sort par des ouvertures pratiquées au couvercle supérieur.

Comme dans tous les pays du Nord, les blés sont toujours humides, Duhamel conseille, avant de venter le grain dans le grenier de conservation, de le nettoyer et de le faire passer à l'étuve.

Un procédé qui se rapproche de celui de Duhamel, et que le Journal économique de 1752 (mois de novembre) a décrit, consiste à faire construire en lieu sec un bâtiment de forme circulaire, pouvant contenir toute la récolte d'une bonne année.

Ce mur en pierres de taille, briques ou mocllons unis avec un mortier de chaux et sable, devra avoir au moins deux pieds d'épaisseur. On n'y percera aucune ouverture; il sera élevé au-dessus du rez-de-chaussée de neuf à dix 
pieds avec un entablement ou corniche fort saillant. Le plancher, établi à trois ou quatre pieds au-dessus du sol, sera soutenu de bomnes solives bien étayées par le bas, soit par des piliers de pierre ou de bois debout. "Ne rous servez que de planches de chêne d'un pouce et demi d'èpaisseur, double joint, bien clouées; après quoi, dans les intervalles des solives, faites à ces planches des trous de tarière de deux pouces de diamètre qui percent le plancher d'outre en outre. Ayez soin que les trous soient près les uns des autres, également distants et disposés en échiquier ou en quinconce. ILes trous seront couverts de petites plaques de fer-blanc, percées comme une râpe à tabac et clouées au plancher, afin qu'elles ne se dérangent point. On pourra mettre sur ce plancher du blé ou tout autre espèce de grains à la hauteur de douze pieds et plus sans avoir peur qu'il ne s'échauffe; mais aussi aura-t-on soin audessus du toit qui est percé de lucarnes, d'établir un moulin à vent qui mettra en mouvement un ventilateur qui prendra le vent extérieur et le chassera par un tuyau de planches ou de fer-blanc ru diamètre de huit ou neuf pouces. Ce tuyau sera toujours proportionné à la grandeur du diamètre du bâtiment, et aura un demi-pouce pour un pied du diamètre du plancher; il sera introduit dans la cave qui est sous le plancher, et l'air extérieur comprimera ainsi celui de la cave et l'obligera par conséquent de passer par les petits trous de fer-blanc et dans tous les interstices qui se trouvent entre les grains de froment. L'air étant renouvelé de la sorte par le mourement continuel du ventilateur, le blé s'en trouvera rafraichi, ce qui empêchera les œufs des Charançons d'y éclore. On laisse le blé passer ainsi 
I'hiver, on le tire ensuite pour le mettre dans un lien sec et clos, et on peut par ce moyen le conserver pendant un siècle. ")

Telle est la méthode employée contre les Charançons, décrite par I. de Plombange, dans le Journal économique. On rerra plus tard pourquoi nous avons tenu à reproduire en entier ce procédé.

M. Doyère, qui a chez nous remis en houneur le procédé de conservation par l'ensilage, croit que le système d'aération n'empêche pas la fermentation des grains humides, par conséquent les déchets et l'altération qui en sont l'effet inévitable. Pour lui, les greniers ventilateurs dérivent tous plus ou moins immédiatement du pelletage, et reposent sur ce principe, que le pelletage, ou senlement l'une de ses parties, l'aérage, portés à leur maximum d'effet, seraient des moyens parfaits, absolus, de conserver les grains. Il est évident qu'en faisant pelleter continuellement les blés, on les conserve mieux et plus longtemps qu'en les laissant en repos. On sait aussi que passé un certain point, il est inutile de multiplier les pelletages. L'action de l'air a cet inconvénient que si l'on prend de l'air hors du magasin pour le mettre en contact arec une masse de grains, tout ce qu'on peut obtenir, c'est de mettre cette masse en équilibre de température arec l'atmosphère extérieure. Et comme c'est pendant le jour que les rentilations ont lieu, cet état d'équilibre ne sera même pas celui de la température moyenne, il lui sera supérieur de plusieurs degrés. En sorte qu'en réalité, au lieu de rafraichir les grains on les échauffe, on les met dans les conditions de fermentation. 
Non-seulement l'aérage échauffe les grains, mais il n'a aucume propriété desséchante, car le blé est une substance très-hygrométrique, c'est-à-dire très-impressionnableà l'humidité ou à la sécheresse; exposé à l'air, il perd de l'eau, s'il est plus humide que l'atmosphère; en prend s'il est plus sec; en sorte que la ventilation ne devra être employée qu'arec connaissance de cause. Alors on pourra rendre humides les blés secs, et sécher les blés humides. Pour cela il faut savoir que ce que l'on appelle un temps sec n'est pas toujours, à beaucoup près, un temps où il y a très-peu d'eau dans l'atmosphère. La sécheresse et l'humidité atmosphériques se compliquent de la température et de l'air qui, pris sec extérieurement à midi par 25 degrés centigrades, sera de l'air humide après avoir été introduit dans l'intérieur d'une masse de grains offrant seulement 7 ou 8 degrés de moins. Il n'en sortira qu'après y avoir déposé une quantité d'eau plus ou moins forte suivant l'ètat du blé lui-même.

Il ne faut donc pas croire que l'air, en traversant une masse de grains ; se charge d'humidité pour l'entraîner au dehors.

L'air est déjà plus ou moins chargé d'humidité; il n'en peut comporter tout au plus qu'un certain excès, et cet excès est généralement très-faible. Le blè, en effet, ne se comporte pas avec l'eau, comme le ferait le sable mouillé. Il la retient par une force spéciale, par une certaine affinité; c'est le caractère de toutes les substances hygrométriques.

La surface du grain seule, même lor'squ'il est fortement mouillé, abandonne l'eau avec facilité, après quoi la ven- 
tilation ne peut plus avoir qu'un effet presque nul. Aussi, M. Doyère, sans nier absolument que, placé dans de bonnes conditions, on n'ait pu obtenir des résultats avantageux par l'aérage; préfère-t-il le système de l'ensilage rationnel qui consiste à ne conserver que des grains secs, et à les renfermer dans des vases imperméables hermétiquement clos et souterrains. Là, plus de conditions inconnues et variables, plus d'action de l'air, principe de toute fermentation, et partant, plus de déchets en poids ni d'altération, plus de manipulations, plus de travaux, plus de frais de conservation proprement dits, et des frais de premier établissement au-dessous de ceux qu'exigent les greniers les plus avantageux sous ce rapport.

Le système qui réunit tous ces avantages consiste dans des enveloppes en tôle très-mince préservés extérieurement contre l'oxydation ou la rouille par un revêtement inattaquable et comme noyés dans une maconnerie en béton qui porte toutes les charges. La tòle n'a d'autre rôle que celui d'un rernis imperméable et indestructible où le blé se conservera presque indéfiniment, surtout si l'on a soin préalablement de lui donner le degré de sécheresse nécessaire en l'exposant au soleil, en lui enlevant son humidité par la dessiccation artificielle au moyen de l'étuvage, qui est aussi un procédé excellent pour la destruction des insectes. La chaleur, dans ce cas, n'aura aucun effet nuisible si elle est employée au-dessous de 65 degr'és.

L'ensilage rationnel de M. Doyère s'appuie entièrement sur le système de conservation souterraine des Romains et des Maures, approprié à nos blès et à nos climats.

Pendant longtemps on a eu l'habitude à Velz de con- 
server le blé dans des magasins souterrains, en ayant soin de le couvrir de chaux. La couche la plus superficielle du blé germe et pousse une tige qui meurt l'hiver. Après cela on est sûr que le tas de blé se conservera. On rapporte que dans la citadelle de Metz on a gardé pendant cent trente-deux ans du blé qui n'avait subi aucune altération. En Afrique, en Ukraine et dans le grand-duché de Lithuanie, on conserve les grains dans des puits très-profonds. Deslandes, dans son Traitésur la manière de conserver les grains, a décrit ce procédé.

Ce qui distingue l'ensilage de tous les autres modes de conservation, c'est qu'il met les grains en situation de ne s'élever jamais au-dessus de 15 ou 16 degrés centigrades, et qu'il les soustrait à l'action de l'oxygène, lequel, suivant M. Doyère, n'agit pas seulement par une impulsion première et comme principe primitif de leurs fermentations, mais, de plus, renouvelle, active et multiplie ces fermentations en se renouvelant lui-même dans la masse des grains. Dans l'ensilage il y a donc une perte de qualité insensible, et par suite une dépréciation faible ou même nuille; la suppression de tout déchet et de tout frais de main-d'œurre; le capital de premier établissement comparé all grenier est moindre, voilà ce qui recommande le silo comme grenier temporaire. De plus, la réduction sur les frais d'assurance, car on ne roit pas contre quels dangers les blés en silos pourraient avoir besoin d'être assurés, une fois reconnu quils ne courent pas celui de se gâter: Ils sont à l'abri rle l’incendic, à l'abri des animaux; à l'abri du rol, à l'abri des bombes de l'ennemi dans une place assiégée. La réserve est logée comme le festin de la cigogne. 
Nous avons exposé tous les avantages que M. Doyère altribuait à l'ensilage. Examinons maintenant si ces avantages sont rraiment aussi positifs que l'auteur se l'était imag̈iné. Le silo, nous le sarons, est un appareil ou réservoir souterrain dans lequel on conserve le blé sec, a l'abri du contact de l'air et de la lumière, dans une atmosphère désoxygénée (azote, acide carbonique), à une basse température et dans les conditions propres à empêcher les fermentations et les réactions des éléments du grain, à suspendre ou anéantir la vie chez les animaux et les insectes destructeurs. Nul doute qu'en certains pays, dans le midi de l'Europe par exemple, on ne puisse conserver des grains par ce procédé; néanmoins, en France, les tentatives.faites à ce sujet ont répondu très-imparfaitement aux expériences de leurs auteurs, parce que toujours le blé a èté trouvé avarié, moisi et altéré par l'effet de l'humidité. Le docteur Herpin, dans un excellent mémoire présenté à l'Académie des sciences (séance du 5 mars 185̌6), a parfaitement démontré que l'obstacle principal à la conservation vient de la nature même et de la qualité de nos blés français, de leur composition chimique, en un mot de la trop grande proportion d'eau qu'ils contiennent naturellement, et qu'ils conservent même après avoir été séchès à l'air ou au soleil. Tandis que les blés d'Afrique, d'Espagne, etc., ne renferment que 8 à 10 pour 100 de leur poids d'eau, nos blés de France, même lorsqu'ils sont bien secs (commercialement parlant), conservent encore une proportion d'eau qui est double de celle des premier's, 15 a 20 pour 100 et au delà. Or cette forte proportion d'eau, cette humidıté inhérente à nos blés, est la cause principale 
de leur altération lorsqu'ils sont renfermés dans les silos. Telle est l'opinion formelle dı docteur Herpin, de Metz. Lasteyrie n'a-t-il pas dit que l'humidité est le plus grand fléau des grains? Elle les échaufie et produit une fermentation qui les ararie et amène leur entière destruction.

Si l'on enlève, par une dessiccation artificielle, par l'étuvage, etc., l'eau qui est en excès dans nos blés, ceux-ci étant renfermés dans des silos souterrains ou même simplement exposés à l'air, ne tardent pas à absorber et à reprendre l'humidité qu'on leur à enlevée par l'éturage. Ainsi, du blé déposé par Ternaux dans un silo à SaintOuen s'est trouré aroir absorbé 8 à 10 kilogrammes. Le rolume dı grain avait augmenté dans la même proportion. Cela ne doit pas nous étonner, puisque du blé bien séché à l'air et au soleil, renfermé dans un flacon hermétiquement bouché, et par conséquent complétement soustrait à l'action de l'humidité extérieure, se moisit et se gàte, parce quc le blé, quoique sec à la main, ou en apparence, contient encore 1 à 20 pour 100 d'eau, quantité bien suffisante pour faroriser les fermentations et les réactions intimes des éléments chimiques du blé.

C'est une erreur assez générale et fort grave de croire que l'altération des grains dans les silos a pour cause unique l'humidite du sol, les infiltrations ou le contact de l'eau provenant de l'extérieur; lc blé s'altère par son humidité propre, à laquelle on n’a pas songé à donner une issue. Le géneral Demarçay a constaté que le blé se moisit principalement à sa partie supérieure et dans l'axe du silo; cela résulte de la condensation des rapeurs qui s'élerant du ble, viennent frapper le dessous de la voutte du silo, et 
retomber ensuite sous forme de pluie à la surface des grains.

L'humidité tant de l'extérieur que de l'intérieur, roilà, en définitive, l'obstacle qu'il s'agit de vaincre.

La construction des silos devrait présenter deux conditions auxquelles il est indispensable de satisfaire pour opérer avec succès.

$1^{\circ}$ Empêcher le contact de l'eau ou de l'humidité extérieure.

$2^{\circ}$ Donner issue à l'humidité naturelle et surabondante des grains.

Si le raisseau est exactement clos et imperméable, le blé s'y gâte par l'effet de son humidité propre qui n'a pas d'issue.

Si, au contraire, le silo est perméable à l'air et à l'humidité extérieure, le grain s y altérera par la même cause.

Pour conserver les blés dans les silos il ne suffit donc: pas de les y renfermer bien secs, mais il faut encore les prémunir contre les influences hygrométriques de l'air et du sol, enlever au grain, à l'aide de certains artifices particuliers, l'excès d'eau qu'il contient naturellement ou qu'il pourrait emprunter accidentellement aux corps arec lesquels il se troure en contact; en un mot, il faut maintenir le blé dans un état de siccité constant et suffisant pour que les fermentations et les réactions intérieures ne puissent jamais avoir lieu, conditions qui ne sont pas remplies dans le système Doyère.

Ce qui fait aussi que la conservation des blés français dans des silos souterrains exige des conditions et des précautions particulières qui ne sont pas nécessaires pour les 
blés d'Espagne et des pays chauds. Il ne nous reste plus maintenant qu'à examiner si le noureau système imaginé par M. Mlexandre Deraux peut satisfaire aux exigences que nous arons signalées. Ce système, dit grenier aérateur, rappelle celui de Plombange; il a pour but d'emmagasiner toute espece de grains, par couches verticales; il consiste à établir des cages dites aératrices, jixtaposées, pourant être construites entièrement en fer ou partie en fonte et bois, mais dont les parois doirent toujours être en fonte ou en tôle perforée. Ĺn grenier modèle a èté construit au West-India Docks à Londres; il se compose de 8 cages carrées entièrement en fer, de $12^{\mathrm{m}}, 15$ de hauteur sur $1^{\mathrm{m}}, 60$ de côté, qui contiennent chacune 550 hectolitres, et de 4 cages carrées, dont l'armature est en bois, d'une hauteur de $12^{\mathrm{m}}, 75$ sur $1^{\mathrm{m}}, 22$ de côté, chacune de 210 hectolitres, arec parois en tôle perforée.

Un autre grenier de 300,000 hectolitres est établi à Trieste; il se compose rle 474 cages carrées, entièrement en fer, de 15 $5^{\mathrm{m}}, 72$ de hauteur sur $2^{\mathrm{m}}, 204$ de côté, pouvant contenir chacune 650 hectolitres de blé. La hauteur et la largeur des cages est variable suivant les besoins et les convenances. Chacune d'elles est munie à son centre d'un tube également en tôle ou autre matière perforée, dont le diamètre varie suivant la largeur de chaque cage. Pour celles qui ont $\mathrm{I}^{\mathrm{m}}, 22$ de côté, le diamètre des tubes centraux est de $0,30 \%$. Le blé se trouve ainsi logé verticalement entre le tube central et les parois de chaque cage. $\mathrm{A}$ la base et aboutissant au tube central sont placés deux tuyaux dont l'un correspond arec l'air extérieur, el l'autre arec un ventilateur mù par un moteur quelconque. Le premier de 
ces tuyaux sert à l'aération naturelle, le second à la rentilation artificielle.

Aćration maturelle. - La couche du blé étant, comme il a été dit plus haut, verticale, se trouve en contact arec l'air anbiant: à l'extérieur des cages, par les trous de la tôle perforée des parois, et à l'intérieur par le tube central en tôle perforée au mojen du tuyau communiquant à la base avec l"intérieur. Le tube central, ouvert au sommet, ouvert aussi à la base, fait pour ainsi dire cheminée d'appel, et l'air s'y précipite arec d'autant plus de rapidité, que le blé est plus échauffé. M. Devaux assure que la couche de blé se trouvant ainsi toujours en contact, à l'intérieur et à l'extérieur, avec l'air ambiant, est maintenue par conséquent à l'abri de l'échauffement.

Ventilation artifieielle. - La ventilation artificielle est nécessaire lorsque le blé est en mauvais état et infesté d'insectes. Le tube central est à cet effet fermé au sommet, le tuyau en communication en bas du tube avec l'air extérieur est également fermé; alors l'air froid, lancé par le ventilateur dans le tube central, ne trouvant pas d'autre issue, passe par les trous de la tôle dudit tube, il traverse la couche de blé et ressort par les trous des parois de la cage. M. Devaux affirme que cette opération remet le blé en bonne condition, le débarrasse promptement des Charancons qui peuvent s'y trouver, et il ajoute que l'expirience a prouvé que le blé était amélioré.

Evidemment le Charançon qui aime la chaleur et craint le mouvement ne pourra résister au courant d'air du grand aérateur. Quant à la question si bien posée par le docteur Herpin de préserver le grain de l'humidité exté- 
rieure et intérieure, est-elle résolue? Nous pensons qu'elle peut l'ètre. Il s'agit tout simplement de faire passer à travers les grains un air assez sec, de sorte qu'en traversant les couches de grains, non-seulement cet air ne leur laisse pas d'humidité, mais que de plus il puisse au besoin se charger de celle qui en sortirait, si cela ètait possible, avec une rentilation aussi puissante. L'expérience, du reste, apprendra tous les détails dont on devra tenir compte dans les différentes saisons où la température et l'état hygrométrique de l'air subissent des variations.

Le prix d'un grenier, d'après le système Alexandre Devaux, est de $5 \mathrm{fr} .75$ à $4 \mathrm{fr}$. par hectolitre, tandis que celui d'un grenier ordinaire dépasse $8 \mathrm{fr}$. par hectolitre.

On nous pardonnera de nous être un peu étendu sur la question de la conservation des grains. Mais, comme l'a dit M. Payen, elle intéresse d'autant plus les producteurs et les consommateurs que la solution d'un problème aussi important aurait pour résultat de rendre le prix du grain beaucoup moins variable et par suite d'éviter ces brusques changements dans les achats des divers produits de nos manufactures, qui occasionnent les crises manufacturières et commerciales; elle aurait pour effet d'empêcher qu'il ne soit introduit dans la préparation du pain des farines prorenant de blés altérés et insalubres. Si donc cette solution intéresse la salubrité générale, elle n’importe pas moins à la tranquillité publique.

On sait que tous les fruits parvenus à leur maturité tendent à se décomposer. Ce dépérissement pour les grains est retardé par les soins qu'on apporte à leur conservation. Cepenpant, malgré les procédés usuels, la perte du blé 
conservé dans les greniers excède parfois 12 ou 14 pour 100 en une année.

Deux causes principales concourent à déterminer cette perte énorme $: 1^{\circ}$ les insectes; $2^{\circ}$ les moisissures et les fermentations qui se déreloppent sous l'influence de l'humidité. Pendant la saison où le thermomètre ne descend pas au-dessous de $10^{\circ}$ ou $12^{\circ}$, il suffit de douze paires de Charançons dans un hectolitre de blé pour procréer près de 75,000 individus de leur espèce, dont chacun détruit 5 grains par année pour sa subsistance, ce qui représente plus de 9 kilog. de blé pour 7 כ̆ kilog. ou 12 pour 100. Les altérations secondaires par la fermentation et les moisissures qu'occasionnent les débris des grains arariés ainsi par le Charançon augmentent beaucoup et peurent doubler cette perte directe. Ces chiffres sont bien faits, ce nous semble, pour attirer l'attention des agriculteurs.

\section{CHARANÇON DU TRĖFLE}

(Apion).

Le trèfle cultivé est attaqué sur pied, dans les champs, par une larve de la famille des Charançons qui appartient à cette grande famille de coléoptères rhynchophores ou porte-bec, qui formait seulement trois genres pour Linné. Les nombreuses espèces de cette famille, dit Guérin-Méne- 
ville, doivent jouer un rôle important dans la nature, car elles sont répandues en quantités immenses, et chaque régétal en nourrit plusieurs. Les unes à l'état de larve et d'insecte parfait, rongent les feuilles et les bourgeons; d'autres pénètrent dans les tiges et jusque dans les racines, mais le plus grand nombre s'attaque aux sources mêmes de l'existence de ces végétaux, à leurs semences qu'elles dètruisent ou rendent infécondes.

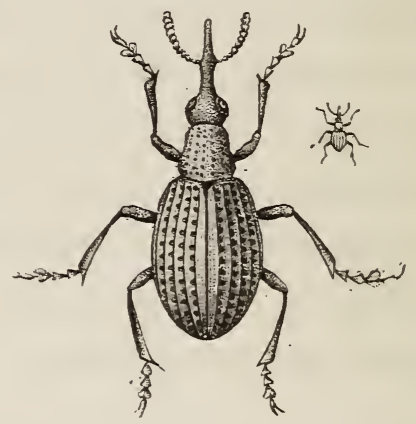

Fig. 6. - Charançon 'du trètle, grossi et de grandeur naturelle.

Les observations des naturalistes ont fait monter leur nombre à environ six mille, répartis en plus de trois cents genres rlifférents.

Celui qui nous occupe appartient au genre apion, créé par Herbet et renfermant actuellement plus de deux cents espèces, presque toutes d'Europe et très-petites. Il a été observé pour la première fois, en Angleterre, par William Marckwick. Cet agriculteur ayant remarqué que les capitules du trèfle commun, d'un champ qu'il destinait à produire de la semence, contenaient de petits vers blancs, mit quelqques-unes de ces tètes de fleurs dans une boite et 
obtint bientôt un petit Charançon. Il adressa une lettre à M. Marsham, entomologiste distingué à Londres, avec une figure très-imparfaite de la larve, de la nymphe et de l'insecte sous son dernier élat, et ce naturaliste ajouta à cette lettre en la publiant (dans le sixième volume des Transactions, de la Société linnéenne de Londres, en 1802), une notice entomologique pour faire connaître à quel genre et quelle espèce l'insecte observé par M. Marckwick appartenait. M. Lehmann de Gœttingue, à qui M. Marckwick avait communiqué son observation, ayant aussi adressé quelques remarques à ce sujet, elles furent publiées à la suite de celles de MM. Marckwick et Marsham.

Il résulterait de la note de M. Narckwick que, en examinant avec attention quelques tètes bien fleuries de trèfle, on verra, parmi la grande quantité de petites fleurs dont la réunion forme ces têtes, qu'il se trouve plusieurs de ces petites fleurs qui ont déjà dépassé le terme de la fleuraison ; elles sont brunes et desséchées.

Cette maturité hâtive et partielle des fleurs est ordinairement un signe caractéristique de la présence de la larve du Charançon dont il s'agit.

En effet, si vous écartez ou si vous arrachez avec précaution quelques-unes de ces fleurs desséchiées, vous aperceverez vers le sommet du calice, c'est-à-dire près de son po.nt d'insertion à la tige, une petite tache noirâtre ou un petit trou, comme celui que ferait une épingle fine; en exerçant une compression très-légère sur le calice, vous verrez sortir par ce petit trou une larve blanche molle, roulée sur elle-même, ayant de 1 à 2 millịmètres de longueur, 
Lorsque cette larre est arrivée au terme de sa croissance, elle forme, au dehors du trou qu'elle a pratiqué dans le calice, une saillie globulaire blanche, de 1 millimètre au plus de diamètre, qu'on pourrait prendre, au premier abord, pour un grain de poussière ou de plâtre.

Ce petit Charançon, dans l'année 1800, avait réduit la récolte de graines de trèfle à la moitié de sa valeur ordinaire. Ainsi, en 1798, un champ de quatre arpents 1/2 planté de trèfle et coupé pour la graine, arait produit 16 boisseaux $3 / 4$ de semence, tandis qu'en 1800 la même quantité de terrain récoltée de même ne produisit que sept boisseaux 1/2 de semence, et encore était-elle de qualité inférieure.

Depuis cette époque, persomne n'arait observé les métamorphoses de ce petit Charançon, et la science ne possédait que les notions incomplètes et les mauraises figures données par les naturalistes anglais. Quand M. Herpin, à qui la science doit tant d'observations judicieuses et utiles, a étudié de noureau ce Charançon qui s'établit dans les fleurs de trèfle et qui, après avoir percé le calice et les enveloppes de la jeune graine, en ronge et en détruit la substance intérieure au fur et à mesure que le travail de la fructification s'arance.

Si vous pénétrez, dit M. Herpin, dans un champ de trèfle lorsqu'il est en pleine fleur, vous remarquerez facilement un assez grand nombre de têtes, dont les corolles brunies et desséchées, les calices noirâtres annoncent qu'elles ont déjà passé fleur depuis longtemps, et elle a acquis cette longueur remarquable qui va caractériser 
l'insecte parfait. Vers la fin du douzième jour, on remarque que la nymphe qui était primitivement d'un blanc d'ivoire est parsemée de points noirâtres; la forme de la trompe, les yeux et les pattes de l'insecte se dessinent très-distinctement sous l'enveloppe qui les recouvre.

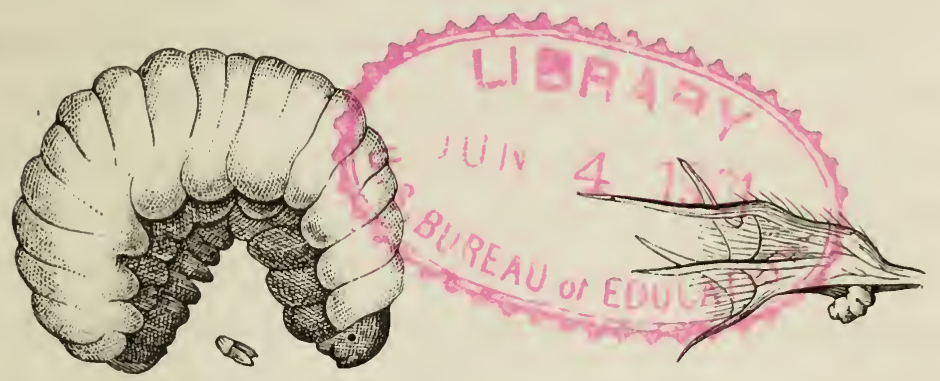

Fig. 7. - Larve de l'Apion, grossi et de grandeur naturelle.
Fig. 8. - Fleuron dı trèfle percé par la larve de l'Apion.

L'insecte qui sort de cette nymphe est un petit Charançon du genre Apion (Apion apricans) dont le corps a la forme d'une poire à poudre; il a la tête armée d'un bec fort et pointu; sa couleur est d'un vert olive foncé; les cuisses sont jaunes, sa longueur totale est d'environ 3 millimètres.

LApion apricans ètait connu depuis longtemps des naturalistes, qui le recueillent sur les murs et dans les champs. Mais on ignorait encore de quelle plante sa larve se nourrit, et même les larves des Apions, bien que ce genre renferme un très-grand nombre d'espèces, ne paraissaient pas ètre connues; du moins ces larves n'ont pas encore été décrites ni figurées dans les ouvrages. Voici la description qu'en donne Guérin-Nléneville: elle est épaisse, arquée et offrant un peu la forme du ver blanc ou Hanneton. Sa tête 
est rougeatre, de consistance un peu cornce, armce de deux fortes mandibules. Les trois premiers anneaux de son corps sont mumis, en dessous, de tubercules saillants qui remplacent les pattes ; les autres sont lisses, mamelonné: sur les côtés en dessous.

M. Guérin-Méneville prètend que cette larve se tient à la base du calice des fleurons des capitules du trèfle; quand elle est arrivéc à tout son accroissement ou quand elle a rongé entièrement la graine qui se trouve à cet endroit, e'est alors qu'elle perce le trou dont nous arons parlé pour sortir du calice et se métamorphoser en nymphe entre les divers fleurons de la tête de fleurs de trifle.

La nymphe est à peu près de la grosseur de la larve, blanche comme elle, assez molle. Sa tête, ses pattes, ses ailes el élytres sont repliées sur les côtés et en dessous, mais on les reconnaît très-bien. La tête, qui dans la larve était ronde et rougeâtre, est ici blanche comme le reste du corps.

C'est à II. Ilerpin que revient réellement l'honneur de la découverte et de la description de ce dangereux ennemi des prairies artificielles.

Voici comment ce savant entomologiste rend compte de ses ohservations :

"Mon trèfle fut fauché en pleine floraison, séché ensuite quoique arec peine, à cause du maurais temps, et rentré au fenil comme à l'ordinaire.

"Qu'allaient devenir ces larves nombreuses qui avaient èté rentrées avec le trèfle? Elles pouvaient être étouffées par la chaleur ou asphyxićes par le dégagement de gaz 
carbonique produit par la fermentation et l'entassement de la plante.

"Connaissant déjà l'insecte parfait, provenant de la larve du trèfle que j’avais observé dans les bocaux et dont j'arais hâté l'éclosion au moyen d'une chaleur artificielle, j'ètais à peu près sûr de le retrouver, si toutefois il devait éclore naturellement dans le cours de la même année.

"Dix à douze jours s'ètaient à peine écoulés depuis la rentrée du trèlle dans le grenier que j’apercus une grande quantité d'Apions cheminant de tous côtés sur les murs du bàtiment et se dirigeant ver's l'extérieur.

"La sortie de ces Charancons se continua pendant lıuit à dix jours.

"Bien que la quantité de ces petits insectes qui s’échappaient des greniers fût imnombrable, puisque les murs en étaient couverts, je ne pus en trouver un seul à quelque distance dans la campagne, ni mème dans les pièces de trêfle les plus voisines. Toutefois, comme cet insecte, ainsi que ses congénères, fuit la lumière du jour et se cache, il pouvait facilement échapper à mes investigations à cauce de sa ténuité extrème et de sa couleur vert foncé.

" Il ètait cependant du plus haut intèrêt de savoir si la deuxième coupe de trèfle qui poussait serait atteinte aussi par le Charançon. Je cherchais avec beaucoup d'attention ; j’aperçus à la fin que les têtes les plus mûres étaient à leur tour attaquées par le même insecte et que, finalement, la denxième coupe n'ètait pas moins maltraitée que ne l’avait été la première.

"Celte coupe fut fauchée, sichée, rentrie an grenier 
comme de coutume, et après une douzaine de jours les petits Charançons commencèrent à éclore et à sortir du grenier; bientôt après, j'en aperçus une très-grande quantité qui descendaient le long des murs et se dirigeaient vers l'extérieur, comme cela s'était passé pour la première coupe.

"Ainsi donc il faut conclure des faits que je viens de rapporter : $1^{\circ}$ que dans l'intervalle de cinq à sept semaines environ, qui est nécessaire pour la croissance de la deuxième coupe de trèfle, la chrysalide a eu le temps de se former; $2^{\circ}$ que l'insecte parfait a pu s'accoupler, se transformer dans les champs et déposer ses œufs sur la plante; $3^{\circ}$ que ceux-ci ont pu se développer et que les larres qui en sont sorties ont eu le temps nécessaire pour arriver à leur entière croissance, et enfin détruire et dívorer les graines produites par la seconde floraison du trèfle. "

N. Herpin n'a obtenu que deux coupes, mais il est pro. bable que la troisième, si elle avait eu lieu, n'aurait pas èté plus ménagée que ne l'ont été les deux premières. Le savant observateur fait encore remarquer que son trèfle avait èté planté au printemps et qu'il était dans sa seconde année, c'est-à-dire qu'il avait èté semé l'année précédente et qu’il n’avait pas encore été coupé. M. Herpin évalue à un dixième de la graine la perte causée chez lui en 1841 par le Charançon dı trèfle.

Marsham assure, d'après le témoignage d'un fermier anglais qui lui fit connaître le Charançon du trèfle, qu'en 1800 la moitié des grains avait été dévorée par cet insecte. 


\section{PARASITES DE L'APION DU TRÈFLE}

Les ennemis naturels de l'Apion sont les Ichneumons à l'ètat de larve, ces hyménoptères vivent aux dépens d'au * tres insectes dans le corps desquels les femelles les déposent. Ces dernières, constamment occupées à la recherche de leurs victimes, sont dans une agitation continuelle. On les voit toujours voletant et plus souvent courant avec vivacité, agitant vivement leurs antennes et cherchant toujours l'endroit où elles déposeront leurs œufs.

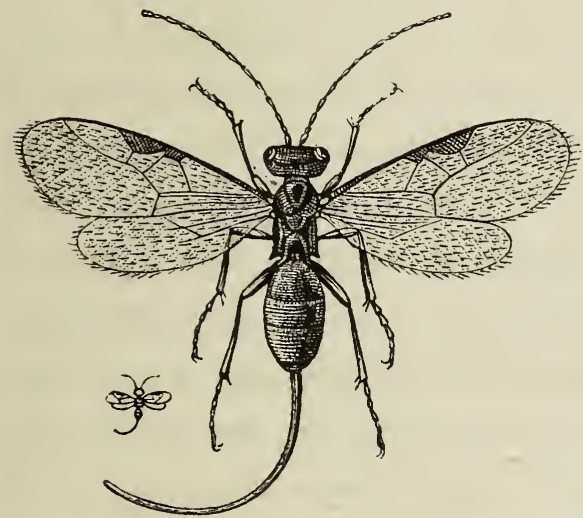

Fig. 9. - Calyptrus macrocephalus.

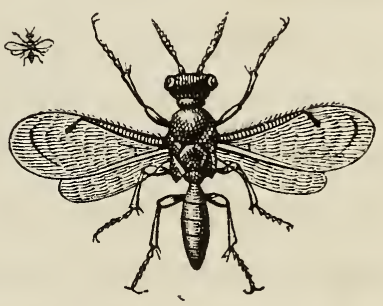

Fig. 10. - Pteromalus pione.

Parasites de l'Apion du trèfle, grossi et grandeur naturelle.

Le premier de ces parasites appartient à la tribu des braconides et au genre calyptus de M. Haliday, genre formé avec quelques espèces retirées du genre Eubazus de M. Nées d'Essembeck, c'est le Calyptus macrocephalus (Eubazus macrocephalus, Nées). Il est long de près de 3 millimètres, noir luisant, avec les ailes transparentes, un peu irisées, et la base des jambes jaunâtres ; la femelle est mu- 
nie d'une tarière ou oviducte plus longue que son corps, qu'elle peut plonger au fond du calice des fleurons du trèfle et au moyen de laquelle elle va déposer un œuf dans le corps des larves de l'Apion.

L'autre parasite appariient au genre nombreux des Pteromalus, dont on comnait deux cent cinquante-quatre espèces propres à l'Angleterre seulement. Il est permis d'estimer que ce nombre serait porté à plus de mille, si les espèces des autres contrées du monde étaient connues; mais ces insectes sont si petits et si difficiles à observer, qu'il est probable que leur étude ne sera pas de sitôt complétée. Celui qui nous occupe aujourd'hui a été décrit par M. Walker, sous le nom de Pteromalus pione. II est d'un vert foncé avec les antennes noires; ses ailes sont diaphanes, irisées; ses pattes sont jaunes avec la base des cuisses noirâtre et soll abdomen est d'un vert bronzè à reflets pourpres. L'individu que nous avons représenté est un mâle; dans la femelle l'abdomen est un peu plus allongé et terminé par un court oviducte; les pattes sont jaunes arec la plus grande partie des cuisses noire; le milieu des jambes et l'extrémité de chaque article des tarses sont de cette même couleur. Ces petits insectes, à peine longs de 2 millimètres, doivent s'introduire dans la fleur du trèfle pour déposer leurs œufs dans ceux de l'apion ou dans sa larve.

En dehors de ces moyens naturels de destruction, M. Herpin conseille de couper de bonne heure et de faire manger en vert les pièces de trèfle qu'on reconnaît et qu'on soupconne être fortement atteintes par l'Apion, d'éviter soigneusement de laisser le trèfle planté pendant plus 
de deux années consécutives sur le mème terrain, d'éviter aussi de laisser mûrir et monter à graine le trèfle qui est fortement attaquée par le Charançon, d'alterner et varier les cultures, c'est-à-dire de faire succéder à une céréale des plantes sarclées ou fourragères et vice versa; il en résulte que les larves nuisibles déposées dans les champs ne trouvant pas au moment de leur éclosion la nourriture qui convient à leur organisation, ne peurent subsister et périssent infailliblement.

Enfin on pourrait opérer la dessication du trèfle par la méthode allemande, c'est-à-dire par la fermentation, en faisant du foin brum. Les rapeurs alcooliques, les gaz délétères qui se forment pendant la fermentation du trèfle entassé tout vert et aussi d'après les expériences de I. Herpin, la température qui se développe dans la meule à plus de 60 degrés centigrades, suffisent pour détruire des milliers de larves d'Apion qui ne peurent résister à une aussi forte chaleur.

\section{CHARANCOON DU COLZA}

(Gripìius brassicæ).

Le Charançon du colza ne parait avoir élé bien étudié que par M. Focillon. Nous devons à ce savant professeur de zoologie un mémoire important sur les insectes qui nuisent aux colzas, dans lequel il rapporte que vers la première quinzaine de juillet en visitant des champs de colzd dont on faisait la récolte; il observa sur les siliques et sur 
les rameaux un trés-grand nombre de Charançons d'une mème espéce, remarquables, aı premicr abord, par un

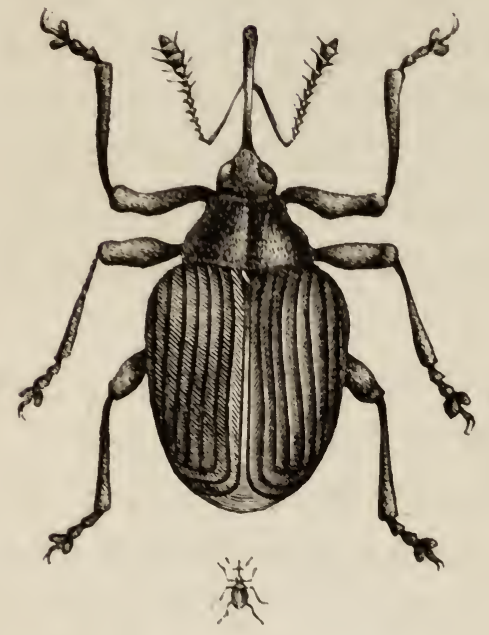

Fig. 11. - Charançon du colza, grossi et grandeur naturelle.

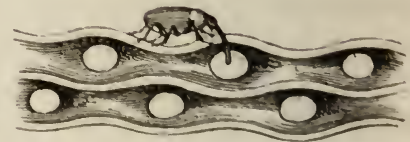

Fig. 12. - Coupe longitudinale d'une silique attaquée par un Charanson. On voit comment le bec pénetre à travers la silique jusqu'au centre de la graine.

bec trés-allongé, courbe et trés-fin. Ils se promenaient assez lentement sur les diverses parties de la plante, de préférence sur les siliques, et, selon l'habitude des insectes de cette famille, se laissaient tomber a terre des qu'il agitait la plante ou qu'il les touchait. En suivant attentivement leurs manoures, il recommut bientot quel mal ils faisarent aux siliques. Il vit en effet qu'après aroir cherché pendant quelque temps, l'animal s'arrêtait sur une des protubérances correspondant aux graines, et, plongeant au milieu son bec effilé, l’y enfonçait jusqu’à la hase ef restait longtemps dans cette position. Après quoi l'animal, dégigeant son organe perforant, allait chercher un autre point pour y recommencer son manége. Il prit 
une des siliques ainsi attaquées: à la place où venait d'opérer le Charançon, il distingua le trou très-petit qu'il avait fait; c'est à peu près la grandeur d'un trou d'aiguille. Il enleva la portion de silique où il se trouvait et, mettant ainsi la graine à nu, il aperçut un trou correspondant à celui qu'il avait observé à l'extérieur, mais plus grand, à bords déchiquetés, évidemment rongés, et qui pénétrait jusqu'au centre de la graine où il se terminait en large cul-de-sac. Il renouvela nombre de fois cette observation, qui lui donna invariablement le même résultat. Restait à se préoccuper d'une double question: quelle est la fréquence de semblables dégâts?.par quel mécanisme organique l'animal peut-il le produire?

Il rechercha immédiatement sur les siliques les traces du passage du Charançon; plus tard même, dans une recherche plus minutieuse, il vit que, sur 20 siliques quelconques, il en trouva 19 portant les traces des attaques du Charancon; et ces attaques avaient èté nombreuses, puisqu'il comptait, sur ces 19 siliques, 40 perforations faites à diverses époques du développement des graines. Celles de ces perforations faites avant la maturité de la graine sont d'autant plus préjudiciables que le colza est plus jeune; car alors, au lieu d'y creuser seulement un trou qui n'en détruit qu'une portion, le Charançon ronge complétement, ou presque complétement, la jeune graine; la silique ne se développe plus au niveau de ce grain détruit, et présente extérieurement un étranglement qui la déforme plus ou moins, et rend ses dégâts assez facilement reconnaissables au premier abord. A l'intérieur, et partant de la paroi interne de la silique, au niveai du 
trou, visible extérieurement, on aperçoit une excroissance irrégulièrement conique, exsudation morbide des tissus blessés, au centre de laquelie persiste le canal foré par le bec de l'insecte, et cette excroissance occupe en grande partie le faible espace laissé vide par la graine dètruite. Quand ces déformations se présentent au nombre de trois ou quatre sur la même silique, elle se contourne, et son déreloppement général se fait arec une extrême irrégularité. Plus la graine a été attaquée à une époque voisine de sa maturité, moins la déformation est marquée; enfin les graines mûres ne présentent que les dégâts indiqués en premier lieu; ce sont d'ailleurs les moins nombreux. Sur les 40 piqûres dont il a été question plus haut, 12 seulement avaient été pratiquées sur des graines à maturité, et n'avaient, par conséquent, pas entrainé la destruction du grain.

Ces observations donnèrent à M. Focillon la connaissance exacte du dégât produit par le Charançon, il voulut se rendre compte des moyens qu'il avait à sa disposition et des procédés organiques qu'il employait. La tête de cet insecte globuleuse et munie de deux yeux réniformes, se prolonge antérieurement en un bec cylindrique, courbé en dessous et légèrement plus gros à son extrémité. Vers le milieu de sa longueur s'insèrent les antennes, géniculées, terminées par une massue de quatre articles portée sur un filet de sept articles, qui s'attache luimême à un scape allongé et grêle, moitié moins long que le bec, et se cachant dans une rainure prolongée jusqu'à la base du bec au moment oủ l'animal plonge cet organe dans la silique. Mais l'extrémité de ce bec attira surtout son attention. Il y trouva la bouche de l'animal, et 
quoique cette extrémité ait à peu près un quart de millimètre de diamètre, le microscope lui montra un appareil corrodant bien constitué. Ce labre ou lèvre supérieure lui parut soudé au bec; mais son bord libre, courbé en biseau tranchant, avance sur les parties de la bouche, de manière à attaquer, en premier lieu, la substance végétale et à fournir une sorte de point d'appui aux autres organes. En dessous de cette première pièce se trouvent les mandibules dont la disposition est fort curieuse. Elles sont insérées sur le bord interne d'un prolongement latéral du bec, qui se renfle au point de cette insertion et se termine par une pointe aiguë légèrement oblique en dedans. Cette pointe avance un peu sur le niveau de l'extrémité de la mandibule, se trouve ainsi presque sur celui du bord tranchant du labre et semble compléter arec lui une sorte d'emporte-pièce destiné à ébaucher le trou où doit s'enfoncer le bec de l'animal avec son appareil masticateur. La mandibule articulée par un condyle très-marqué, prolonge sa base en arrière et en dedans pour donner insertion à des tendons musculaires énergiques, qui, formant, avec ceux insérés près du condyle, un système adducteur et abducteur, impriment à l'organe des mouvements énergiques autour du pivot fourni par l'articulation. Le bord libre de la mandibule est hérissé de dents fortes et crochues; enfin un fait qui a vivement excité l'attention de ce savant observateur, c'est l'existence, près de l'angle postérieur de ce bord libre, d'un prolongement flexible, incolore, transparent au microscope, allongé, légèrement conique, couvert de poils et dirigé d'avant en arrière dans le conduit ossophagien. Ce prolongement qui, bien que dans 
une position différente, rappelle le fouet des mâchoires des crustacés, doit, par son insertion sur la mandibule se mouvoir arec elle; remontant dans l'œsophage lors de l'abduction, descendant au contraire dans l'adduction, il exécute des mouvements de ra-et-rient qui l'ont déterminé à y voir un appareil de succion des liquides exprimés par le broiement de la substance des graines.

Les mâchoires que l'on trouve au-dessous des mandibules sont petites, presque complétement dissimulées sous ces organes, et présentent au bord interne une série de dents fines et crochues. On y recomnait le palpe maxillaire très-court et peu développé. Enfin la bouche est fermée en dessous par une languette ou lèvre inférieure petite, en forme de losange, et terminée antérieurement par les rudiments des deux palpes labiaux.

Telle est cette bouche portée à l'extrémité d'un bec long et effilé. On comprend maintenant bien facilement que lorsque l'animal a choisi le point renflé de la silique, où se trouve le grain qu'il veut attaquer, il appuie sur l'épiderme l'extrémité de son bec. Comme il ne perfore que les siliques encore rertes, et jamais celles qui sont déjà desséchées, le tissu cède facilement au tranchant du labre et aux crochets de la base des mandibules; et acherant à l'aide de ces derniers organes la destruction de la substance végétale, il pénètre de proche en proche à travers les parois de la silique et l'enveloppe de la graine jusque dans son amande. A mesure que cette pénétration a lieu, le scape ou premier article de ses antennes se couche dans sa rainure le long du bec, et cesse d'offrir aucun obstacle, de manière que cette espèce de sonde virante se troure bientôt plongée 
jusqu’à sa base dans le fruit du colza. La bouche se trouve alor's avec l'extrémité mème du bec au milieu de la graine, et l'animal y fait jouer sans difficulté l'appareil masticateur et suceur indiqué plus haut. Voilà pourquoi le trou qu'on observe dans la graine est beaucoup plus grand que le trou extérieur ou d'introduction ; voilà pourquoi la graine peut être dévorée en tout ou partie, sans qu'à l'extérieur on en voie d'autre trace que la dépression causée par son absence, et le trou d'aiguille par lequel a pénétré l'organe destructeur du charançon.

Cet animal se nourrit donc du parenchyme des graines et peut par conséquent produire un sérieux dommage, soit par celles qu'il dètruit, soit par celles qu'il altère partiellement. On comprend surtout que ce dommage puisse devenir considérable, en songeant qu'un même animal peut ainsi attaquer successivement un grand nombre de graines, et multiplier en peu de temps ces ravages. Il est d'ailleurs pourvu d'ailes très-bien développées qui rendent ces dègâts plus rapides et plus inévitables.

En étudiant les caractères zoologiques de ce curieux ennemi du colza, M. Focillon s'est convaincu qu'il rentre dans le grand genre rhynchène de Fabricius, et doit être rapporté, si l'on suit la classification des entomologistes modernes, au petit genre grypidius de Schœnher. Il pense qu'aucume des espèces décrites ne se rapporte suffisamment à celle dont il s'est occupé. Il la regarde comme n'ayant pas encore été caractérisée. Il la désigne sous le nom de grypidie du colza. Nous donnons le texte latin de sa description ${ }^{1}$.

1 Grypidius neneoviridis, totus eodem colore tinctus, sed varie 
IV. Focillon a également eu l'occasion d'oloserver la larve d'un coléoptère inconnu qu'il croit devoir jusqu'à plus amples informations attribuer au Charançon du colza.

Cette larve que l'on peut provisoirement attribuer au Charançon, est d'un blanc légèremeut jaunâtre sans la moindre trace de membres. On ristingue derrière la tête sur la face dorsale du corps, à droite et à gaiche, deux petites plaques de nature cornée qui domnent intérieurement insertion à des muscles.

Comment cette larve pénètre-t-elle dans la gousse? C'est une question à résoudre encore. Elle se présente le plus souvent logée dans un grain dont elle fait sa pâture. Le développement de la larve coute au plus quatre graines à la silique. Les autres ne paraissent pas en souffrir notablement et parviennent sans encombre à la maturité.

Les gousses attaquées sont, dit $\mathbf{Y}$. Focillon, aisément reconnaissables à une petite tache d'un brun noirâtre, qui se roit par transparence sur la face interne de la silique. C'est en ce point que la larve, quand le moment est venu de sortir, perce un trou de 1 millimètre de diamètre.

dispositus : rostrum elongatum, dimidiæ corporis longitudini æquale, omnino nigrum et nitide glabrum; antennæ nigree, præter ultimos articulos pilis flarescentibus marginatos : caput brere, globulosum, oculis brunneis distinctum; thorax linea media longitudinali excavatus, utrinque rotundatus, sed antea strictus subitoque truncatus, postea curratim incrassatus; pedes æquales, cruribus paululum crassis, sed omnino muticis, tibiis tenuibus et elongatis, inermibus; caput, thorax, pedes et abdomen qua non elytris tegitur, requaliter pilis flavescentibus dense pubescunt; elytri ovato-cordati, lineis nigris circiter septem longitudinalibus eleganter notati, quorum spatia viridescentia flaris pilis distinguuntur; abdomen postea detectum haud secus ac subtus nigro viridi, pilis iisdem flarescentibus variegatum. Longitudo : 2 aut 3 millin.; latit. : 1 millim. $1 / 2$. 
Comme on ne rencontre jamais ni nymphe ni chrysalide qu'il soit possible de lui attribuer, il est probable qu'elle se laisse tomber à terre et s'y enfonce pour y subir ses métamorphoses.

S'il n'y avait jamais qu'une larve daus la même silique, les dégâts resteraient encore assez bornés, mais il s'en trouve ordinairement plusieurs, et il suffit d'en supposer deux pour que la perte s'élève au tiers ou au quart.

Sur cent graines, cinquante dépérissent sous l'atteinte des insectes, ennemis reconnus de la graine de colza. Le Charancon en détruit 10 ; - la chenille de la Teigne, 5 ; e'est 9 qu'il faut compter pour la larve dont il est ici question.

\section{CIIARANCON COU SILLONNE OU DES NAVETS}

(Geutorhynchus sulcicollis, Sch(rn).

On a souvent l'occasion de remarquer, lorsque l'on arrache des navets dans les champs, pendant l'ètẻ et l'automne, que la partie supérieure de la racine voisine du collet est couverte de tubercules plus ou moins gros ou saillants, d'une forme simple ou compliquéc, ordinairement très-irrégulière, qui donnent à cette racine une apparence galleuse. Si on ouvre ces excroissances avec un couteau on voit que le centre est vide et forme une cellule qui contient un petit ver. Lorsque la galle est simple, elle ne contient qu'une cellule et une seule larve, mais lorsqu'clle est compligućc et formée de plusieurs galles 
roisines qui se sont pénétrées, elle renferme autant de cellules qu'il y a de galles et autant de larres qu'il y a de

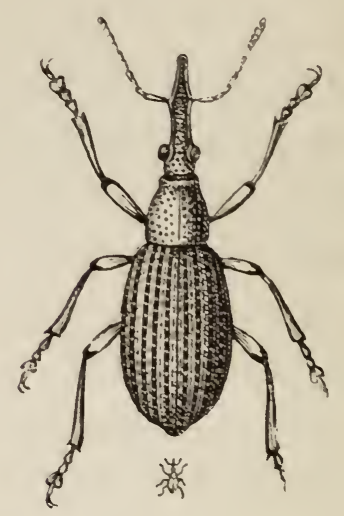

- Fig. 15. - Charaņon des navets, grossi et grandeur naturelle.

cellules ; chacume vivant à part sans troubler ses roisines. Ces vers, qui se trourent ordinairement en nombre considérable sur la mème racine, l'altèrent profondément et en consomment une partie pour leur nourriture, et lorsqu'on veut en faire usage pour la cuisine, on est obligé d'enlever les tubercules, d'extraire les larves et de creuser les cellules pour les nettoyer et atteindre la substance vive, ce qui cause une perte notable.

La larve ayant atteint toute sa grandeur vers la fin de l'automne, a 4 mill. de longueur. M. Goureau, à qui nous devons cette description, dit que cette larve est blanche, presque cylindrique, couverte de rides transversales et privée de pattes, sa tète est ronde, en partie cachée dans le premier segment du corps, et armée de deux mâchoires; elle se tient courbée en cercle dans sa cellule et peut s'y tourner au moyen de petits mamelons qu'elle 
fait sortir de son dos et de ses côtés. Lorsqu'elle n'a plus besoin de manger elle perce sa cellule et s'enfonce dans la terre oi elle se construit une coque sphérique avec des parcelles menues de terre qu'eile agglutine autour d'elle.

Cette ceque est très-grossière à l'extérieur, mais elle est lisse et unie à l'intérieur. La larve y passe l'hiver et le printemps, et se change en chrysalide dès les premiers jours du mois de juin, et en insecte parfait au commencement de juillet.

Quant à l'insecte, sa longueur est de 3 mill. Noir, couvert en dessus d'une pubescence d'un gris jaunâtre et en dessous de petites écailles grises; les antennes sont coudées, noires die douze articles, dont les trois derniers en massue; le rostre est long, filiforme, menu, arqué, appliqué contre la poitrine dans le repos; la tête et le corselet sont ponctués; ce dernier est plus étroit en devant qu'en arrière, arrondi sur les côtes et porte un sillon lorigitudinal sur le dos; ies élytres sont ovalaires, plus larges à la base que le corselet, deux fois aussi longues, avec dix stries sur chacune, arrondies à l'extrémité ; les cuisses sont renflées ; les postérieurs sont armés d'une petite dent à leur extrémité; tout l'insecte est noir.

Aussitót qu'il est sorti de terre et qu'il s'est mis en liberté, il se porte sur les navets où il s'accouple. La femelle fécondée descend de la plante, se glisse entre la terre et le haut de la racine pour faire sa ponte; elle perce celle-ci avec son rostre et introduit un œuf dans la blessure; elle fait autant de piqûres qu'elle a d'œufs à 
déposer, les plaçant dans le voisinage les uns des autres ou à quelque distance isolément. Il sort de chaque œuf une petite larre qui ronge autour d'elle et provoque un afflux de séve autour du point blessé, ce qui engendre une excroissance ou galle.

Le même insecte se porte sur les choux dont les racines sont très-souvent difformes et chargées d'une multitude d'excroissances plus ou moins grosses amoncelées les unes sur les autres; mais comme il n'altère pas les feuilles que nous employons à notre usage, il nous cause moins de préjudice que lorsqu'il attaque les navets. Il envahit aussi les racines de la moutarde des champs (sinapis arvensis) appelée cendre dans nos villages et ne paraît pas nuire à cette mauvaise plante qui infeste les cultures.

Il n'est pas facile de se défaire d'un insecte aussi généralement répandu. On en diminuerait cependant le nombre si l'on avait soin de brûler toutes les racines de choux tuberculées, lorsqu'on arrache cette plante en automne, et de nettoyer de leurs larves les racines de navet que l'on arrache pour les conserver.

On connait deux parasites du Charançon des navets. Tous les deux font partie de la tribu des ichneumoniens et de la sous-tribu des braconites, mais l'un entre dans le genre Sigalphus, et l'autre dans le genre Taphxus. Les femelles de ces insectes descendent des choux jusqu'au collet de la racine, s'insinuent entre la racine et la terre jusqu'aux galles qu'elles percent arec leur tarière, et parviennent à loger un œuf dans la larve que renferme la galle. Cet œuf donne naissance à une larre d'ichneu-. 
monien qui dévore celle du Charançon, se change en chrysalide dans son habitation et s'en échappe sous la forme d'insecte parfait après sa dernière métamorphose. Le premier de ces parasites est le Sigalphus pallipes.

Sigalphus pallipes. - La longueur de cet insecte est de 5 mill. Il est noir; les antennes sont noires et de la longueur dı corps; la tête et le corselet sont noirs, luisants; l'abdomen tient au corselet par un pédicule très-court; il est de la longueur et de la largeur de ce dernier, ovalaire, formant une carapace divisée en trois segments dont les deux premiers sont finement striés en long, et le dernier presque lisse et arrondi au bout; les pattes sont rougeàtres, pâles; les cuisses sont tachées de brun en dessus; l'extrémité des tibias postérieurs et leurs tarses sont noirs ; la tarière de la femelle est de la longueur de l'abdomen ; les ailes sont hyalines, dépassant un peu l'extrémité de l'abdomen, avec le stigmate noir et les nervures testacées.

Le deuxième parasite du Charançon cou sillonné est le Taphæus affinis.

Taphaeus affinis. - Cet insecte est noir, luisant; les antennes sont noires et de la longueur du corps qui est de 3 millimètres arec les deux premiers articles roussâtres en dessous; les mandibules sont roussâtres; la tête est noire; le corselet noir, luisant, ayant les sutures bien marqués, de la largeur de la tête; l'abdomen est très-courtement pédiculé, ovalaire, terminé en pointe obtuse, de la longueur et de la largeur du thorax, noir, luisant; les pattes sont d'un fauve jaunâtre, la tarière de la femelle est un peu plus longue que l'abdomen; les 
ailes sont hyalines, dèpassant l'abdomen à stigmate noir et nervures brunes ${ }^{1}$.

\section{MOYENS DE DESTRUCTION}

Joigneaux, après avoir indiqué comme ennemi du Charançon un petit Ichneumon du genre calyptus, ajoute qu'en Angleterre Ch. Morren conseille, comme moyen à emp'oyer contre le Charancon, l'écrasement des rymphes par un roulage pesant, moyen très-usité, dit-il, chez les Anglais. Il faut pour cela saisir l'épeque où ces insectes sont sous la forme de nỵmphes, au mois de décembre ou janvier. La nymphe est molle et délicate, la plus légère pression peut la tuer, lorsque la larve est attachée aux racines, l'insecte parfait caché ảans les feuilles de la plante échappe plus facilement aux movens de destruction.

\section{BRUCHE DU POIS CHICHE}

(Bruchus, Linnè).

La Bruche est un coléoptère de la famille des bruchides; insecte voisin du Charançon, il ne se distingue guère que par le défaut de trompe. Sa croix blanche peinte sur ses élytres la fait aisément remarquer.

De l'œuf introduit par la femelle dans le jeune pois, sort une larve blanche, ovoïde, c'est-à-dire plus grosse à une

1 Goureau, Insectes muisibles. 
extrémité qu'à l'autre. Elle grandit peu à peu et très-lentement, et ne prend d'accroissement considérable qu'au moment oủ la graine est parvenue à toute sa grosseur.

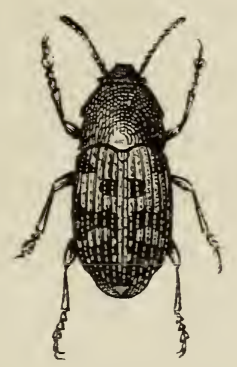

Fig. 14. - Bruche du pois chiche.

Quorque rongés en partie, les grains ne laissent pas que de germer encore souvent, grâce à un heureux instinct qui porte la Bruche à ménager la future plante. Elle se garde au reste également de toucher au placenta par qui la séve est transmise et de se couper ainsi les vivres à elle-même.

Vient l'heure, comme pour tous les coléoptères, de passer à l'état de nymphe. Par une sage prévoyance de l'impuissance où elle serait après sa transformation de conduire à bonne fin un pareil travail, la larve ronge la pellicule extérieure du pcis, et si le pois n'est pas écossé, elle ronge également l'épaisseur de la cosse devenue par la dessication aussi dure que dı parchemin. Si elle n'accomplissait pas cette besogne arant de se changer en nymphe, la race des Bruches cesserait d'exister. La Bruche, devenue insecte parfait, est incapable d'ourrir la porte de sa prison : elle y mourrait donc sans postérité, si la larve r'avait eu soin de lui ménager les moyens d'en sortir. Il est facile de le constater soi-mème, en collant sur l'ouverture un morceau de 
papier. Si l'on ouvre le pois, on trouve la Bruche morte de faim, faute d'avoir pu franchir cet obstacle, bien plus faible pourtant que la peau du pois lui-même.

Il est essentiel de ne g'arder pour semence que les grains intacts, si l'on veut être sûr d'une récolte abcndante. On reconnait les pois attaqués en les jełant dans l'eau ; ceux qui surnagent sont le plus souvent attaques; ceux qui vont an fond de l'eau sont ordinairement sains.

Il y a des années oủ les pois véreux sont très-nombreux, où les deux tiers au moins de la récolte sont atteints, et dans ces années on ne peut douter que les personnes qui mangent des pois verts, ne mangent aussi une quantité considérable de petits vers. Flles ne s'en aperçoivent pas, n'en éprouvent ni dégoût ni incommodité, parce qu'il n’y a rien de malsain dans ces insectes nourris d'une substance végétale très délicate.

\section{BRUCHE DE LA LENTILLE}

La lentille est aussi rongée par une espèce particulière de Bruche dont la larve consomme, pour arriver à toute sa taille, au moins la moitié et peut-être les trois quarts de la substance farineuse du grain. Elle reste dans son habitation pendant l'automne et l'hiver et se transforme en insecte parfait au printemps suivant pour se répandre dans la campagne et pondre sur les jeunes pousses de lentilles, ayant soin de ne confier qu'un seul œuf à chaque semence.

Cet insecte se multiplie tellement dans certaines années, 
qu'on est obligè de suspendre pendant deux ou trois campagnes consécutives la culture de celégumeafin de laisser

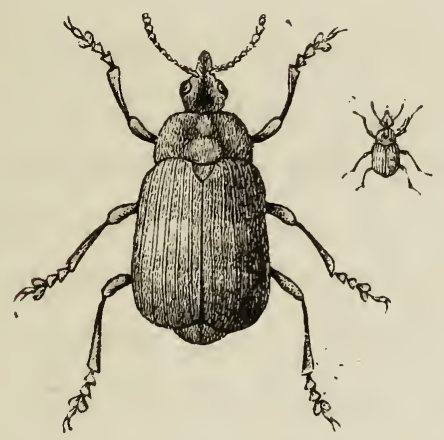

Fig. 15. - Bruche de la lentille, grossie et grandeur naturelle.

périr cet insecte faute de nourriture. Il est extrêmement important de ne semer que des lentilles saines afin d'éviter cet inconvénient, et l'on devra s'assurer de leur qualité en les plongeant dans l'eau pendant un jour ou deux, ce qui permet de séparer les grains véreux de ceux qui sont sains. L'espèce qui s'attache à la lentille est le Bruchus pallidicornis.

3. Bruchus pallidicornis. - M. Goureau, a qui nous empruntons l'excellente description des Bruches, nous dit que la Bruche de la lentille est noire, tacheté de blanc; antennes un peu plus grosses vers l'extrémité qu'à la base, ayant leur cinq premiers articles jaunâtres ainsi que les deux derniers; tête, corselet, élytres noirs, un peu noir devant l'écusson ; deux lignes de taches blanches transversales souvent peu marquées sur les élytres, qui laissent à découvert l'extrémité de l'abdomen; cette extrémité couverte de duvet blanchâtre avec deux grandes taches noires; jambes antérieures rougeâtres, les intermédiäires noires 
avec les extrémités des tibias fauves ; les postérieures noires à cuisses dentées. Sa longueur est de 5 millim. sur 2 de large.

Le moyen de combattre les Bruches et de les détruire en partie consiste à passer au four les pois, les fèves et les lentilles infestées, aussitôt après la récolte, ce qui fera périr les larres qui s'y trouvent et mème les insectes parfaits s'ils sont déjà transformés. On devra mettre à part celles de ses graines qu'on destine à la semence et on ne les passera pas au four, mais on les soumettra à l'épreuve de l'eau, comme on l'a dit. De cette manière on parviendra à détruire les Bruches de sa récolte, mais si les voisins ne prennent pas les mêmes précautions, les insectes nés dans leurs jardins ou sur leurs terres viendront bientôt chez rous et rendront vos soins inutiles.

La Bruche de la lentille a un ennemi naturel qui tend à modérer son excessive multiplication; c'est un petit parasite de l'ordre des hỵménoptères, de la famille des pupivores, de la tribu des chalcidites et du genre pteromalus, dont le nom est pteromalus varians. La femelle pond ses œufs dans les larres de la Bruche, un dans chaque larve, ce qui ne l'empêche pas de grandir malgré le ver qu'elle nourrit dans son corps, mais elle ne peut subir ses transformations et se trouve remplacée dans sa cellule par la chrysalide de ce parasite qui sort de la graine à l'état parfait dans le temps où aurait dù éclore la Bruche. 


\section{BRUCHE DE LA VESCE}

On troure cette Bruche toute formée dans les vesces dès le 15 août et c'est alors qu'elle commence à en sortir pour se répandre dans la campagne. Elle doit passer l'automne et l'hiver pour venir pondre au printemps sur les jeunes gousses des vesces, ce qui exige que plusieurs femelles se cachent dans des abris, et survirent aux rigueurs de la saison froide. Il est probable que des individus tardifs restent dans les semences pendant l'hiver et ne prennent leur essor qu'au printemps, pour assurer la conservation de l'espèce. On ne trouve qu'une seule larve dans le même grain, dont elle consomme presque toute la substance farineuse pour sa nourriture et sa croissance. La larve grandit assez rapidement puisqu'elle accomplit toutes ses érolutions, c'està-dire ses changements en chrysalide et en insecte parfait, dans l'espace de trois à quatre mois. La Bruche de la resce se comporte à l'ègard de cette graine comme la Bruche du pois à l'ègard de ce légume. Toutes les Bruches ont les mèmes mœurs, et si l'on observe des différences entre elles, c'est dans l'époque de l'apparition de l'insecte, dans le temps de la ponte, qui est celui où la fleur tombe et la gousse commence à se montrer et dans le moment oủ la larve a acquis toute sa croissance, qui coïncide arec celui de la maturité de la semence.

L'espèce qui attaque la vesce a reçu le nom de Bruchus nubilus. Sa longueur est 2 mil. 1/2. 11 est noir, oralaire; la tête est noire, penchèe, rétrécie en arrière, les antennes 
sont formées de onze articles, les cinq premier's menus et fauves, les autres plus gros et noirs; le corselet est noir, convexe, arrondi sur les côtés, bisinué en arrière, courert d'une pubescence caduque, arec une tache de poil blanchâtre devant l'écusson. Les élytres sont noires, plus larges que le corselet, près de deux fois aussi longues, en carré dont les angles sont arrondis, strièes et marquées de taches de poils blanchâtres courts et serrés. Les pattes antérieures sont faures arec la base des cuisses noires, les autres sont noires arec les tibias et les tarses moyeus faures.

Cet insecte ne fait aucun mal aux fourrages, car il n'attaque que les semences; en les faisant manger en rert on détruit une multitude de larves, et l'espèce ne se trouve plus que dans la oartie de la prairie conservée pour graines. - Lorsqu'on s'aperçoit que les semences sont attaquées, il faut immédiatement les passer au four, ce qui fait périr les larres et les insectes parfaits qu'elles contiennent. Quant à la paríie conservée pour la semence on doit la passer à l'eau et ne semer que les grains tombés au fond du vase; ceux qui surnagent doirent ètre mis au four et donnés aux rolailles.

La Bruche de la resce a un ennemi naturel qui s'oppose à sa trop grande multiplication el qui la fait momentanément disparaitre lorsqu'elle est derenue par trop abondante : c'est le pteromalus varians, décrit à l'article de la Bruche de lentille. 


\section{HANNETON}

(Melolontha).

Le Hanneton que tout le monde connait, que tous les enfants martyrisent est un coléoptère de la tribu des scarabẻiens, de cette tribu à laquelle appartiennent les in-

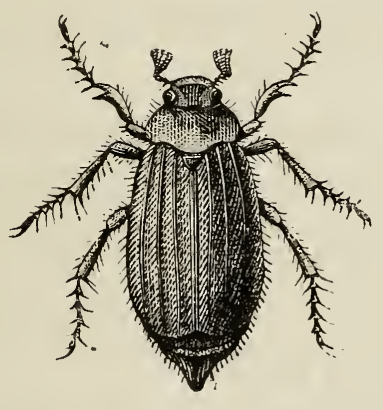

Fig. 16. - Le Hanneton.

sectes les plus beaux et les plus variés. Leurs corps est généralement épais et ramassé. Leurs antennes foliacées à l'extrémité les font reconnaitre dès le premier abord. Beaucoup d'entre eux ont des mandibules membraneuses soit en totalité, soit en partie; et chez tous elles sont fort petites. Ce caractère est réellement en rapport avec les habitudes des scarabéiens. Jamais ils n'ont à triturer de corps bien durs. Les uns vivent sur les fleurs, les autres rongent les feuilles et c'est chez ceux-là qu'on trouve les mandibules les plus robustes.

Quoique les formes paraissent extrêmement variẻes dans cette tribu, lorsqu'on examine les insectes parfaits 
on est vraiment frappé de la similitude qui existe entre toutes les larres, même lorsqu'on compare celle des familles les plus éloignées.

Les larves des scarabéiens virent ou dans la terre, et alors elles rongent les racines, ou bien dans les bois décomposés.

Les nymphes sont grosses et massives et retracent déjà parfaitement toutes les formes des insectes parfaits. La métamorphose s'effectue toujours au lieu rnême où ont vécu les larves, qui se forment une loge pour subir leur transformation.

On compte généralement que ces coléoptères passent trois années à l'état de larve, tandis que leur état de nymphe est très-court, ainsi que celui d'insecte parfait. Le Ilauneton confirme cette loi ; car il ne vit guère plus diun mois à l'ètat d'insecte parfait.

C'est vers la fin de mai que l'accouplement a lieu; on troure alors sous les feuilles les Hannetons attachés l'un à l'autre pendant des journées entières. L'acte accompli, le mâle ne tarde pas à mourir.

Quant à la femelle, sa vie se prolonge encore quelques jours et elle se hâte de les mettre à profit pour s'assurer une postérité. Elle cherche les terres les plus légères et les mieux fumées pour y déposer sa progéniture; ce sont les terres où les régétaux abondent et qui sont le mieux perméables à l'air nécessaire à tout être virant: la culture, les labours produisent ce résultat et attirent le Hanneton.

Jans les années où ces insectes sont très-abondants, on peut en effet remarquer dans les bois que ce sont les 
arbres des lisières, contre les champs cultivès, qui sont dépouillés de leur feuillage, et que le Ilanneton n'est jamais dévastateur au centre des bois. La femelle fait si bien de ses mandibules et de ses fortes pattes de derant qu'elle parvient à creuser un trou profond de 20 et même 50 centimètres. C'est au fond, dans un cul-de-sac de forme arrondie, qu'elle pond une vingtaine d'œufs; le nombre peut même aller jusqu'à quarante et cinquante. Quatre, cinq ou six semaines après la ponte, sortent des œufs ces larves connues sous le nom de ver blanc, turc, man, terre, engraisse-poule.

Les vers blancs sont d'assez grosses larves contournées en demi-cercles comme toutes les larves des scarabéiens, seulement leurs pattes sont plus longues que dans la plu-
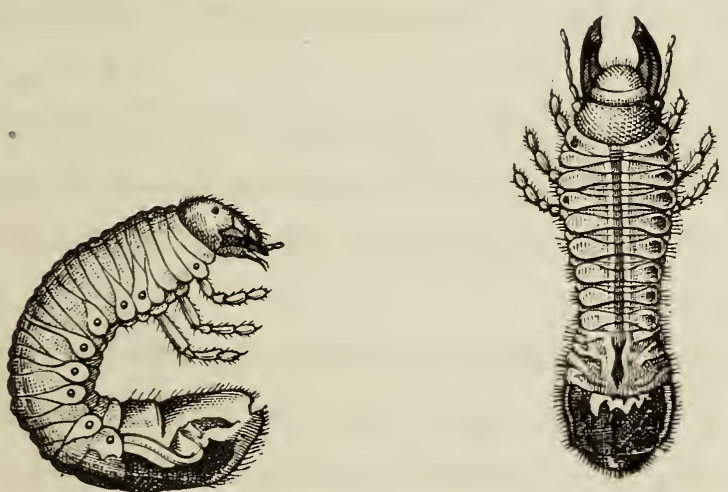

Hig. 17 et 18. - Larves du Hanneton.

part des espèces de cette tribu. Toute la surface de leur corps est d'un blanc sale, pointillé. Sur la partie médiane du corps, on aperçoit le vaisseau dorsal, dont les mouvements se distinguent parfaitement sous la peau qui est très-transparente. 
La partie postérieure paraît noiràtre comme chez la plupart des larres des scarabéiens; ce qui est dù à la coloration des matières renfermées dans les voies digestives. Sur les parties latérales de chaque anneau, en exceptant les deuxiëme et troisième ainsi que le dernier, on voit un stigmate, rendu très-visible par le bord corné qui l'entoure; sa couleur rouge tranche parfaitement sur la teinte générale blanchàtre de la larre. La tête et les parties de la bouche ont une nuance rougeàtre, les mandibules seules sont noires à l'extrémité,

Ces jeunes larves d'abord peu rolumineuses commencent à s'accroître pendant les six derniers mois de l'année et pendant les deux années suivantes tout entières. La première année elles se nourrissent probablement des débris des végétaux décomposés que la terre renferme autour d'elles.

A l'entrée de l'hiver (elles sont encore toutes dans la cavité qui leur a servi de berceau) l'engourdissement les gagne et elles ne se réveillent qu'au printemps de l'année suivante.

A ce moment la petite famille se sépare, chacun tire de son côté, s'ourre une galerie qui monte obliquement, mais sans jamais arriver jusqu’à la surface extérieure. La larve s'arrête aux racines, elle dérore d'abord celles des céréales et des légumes, puis, lorsque les larves sont plus fortes, les racines des arbustes et des arlires. D'immenses pièces de gazon; de luzerne, d’avoine ou de blé jaunissent $\in \mathbb{l}$ meurent. Aussi, jadis, les foudres de l'excommunication furent lancées contre ces emnemis souterrains et aussi contre les chenilles. Les mans, cause d'une famine, 
ètaient cités en 1479 devant le tribunal ecclésiastique de Lausanne, défendus par un avocat de Fribourg qui perdit son procès. Le tribunal, après mûre délibération, les bannit formellement du territoire.

Dès que le second hiver arrive, ne se sentant pas assez protégées contre le froid, les larves redescendent dans la terre et passent la mauraise saison dans une sorte d'engourdissement qui les dispense de boire et de manger.

Au printemps suivant, réveil, nouvelle ascension et en hiver descente dans les couches inférieures; mais vers la fin de l'èté de la seconde année qui a suivi la ponte, le ver blanc, parvenu à toute sa croissance, par une sorte d'instinct de conservation, s'enfonce profondément à plus d'un demi-mètre, se façonne une loge ovalaire dont les parois sont assujetties au moyen d'une bave glutineuse sécrétée par l'animal, qui s'y change en nymphe.

Dans cet état les élytres et les ailes couchées recouvrent les pattes et les antennes. Dès la fin d'octobre, la plus
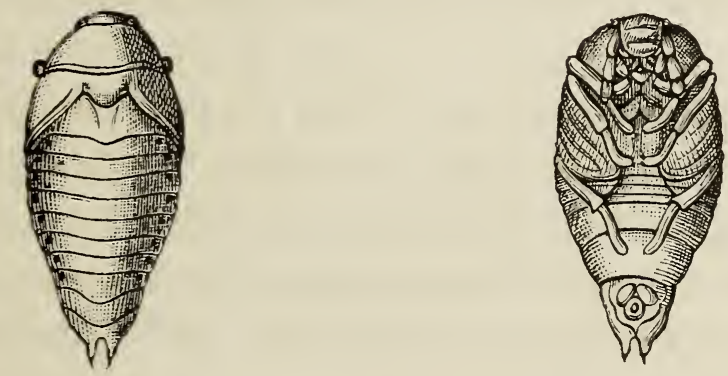

Fig. 19 et 20. - Nymphes du Hanneton.

grande partie des Hannetons sont devenus insectes parfaits, mais encore d'un blanc jaunâtre, mous et sans force. Ils passent l'hiver dans la chambre natale, se durcissent 
et se colorent vers la fin de février et remontent peu à peu pour sortir de terre en mai.

La durée de la vie de nymphe est d'environ six semaines. L'insecte parfait éclôt ainsi au printemps, trois années entières après ceux qui lui ont donné le jour.

Voilà pourquoi il y a, tous les trois ans, une année à Hanneton. Dans les années intermédiaires ils ne sont jamais très-abondants, et la même régularité dans les apparitions s'observe constamment. On les voit quelquefois apparaitre quand la saison est chaude. Dès la fin d'avril, mais c'est toujours en mai qu'ils se montrent en grande quantité ; on les trouve jusqu'en juin. Ils se tiennent pendant tout le jour à la partie inférieure des feuilles des arbres; sans doute pour se mettre à l'abri des rayons du soleil, c'est seulement le matin, de bonne heure et surtout le soir au coucher du soleil qu'ils prennent leur essor. Ils volent à ce moment avec rapidité, en faisant entendre un bruit monotone produit par le frottement de leurs ailes, ils se dirigent mal et s'en vont se cognant les uns contre les autres.

Le Hanneton, dont le corps est lourd, prend difficilement son essor. Aussi agite-t-il ses ailes pendant plusieurs minutes et gonfle son abdomen, de manière à faire pénétrer dans les stigmates la plus grande quantité d'air possible. Les enfants disent alors que le hanneton compte ses écus et ils répètent la chanson: Hanneton, vole, vole, va-t'en à l'école.

A l'état d'insecte parfait, le Hanneton est nuisible aux arbres dont ils rongent quelquefois toutes les feuilles, surtout quand un hiver doux et sec coïncide avec l'année de leur apparition. 
En 1574, les Hannetons furent si abondants en Angleterre que leurs corps empêchèrent plusieurs moulins de tourner sur la Savern. En 1688, l'air en était obscurci en Irlande. En 1841, ảans les environs de Mâcon, des nuées de Hannetons franchirent la Saône dans la direction du sud-est et s'abattirent sur les vignes. Les rues en étaient jonchées, et à certaines heures en passant sur le pont, il fallait faire des moulinets avec sa canne pour n'en être pas couverts.

0 . Heer rapporte qu'en 1807 on prit en Suisse plus de 17,000 mesures pouvant renfermer 9,000 Hannetons chacune; on en détruisit plus de 150,000,000.

Le conseil général du département de la Sarthe vota, en 1855, une somme de 20,000 francs pour détruire les Hannetons. Près de 60,000 décalitres contre autant de primes de 0 fr. $30 \mathrm{c}$. Or, comme un décalitre en contient plus de 5,000 , on détruisit environ $300,000,000$ de Hannetons.

Voici un exemple de l'énorme quantité de vers blancs qu'un territoire peut quelquefois renfermer. Dans une pièce de terre de 29 ares, on a donné trois labours et fait 72 raies. Dans le premier labour, on a ramassé par raies 300 vers blancs; dans le deuxième labour, 250; dans le troisième 50 , toujours par raie, ce qui fait 600 par raie. Ce qui, tous calculs établis, porte le chiffre à 60,000 par arpents et 141,000 par hectare.

\section{MOYENS DE DESTRUCTION}

Quels sont maintenant, pour l'agriculture, les moyens de combattre un aussi redoutable ennemi? 
$1^{\circ}$ Une fois qu'on sait sa terre infectée, mener aussitôt après le labour une bande de dindons dans le champ. Ils se feront une fète d'avoir été invitè à pareil repas.

$2^{\circ}$ Semer dans le champ infesté du colza très-épais : lorsqu'il a quinze à vingt centimètres de hauteur, on l'enterre par un labour profond. Le contact de colza pourri dans l'intérieur du sol fait périr les larves de Hanneton, et le colza enfoui vert produit, quant à la fertilitè du sol, l'effet d'une demi-fumure.

On laboure la terre à l'approche des fortes gelées et le ver blanc meurt des rigueurs de la saison.

On a conseillé dans ces derniers temps d'arroser les champs avec de l'huile de houille ou d'y répandre des cendres de buis.

\section{PARASITES JDES LARVES DE HANNETON.}

II. Bourgeois a lu, en 1864, à la Socièté d'agriculture la note suivante sur les parasites des larves de Hannetons.

" J'ai déjà eu l'honneur d'entretenir la Socièté d'agriculture des dommages que j'ai éprouvés dans une partie haute de 7 hectares 50 ares, situés au Perray, près Rambouillet, qui a èté envahie par les Hannetons. Au mois de mai de l'année 1863, une quantité innombrable de Hannetons avaient déposé leurs œufs dans l'herbe de la prairie, recouvrant une terre assez meuble; dans cette même année, mon pré me donna plus que 40,000 kilogrammes de foin, près de 1,100 bottes de 5 kilogrammes à l'hectare; à la fin du dernier hiver, je m'aperçus que la moitié des graminées avaient péri, mangées par les vers blancs. Je 
fis semer, en février, une assez grande quantité de graines ; ces graines levèrent assez bien, mais elles ne résistèrent pas à la sécheresse de l'année; seulement la prairie se regarnit, en partie, naturellement par de la grande paquerette dont les touffes vigoureuses avaient d'abondantes racines qui fournirent longtemps après la récolte du foin, à la voracité des larves, parvenues déjà à plus de la moitié de leur grosseur. Mlais au mois de septembre, les plantes, paquerettes et autres, n'adhérant plus au sol, dont elles étaient séparées par les nombreuses galeries qu'avaient pratiquées les vers blancs en coupant les racines, s'enlevaient comme des toisous et l'on comptait jusqu'à 40 et 50 vers blancs par mètre carré dans certaines parties. Toutefois la récolte de cette année n éprouva de déficit, en quantité, que d'environ un quart.

«Je ne vis d'autre parti à prendre que de faire labourer toute la prairie, en profitant de la sécheresse pour détruire plus facilement cette énorme quantité de vers qui ne permettait plus de tenter aucune culture. Je mis dix femmes et enfants, espacés derrière la charrue dans la longueur du réage, pour ramasser les larves que l'on découvrait; on put en recueillir environ 15 hectolitres au premier labour, qui fut fait à 10 centimètres au plus de profondeur ; et, comme on en laissait à peu près un tiers dans l'épaisseur du labour, quinze jours plus tard je fis donner un hersage, après lequel on en ramassa encore une certaine quantité; puis enfin on fit un second labour, où quatre femmes suivirent encore la charrue et ramassaient ce qu'elles pouvaient en trouver, non sans en laisser encore un assez grand nombre. 
"Une chose fort remarquable, c'est que les vers blancs que l'on trouvait dans les derniers temps, c'était à la fin d'octobre, avaient, dans la proporticn d'un quart de leur nombre, comme un ver solitaire lisse et blanc dans le corps de 10 et 12 centimètres de longueur et de la grosseur d'ine corde chanterelle de violon, souvent on leur voyait rendre ces vers, ou on en trouvait dans la terre séparément enroulés; quelques-uns avaient encore de la vie ; la larve, après cette évacuation relativement considérable, était devenu très-flasque et prenait une couleur jaunâtre; probablement elle ne tardait pas à périr, cependant on n'en trouvait pas de morte. J'ai fait, à cet égard, une expérience: il faut dire que les larves qui ont cette maladie se distinguent aisément ; on voit, à travers la membrane transparen:e de l'abdomen, le ver enroulé. J'ai donc mis dix de ces dernières larves dans un pot à fleurs rempli aux trois quarts par une forte touffe d'herbes bien enracinée qui avait été levée en motte ; quinze jours après, j'ai renversé ce pot et j'y ai trouvé huit larres mortes et, séparément, le même nombre de vers (je pense que chaque larve n'a jamais qu'un vers); je n'ai rien vu des deux autres larves; je présume que, mortes les premières, elles se seront décomposées et confondues avec la terre. J'ai l'homneur de mettre sous les yeux de la Société les huit larves et leurs vers; je n'ai pu retrouver en terre aucune larve malade, toutes celles qui étaient atteintes du ver solitaire auront péri ; leurs vestiges ont eu le temps de se décomposer. Si cette maladie est générale, ce que je n'ai pas eu le temps de vérifier, ce serait toujours une destruction d'un quart au moins pour cette année-ci. 
Ce qui corrobore cette épreuve, c'est que j'ai, dans d'autres pots, des larves saines qui sont parfaitement vivantes, même dans un pot où il n'y a que de la terre sans herbe qui puisse les nourrir, car je voudrais voir si elles périraient par la famine. ")

M. Guérin-Méneville a demandé ensuite à placer quelques observations au sujet du parasite trouvé sur le ver blanc du Ilanneton. Il a dit que ce parasite appartient au genre filaire, dont beaucoup d'espèces vivent sur le corps des animaux. Le plus grand des filaires est le fameux ver de Médine, qui vit dans les muscles des jambes de l'homme et atteint là jusqu'à 4 mètres de longueur.

Les insectes sont donc également sujets à porter et à nourrir de leur propre substance de pareils hótes. L'étude n'a pu découvrir dans ces parasites aucune trace d'organes de reproduction. Il est probable qu'ils traversent seulement une période de leur existence dans le corps de l'animal. Quand ils ont quitté l'insecte qui leur a donné l'hospitalité momentanée, quand on les trouve dans la terre, sous les feuilles humides, sur le sol, ils sont déjà pourvus d'organes mâles et femelles. On pense qu'ils doivent pondre dans la terre et que les jeunes sujets provenant de ces œufs pénètrent dans les larves de ces Hannetons. Ceci n'est qu'une conjecture et l'on ne sait au reste rien sur la manière dont ils se développent, une fois sorti du sein de la larve dont ils ont fait leur pâture. 


\section{ANISOPLIE}

(Anisoplia agricola).

Au moment oủ les seigles et les froments sont en fleurs on voit fréquemment accrochè à l'épi un petit Hanneton semblable à celui des jardins. Il a 10 millimètres de longueur et 5 millimètres de largeur. La tête et le corselet sont d'un vert foncé avec un sillon au milieu. La tête est
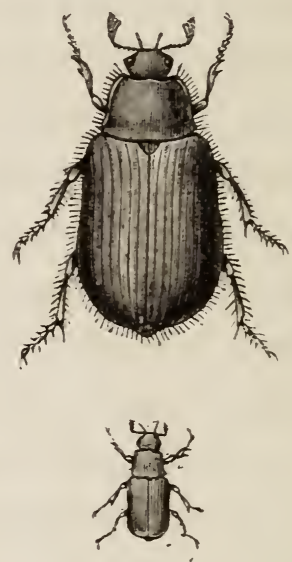

Fig. 21. - Anisoplie, grosssie et grandeur naturelle.

rétrécie en devant, formant un chaperon avancé à bord relevé; antemnes de neuf articles, noires, à massue de trois feuillets; les yeux sont petits; le thorax plus large que la tête, légèrement rétrécie en devant, à côtés arrondis et base sinuée; élytres ovales, un peu courtes, larges, brillantes, d'une couleur ocreuse rouillée, couvertes d'une faible ponctuation et de sept stries indistinctes; tache carrée nnire autour de l'écusson; épaules et bords 
externes irrégulièrement noirs; une raie transversale, formée de taches réunies, plus ou moins brune ou ferrugineuse indique des variètés. Les deux derniers segments de l'abdomen sont visibles, noirs, couverts de poils jaunàtres, ainsi que les côtés de l'abdomen ; pattes fortes, ponctuées arec une teinte verte.

Ce petit Hanneton est commun dans le midi de la lirance et se troure isolément ou en groupes sur les épis, rongeant les grains tendres du seigle et ceux du blé qui, à ce qu'il parait, sont plus de son goût. Kollar rapporte qu'il a trouvé des épis dont le tiers des grains était détruit par cet insecte. Cet observateur ajoute qu'il ne sait pas si les larres attaquent les racines du blé ou si elles vivent dans le fumier. M. Goureau dit qu'elle vit probablement dans la terre comme ses congénères en rongeant la racine des régétaux. Les corbeaux, les taupes et les mulots sont leurs ennemis naturels.

Dans les amnées où elles sont en grand nombre, M. Joigneaux conseille, si la disposition des champs le permet, de faire marcher des enfants entre les sillons pour les prendre. On pourrait en détruire ainsi un très-grand nombre dans une journée, mais comme ces insectes peuvent voler d'un champ à l'autre il serait indispensable, pour que ce moyen eût du succès, que tous les fermier's d'un canton le pratiquassent ensemble. 


\section{TA UPIN}

(Elater, Diacanthus latus. - Maréchal, Toque-Marteaux).

Le Taupin est un coléoptère de la tribu des élatériens dont les insectes ont une texture non-seulement solide mais sourent très-dure : ils sont généralement d'assez grande taille, rarement très-petits. Les élatérides parmi lesquelles on range les Taupins ont un caractère particulier. Leur prosternum se prolonge en arrière en une pointe comprımée, pouvant pénétrer dans une fossette située à la base du mésosternum entre la base des pattes intermédiaires.

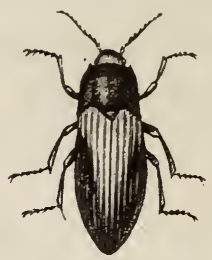

Fig. 22. - Taupin maréchal.

L'animal fait entrer à rolonté cette pointe dans cette cavitẻ du mésosternum, et la fait ressortir au moyen d'un effor't brusque qui détermine la projection du corps en l'air. C'est cette particularité qui a valu aux élatérides les noms de Taupins maréchals, etc. Ces coléoptères ont des pattes assez courtes et un corps généralement allongé, conformation qui permet difficilement à l'insecte de se redresser lorsqu'il tombe sur le dos. C'est done, dit II. Blanchard, au moyen de sauts qu'il parvient à se remettre sur ses pattes; et quelquefois il est obligé d'en exécuter plusieurs avant 
d'y réussir. Dans cet exercice la tète et le corselet de l'insecte se redressent d'abord lentement et tout d'une pièce; puis comme par l'effet d'un ressort brusquement détendu, la tète est violemment rejetée en arrière. Linsecte fait un saut et retombe sur' ses pittes.

Au mois de juillet surtout on voit "Certaines espèces sur les épis de blé. Mais on pense que ce sont spécialement les larves des Taupins qui sont nuisibles en rongeant les racines du blé et la partic de la tige cachée dans la terre.

II. Gourenu décrit ainsi les larves : elles sont cylindriques, allongées, luisantes, à peau écailleuse, de couleur jaunàtre, formées de 12 segments sans compter la tête, qui est aplatie en forme de coin armée de deux mandibules et pourrues de deux petites antennes, de trois articles et de deux palpes de quatre articles. Elles ont six pattes thoraciques et un namelon à l'extrémité du corps, faisant l'óffice d'une septième patte. L'anneau qui porte ce mamelon est plus long que les autres et de forme conique. res larres ressemblent beaucoup, pour la forme, la couleur et la peau écailleuse, a celles qui virent dans la farine et qu'on appelle vers de farine, lesquelles produisent le Ténébrion meunier.

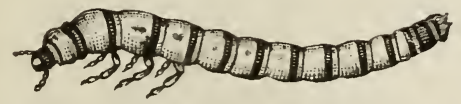

Fig. 22. - Larve du Ténébrion meunier.

Un pense que la femelle pond six oufs au pied des jeunes plantes deblé, contre la racine ou entre les fenilles qui enveloppent cette jeune plante. C'es œuls sont très-petıls, globuleux ou un peu ovales, d'un blanc jaunatre ; les petits ver's qui en sortent crissent très-lentement et finissent par 
atteindre la longueur de 18 à 25 mill. Ils passent cing ans dans cet état. Lorsqu'ils ont pris toute leur croissance, ils descendent dans le sol à une profondeur considérable et construisent une cellule ovale arec des parcelles de terre, sans aucun mélange de soie. Ils se dépouillent rle leur peau et se changent en chrysalide à la fin de juillet et au commencement d'août. Cette chrysalide est étroite et allongée, molle, d'un bilanc jaunâtre et immobile. Plusieurs ont été trouvées dans cet état, le 26 juillet 1841 .

Les espèces que l'on voit le plus communément dans les champs de blé sont au nombre de quatre, très-bien décrites par M. Goureau.

\section{TAUPIN CRACHEUR}

(Elater (agriotes) sputator.)

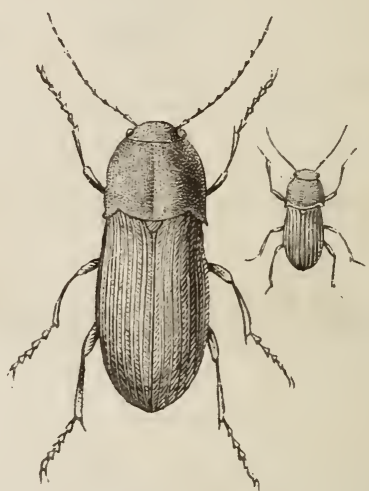

Fig. 25 - Taupin cracheur, grossi et grandeur naturclle.

Le Taupin cracheur a 7 à 8 mill. de long; il est brillant, coulem de poix, recouvert d'une très-courte pubescence jaunâtre; la tête, le thorax sont noirs, finement pointillés ; 
ce dernier est orbiculaire, convexe arec les angles postérieurs prolongés en une forte dent, quelquefois roussi, le dos est canaliculé, les élytres sont de la largeur du thorax, mais plus de deux fois aussi longues, elliptiques, courertes, légèrement rugueuses arec neuf stries ponctuées sur chacune; les antemnes et les pattes sont rousses, les premières de la longueur du thorax et grêles.

Cet insecte varie pour la couleur, ce qui a donné lieu d'en faire plusieurs espèces. Il a été nommé Elater variabilis par Herbst; Elater obscurus par Paykull. Il est très-abondant partout depuis le commencement de mai jusqu’à la fin de juin dans les haies, sur le gazon; dans les champs de blé.

\section{TAUPIN OBSCUR}

Elater (agriotes) obscurus.)

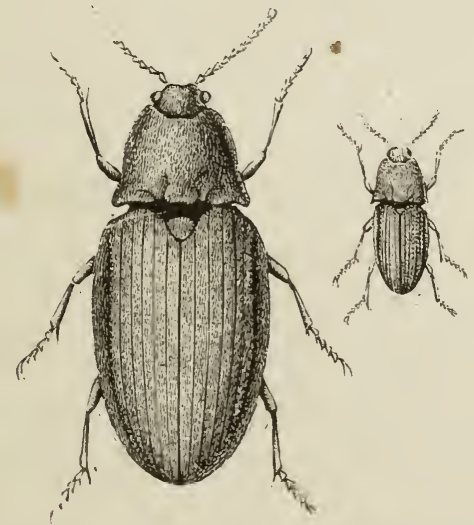

Fig. 24. - Taupin obscur, grossi et grandeur naturelle.

Le Taupin obscur, nommé aussi Elater variabilis, par Fabricius, et Elater obscurus, par de Geer, a 9 mil. de lon- 
gueur; il est brun couleur de poix, courert d'une épaisse pubescence jaunàtre, la tète et le corselet sont distinctement ponctués ; le second est aussi large que long, orbiculaire, très-conrexe, arec les angles postérieurs prolongés en forte épine et un sillon au milieu du dos; l'écusson est ovale, les élytres sont de la largeur du thorax, presque trois fois aussi longues, elliptiques, conrexes, coniques à l'extrémité, quand elles sont réunies, d'un brun rougeâtre, ponctues, ayant chacun neuf stries ponctuées, quelquefois par paires ; les antennes sont un peu en massue, aussi longue que le thorax, d'un brun rougeàtre ainsi que les pattes.

La pubescence est quelquefois si épaisse qu'elle domne à certains individus une apparence brun foncé, tandis que d'autres paraissent noirâtres. Depuis avril jusqu'au milieu de l'été, ce Taupin est abondant dans les champs, les pàturages, les bois et les jardins.

\section{TAUPIN A LIGIES}

(Elater (agriotes) lineatus.)

Le Taupin ì lignes, est appelé Elater striatus, par Panzer; E. segetis, par Bierkander. On suppose qu’il est une simple rariété de l'Agriotes obscurus dont les élytres sont rayées, les espaces entre les lignes étant alternativement obscurs et clairs, formant quatre lignes brumes et cinq lig̨nes testacés.

Il est excessivement commun dans ses diffèrents états et 
s'obtient facilement lorsque l'on veut récolter ces larres. M. Curtis en a trouvé abondamment sous les pierres en avril ; le 25 mai il y en avait de rassemblés sur une renoncule jaune; ils s'en nourrissaient ; ils abondent aussi dans les haies et dans les champs de blé.

II. Émile Blanchard a décrit cet insecte sous le nom d'Elater segetis. Il est, dit-il, long de 10 centimètres et entièrement d'un faure obscur, tant en dessus qu'en dessous ; sa tête est courte et très-engagée dans le corselet; Ses élytres sont oblongues, assez convexes, ayant chacune neuf stries longitudinales assez profondes et fortement ponctuées ; les intervalles des stries sont alternativement lisses et garnies d'un fin duvet d'un gris jaunâtre, en sorte que les élytres, vues sans le secours de la loupe, semblent présenter une série de lignes longitudinales grisâtres, sur un fond plus obscur.

La larve a quelquefois plus de 2 centimètres de longueur ; elle est mince, presque cylindrique, entièrement d'un jaune uniforme, brillant, quelquefois brunâtre. La tête de forme un peu carrée, présente, en dessus, deux sillons longitudinaux; et, sur les côtés antérieurement elle est munie d'antennes, triarticulées, extrêmement courtes, etc. Les rarages de ces larves portent sur les racines du blé, du seigle, de l'orge. Ils sont parfois considérables et d'autant plus graves qu'on n'a pas de moyen d'action contre elle. Il serait essentiel, dit M. Blanchard, de savoir d'une manière précise, le moment de la ponte et à quel endroit elle s'effectue ${ }^{1}$.

1 Voir l'excellent travail de II. Blanchard, Bulletin des séances de la Société d'agriculture, 2e série, t. III. p. 35 't et suirantes. 


\section{TAUPIN HEMORRHOÏDAL}

(Elater (athous) rufiarudis.)

Le Taupin hémorrhoüdal. Elater sputator, Oliv., E. hæmorrhö̈dalis, Fab., E. analis, Herbst. Il est long de 15 millimètres et large de $\overline{5}$ millimètres. Sa couleur est d'un brun

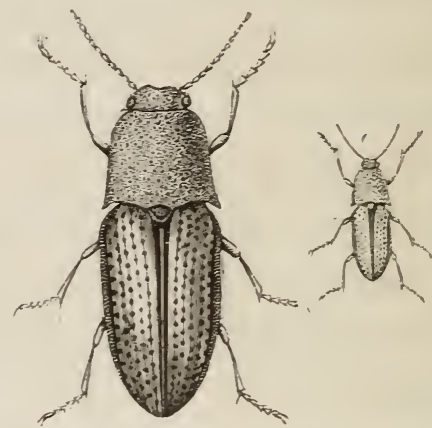

Fiø. 2ว̃. - Taupin hẻmorrhoïdal, grossi et grandeur naturelle.

de poix brillant; il est couvert de longs poils jaunâtres ; les antennes sont brunes, aussi longues que le thorax; la tête et le corselet sont noirs, finement ponctués; la première est semi-orbiculaire; le chaperon est tronqué et réfléchi; le second est plus long que large, un peu plus étroit aux angles antérieurs; les angles postérieurs sont prolongés en épines courtes, triangulaires, et le bord inférieur s'avance considérablement pour receroir la tête; l'écusson est noir ; les élỵtres sont d'un rougeâtre brun, deux fois aussi longues que la tête et le thorax, plus larges que ce dernier; elles sont finement pointillées arec neuf stries sur chacune; l'abdomen est ferrugineux; les pattes sont courtes et fer- 
rugineuses, les tarses paraissent de quatre articles trèspubescents en dessous.

Il est abondant depuis avril jusqu'au commencement de juin dans les champs de blé, sur les orties et dans les pâturages.

\section{TAUPIN GRISELLE}

(Elater (agriotes) gilvellus, Zigler.)

Le Taupin griselle (Elater blandus, Germar) a une longueur de 10 millimètres, une largeur de 3 millimètres. Tête et corselet noirs, finement ponctués; antennes filiformes, de la longueur du corselet, rougeâtre, à premier article noir ; écusson noir ; corselet bombé à angles postérieurs prolongés en épines; élytres de la largeur du corselet, deux fois aussi longues que ce dernier et la tête réunis, testacées, finement pointillées avec neuf stries sur chacune; brunes vers l'extrémité qui est arrondie lorsqu'elles soint jointes; dessous brun de poix; cuisses brunes; tibias testacés ainsi que les tarses.

Cet insecte varie pour l'étendue de la nuance brune de l'extrémité des élytres. Il est excessivement abondant ả Santigny sur les fleurs d'hièble, le long des chemins qui traversent les champs. 


\section{HYLASTE DU TREFLE}

(Hylastes trifolii.)

L'Hylaste du trèfle fait "partie d'un groupe de coléoptères bien connus sous le nom de bostrichiens, les-

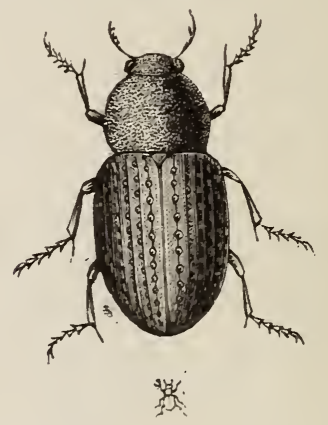

Fig. 26. - Hylaste du trèfle, grossi et grandeur naturelle.

quels ont la plus grande analogie avec les ptinides, insectes très-petits, la plupart d'une couleur grisâtre ou brunâtre, la tête très-enfoncée dans le thorax ; ils contrefont le mort dès qu'on les inquiète et se laissent choir en contractant toutes leurs pattes. Leurs larves ressemblent à de petits vers.

Les bostrichiens attaquent surtout les bois, mais l'hylaste du trèfle fait exception, il vit dans les racines du trèfle commun, auquel il nuit parfois beaucoup lorsqu'il se multiplie outre mesure.

C'est un petit insecte long de $0^{\mathrm{m}}, 002$ eylindrique, bru$n$ âtre, avec antennes ayant leurs dernicrs articles trèsgrands, aussi longs que le reste de l'antemne. 


\section{CARABE}

(Jardinière. - Couturière. - Sergent. - Vinaigrier.)

Les Carales appartiennent à l'une des plus nombreuses tribus des coléoptères. Insectes à pattes longues et bien développées, toujours propres à la course et à mâchoires

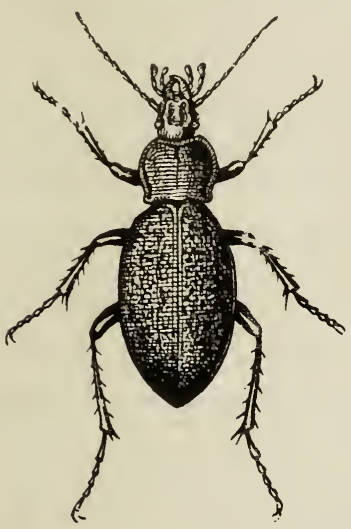

Fig. 27. - Type du Carabe.

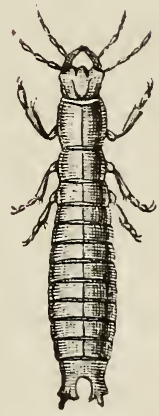

Fig. 28. - Larve du Carabe dolé

munies de deux palpes. Les carabiens sont, en général, de forme oblongue et assez déprimée; leur consistance, sans être aussi solide que chez beaucoup d'autres coléoptères est encore très-ferme.

Les carabiens se réfugient sous les pierres et sous les écorces; mais souvent, pendant les beaux jours du printemps, on les voit courir dans les chemins, quand on veut les saisir, ils vous lâchent dans les mains un liquide brunâtre.

II. Émile Blanchard dit yu'on s'accorde à regarder comme type du genre le Carabe doré (Carabus auratus, 
Lin.), connu dans les campagnes sous le nom de Jardinière. La fierté de sa démarche, la liberté de ses allures, l'éclat de son baudrier font reconnaitre, à distance, cet insecte d'un beau rert doré arec trois côtes sur les élytres et dont les pattes et les antennes sont roussâtres.

On ne saurait, au reste, se plaindre, dit le sarant naturaliste que nous venons de citer, de l'abondance d'un tel insecte; car il détruit nombre d'insectes nuisibles à l'agriculture.

Il s'en prend même à des Hanmetons. C'est, ajoute I. Blanchard, ce que nous arons observé nous-même plusieurs fois. Un Carabe doré, au milieu d'un chemin tenait un Hameton, lui ouvrait le ventre arec ses mandibules et lui dévorait les intestins, tandis que le Hanneton se remuait et quelquefois marchait en subissant ce singulier supplice; car le Carabe doré, loin de le lâcher, le suivait sans arrêter sa manœurre un seul moment. Quant à moi, j'ai vu un Carabe dévorer une chenille, mais ce qui m'a surtout frappé c'est le goût prononcé de cet insecte pour les vers de terre. Je l'ai vu manger sans interruption un ver qui avait près de 10 centimètres de longueur.

La larve du Carabe doré a èté observée plusieurs fois par II. Blanchard, mais comme il n'a pas réussi à obtenir la nymphe, il n'a pas décrit cette larve qui a été étudiée par II. Ratzeburg. Elle est très-carnassière et détruit un grand nombre d'insectes parfaits et d'autres larves dans les pays où il y a beaucoup de Hannetons. A ce titre les Carabes seraient donc des insectes utiles et non pas nuisibles à l'agriculture. 
Mais il y a une espèce de la même famille qui est réellement nuisible, c'est le Zabre bossu (Zabrus gibbus), décrit par Curtis.

\section{ZABRE BOSSU OU CARABE BOSSU}

(Carabus gibbus. Fah. - Zabrus gibbus.)

Cet insecte très-commun en Europe est long de 12 à 15 millimètres, d'un brun noiràtre, plus clair en dessous qu'en dessus, ses élytres sont striées, ses antemnes,

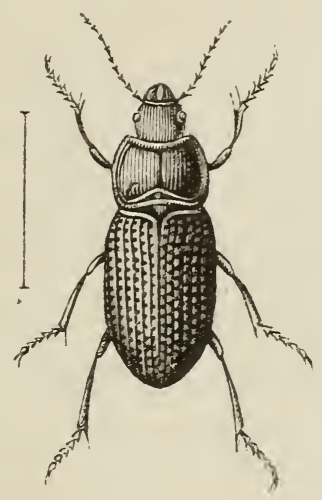

Fig. 2). - Carabe bossu.

ses tarses ferrugineux. Sa larve est de forme oblonglie avec le dernier anneau terminé par deux pointes aiguës. Les entomologistes allemands assurent qu'elle vit pendant la nuit sur les jemes pousses du blé auxquelles clle cause de grands dégâts et que, pendant le jour, clle s'enfonce dans la terre. 
A l'ètat parfait, l'insecte est d'un noir brun, luisant, ressemblant assez pour la forme et la couleur à l'espèce que produit le ver de farine mais moins allongé, plus trapu. On le trouve fréquemment, surtout en automne, dans les sentiers qui traversent les champs de blé ou dans les fossés qui les bordent. M. Goureau a décrit cet insecte sous le nom de Carabe bossu. On l'appelle encore Carabe paresseux.

Quoiqu'il fasse partie de la famille des coléoptères carnassiers et que ses associés vivent de matières animales, sous leurs deux états de larve et d'insecte parfait, il fait exception à la règle générale et se nourrit de substances régétales, au moins pendant son premier âge, et pendant ce temps il cause du tort au blé dans les cultures.

La femelle pond ses œufs en une seule masse dans la terre; les larves qu'ils produisent paraissent mettre trois ans à prendre toute leur croissance, car on en troure qui ont atteint la moitié de leur taille et dans le même temps on rencontre des nymphes. Elles sont sourent accompagnées des larves du petit Ilanneton ou Hanneton d'èté. Elles sont d'une couleur brune sur les côtés et le dessous, blanchâtres, presque lincaires, atténuées à l'extrémité postérieure, un peu déprimées, légèrement velues et de la longueur de 2ə̆ mill. La tète est large, armée de deux fortes mâchoires, de palpes grêles et de deux jolies antennes de quatre articles, placés devant les yeux.

Les larves creusent dans la terre et font quelquefois un immense nombre de galeries verticales qui commencent souvent en ligne courbe et s'étendent de $\breve{~ a ̀ ~} 50$ centimètres de profondeur; et dès qu'elles ont pris toute leur 
croissance elles pratiquent à l'extrémité de leur galerie une cellule lisse en dedans, dans laquelle elles se transforment en nymphes molles, sensibles, d'un blanc jannâtre avec deux yeux noirs. Elles restent dans cet état pendant trois à quatre semaines seulement, car la larve qui s'est clrangée en nymphe au commencement de juin se transforme en insecte parfait à la fin de ce mois et an commencement de juillet.

Joigneaux donne les détails suivants sur ses habitudes: pendant le jour elle se tient dans des trous de 15 centimètres environ de profondeur; à l'approche de la nuit elle en sort pour commettre ses déprédations. Au moyen de puissantes mandibules elle fouille à la base de la plante. Si celle-ci est jeune, elle la coupe et l'attire dans son trou, d'autres fois elle ronge sur pied le dedans de la tige dı blé près du sol et se nourrit de la moelle.

Lorsqu'elle est sur le point de se métamorphoser elle s'enfonce en terre et y reste, comme nous venons de le dire, trois à quatre semaines. Vers le mois de juillet elle est insecte parfait et, dans cet état, le Zabre bossu est encore nuisible au blé. Le jour il est caché sous les pierres, sous les mottes de terre, enfin sous tout ce qui peut lui servir d'abri et ce n'est que le soir qu'il se met en mouvement. 11 grimpe alors le long des chaumes et va dévorer le grain dans l'épi ; comme il est d'assez grande taille, on concoit quel dommage il peut causer aux rícoltes surtout lorsque, par exception hemrensement, il se montre en grande quantité.

En 1776, il dévasta complétement toutes les campaagnes de la haute Italie. 
En 1812, les dégàts qu'il commit dans certaines localités de la Prusse furent tels que les cultivateurs s'en plaignirent hautement et s'adressèrent à l'autorité pour qu'elle prit des mesures contre cet ennemi commun.

Les campagnes des environs de Huy en Belgique eurent à souffrir du Zabre pendant les derniers mois de l'année 1858 et le printemps de l'année suivante.

Dans un rapport fait à l'une des sociétés agricoles du pays, on trouve que dans sept communes seulement, 11 ' hectares sur 457 ensemencés de seigle furent complétement rasés. Le seigle ne fut pas la seule plante attaquée; quelques pièces de froment eurent également à souffrir de la voracité des Zabres.

\section{MOYENS DE DESTRUCTION}

Moyens de destruction. - Ils sont nombreux sinon d'une efficacité parfaite. On recommande $1^{\circ}$ de faire connaitre l'insecte parfait aux cultivateurs, aux maîtres d'école des villages et par ceux-ci aux enfants qui, pour une légère récompense, en détruiront une grande quantité; $2^{\circ}$ de ménager les oiseaux insectivores, notamment les corneilles, qui en consomment beaucoup. Les chouettes et l'engoulerent en détruisent également une certaine quantité.

Contre la larve on a proposé de semer sur les terres, au printemps, des cendres de tourbe ou de chaux; de retourner profondément la ter'e au commencement de l'automne et de choisir, pour faire cette opération, un 
jour de gelée légère; par ce moyen, les onseaux en détruiront un certain nombre; de passer sur les terres infestées un rouleau étroit et très-pesant; ce moyen ne sera du reste efficace que s'il est pratiqué pendant la nuit; alors que les larves sont sorties de leurs retraites, on en écrasera de la sorte une bonne partie. Les larves des Zabres, comme celle de tous les carabiques sont très-délicates et la moindre blessure les tue.

\section{TROGOSITE MAURITANIQUE OU CADELLE}

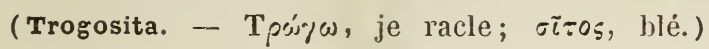

On appelle Trogosite un insecte nuisible aux grains, son nom a été formé de deux mots grecs qui signifient : Je racle le blé. Il appartient à la famille des coléoptères. Ce genre,

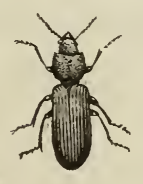

Fig. 50. - Trogosite ou Cadelle.

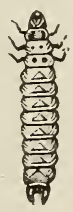

Fig. 51. - Larve du Trogosite.

créé par Olivier, pour y placer des espèces que Linné rangeait avec les Tenebrio et Geoffroy avec les Platycerus, était placé dans la famille des Xylophages et renfermait une soixantaine d'espèces propres à l'Europe, à l'Afrique et à l'Amérique. Erichson l'a placé dans la famille des Nitidulaires. Le Trogosite appartient à la tribu des Eroty- 
liens, insectes lisses et brillants dont les formes varient beaucoup, la plupart sont assez convexes. Les larves de ces coléoptères sont' blanchâtres et presque cỵlindriques.

Le trogosite mauritanique, comme les Erotyliens, possède des tarses qui sont composés de quatre articles (tétramères) peu ou point dilatés. Palpes filiformes, corps déprimé long de 3 lignes.

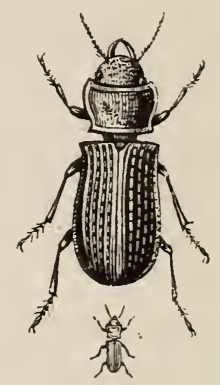

Fig. 52. - Trogosite mauritanique.

Voici ses caractères distinctifs : antennes in peu g̨renues, avec les trois derniers articles grands, un peu en dents de scie. Mandibules courtes.

La larve du Trogosite qui, dans le Midi, cause de grands ravages an blé, est blanche avec la tête noire, armée de deux mâchoires cornées, courbées et aiguës. 11 attaque le grain à l'extérieur. Bien différent en cela de l'Alucite et. du Charançon, lorsque l'approche de sa métamorphose la force à chercher un abri paisible dans les crevasses des murs ou les fentes des planchers, elle fait la guerre aux larves des autres rongeur's de blé qu'elle y rencontre. L'insecte parfait, quoique habitant ainsi les greniers, ne tou- 
che pas aux grains et continue d'attaquer les larres des autres insectes nuisibles.

A la fin de juillet, cet insecte vient faire sa ponte sur le grain; on a remarqué que la larve, lorsqu'elle quitte les monceaux de blé, se sert de ces deux crochets abdominaux pour se suspendre aux murailles, aux plafonds, pour y faire la chasse.

Cet insecte, suivant certain auteur, nous serait venu d'Algérie avec les blés de Barbarie. On peut citer à l'appui de cette opinion qu'il est rare au centre de la France, où la rigueur du climat lui est contraire, de mème que dans le Midi, il disparait presque complétement quand l'hiver est un peu froid.

On a conseillé des moyens plus ou moins difficiles à employer et plus ou moins infructueux, pour se mettre à l'abri des dégâts de ces larves, nous croyons devoir exposer les plus simples et sans doute les plus utiles. La Cadelle n'attaque pas le blé renfermé dans des sacs dès qu'il est battu. Il est prouvé aussi que le blé vanné dans le mois d'octobre et de novembre est bien moins endommagé, sans doute parce que les insectes nouvellement nés se détachent et tombent du grain, par le mouvement et les secousses du van. On pourrait s'en garantir encore plus aisément en soumettant le blé à un lavage vers le commencement de l'hiver. En choisissant un courant peu rapide, le grain se précipite et l'eau emporte les œufs ou les insectes déjà éclos.

Le meilleur moyen de garantir le blé de la Cadelle dans le grenier serait de bien crépir les murs et les voûtes, ef de glacer le pavé. 
Alors les larves ne trourant plus à se réfugier, pour subir leurs métamorphoses, périraient comme elles font dans les bouteilles.

On pourrait encore les faire manger dans les çreniers par les poules ou les oiseaux.

\section{CHRYSOMĖLE}

La Chrysomèle est un coléoptère de la tribu des Chrysoméliens, c'est-à-dire de ces insectes phyytophages, généralement petits, parés des plus vires couleurs, et qui, à l'état

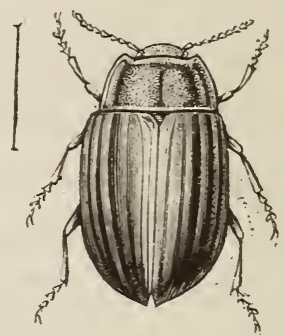

Fig. 55. - Chrysomèle du sarrasin.

parfait, fréquentent les fleurs. Certaines espèces sont, pendant l'été, extrêmement communes sur toutes les plantes. Leurs larves sont pourvues de trois paires de pattes écailleuses, qui leur permettent de marcher ou au moins de se cramponner sur les feuilles ; car leurs corps est parfois très-renflé et très-lourd. Les Chrysoméliens, pendant le premier état de leur vie, rongent les feuilles des arbres, ou les plantes et leur nuisent beaucoup. Les larves se transforment en nỵmphes sur les plantes mêmes où 
elles ont vécu ou dans les endroits voisins, en se fixant par l'extrémité du corps.

Le groupe des Chrysomélites se distingue par la tête dégagée du corselet, le corps orbiculaire, la lèrre inférieure assez longue. Antennes ayant leurs divers articles presque aussi courts que les autres.

Ces insectes sont assez petits, les plus grands n'ont pas plus de $0^{\mathrm{m}}, 012$ à $0^{\mathrm{m}}, 01$ k de longueur.

La Chrysomèle des céréales qu'on rencontre quelquefois sur les genêts, vit le plus ordinairement sur les tiges des céréales, aux dépens desquelles elle se nourrit. Elle est d'un beau vert doré, arec trois bandes bleues sur le corselet et cinq sur les élytres, toutes dirigées longitudinalement. Elle est longue de quatre lignes.

La Chrysomẻle du sarrasin est d'un bleu verdâtre avec les pattes rouges. La larve ravage les cultures de sarrasin.

Les larves de ces deux insectes sont oblongues, pourvues de petites pattes écailleuses. Un mamelon, situé à l'extrémité de l'abdomen, leur sert à s'aider dans leur marche et à se suspendre pour se transformer.

Comme celles du bouleau du peuplier, ces Chrysomèles ont, à l'état parfait, les antennes insérées au-derant de la tête et écartées à la base, la tête droite un peu cachée sous le corselet.

\section{LE CRIOCERE DE L'ORGE}

Les Criocérites appartiennent à la tribu des Chrysoméliens, ils sont caractérisés par une lèvre inférieure petite, 
courte, carrée, par des antennes assez épaisses, moniliformes, un peu épaissies vers le bout.

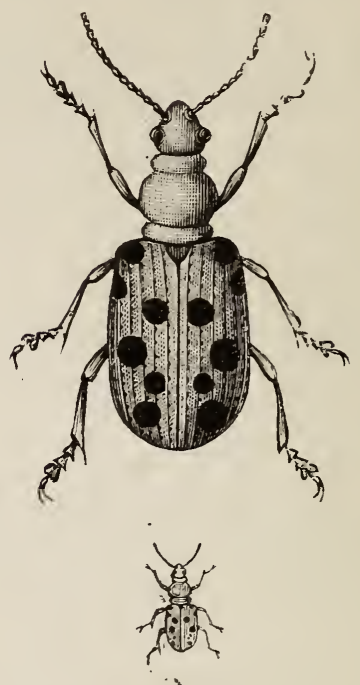

lig. 5\%. - Criocère de l’orge, grossi et grandeur raturelle.

Leurs larves offrent une particularité très-curieuse; elles sunt molles, pourvues de six pattes écailleuses; leur ouverture anale est très-relevée, en sorte que l'animal peut rejeter ses excréments sur son dos; il s'en recouvre amsi complétement; ce qui parait avoir pour but de le protéger des rayons du soleil; car il vit à découvert sur les plantes. Si l'on vient à faire tomber ces matières, la larve commence à manger avec une voracité inaccoutumée pour . se couvrir de nouveau de cet abri protecteur.

C'est dans un intérèt purement spéculatif, afin d'épargner à l'agriculteur les soins d'une gucre inutile, que nous parlerons du Crincère de l'orge. Il peut s'effrayer en effet et craindre pour sa récolte à la vue de petites masses globuleuses un peu allongées, visqueuses ou sales qui 
recouvrent les feuilles d'crece et d'aroine vers la fin de mai ou dans le mois de juin ; ces petites masses luisantes sont des larves ovalaires d'une couleur rougeàtre trèspâle, ayant une petite tête écailleuse et douze segments sur le corps et six pattes écailleuses attachées sous les trois premiers. L'anus, selon M. Goureau, serait placé en c'essus entre le dernier et l'arant dernier segment.

A la fin de juin, la larve a pris tout son accroissement. Elle quitte les feuilles et descend à terre; s'y enfonce à une petite profondeur et se construit une coque ovale arec des parcelles de terre liées par une salive visqueuse. Elle a mème soin de tapisser l'intérieur de la chambre d'une couche de cette espèce de vernis-ciment, afin qu'il soit lisse et doux.

Elle subit dans cette retraite la transformation en nymphe d'abord, et en insecte parfait ensuite. Après quoi elle brise sa prison et prend son essor au commencement d'acuit.

Le Criocère de l'orge a la tète noire, le corselet rouge et les élytres bleues.

\section{LES ALTISLS \\ (Puces ces :ardins. - Tiquets.)}

Les Altises sont encore des insectes de la tribu des Chrysoméliens; on les reconnait facilement à leurs cuisses très-renflécs qui leur permettent d'exécuter des sauts très-consi dérahles. Ces insectes sont petits, ornís de cou- 
leurs brillantes. Les jardiniers leur domnent le nom de Tiquets ou de puces des jardins. Cie sont, en effet, des insectes qui, à l'état de larves comme à celui d'insectes parfaits, vivent aux dépens des régétaux, leur font beaucoup de tort parce qu'ils se multiplient prodigieusement. Ils s'attaquent surtout aux crucifères, par conséquent aux choux, aux navets, aux colzas, et aussi aux céréales. A ce titre on peut les ranger parmi les insectes qui peuvent nuire à l'agriculture.

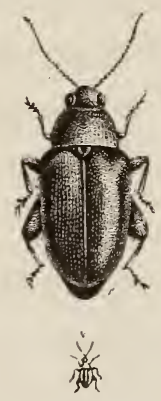

Fig. 33̈. - Altise à pieds noirs, grossie et grandeur naturelle.

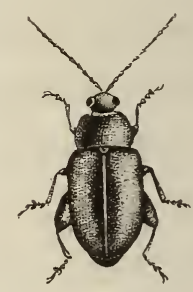

零
Fig. 5b. - Altise des bois, grossie et grandeur naturelle.

Guoique ces insectes soient très-nombreux, on ne connait guère leurs larves.

M. Curtis est le premier qui ait donné des détails intéressants sur les diverses transformations de l'Altise des bois. Si le printemps est chaud, l'Altise s'accouple d'avril en septembre. Pendant cette période les œufs sont déposés par la femelle sur le revers des feuilles rugueuses des turneps. Elle pond viaisemblablement un œuf par jour et dix paires pondent seulement quarante-trois œufs dans une semaine; c'est ce qui a lieu dans l'état de captivité; mais l'exactitude de cette estimation est établie sur' ce fait 
que, dans les feulles prises dans les champs, contenant six larves, ces dernières ètaient de taille différente, indiquant une varièté d’àge. Les œufs sont très-petits, lisses, participant de la couleur de la feuille. Ils éclosent au bout de dix jours et les petites larves commencent immédiatement à manger sous la pellicule inférieure el à former des galeries tournantes dont la pulpe détachée les nourrit. Les galeries sont assez visibles à l'œil nu lor'sque les larves les ont abandonnées et que les pellicules sont derenues blanches et décolorées; mais dans leur premier âge on les découvre difficilement; il faut regarder la feuille de trèsprès et l'exposer à la lumière pour les aperceroir'.

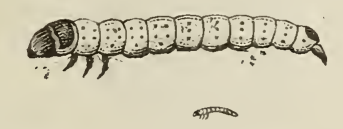

Fig. 57. - Larve de l'Altise.

Les larves sont pâles ou d'une couleur jaune doré, charnues, cylindriques, arec six pattes pectorales et un mamelon anal. La tête est pourvue de deux mâchoires et de grands yeux bruns; le premier et le dernier segment portent des taches noirâtres. Elles ont pris toute la nourriture dont elles ont besoin en six jours environ et alors elles sortent de leurs galeries pour s'enterrer à la profondeur de כ̌ centimètres aux plus, choisissant un emplacement près de la racine où les feuilles des turneps les protégent contre la sécheresse et l'humidité.

Elles se changent dans la terre en chrysalides immobiles qui arrivent à leur maturité dans une quinzaine de 
jours au bout desquels l'insecte parfait sort de terre et prend son essor.

L'Altise des bois a une longueur de 1 mil. $1 / 2$ à 2 mil. Elle est noire, finement pointillée, la tête est petite, les yeux orbiculaires, proéminents; les antennes sont filiformes, assez longues, composées de onze articles; le thorax est plus large que la tête, un peu rétréci en devant, arrondi sur les côtés; les élytres sont orales, deux fois aussi larges que le thorax et quatre fois aussi longues; elles ont chacune une bande jaune quelquefois approchant du blanc sur le milieu, très-légèrement flexueuse; les ailes sont deux fois aussi longues que le corps; les pattes sont d'un jaune de rouille; les cuisses couleur de poix, les dernières très-épaisses et propres à sauter.

Ces.Altise's passent l'hiver engourdies; on en troure sous les écorces d'arbres soulerées, sous les feuilles tombées et dans d'autres gites. Au retour du printemps, dès que la chaleur se fait sentir, elles sortent de leurs retraites. On en roit dans les jardins sur les navets et les choux, dès le commeneement de mars.

Il y a une autre espèce d'Altise dont les habitudes sont les mêmes que celles de l'Altica nemorum, qui concourt arec cette dernière aux dégâts; mais on peut supposer qu'ils sont les mêmes. Elle est appelée Altica concinna Varsh, et Alticu dertipes Gyll. 


\section{ALTISE DE LA JUSQUIAME}

II. Focillon a également observé les Altises au point de vue des dommages qu'elles peuvent causer aux colzas. Ces observations ont porté d'abor'd sur l'Altise de la jusquiame (Aliica hyoscyami, Latreille).

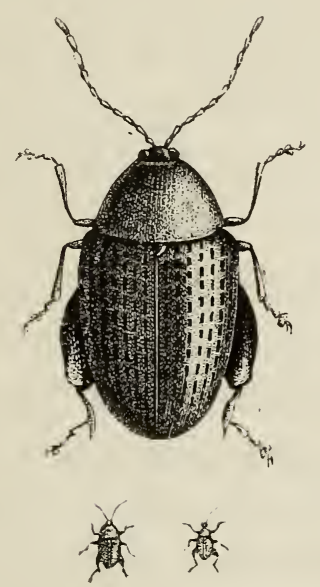

Fig. - - Altise de la jusquiame grossie el grandeur naturelle.

Altise femelle. Altise mâle.

Cette Altise ronge le parenchyme de la silique sans la perforer et en respectant la lame épidermique qui en constitue l'endocarpe ou membrane intérieure. L'épicarpe ou pellicule externe, et le tissu cellulaire vert qu'on nomme mésocarpe sont seuls intéressés, quelquefois les siliques sont déformées par suite de ces lésions, mais souvent aussi la plaie séchée et d'un gris jamàtre atteste seule le passage de l'Altise et le fruit parait n’en avoir éprouré aucun dommage important. 
On ne peut donc considérer cette Altise comme sérieusement nuisible aux colzas, d'autant plus que le nombre de ces animaux est assez restreint et qu'on a compté que sur vingt siliques trois seulement araient souffert de leur passage.

Parmi toutes les espèces connues d'Altises, nous décrirons spécialement celles qui nuisent particulièrement aux plantes cultivées par les agriculteurs. Les dégâts causés par ces insectes sont tous à peu près de la même nature; ils portent essentiellement sur le parenchyme rert soit des siliques, soit des feuilles. La composition presque identique de leur appareil buccal est en rapport arec cette uniformité de mœurs.

Aussi croyons-nous utile, avant d'entrer dans l'étude des caractères spécifiques de décrire cet appareil.

L'Altise de la jusquiame a la bouche composée d'un labre presque demi circulaire arec une échancrure médiane; d'une paire de mandibules triangulaires, fortes et terminées par quatre dents acérées. Près de l'angle interne de leur face inférieure, naît un organe pédiculé qui se renfle en un appendice ovale couvert de poils, d'un aspect analogue à celui que 11 . Focillon a ru dans le Charançon, quoique d'une forme toute différente. Les màchoires sont médiocres, munies de leurs palpes et terminées par un double prolongement hérissé de dents fines et crochues. La languette est allongée, munie de deux palpes très-courts. L'appendice de la mandibule récrit par II. Focillon dans le Charançon du colza a été depuis observé par ce savant chez d'autres coléoptères et surtout chez les Carabiques. 


\section{A LTISE DES CHOUX \\ (Altica (phyllotreta) brassicæ.)}

L'Altise des choux a une longueur de 1 mill. 1/4. Elle est raccourcie, convexe, d'un noir intense, couverte d'une ponctuation, fine, serrée, deux petites lignes

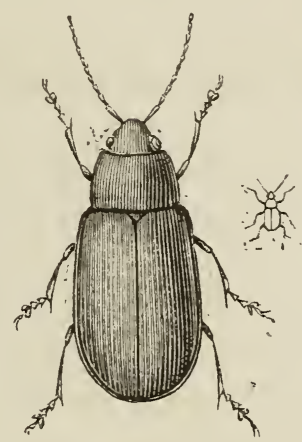

Fig. 59. - .ltise du chou, grossie et grandeur naturelle.

d'un testacé jaunâtre sur chaque élytre; antennes noires arec les trois premiers articles testacés; corselet plus court que large; élytres plus larges que le corselet, trèsconvexes, marquées de deux taches longitudinales, jaunàtres, l'une près de l'autre; la première au milieu de la base, la deuxième près de l'extrémité en forme de coin; pattes noires avec les tibias et les tarses d'un roux brunàtre.

Elle se troure sur les choux dans les jardins.

C'est au commencement du printemps que l'Altise se montre dans les jardins. Les femelles pondent alors leurs oufs sur les jeunes plants de choux. Les petites larves qui 
en sortent s'enfoncent dans le parenchyme de la feuille et y tracent de nombreuses galeries en rongeant sa substance.

Les points attaqués de la sorte se flétrissént, se dessèchent et se manifestent par des taches blanchâtres. Lorsque la larve a atteint sa taille définitive, c'est-à-dire 0,002 , elle se laisse tomber sur le sol et s'y enfonce à quelques pouces pour se métamorphoser. C'est là qu'elle passe l'hiver dans l'inaction attendant le printemps.

\section{MOYENS DE DESTRUCTION}

Les Altises étant très-nuisibles dans les potagers et quelquefois dans les grandes cultures, on a cherché les moyens de les détruire ou de les éloigner; celui qui est le plus usité dans les jardins consiste à recourrir d'une légère couche de cendre lessivée les semis de choux, de navets, de radis. Beaucoup de personnes attendent, pour faire cette opération, que les jeunes plantes commencent à pousser et que les Altises s'y montrent. On doit être trèsattentif, car il ne faut pas longtemps à ces insectes pour ronger les premières feuilles et faire périr les plantes.

On a recommandé d'arroser les plantes envahies par ces insectes arec un liquide formé d'un mélange de 1 kil. $250 \mathrm{gr}$. de saron noir, 1 kil. $250 \mathrm{gr}$. de soufre, 1 kil. champignons de bois ou de couche et 60 litres d'eau. On met d'abord dans 50 litres d'eau le savon et les champignons concassés, on fait bouillir dans 50 litres d'eau le soufre renfermé dans un sachet de toile; on mélange les deux liquirles qu'on laisse fermenter jusqu'à ce qu'il s'en élève une odeur infecte; puis on arrose avec cette eau. 
Une autre recette, beaucoup plus simple, bien moins dégoûtante et en même temps plus économique, consiste à recouvir les semis d'une légère couche de sciure de bois, imprégnée de goudron de houille appelée coltar (coal-tar), dans la proportion de $20 / 0$ de goudron mesuré en poids. Pour 100 kil. de sciure on emploie 2 kilng. de coltar. On mélange le plus exactement possible et on répand la sciure sur les semis dans les jardins ou dans les champs infestés par les Altises. Ce procédé, employé en grand dans la culture de la betterave à sucre, a éloigné l'Altica oleracea qui vit sur les blés, les haricots, le lin, les luzernes et les tréfles, Cette Altise est entièrement bleue excepté les antennes qui sont noires. On a encore conseillé de mêler de la fleur de soufre à la sernence oul d'arroser les plantes arec une infusion d'absinthe ou ou enfin de réprandre sur ces plantes de la poussière de rue.

\section{CASSIDES}

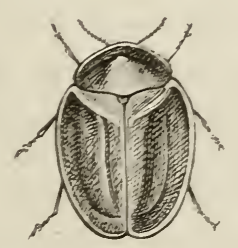

Fig. 40. - Casside érues!re.

La dernière famille que nous ayons à décrire dans la tribu des Chrysoméliens est celle des Cassidides dont le 
corsclet recourre entièrement la tête et chez lesquelles la forme circulaire du corps domine manifestement et leur a valu autrefois le nom de Cycliques.

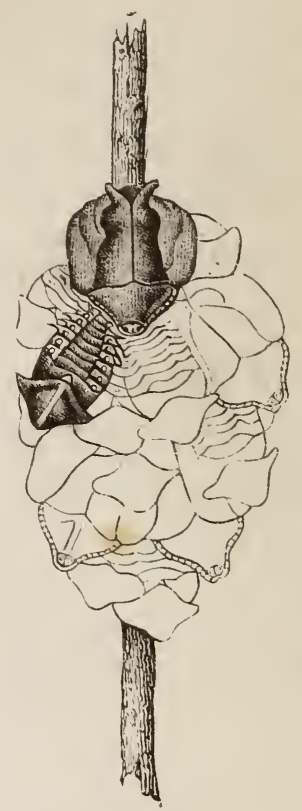

Fig. 41, - Groupe de Cassides à l'état de nymphes et à l'état d'insectes adultes ${ }^{1}$.

Au premier aspect on remarque que les Cassides ressemblent à la tortue. Le corps tout entier, tête comprise, est enveloppé par le corselet et les élytres qui forment dans leur réunion comme une espèce de carapace sous laquelle l'insecte se trouve abrité. C'est surtout en Amérique que les cassides se trouvent en grande quantité. Elles diffèrent entre elles par la variété de leurs formes, par la vivacité et sourent par l'éclat métallique de leurs couleurs.

' Émile Blanchard, Ilistvire des insectes. 
On n'a guère obscrvé en France que la Casside verte et la Casside nébuleuse.

Goureau rapporte que M. Bazin, propriétaire au MenilSaint-Firmin (Yonne), a découvert en 1816 un nombre considérable de larves fort remarquables de la Casside nébuleuse, vivant sur les feuilles de betterave rouge. Elles se tiennent sur le revers des feuilles qu'elles rongent en petits espaces ronds et qu'elles criblent de trous.

Ces larves sont à ce qu'il parait d'un joli rert taché de blanc et les côtés du corps sont armés d'épines barbelées. Elles sont ovales, déprimées; elles ont une petite tête écailleuse, munie de deux dents et pourve de trois petits yeux en ligne oblique comme des petits tubercules et de quatre autres plus élevés au-dessus; chaque côté est garni de six épines aiguës en forme de scies. A l'extrémité du corps sont deux queues droites que l'animal couche sur son dios dans le repos pour soutenir la peau chiffonnée de sa dernière mue et les excréments qu'il rend, se formant de la sorte un abri contre le soleil qui le grarantit en même temps de la piqûre des parasites; mais ces queues se rabattent et s'étendent lorsqu'il marche; les six pattes thoraciques dont il est pourvu sont cachées sous le thorax.

Lorsque les larres se changent en chrysalides, elles se fixent contre le revers de la feuille sur laquelle elles ont vécu, et se dépouillent de leur peau au bout de deux ou trois jours. Cette nymphe est plus remarquable que la larve. Elle est ovale, déprimée, avec le corselet en forme de large bouclier cachant la tète, ciliće sur les bords, portant deux taches blanches sur le dos; les segments du corps sont 
découpés sur les côtés en dents de scie et le dernier est épineux en forme de queue fourchue. Elle est d'un rert vif et luisant, avec les bords du thorax et de l'abdomen blanchâtres et deux raies jaunâtres sur le dos. En moins de quinze jours elle se transforme en insecte parfait.

M. Blancharl qui a également observé les cassides conrient qu'à l'état de larve comme à l'état d'insecte parfait, elles dévorent les feuilles et les percent de nombreux trous plus ou moins arrondis, mais il ne pense pas qu'elles puissent nuire d'une manière bien notable.

\section{CASSIDE NEBULEUSE}

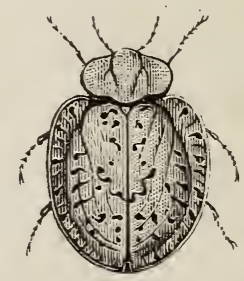

Figr. 42. - Cass'de nébuleuse, grossie el grandeur naturelle.

A sa naissance la Casside nébuleuse est verte, mais elle devient graduellement couleur de tan en dessus et noire en dessous; sa forme est elliptique; la tête, petite, est cachée sous un large corselet demi-circulaire qui est

1 Mémoires de la Société d'agricullure, année 1850,2e partie.p. 498. 
marqué de petites impressions et de deux taches à la base; les antennes, insérées sur le devant de la tête sont composées de onze articles légèrement épaissis et noirâtres à l'extrémité; les élytres sont ovales, convexes arec un bord plat et cinq doubles lignes de points sur chacune; elles sont parsemées de taches noires épaisses; les ailes sont amples; les pattes courtes, les tarses for'mées de quatre articles, arec une paire de crochets.

Les larves sont quelquefois victimes d'un petit parasite de la tribu des Chalcidites et du genre Pteromalus dont le nom n’a pas été déterminé et qui se déreloppe au nombre d'une trentaine d'individus dans une seule nymphe.

\section{COLASPIS DES LUZERNES}

NÉGRIL OU BARBOTTE

(Colaphus ater.)

M. Dufour, le savant entomologiste, nous a signalé cet insecte dès 1815. Dans le mois de mai de cette année, dit-il, en parcourant la riche plaine de Saint-Philippe dans le midi du royaume de Valence, je vis des luzernières fort étendues, tellement dérastées par cette larve rorace qu'il ne restait plus de la plante que la base des tiges et les pétioles dépourvus de folioles. La larve de ce Colaspis a la structure générale de celle des autres coléoptères de la famille des Chrysoméliens. Elle est hexapode, c'est-à-dir'e qu'elle a six pieds ; sa couleur est noirâtre, elle est glabre, longue de trois lignes sur une d'épaisseur. Les paysans valenciens 
la comnaissent sous le nom du Cuc (kouk) terme générique qui signifie ver ou chenille.

M. A. de Gasparin signala, en 185\%, un insecte nommé Colaspis atra, qui commettait ses ravages sur les luzernes du département de Vaucluse et qui s'est multiplié au point de faire manquer la seconde coupe de luzerne. Son corps est entièrement noir, arec les antennes filiformes plus longues que la moitié du corps, qui a environ 6 à 7 millimètres de long; les antemnes sont jaunes à leur base. Sa larve est noiràtre et entièrement lisse.

Ce Colaspis est appelé Négril ou Barbotte dans le Midi. Il se réunit, pour pondre, dans un espace relativement étroit; on peut profiter de ce fait, recourrir exactement l'espace qu'il occupe arec de la paille sèche et y mettre le feu; la luzerne n'en souffrira pas et n'en sera mème que plus verte et plus vigoureuse. On a conscillé de ré pandre sur les luzernes et autant que possible par un beau soleil, vers la première quinzaine de juin, la poudre suivante :

Cendre de bois desséchés. . 25 litres.

Goudron de houille.

$2-$

Eau.

3 -

Aloès hépatique en poudre.

Trente-six ou quarante-huit heures après, tous les insectes sont, à ce qu'il parait, détruits.

Les paysans valenciens n'ont d'autre moyen d'arrêter les progrès de cette rapide dérastation que d'enlerer ces larves arec une sorte de sac court, large, mais peu profond, formé d'une toile grossière et forte et fixé autour 
d'un cerceau emmanché d'une longue barre. C'est à peu près le filet faucheur des entomologistes. Ils le promènent sur la luzerue, en faisant le mouvement de faucher et en moins de dix minutes il y a au fond du filet plusieurs livres de ces larves. On les écrase sous les pieds pour recommencer ensuite la chasse. L'insecte parfait se trouve pour un vingtieme environ dans les larves.

\section{EUMOLPE NOIR}

(Eumolpus obscurus.)

Un autre coléoptère de la famille des Chrysomélicns, fort redoutable pour le trèlle dans les provinces méridionales, est l'Eumolpe noir, espèce voisine de l'Eumolpe

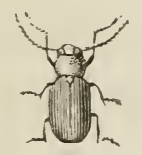

Fig. 43. - Eumolpe noir.

de la vigue décrite par Audouin. Cet insecte est trapu de formes; ses élytres sont carrées, plus larges que le corselet, ses antemnes sont longues, de coulcur noire et d'un luisant tempéré par une fine pubescence grise.

La larve qui ressemble beaucoup à celle du Colaspis des luzernes se comporte de la même manière à l'égard du trèfle. On peut la combattre par le même procédé. 


\section{COGGINELLE GLOBULEUSE}

(Bêtes à bon Dieu.)

Les Coccinelliens présentent de grandes analogies avec les Chrysoméliens, surtout si on les considère à l'état de larve. Les Coccinelliens sont cependant pour la plupart des insectes carnassiers; ils se nourrissent en général,

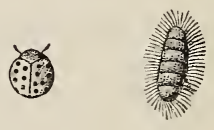

Fig. 44. - Coccinelle globuleuse et sa larve.

dans tous leurs états, de Pucerons, de Cochenilles et de Kermès. A ce point de vue, ils rendent de grands services à l'arboriculture et peuvent être considérés comme utiles. lls dévorent des quantités innombrables de parasites. Mais tous les Coccinelliens ne sont pas carnassiers, il en est beaucoup parni eux qui sont phytophages c'est-à-dire qui se nourrissent de plantes comme les Chrysoméliens. Parmi ces derniers, il faut ranger la Coccinelle globuleuse qui vit de trèfle, de luzerne et de vesces.

La femelle pond au printemps sur les feuilles. Les jeunes larves qui ne tardent pas à sortir des œufs se rípandent sur la plante et rongent le parenchyme des feuilles en y laissant des traces semblables à celles qu'y feraient un peigne rudement promené sur leur surface. Cette larve est longue de $0{ }^{n} 005$ à 006 grisâtre, hérissée 
de poils rutes pen serres. Quant a l'insecte partait, il est hemispherique, rougeatre, aree quelques taches noires cl légèrement velu, ce qui le distingne de la phus zrande partie des Coccinelles qui sont gilabues.

\section{IIGUILLOMER. - SAPERDE}

(Agapanthia marginella. - Genre Calamobie, Guérin-llineville)

Ponr la première fois, en 1840̆, M. Guérin-Néneville a observé aux environs de Barbezienx (Charente) 111 ro-

\section{独}

Fig. 亿.. - Aiguillonier.

lioptère du groupe des Saperdites, formant le sous-genre Calamobie et qui s'appelle Agapanthia marginella ou Calamobie de Méneville. La taille de l'insecte parfait varie de 10 à 12 millimètres. Son corps est cylindrique, pubescent; ses antemnes sétacées; frangées en dessous; elles ont la longueur du corps; les femelles les ont beaucoup plus grandes que les màles et toujours de douze articles; les élytres sont linéaires, arrondies; les pattes de longueur moyenne et égales.

On aurait remarqué que cet insecte s'altaque de prélérence au blé de Saint-Léonard. La femelle perce un petil 
trou circulaire dans la tige près de l'épi et y introduit un ceuf qui tombe au premier nœud du chaume; il domne naissance \& une petite larve qui recommence le mème trajet en sens inverse, arrive près de l'épi et ronge circulairement l'intérieur du tuyau. L’épi se flétrit, reste vide de grains et, au premier coup de vent, tombe. La larve alor's descend dans le chamme et, perçant successirement tous les nouds, va se loger tout au bas de la tige a jou 8 centimètres du collet, pour' y passer l'hiver.

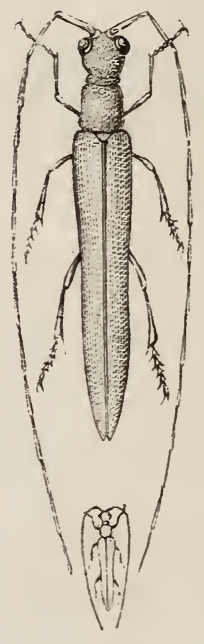

Fig. 46. - Calanobie, grossi et grandeur naturelle.

L'Aiguillonier est un coléoptère de la tribu des Círanhyciens, magnifiques insectes, tant sous le rapport de la grande dimension de la plupart d'entre eux, que sous celui de leurs formes élégantes et variées et de leurs couleurs, parfois très-belles.

Les Céranbyciens onl des antennes d'une longueur extrème, qui les fait recommaitre an premier abord. Cé 
ceractère facile à saisir leur avait fait domer par Latreille le nom de Longicormes. Ces antemnes sont toujours un peu plus evurtes dans les femelles que dans les mâles.

I.es Cérambyciens, dans leur's habitudes et dans leurs métamorphoses, se ressemblent au plus haut degré ; à l'état d'insecte parfait, ils fréquentent les fleurs, les arbres pourris, etc. Dans leur premier état, tous, sans exception, vivent dans le tronc, dans les branches des arbres ou daus la tige des blés. Les larves se ressemblent aussi considérablement; ce sont toujours de gros vers allongés, blanchàtres ou jaunàtres, ayant une tète un peu cornéc. des mandibules très-robustes, le premier anneau du corps plus grand que les autres: cenx-ci offrent ordinairentent dans le milieu des espaces garnis de petites rugosités. G'est rers le mois de juin lorsque les blés sont épiès et en flem', que la femelle perce um petit trou dans la tige et y introduit un œuf; elle continue sa ponte en ne confiant yu’un seul œuf à la mème tige. L'œul' descend jusqu'au premier nœud du chaume, domne bientòt naissance à un petit ver ou larve qui monte le long du tuyau jusqu’à la base de l'épi et ronge circulairement ce tuyau, ne laissant intact que l'épider'me. Toute communication de l'épi avec les racines se trouvant dès lor's mterceptée, la séve n'arrive plus puisque les cauaux sont rompus, l'épi reste vide de grains, se dessiche et tombe au noindre soulfle.

Cette larve, après avoir aftaibli ainsi l'intérieur de la lige près de l'épi, descend dans le chanme, se fraye un passage a travers les noeuds qu'elle rencontre successirement et ra se loger au bas de la tige à me hauteur de is a 8 centimètres au-dessus du sol. Elle passe l'hirer. 
dans ce belvédere, blottie dans une poussière de détritus et de ses excréments. Au moment de la moisson, quand le blé est mur, elle est arrivée dans son gite et complétement installèe. - Au mois de juin de l'année suivante, elle se métamorphose en chrysalide et quelques jours après en insecte parfait.

La Saperde définitivement formée perce un trou dans le luyau de blé avec ses mandibules, et prend la clef des champs.

Le moyen proposé pour combattre cel insecte consiste i arracher le clraume après la moisson el à le brùler sur place, ce qui fait périr les larves dans leur gite. On peut encore couper le blé très-près de terre : on emporte ainsi les larves dans la grange où elles sont écrasées par le battage.

\section{SILPHIENS}

Parmi les coléoptères, il existe une tribu qui, sans présenter les caractères homogènes des Scarabéiens, des Carabiens et autres, ont cependant un aspect particulier et divers caractères qui ne permettent pas de les confondre. Nous n'avons à décrire dans cette tribu qu'un insecte de la famille des Silphides, peu nombreuse du reste en espèces, peu nombreuse aussi en genres.

Le genre silphe est le type de la famille des Silphides. On en connait une cinquantaine d'espèces, la plupart européennes, le plus souvent de couleur noire, vivant 
sur des cadavres d'animaux; on les rencontre fréquemment aussi courant les chemins secs et arides. Le silphe obscur est le plus commun du genre; il est long de 6 à 8 lignes, d'un noir olsscur, finement ponctué avec trois rotes sur les élytres.

La larve de cette espèce se rencontre communément dans notre pays; elle est noire, fortement aplatie, brillante, avec la tête arrondie et tous les amneaux du corps très-distincts, aỵant leurs angles postérieurs très-aigus. Le deuxième anneau supporte une paire de petits prolongements coniques. Cette larve court avec beaucoup do vitesse, de mîme que toutes celles des Silphes, Et les différences qui existent entre les différents genres de larves sont très-légères et consistent surtout dans la forme plus ou moins large ou plus ou moins étroite de leir corps.

\section{SILPIIE}

(Silpha opaca).

Au mois de mai 1865, M. Payen a donné lecture d'une lettre adressée par II. Pilat, de Brebières (Pas-de-Calais).

"J'ai découvert, il y a quelques jours, dit M. l'ilat, dans ma culture de Brebieres, un ennemi de la betterave; il est possible qu’il se soit montré chez noi la campagne dernière, quand cette plante était trop développée pour que je pusse le remarquer, car cette année je le trouve particulièrement sur les lisières de mes pièess de betleraves qui 
avoisinent des champs qui ont produit celte plante l'année prérédente.

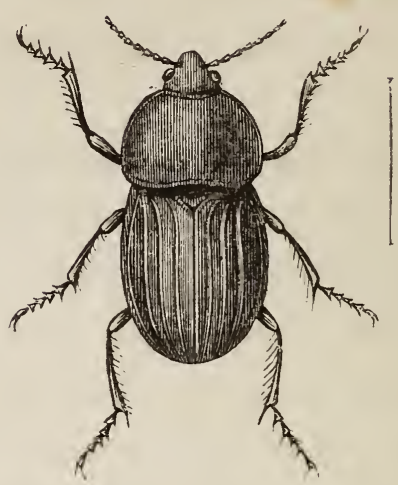

Fig. 17. - Silphe olscur.

Quand cet insecte, qui n'attaque que les feuilles de la hetterare, sans toucher à la racine, se montre au moment de la levée, ses ravages sont considérables: des champs ont été entièrement dévorés; et craignant que le second semis ait le même sort que le premier, M. Pilat demande à la Société de l'éclairer sur ce sujet. "

I. Guérin-Méneville a répondu que l'insecte qui faisail l'objet de cette communication a déjà été observé plusieurs fois; il appartient à une espèce du genre Sỵlphe qu dérore les jeunes feuilles des plantes et qui a été déjà signalée en Nllemagne, en Suède et enfin en France oì elle s'attaque aux folioles des betteraves qui viemnent do lever.

Les Silphes en général sont carnassiers, mais l'espèce dí. signée sous le nom de Silpha opaca, et à laquelle appartiennent les insectes enroyés par M. Pilat, mange les jeunes feuilles de hetteraves et d'autres végètaux. 
I. Payen a demandé si l'exception signalée par II. Guérin-Méneville est aussi absolue qu'on pourrait le croire au premier abord, il a fait remarquer ensuite que les jeunes feuilles attaquées par le Silpha opaca, ainsi que tous les très-jeunes organismes des plantes, sont trèsriches en matières azotées et se rapprochent ainsi, jusqu'ii un certain point, de la composition des matières animales.

Pendant ringt-cing ans un cultivateur, M. Crespel, a ensemencé en betterares un champ dont toutes les plantes étaient intégralement dévorées tous les ans par minsecte, au moment de la levée. On procédait alors à m second ensemencement, qui se développait dans des conditions nopmales, sans doute parce que l'insecte qui avait déroré les jeunes feuilles des plantes provenant du premier semis était parrenu à une autre phase de ses métamorphoses.

II. Guérin-Méneville rappelle que II. Crespel avait aussi recours à l'emploi du rouleau pour détruire les insectes qui ravageaient ses semis de betteraves au moment où les premières folioles commencaient à sortir de terre.

\section{ITIIIILS}

On connait une famille d'élégants coléoptères qu'on appelle Nitidules (nitidus brillant). Ces insectes sont on griméral d'une taille très-petite.

l.es Vilidules proprement ditessont fort nombrenses; res 
espèces et plusieurs autres sont très-communes en France ; parmi ces dernières on cite spécialement la Nitidule hronzée ( $N$. ænea) type du genre, ayant moins d'une ligne de long et d'une couleur vert bronzé. Cet insecte, comme la plupart des Nitidules, à l'état d'insecte parfait, vit l'été

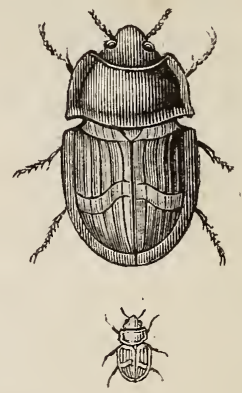

Fig. 48. - Nitıdule, grossie et grandeur naturelle.

sur les fleurs. Elle est si commune chez nous, qu'on peut la récolter par milliers en passant un filet de toile sur les plantes. Cependant les métamorphoses de cet insecte sont encore ignorées.

Certains de ces insectes, comme la Nitidule tomenteuse, la Nitidule à quatre mouchetures et la Nitidule rerte attaquent les arbres.

\section{CRYPTOPHAGES}

(Atomaria linearis (Stephens). - Atomaria pygmea (Hleer).

Un autre genre du groupe des Engidites, genre Cryptnphage, a èté ohservé pour la première fois, en 1859, par V. Armand Bazin. Cet insecte est étroit, linéaire, long ì 
peine d'un demi-millimètre. Sa couleur varie du roux ferrugineux au brun noir. Il se montre en mai et juin, plus rarcment en juillet et en août. Très-friand de la hetterave, il so reprodunt avec une rapidité surprenante et sait se dérober ¿ tous les yeux, il va se cachant dans le sol où il ronge les germes des betteraves au fur et à mesure qu’ils apparaissent. Il n'est pas rare d'en trouver plusieurs autour d'une même graine. Quand leur nombre est considérable ef que leur éclosion précède la levée des betteraves, la r'écolte est entierement compromise. Mais si les insectes ne. paraissent qu'après les plantes, les dommages sont moins crands. Ils attaquent les racines, y creusent de petits trous et les minent en partie, mais ne les détruisent pas toujours. Les betteraves échappent souvent à la mort si la terre est humide, compacte et la régétation active. Cel insecte ne se contente pas de dévorer les racines: quand le temps est beau, il sort de terre, monte sur la tige et mange les feuilles. II arrive souvent qu'un certain nombre d'insectes sont occupés à ronger la racine pendant que d'autres se nourrissent aux dépens de la feuille.

Les moyens employés avec le plus de succès par M. Bazin contre cet insecte sont les suivants: $1^{\circ}$ faire altemer les récoltes; $2^{\circ}$ plomber le sol avec les rouleaux; $5^{\circ}$ fumer fortement le sol pour activer la végétation; fo ne pas économiser la semence ${ }^{1}$.

I M. Blanchard a décrit sous le nom de Cryptophage ipsoïde (Cryptophrgus ipsoïdes) le même insecte qui produit les mìmes dégâts sur les betteraves. - Voir son mémoire dans la Société d'agriculture, année 1850, t. II, p. 494 et suivantes. 


\section{HÉMIPTĖRES}

\section{PICEROY DI BLE}

Le Puceron appartient à l'ordre des hémiptères, insectes chez lesquels on remarque une bouche formée de pièces constituant un suçoir.

Les hémiptères vivent en général du suc des végétaux; rependant beaucoup d'entre eux sucent d'autres insectes et même le sang de l'homme et des animaux. On compte parmi eux tous les insectes connus sous le nom vulgaire de punaises; ils ont des métamorphoses incomplètes. Au sortir de l'ouf, ils ressemblent complétement aux adultes, seulement ils sont privés d'ailes. Ils n'en acquièrent des rudiments qu'après plusieurs mues; ils sont considérés alors comme nymphes; ils sont insectes parfaits après un dernier changement de pean.

Les Pucerons rentrent dans la petite tribu des Aphidieṇs; ils ont des antennes composées de sept articles et 
un abrlomen avant à l'extrémite denx petits lubes sécréteitis.

Les Pucerons offrent une particularité lris-remarfuahle dans leur mode de génération; ces insectes ovipares ì me certaine époque, sont vivipares pendant une grand. parlie de l'amnéc.

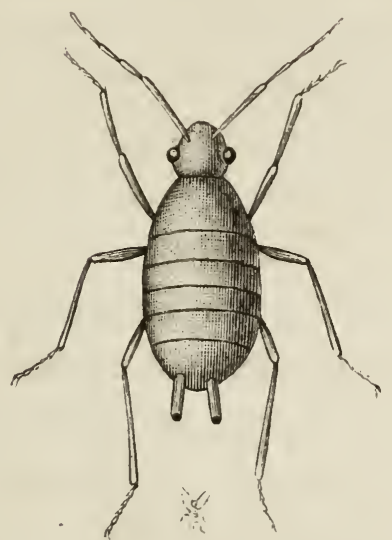

Fig. 49. - Puseron du blé, gerossi el grandem nalurelle.

Les espèces de Pucerons sont nombreuses; mais le Pureron vert et le Puceron noir forment les deux classes les plus tranchées, et c’est dans la deruière espèce qu’il faul ranger le Puceron du blé.

Ces insectes vivent en troupes compactes i peu pris sur toutes les plantes. Ils se tiennent ì la partie infériempe des tiges, pour être protégís de la pluie; sucant le sure des plantes, et y déterminant fréquemment des excroissances considérahles très-muisibles aux rigétaux.

I.es Pucerons portent an derrière deux petites rormes qui distillent contimellement la seve qu'ils rnt absorbée. 
et qui la rendent en liquide légèèment sucré. C.est comme des outres qui absorbent la séve, l'élaborent et la rejettent au profit des fourmis qui en sont très-friandes.

I.es Pucerons mettent leurs petits au monde virants, exception remarquable à la loi générale qui gonverne à cet égard les insectes. Si l'on regarde un groupe arec allention, on en observe plusieurs qui expulsent par leur anus de petits corps verdâtres. Ce sont de petits Pucerons qui sortent dı rentre de leurs mères, mais dans un sens différent de celui des autres animaux, r'est-i-dire que le derrière sort le premier. L'accouchement entier ne dure pas plus de six à sept minutes.

La fécondité des mères puceromnes est prodigieuse. Int-elles une fois commencé à mettre bas, elles semhleul ne faire plus autre chose ; elles jettent de quinze à ringt petits dans une journée, et tout le reste de leur vie jusqu’a l'hiver, se passe dans ce pénible travail. Si l'on prend une de ces mères et qu'on la presse doucement, on fail sortir de son ventre encore un plus grand nombre de Pucerons de plus en plus petits, qui filent comme des grains de chapelet. Dès que le petit Puceron est né, il commence à sucer les feuilles.

Nourelle et étrange particularité! Ces petits sont tous des femelles qui mettront au monde d'autres femelles sans s'être accouplées arec un mâle, lesquelles produiront sans accouplement de nourelles femelles fécondes, ainsi de suite pendant neuf ou dix générations qui se sucrèderont durant le printemps, l'été et l'automne; mais la dernière génération pond des neufs qui passent l'hiver sur les arbres ef les plantes, et rui éclosent au printemps sui- 
vant. Ceux-ci donment naissance à des mâles ot ì des femelles qui s'accomplent une soule fois. Il n'y a donc qu'un seul accouplement qui föronde la femelle ef toutes colles qui sortiront d'elles pendant une surcession de nenf ou dix générations. Réaumur a calculé qu’une seule femelltr idait dans une seule anmée la soncle de 100,000 individus.

si les Pucerons n’itaient pas sommis à de numbreuses rauses de destruction, ils auraient bientôt étouffé la vigitation. Yais leurs ennemis sont nombreux et les dimoisent en grand nombre. Il est bon de les faire connaitre, afin guion les respecte puisqu'ils nous remdent service.

Lu premier rang se placent les larves d'une monche du zenre syrphe. La bouche de ces larves consiste dans un simple tube qui renferme denx soies écaillenses, de la grossem d'un crin, arec lesquelles elles percent les pucerous, les enlèvent en l'air par un mourement de tête semblable i celui d'une poule qui boit, et les sucent. Elles rejettent la peau vidée et percent un nouveau puceron qu'elles sucent de mime et contimnent ainsi presque sans interruption. Elles nettoient en peu de temps une branche chargée de relte rermine, sans qu'il en reste un seul. Elles les mangent ou plutôt elles les boivent plus vite qu’ils ne se reproduisent, malgrè leur fécondité. Parvenues à lemr complet développement, les sypphes se transforment en jolies mouches, de forme élégante et de couleur luisante.

En second lien viennent les larves de petits coléoptères fort rommus, auxquels on domne les noms vulgaires de Bête-à-Jieu, et dont le nom entomologique est Coccinelle. Elles vivent en général de Pucerous qu'elles saisisseml 
arec leurs pattes de derant et portent à leur bouche. Comme elles sont très-roraces, elles ne s'épargnent pas entre elles et s'entre-mangent Iorsqu'elles peurent s'attraper.

D'autres insectes ne se nomrissent pal ceux-mèmes de Pucerons, mais ils les premnent dans leurs dents et les emportent dans leurs nids pour leurs petits. Les femelles ètablıssent leurs nids dans une galerie creusée dans la terre ou dans le bois mort ou dans la moelle des branches sèches, comme le sureau. Elles empilent des Pucerons dans le fond de la cellule en nombre suffisant et pondent un ouf dessus, puis elles ferment la cellule aree une cloison de terre ou de moelle; elles approvisionnent de même une seconde et une troisième cellule et tant qu'elles ont d'œufs à pondre. Chaque ouf coûte la vie à 20 Purerons an moins ef sourent plus.

\section{PTCEROY DE COLZA}

Le colza souffre également des attaques du Puceron, ot voici un remède qu'on dit héroïque contre les ravages qu'il produit sur cette plante.

En 1864, M. Bethmont rapportait les résultats avantageux qu'il avait obtenus par l'emploi du pincement sur des plants de colza dont les premières fleurs avaient éti détruites par les gelées dı printemps; en $186 \mathrm{j}$ la 
même opiration lui a encore rendu d'iminents services dans des circonstances bien diffirentes. Voici, du reste, comment il s'exprime a cet égard! : Cette ammée j’ai semi de bonne hemre, mon colza a bien levé, les froids de l'hiver ont empêché une floraison trop hàtive, il n'y avait pas lieu de pincer, ou du moins il n’y arait pas nécessité, il n'y avait qu'utilité possible.

"Mais, an moment de lit floraison, le Puceron, par millions, se jeta sur le colza. l'espérais, c’était au commencement d'arril, que les gelées détruiraient l'ennemi. Point! En huit jours, 5a heetares de colza étaient dévorés, et, sur les 55, on en comptait 25 qui ne laissaient plus aucun espoir. Malgré l'époque avancée de l'année (I0 avril); je fis faucher la tête de mes colzas sur les 25 heetares perdus, réservant les 12 qui, bien qu'altaqués, itaient cependant porteurs l'une récolte encore acceptable. Je pris ce qui me restait ef confiai au hasard d'une pousse nouvelle et hien tardive les 25 hectares totalement ravagés.

"Le colza pincé repoussa avec unc vigueur incroyable, et les branches latérales atteignirent une movenne de 90 centimètres dans leurs noureaux rejetons. Nais le Puceron se chargea de la récolte et ne me laissa pas intacte une seule fleur sur ces 25 hectares. Seulement, cette plante nouvelle, fraìche et plus tendre lui fit abandome? immédiatement les colzas non pincés dans les 12 hectares cités plus haut, lesquels étaient placés au milieu des 25 soumis au pincement. Le Puceron quilta la plante plus dure pour la plante dont les pousses nourelles et tendres lui offraient une nourriture plus agréable ef plus appé- 
lissante. Mes 25 hectares furent sacrifiés, mais ils saurèrent complétement les colzas non pincés. "

Le sacrifice est assurénent énor'une, comparativement au résultat; aussi, II. Bethmont propose-t-il, en définilive, de corriger le hasard qui l'a si mal servi cette année, et de ronjurer les ravages du Puceron en pinçant une rangée ou une planche de colza sur quatre, de manière à laire la part du écu, i allécher l’insecte dévastateur par l'attrait d'une nomrerture fraîche et tendre, et à diviser le lléau sur une minime fraction de la récolte. L’irlée paraîl ingénieuse, et n'est peut-ètre pas saus précédents. C'est ì savoir maintenant re cu'elle vaudra dans l'application.

\section{PICEROX DU SAINFOIN}

(Aphis onobrychidis, de Goureau).

Le sainfoin est quelquefois attaqué par les Pucerons que l'on voit fixés à l'enfourchure des branches ou audessous de l'épi. Ils paraissent au mois de mai, au moment où se montre la fleur. Certaines plantes en sonl tellement garnies, qu'elles en paraissent noires et rependant elles ne semblent pas en souffrir sensiblement, car elles ne sont ni moins fraiches, ni plus faibles, ni plus chétives que les plantes exemptes de cette rermine.

Lorsque la plante est coupée et qu'elle commence ì sécher, les Pucerons n’y trouvant plus de séve pour se nourrir, l'abandonnent ef se portent ailleurs dans le but 
de chercher lemr nourrilure, on périssent fante d'aliments. Sans ancun doute, les bestiaux, hroutant la prairie artificielle, dédaignent les liges chargées de Pucerons u les foulent anx pieds, ce qui est une perte réelle.

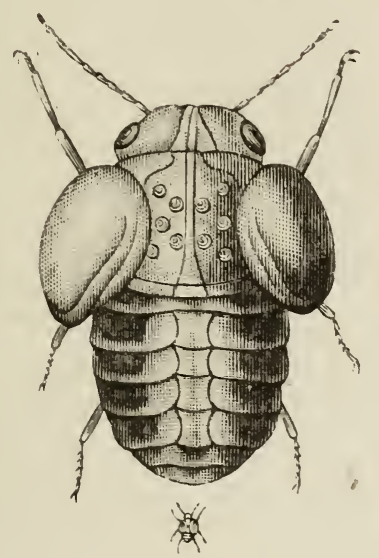

Fig. :0. - Puceron du sainfoin, grossi et grandeur naturelle.

Quant au sainfoin rentré see pour la nourriture d'hiver, il n'en contient plus et ne parait pas différer de celui qui: en est exempt.

II. Goureau dit que, vers l'époque dı 12 mai, on roil de nombreuses familles de ce Puceron sur le sainfoin dans lesquelles on remarque des individus aptères de toutes les tailles, depuis les plus jeunes qui viemnent de naître jusqu'à ceux qui sont adultes; des individus apteres qui prendront des ailes plus tard, qui sont à l'état de larve ou à l'ètat de nymphe; enfin des mdividus pourvus d'ailes qui sont des femelles adultes. Le Puceron du sainfoin (Aphis onobrychidiss a été décrit par M. Gourean : il est aptipe ef a me longueur de I mill. 1'o . Il est d'un 
nolr luisant, prriforme, c'est-à-dire plus étroit vers la tète qui est petite. Les antennes sont sétacées, un peı moins longues que le corps, formées de sept articles, les deux premiers courts et noirs; les suivants composant la tige, blanchâtre à la base, allant en diminuant d'épaisseur jusqu'à l'extrémité qui est noire; le bec est blanchâtre à la base; le corselet, non distinct, forme arec l'abdomen un corps pyriforme arrondi au bout et terminé par une petite queue. Les cornicules sont noires, assez longues; les pattes sont blanchâtres, arec la moitié inférieure des cuisses et les tarses noirs.

Le Puceron ailé est semblable pour la couleur à l'espèce aptère; mais le corps est ovale, le corselet distinct et l'abdomen est un peu étranglé à la base; les ailes sont blanches, deux fois aussi longues que l'abdomen; les antennes, le bec, les cornicules et les pattes sont comme dans le précédent. On ne connaît aucun moyen de destruction contre ce Puceron qui, rraisemblablement, ne se multiplie extrordinairement que dans les sainfoins qui manquent de rignueur et dans les années défarorables ì rette plante.

\section{PICEROX IOES RACIIVES}

(Aphis radicum.)

V. Goureau est encore le premier qui ait appelé l'atlention sur cette espèce qui ne vit pas à découvert comme les autres sur les feuilles ou sur les tiges des végcétaux, mais qui s'attache à leurs racines. 


\section{JASSE DEVIST ITEUR}

(Jassus ciccadellina ou devastans.)

Le Jasse ciccadelline ou devastans est un hémiptère qui, depuis 1844, parait s'être fixé dans la commune de Saint-Paul (Basses-Alpes).

Voici, d'après Guérin-Méneville, la description de cet insecte: Sa tête est jaune d'ocre avec le sommet marqué de taches noires, le front jaune, allongé, sillonné de raies transverses arquées noires, de chaque côté. Le rlypeus est allongé, bordé de noir avec une ligne de cette couleur au milieu. Le prothorax et l'écusson sont jaune d'ocre, arec des taches brunes. Les élytres transparents sont d'un jame pâle avee quelques taches brunes. Les pattes sont james, rayées de noir. Les ailes sont transparentes of un peu enfumées à l'extrémité. Sa longueur est de deux millimètres et demi.

Cet insecte ne ronge pas les céréales (blé, orge, avoine), mais il en suce les feuilles et la tige, qui se dessèchent. l’est surtout le matin quı’il commet ses dégâts, sautant ou s'envolant à l'approche de l'homme. On le troure même en hiver sur les jeunes blés, mais surtout au printemps. On croit avoir remarqué que le sulfate de fer, rouperose verte, répandu sur le sol a la propriété de les bloigmer. 


\section{THRIPS}

Les Thrips ont une certaine analogie arec les Pucerons. Ils constituent un petit ordre qui a recu le nom de Thỵsanoptères. Ils possèdent huit articles grenus anx anlennes, le dernier non terminé par denx soies; élytres et ailes linéaires, frangés de poils, conchés horizontalement sur le corps, qui est cylindrique; bec très-petit ou peu distinct: tarses terminés par un article résiculeux sans crochets.

Ces insectes sont très-petits et vivent sur les fleurs ou les écorces d'arbres; leur corps est étroit, allongé, terminé en queue: leur tête est carrée et allongée. Le premier segment de leur prothorax est très-risible. II. Goureau est ın des auteurs qui aient, en France, donné la meilleure description des Thrips. On voit souvent, dit-il, sur le blé, dans les champs, depuis le moment où se montre l'épi, au mois de juin jusqu'à l'époque de la moisson, de très-petits insectes noirs allongés, agiles, n'ayant pas plus de 2 mill. de longueur, sur 1/5 mill. de largeur, qui courent rapidement et qui se cachent volontiers entre les écailles renfermant les grains: ils sont en nombre plus ou moins considérable sur chaque épi, et l'on trouve parmi eux, entre les écailles, des petites larves d'un rouge de sang, atténuées du côté de la queue, ayant une tête distincte et six pattes. Ces larves produisent des insertes noirs. Il est prohahle que les mes ef les autres 
se nourissent anx dépens du blé, en suçant la séve qui arrive au grain, mais on n'en est pas parfaitement sir. Si réellement ils sont suceurs, conme on le suppose, ils ne font pas un tort considérable aux l'écoltes et on pent les placer à côté des pucerons sous le rapport des dégâts qu'ils produisent.

La larve de ce petit insecte, observée d Santign!, a \& mill. de longueur. Elle est d’un rouge de sang; la tèle est petite, séparée du premier segment par une sulure peu marquée; elle porte deux antennes de cinq articles terninées par une pointe formant peut-ètre m sixième article; le corps contient douze segments dont les trois premiers sont les plus grands : les autres diminuent graduellement de largeur jusqu'au dernier qui est terminé par une petite quene noire: les six pattes thoraciques sont noires.

L’insecte parfait, obser'vé le 1⁄2 aout suivant, se r‘approche beaucoup du Thrips decora.

1. Thrips decora, Halid. - Longueur I mill. 1/2, nuir; antennes filiformes, de la Jongueur du thorax, droites, de sept articles, le dernier terminé en appendice sétiforme, le premier noir, les troisième et septiène presque entièrement blanchàtres; tous les autres blanchàtres à la base, noirs à l'extrémité; tète et thorax noirs luisants; abdomen de la long'ueur de la tête et du thorax légèrement renflé au milieu, un peu resserré à la base terminée par une petite queue droite, lisse, luisant, noir; pattes noires, cuisses antérieures renflées, les quatre ailes blanches, de la longueur de l'abdonen, à bords garnis d'une longue frange de poils. 
Il prend sa nourriture au moyen d'un suçoir formé de trois soies qui sortent d'une fente située sur la tête.

On lit dans le Farm Insects de M. Curtis les observations suivantes, communiquées par Kirby ${ }^{1}$ à Marsham: " J'ai examiné un grand nombre d'épis dans lesquels se treure cet insecte à tous ses états, entre la valve intérieure de la corolle et le grain. Il se tient dans le sillon longiludinal du grain dans le bout duquel il semble enfoncer son bec; il suce probablement la sére sucrée qui gonfle le grain, et en le privant d'une partie de cette séve nourricière, il le fait tontracter et devenir ce que les fermiers appellent pungled (raccorni). Si votre correspondant de l'Hertfordshire entend parler du même insecte, il se trompe ell assurant qu'il ne gâte qu'un grain. J'ai vu moi-mème des épis dont le quart des grains étaient détruits ou matériellement attaqués. L'e qui est singulier c'est que lorsque j'en trouvais deux sur le même grain l'un était ailé et l'autre aptère, formant les deux sexes. J'ai rencontré une grande espèce (T/hrips aculeata) sur laquelle j'ai fait la mème observation. »)

Lalarve du Thrips physapus est jaume; elle a six pattes qui, arec la tète et les antennes, sont noires et blanches; quelquefois elle est entièrement jaune, elle est trèsagile, et, lorsqu'on enlève le grain qui la porte, elle s’è= chappe aussitôt. La nymphe est blanchàtre avec les yeux noirs et les ailes apparentes, elle est très-lente et paresseuse dans ses mourements. On roit souvent une poudre de couleur orange dans les grains sur lesquels l'in-

1 Kirby, célèbre entomologiste anglais, 
secte a été trouve; il suppose que de sont ses excréments.

'Tous les fermiers que M. Goureau a consultés s'aceordent à dire que les blés les demiers semés sont les plus exposés aux dégâts de cet insecte, tandis que les premiers faits en souffrent peu ou point du tout; ce qu'il regarde comme très-probable, parce que le blé parvenu à unc certaine dureté (ce qui arrive aux premiers semés) n'esl plus susceptible de se crisper. limné dit de cet insecte quil rend vides les ipis de seigle.

Voici, d'après M. Curtis, la deseription de ce Thrips.

2. 'Thrips cerealium, Haliday; Thrips physapus, liiby. - La larve et la nymple sont semblables de forme à l'insecte parfait, mais plus petites. La larve est d'un jaune oncé avec la plus graude partie de la tète, et deux taches sur le prothorax brumes; les antemnes et les pattes sont alternativement cerclées de pâle et de brum. La nymphe est d'un jame pàle, avec les antemnes, les pattes, les fourreaux des ailes blanchâtres, cette dernicre couleur atteignant le milieu de l'abdomen; les yeux sont d'un rouge brum. L'insecte parfait est lisse, luisant, couleur de poix, quelquefois noir, déprimé, d'une longueur de I mill. 1/2. Le mâle est aptire et la femelle ailée.

La tète est tronquée, convexe en dessus avec 111 sillon au mlieu; les yeux sont écarlés, ovales, latéraux; le cou n'est pas contraclé; les antemnes, insérées devant les yeux, sont plus longues que la tête, tiliformes de neut anlicles; la face est obliquement inclinec en bas, temminéc par les trophi qui forment mor sorte de bec qui se ter= minc aux hanches antérieures; le thorax est presque 
carré, quelquefois un peu plus étroit en devant, are. quatre points imprimés, deux de chaque còté; l'écusson est court, un peu lumule; l'abdomen est long, étroit, lisse', composé de neuf segnents; l'oxtrémite est ovée ou couique, garnic de soies; le dernier segment est armé de deux épines, latérales chez le màle, et pointu chez la fénelle, les quatre ailes sont aussi longues que le corps, itroites, horizontales, incumbantes et parallèles dans le repos, mais courbees en dehors et ne se rencontrant pas; les supériemes sont coriaces, hrumes, arec la base pàle, ciliees, de longs poils, ayant trois nervures longitudinales; les inférieures sont un peu plus courtes, nembraneuses, transparentes et égalenent ciliées ; les pattes sont écartées, les antérieures très-courtes et robustes chez la femelle; les tibias antérieur's couleur de paille dans le mème sexe, avec une protubérance sur les côtés et un crochet courbé à l'extrémité; les autres sont simples, les tarses très-courts, de couleur paille, bi-articulés, terminés par une glande.

Celte espèce parait diflérente de celle qui a élé observée a santigny, par la coulem de la larve et par la description de l'insecte parfait.

II. Curtis dit qu’il a sourent observé ces insectes courant sur la tige el sur les épillets du blé, en grand nombre, en compagnie de la Cécydomye du froment, pendant le mois de juin ef en compagnie du Puceron du blé, pendant le mois d'aoùt, et qu'en ouvrant la feuille qui enveloppe la tige de l'orge pour rechercher le Chlorops de cette céréale ainsi que ses parasites, il a rencontré des groupes de larves oranges el des Thrips noirs à l'etal 
parfait; les premieres se trouvaient anssi daus les épis, au milieu du grain qui commençait à paraître.

On voit quelquefois des Thrips en nombre prodigieur de la mème espèce posés sur des roses ou sur d'autres fleurs: on les roit aussi voler en essaim sur les pèchers et autres fruits en espalier's, sur les melons, sur less chàssis, etc. 


\section{HYMENOPTERES}

\section{CEPHE PYILE}

(Gephus pygmæus)

Le lièphe est un hyménoptère de la tribu des T'enthrédiniens remarquable par la jonction intime de l'abdomen arec le thorax, par une double tarière mobile, écailleuse, dentelée en scie, pointue, et logée entre deux autres lames yui lui servent d'étui, et lorme un caractère spécial. C'est en considération de cette structure que Latreille domrait a cet insecte le nom de Porte-scie. Les femelles se servent de cette tarière pour fendre des tiges, dans lesquelles clles déposent un ouf, répandant en mème temps une sorte d'écume, a laquelle on attribue la propriétí d'empècher l'ouverture de se fermer. Ses entailles augntmentent promptement de volume et forment, dans certains cas, des excroissances qui servent de domicile aux larves. 
C'ependant, la plupart des Tenthrédiniens vivent dans leur premier état à découvert sur les végétaux et se nourrissent de leurs fenilles; ils ressemblent beancoup aux chenilles par leur formes et par leurs couleurs, mais les pattes membraneuses (c'est ainsi que l'on désigne des espèces de mamelons qui existent par paires à certains anneaux dı corps de l'animal) sont en nombre plus considérable, de 1/4 a 16, tandis que chez les chenilles on n'en compte jamais

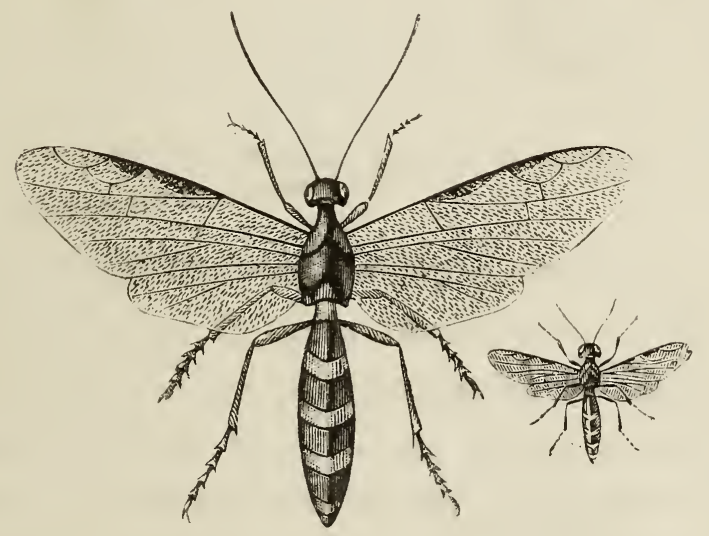

Fig. 今̈l. - Cèphe pygnmée, grossi et grandeur naturelle.

plus de 10. Ils sont au reste, en général, pourvus, comme ces dernières, de trois paires de pattes écailleuses (c'est ainsi qu'on appelle les pattes articulées appartenant seulement aux trois premiers anneaux du corps et qui représentent les six pattes de l'insecte parfait). Il faut noter cefait que des larves d'hyménoptères sont pourvues d'organes de locomotion. Il ètait nécessaire, en effet, dit M. Blanchard, qu'elles puissent marcher de fenille en fenille pour que la nourriture ne vienne pas à leur manquer, si elles restaient toujours à la même place. Le nom de 
fausses chenilles, qu'on leur a appliqué, leur convient réellement très-bien. Plusieurs se roulent en spirale et d'autres se relèvent le corps en forme d'arc quand on les inquiète. Pour se métamorphoser en nymphe les larves du
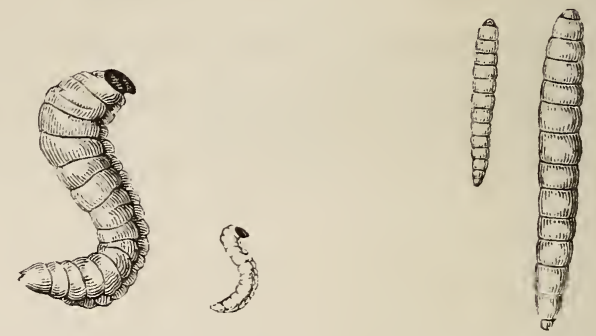

Fig. :32. - Larves du Cèphe pygmée, grossi et grandeur naturelle.

Cephus se filent une coque soyeuse soit rlans la terre, soit sur les plantes où elles ont vécu. Ce qu'il y a de remarquable dans la métamorphose de ces hỵménoptères, c'est que leurs larves, après s'ètre enfermées dans leurs cocons y demeurent, souvent fort longtemps, quelquefois même y passent l'hiver, avant de subir leur transformation en nymphe; l'insecte parfait éclôt toujours très-promptement après ce dernier changement. Le groupe des Céphites est distinct entre tous les autres Tenthrédiniens par de longues antennes multi-articulées, ordinairement épaissies à l'extrémité. Le genre principal, celui des Cìphes est peu nombreux en espèces; toutes sont européennes; leurs larves sont molles avec des pattes écailleuses, leur corps acuminé à l'extrémité, les divers anneaux du corps privés de pattes membranenses. Ces larves vivent dans l'intérieur des tiges.

Si l'on traverse un champ de blé ou de seigle, huit ou 
quinze jours avant la moisson, on remarque un nombre plus ou mons considérable de tiges qui portent des épis blancs et droits, s'élèvent au-dessus des autres et paraissent avoir atteint leur maturité. Ils offrent un contraste frappant avec les plantes voisines qui sont encore rertes it dont les épis remplis de grains sont courbés vers la lerre, tandis que les autres sont vides ou ne contiennent yu'un petit nombre de grains maigres ef déformés.

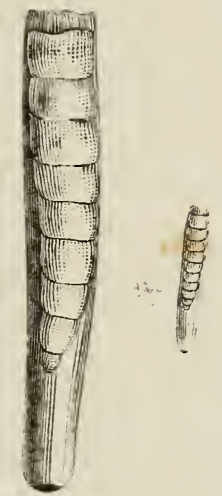

Fig. :5.5. - Nymphe du Cèphe pygmée renfermée dans son tube, grossi et grandeur naturelle.

Ces épis blancs, vieux avant l'àge, doivent leur caducité précoce à la présence d'une larve armée de deux fortes mâchoires et qui ronge intérieurement la partic médullaire de la plante. En fendant longitudinalement le chaume on remarque une poudre jaunattre formée par les débris qui attestent la voracité de l'insecte. De plıs les nœuds de la paille sont perforés. Quoi d'étonnant après cela qu'une dégénérescence semblable se produise dans l'épi. 
II. Herpin a étudiè avec succès les métamorphoses du Cèphe pymée. Déjà, en 1819, un agronome instruit, dı département dı Loiret, Dugaigneau, faisait connaitre, dans le tome $\mathrm{I}^{\mathrm{er}}$ des Annales de la Société des sciences, bclles-lettres et arts d'Orléans, les métamorphoses de cette espèce et les altérations qu'elle produit dans le froment, et le comte de Tristan donnait à la suite de I. Dugaigneau une notice entomologique très-bien faite, en rapportant l'espèce observée par cet agronome au Céphus pygmæus des auteurs. Voici un extrait de l'article de M. Dugaigneau rapporté par M. Guérin-Méneville dans ses notices entomologiques.

Ayant arraché, au moment de la récolte, une quantité de pieds de seigle, M: Dugaigneau a trouvé dans le chaume des larves blanches du Sirex. Après l'hiver rigoureux de 1812 à 1815, il a voulu voir si les larves avaient péri, il a arraché des chaumes et il les a trouvées virantes. Elles n'avaient nullement souffert. A la fin de mars, il y en avait dẻjà beaucoup de transformées en chrysalides et plusieurs sont écloses dans les premiers jours d'avril.

"L'insecte, après son accouplement, pique le tuyau du seigle au-dessous du premier nœud pour déposer dans son intérieur un œuf qui doit éclore d'autant plus promptement qu'il est plus échauffé par les rayons du soleil, concentrés près de la terre entre toutes les pailles du seigle; la petite larve se nourrit de la partie intérieure de cette paille qui est très-tendre alors et des sucs nutritifs de la séve qui doit former les grains de l'épi ; bientôt elle acquiert assez de force pour ètre en ètat de perforer les noeudds de cette paille, passe au travers et monte plus 
ou moins haut dans l'intérienr; j'en ai trouvé, mais en petit nombre, qui avaient franchi tous les nouds: elle redescend ensuite et arrive au pied de la paille lorsqu'elle a atteint tout son développement, alors elle scie cette paille à fleur de terre avant et même au moment de la maturité du grain; il s'en trouve aussi qui n'est pas totalement sciée lorsqu'on fait la récolte. )

M. Digaigneau dit comment cette larve descend dans la souche du seigle un peu au-dessous du sol, comment elle ferme son tuyau avec un tampon de sciure et de ses excréments, comment elle s'enveloppe d'me coiffe transparente beaucoup plus grande qu'elle et dans laquelle clle reste huit mois.

11 propose, cornme moven de destruction, de labourer en mars ou au commencement d'avril. Il croit que le bouleversement et l'enfouissement des chaumes feraient périr les larres ou les insectes parfaits qui, au moment de leur éclosion, ne pourraient percer la terre pour sortir.

A la suite de ces observations, M. le cor..te de Tristan a inséré le mémoire suivant.

Description du Syrex pygmaus (Lin.), insecte qui a ravage les seigles de la Sologne en 1811 et 1812.

L'auteur se borne à bien faire commaitre l'insecte observé par M. Dugaigneau. II établit sa synonymie, cite Klug, Panzer, Latreille et Fabricius. Il critique la figure que Coquebert a donnée des mâchoires et il donne une homme description de la larve.

Il parle d'un moven qui lui semblerait bon poụ dé- 
Iruire ces larves; ce serait de brûler les chaumes. Alors, dit-il, pour éviter la perte qui en résulterait, il faudrait avoir fait couper le blé très-bas ; mais, dans ce cas, il fauIrait voir si la flamme se propagerait facilement, ou bien si elle serait fugace, et dans ce cas, cet insecte, un peu enfoncé dans la terre, serait-il atteint?

Le mémoire est accompagné d'un planche lithographié représentant l'insecte parfait, ses diverses parties et li larve rue en dessus et de profil.

Depuis ce trarail, qui est resté ignoré des entomologistes, la larve du Cephus a été signalée plusieurs fois, et, entre autres, dans le département de la Charente, sous le nom d'Aiguillonier. М. Dagonet et Ilerpin ont suivi aver soin les métamorphoses du Céphus.

On trouve, dit II. Herpin, la larve du Céphus dans le commencement du mois de juin; elle est placée dans l'intérieur de la tige, d'autant plus bas et plus près de la terre qu'elle est plus àgée et que la maturité de la plante est plus avancée.

Quelques jours avant l'époque de la moisson, cette larve se retire près des racines de la plante; elle se construit, dans l'intérieur du chaume, un fourreau soyeux transparent où elle se renferme et passe l'hiver, après avoir eu toutefois la précaution de couper circulairement la paille en dedans à 18 ou 14 millimètres environ de la terre, afin que l'insecte parfait n'éprouve aucune difficulté à sortir de sa prison.

Par suite de cette section, la paille n'ayant plus de soutien, se rompt au pied et tombe à terre lorsque le vent devient un peu fort: alors le champ présente le 
mème aspect que s’il avait été traversé dans tous les sens par des chasseurs ou par des animaux.

On peut longtemps encore après la moisson et même pendant l'hiver retrouver la larve renfermée dans les rarines du chaume, il suffit pour cela de tirer plusieurs brins de paille restés adhérents aux racines. Ceux qui contiemnent une larve se détachent avec la plus grande facilité parce que la paille est sciée circulairement. En regardant arec attention, on trouve aussı, à la mèmf époque, tout près de la terre, des étais très-courts du chaume coupés horizontalement, qui renferment l'insecte.

M. Guérin-Méneville a démontré le côté intéressant que présente au point de vue entomologique la larve du Cèphe pıgmée; elle établit un passage entre les Porte-scie et les Pupirores. Elle est apode et très-diffèrente de toutes celles des Tenthrédines, qui ont toujours six pattes thoraciques et dans le plus grand nombre de douze à seize pattes membraneuses. Comme celles-ci, elle se nourrit de la substance des végétaux, mais au lieu d'ètre très-active, de pouvoir marcher sur ces régétaux et ronger leurs parties externes, elle est destinée à vivre dans l'intérieur des plantes, elle ne jouit que de facultés locomotives très-limitées, n'ayant pas de pattes et ne pouvant que monter et descendre dans un tube en s'appuyant entre les parois, au moyen des segments de son rolps.

Trompé par ce caractère anormal qui la distingue de toutes celles des hyménoptères porte-scie, l'absence des pattes, M. Dagonel, qui l'avait signalée en 1859, n'avait pu penser qu'elle dut produire une Tenthrédine. 
Sachant d'un autre côté que toutes les larves des Pupivores sont carnassières, les habiturles phytophages qu'il lui avait reconnues l'empêchaient de la ranger dans cette catégorie et il ne lui avait trouvé de rapports qu'arec certaines larves de diptères tipulaires.

Cette larve complétement développée a une longueur de 14 millimètres et une largeur de 2, elle est un peu épaissie vers l'extrémité antérieure, à peu près cylindrique, d'un blanc laiteux un peu jaunâtre, d'une consistance presque cornée et d'une couleur rougeâtre pâle. Elle offre, de chaque côté, une petite antenne très-courte, conique, composée de quatre articles peu distincts, au-dessous de laquelle on aperçoit un petit oil rond. La lèvre supérieure ou labre est. arrondie, membraneuse, et ne couvre qu'en partie les mandibules: celles-ci prennent leur insertion latéralement, elles sont presque cornées, de forme carrée, tronquées au bout et offrant à cette extrémité plusieurs dentelures, dont les deux latérales sont les plus fortes. Les mâchoires situées immédiatement audessous de ces organes sont moins solides, de forme également carrée, moins larges, leur lobe interne est un peu arrondi et cilié à l'angle supérieur et en dedans. Il y a au côté externe, et en arrière de celui-ci, au côté antérieur', un petit pulpe conique formé de trois ou quatre articles peu distincts.

La lèvre inférieure est assez épaisse, transversale, mI peu échancrée an bord antérieur; elle porte, de chaque côté un petit palpe conique, très-large à la base et com posé de trois articulations. Les trois segments du thorax sont à peu près de la même largeeur, pliés en dessus et en 
dessous, sans pattes, mais offrant à leur partie inférieure des plis qui circonscrivent des espèces de inamelons deslinés à remplacer les pattes. Les autres segments du corps sont semblables aux précédents, mais ils vont un peu en diminuant de largeur et les bosselures dı dessous sont un peu moins marquées. Le dernier segment est terminé par un petit appendice tubuleux susceptible de s'allonger comme un tuyau de lorgnette et qui doit être destiné à servir à l'insecte pour se pousser en avant.

II. Guérin-Neneville déclare ne pas avoir vulanymphe, mais elle doit se métamorphoser dans la coque transparente que la larve se construit.

Vers la fin de mai, ou lorsque le seigle, le blé commenceut à épier et avant la fleuraison, les larves se métanorphosent et domnent naissance à une mouche à quatre ailes du genre Sirex (Linné, Coquebert de Montbret), Cephus (Fabricius et Lepelletier de Saint-Fargeau). Cette mouche se répand dans les champs cusemencés en blé ou en seigle et dépose un ouf sur la tige de la céreale, inmmédiatement all-dessous de l'épi.

Le dommage occasionné par le Céphus sur le froment ef le seigle est assez grave, puisque les épis portés par les tiges attaquées sont généralement stériles ou ne contiennent qu'un tris-petit nombre de grains. M. Herpin estime ce donmage à un soixantiène environ du total de la récolte. 


\section{MOYENS DE DESTRUCTION}

Le moyen qui parait le plus commode et le plus certain pour détruire les larves du Céphus, c'eśt de mettre le feu aux chaumes restés sur terre après la moisson, puisque les larves s'y trouvent renfermées près des racines. L'incinération des chaumes restés sur terre après la muisson est un des excitants les plus actifs et les plus économiques de la végétation surtout dans les terres fortes et argileuses que le feu dessèche et calcine, elles s'ameublissent et s'amendent tout à la fois par cette opération simple, facile et qui ne coûte rien à exécuter.

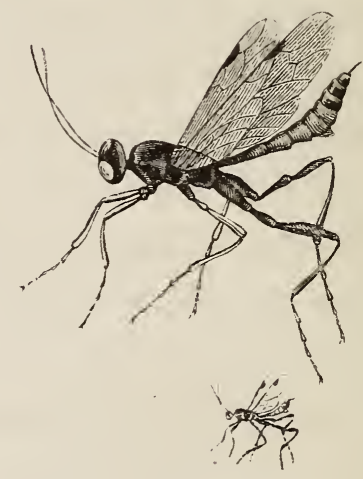

Fig. 34. - Pachymerus calcitrator (parasite du Cèple) grossi et grandeur naturelle.

Le Cièphe a de mème que le Chhlorops un emnemi mortel dans un grand Ichneumon qui le détruit et le dévore, il appartient au genrc 0phion et au sous-genre Pachỵmerus de Gravenhorst. M. Dagonet qui a decrit cet insecte l'a rencontré avec des Cȩ̀̉hes, mais il n’a qu'à le surprendre au moment de sa ponte. 


\section{DIPTERES}

\section{CECYDOMIE DU FROMENT}

(Cecydomia tritici.)

Quand les épis se dégagent de leur gaine de feuilles, le matin au lever du soleil, le soir à son coucher et encore aux heures de la journée où l'air est ie plus calmé, on voit dès

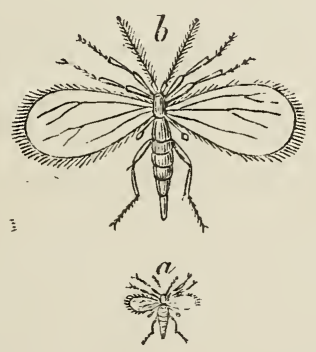

Fig. 5̋. - Cécydomie du froment, grossie et grandeur naturelle.

nuées de très-petites mouches, semblables à des cousins. Elles ont reçu des entomologistes le nom de Cécydomies. Leur corps est d'un jaune pâle, un peu plus foncé que la 
couleur paille; leurs ailes transparentes, lavées de jaune, sont couchées horizontalement sur le dos. Leur's yeux, trèsgrands et saillants, occupent presque toute la tête.

Ces Mouches appartiennent à la tribu des tipulaires ou tipulides, de la division des némocères, de l'ordre des diptères. Elles sont remarquables par la longueur de leur antennes, qui ont 24 articles dans les mâles, 14 dans les femelles. Leurs ailes sont frangées et présentent 5 nervures longitudinales. Elles runt, viennent, tournoient; elles cherchent un lieu sûr pour leurs œufs, dans lequel se rencontrent l'abri avec la provision de vivres nécessaire à l'accroissement du petit. Munies d'un oviducte rétractile en forme de tarière, elles traversent avec cet instrument le grain de blé à peine naissant, bien qu'il soit défendu par la balle ou écaille, et réussissent à loger dans sa substance un ou plusieurs œufs.

Quelques jours après, de ces œufs, sortent autant de pelits vers qui vont s'installer entre les glumes des épillets et rongent les rudiments des étamines, des styles, enfin de toutes les parties constituantes de la fleur future.

Si l'on ouvre dans le courant de juillet l'un des épillets à demi attaqué, on découvre au centre même toute la petite famille de la Cécydomie occupée à le ronger. Ce sont de petits vers d'un jaune pâle, qui finissent par prendre la couleur orange. Ils sucent pour se nourrir, la séve destinée au grain, et, par suite, empêchent son développement. S'il n’y a que deux ou trois vers dans une case, le grain est maigre, irrégulier, mais du moins il se forme. S'il y en a quinze ou vingt, ils dévorent tout et ne laissent que le vide. Dans certaines années où la Cécydomie sévit, le déficit dans 
la récolte s'élève jusqu'à la moitié et aux deux tier's.

La larve, qui commence à se montrer vers le 20 juin, a pris tout son accroissement au 15 juillet. Elle sort alor's de son berceau et s'èlance à terre par un saut brusque et tombe sans se blesser. Elle entre dans le sol, se cache dans un petit trou, s'enferme dans un léger cocon de soie blanche où elle se métamorphose en chrysalide. Elle passe dans la terre l'été, l'automne, l'hiver et devient insecte parfait au commencement de l'èté suivant, c'est-à-dire ver's le 15 juin. C'est une Ciécydomie ailée prète à s'accoupler, à pondre et à fournir enfin une nouvelle génération de petits rer's.

En temps ordinaire, les dégàts commis par cette mouche passent inaperçus; mais il n'en est pas toujour's ainsi. En 1827, elle apparut en si prodigieuse quantité par toute l'lrlande, qu'elle réduisit à un quart le produit ordinaire de la récolte du froment et occasionna au pays une perte de plusieurs millions.

Joigneaux rapporte, d'après les Mémoires de la Socièté agricole de l'État de New-York, que cette Cécydomie fit en 1852 de tels ravages dans les grainés de plusieur's can= lons des États-Unis qu'on dut y abandonner pour quelque temps la culture des céréales. Dans les États du Maine el de Vermont la perte s'éleva à plusieurs millions de dollar's.

D'autre part, M. Morren rapporte dans son Journal d'agriculture ciu'en 1846 le tiers de la récolte en Belgique, fut dévoré par la Cécydonie et il n'estime pas à moins de 2,007,980 hectolitres, soit 40,000,000 francs, la quantite de blé que cette mouche anéantit cette année-là dans le pays. 
En riance, elle causa d'assez grands ravages en $185 \overline{3}$, 18 วั4 et 185ว. II. Bazin eut alor's l'occasion de l'étudier' dans l'Yonne et la Picardie. 11 a évalué à 4 millions de. francs la perte qu'en une seule année cet insecte a causée à l'état de larve en faisant arorter la fécondation ou les grains fécondès.

\section{MOYENS DE DESTRUCTION}

La Cécydomie que nous venons de décrire a heureusement un ennemi dans un petit ichneumonide de la famille des Proctotrupidés, appelé Platygaster dé Bósc (Platygaster Boscii). C'est un très-petit hyménoptère entièrement nör, très-reconnaissable à un appendice redressé èt recourbë en avant qui porte la base de son abdomen. Il pond sés œufs 'dans le corps des larvés de la Cécydomie qu'il sait trourer dans leur retraite; il en détruit de la sorte une grande quantité.

\section{MOYENS ARTIFICIELS}

Si les blés sont déjà envahis par les ver's, le mal est sans remède, car on ne connaît encore aucun moyen et l'on n'en connaitra probablement jamais, d'atteindre ceux-ci au cœur mème de l'épi pour les faire périr. Mais en cè cas, il est nécessaire de prendre certaines précautions pour' atténuer autant que possible les pertes que pourrait causer une nouvelle invasion l'année suirante.

II. E. Dupont, qui a obserré arec soin les mœurs de ces insectes lor's des dégâts qu'ils commirent au Canada en 185 f et pendant les années qui suivirent, a fait quelques remar- 
ques importantes desquelles il a tiré de précieuses indications.

La mouche à blé, dit-il, est délicate et ne peut guère se transporter qu’à quelques arpents de l'endroit qui l'a vue naitre, et encore lui faut-i] un temps calme. Les champs semés en blé et qui ont déjà été attaqués l'année précédente sont beaucoup plus maltraités que les nouveaux dèfrichements. Enfin, un observateur a remarqué des quantités prodigieuses de Cécydomies sur des tiges de patates plantées dans un champ qui avait donné du blé l'èté précédent; ces mouches devenaient désormais inoffensives. De là ressort, comme le fait remarquer avec raison M. Joigneaux, l'indication bien précise d'alterner les cultures et même d'éloigner le plus possible le froment des lieux qui ont été précédemment ravagés.

Autre remarque : le blé n’a guère à redouter la ponte fatale que dans les trois jours qui suivent l'apparition de l'épi entre les feuilles. Si donc pendant les trois jours il règne un rent assez fort pour agiter sans cesse les tiges du froment, ou bien s'il tombe une pluie persistante, ou encore si le thermomètre descend pendant la nuit à $8^{\prime}$ ou $9^{\circ}$ Réaumur et qu'il ne se soit pas élevé pendant la quinzaine précédente au-dessus de $11^{\circ}$; si l'un de ces cas se présente, quelle que soit la quantité des Cécydomies que l'on ait vues dans les champs avant l'épiage, les dégâts seront peu considérables, car la ponte aura été contrariée, et beaucoup d'œufs déposés sur les tiges ou les feuilles produiront des larves qui devront forcément périr faute de nourriture convenable.

L'observation, dit M. Dupont, a encore démontré qu'en 
reculant ou en avançant le moment de l'épiage de façon à le faire arriver avant le 15 juin ou après le 20 juillet, c'està-dire avant ou après le temps pendant lequel apparaît la Cécydomie, on échappe encore aux atteintes de cet insecte.

Itone si l'on redoute la mouche à blé, il ne faut plus semer le grain dans le même champ ni même dans un voisinage trop rapproché; en second lieu, il faut faire, s'il est possible, les semailles en avril, sinon aux premiers jours de juin; enfin il est important que les champs soient nets de mauvaises herbes, qui ne manqueraient point l'offrir des retraites assurées aux mouches.

\section{CECYDOMIE DESTRUCTRICE}

(Gecidomia destructor.)

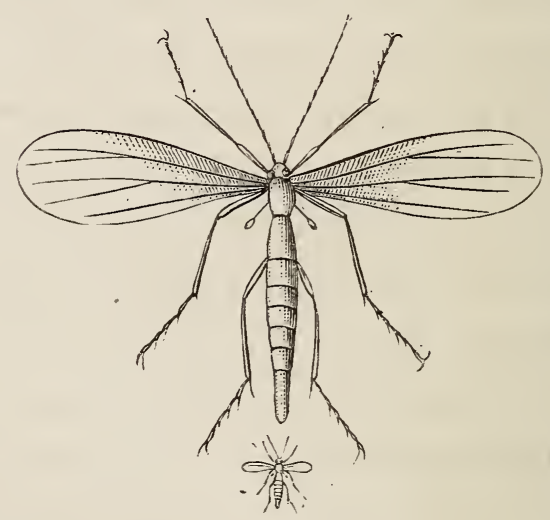

Fig. 56. - Cécydonie destructrice, grossie et grandeuir naturelle.

Une autre varièté de Cécydomie appelée Mouche hessoise (Hessian Fly) qui semble être la même que celle dı 
froment, ravage les froments en Amérique. Sa femelle dépose avant l'hiver ses œufs sur la tige, au point d'insertion des fenilles. La larre qui en résulte mange le chaume, descend dans la racine et fait périr la plante. Cette Cécydomie aurait pour ennemi un petit ichneumonide appelé Ceraphron destructor très-commun à l'époque où les larves atteignent leur développement.

Les Américains lui rlonnent le nom de Hessian Fly, parce qu'elle provient, dit-on, des blés envoyés pendant la guerre de l'Indépendance aux Ilessois, qui faisaient partie de l'armée anglaise.

\section{CHLOROPS LINÉOLE}

(Chlorops Lineata.)

Curtis pense que le Chlorops lineata est la mouche appelée Musca lineata par Fabricius, Oscinis lineata par Latreille, Oscinis pumilionis par Olivier, Chlorops nasuta. par Macquart, Chlorops toniopus par Meigen et Chlorops glabra par Westwood. Il est différent du Chlorops lineata de Macquart. Voici les caractères distinctifs du Chlorops lineata. Sa longueur est de 5 millimètres, il est jaunâtre, avec des antennes noires; une tache triangulaire noire sur le vertex; cinq raies longitudinales noires sur le corselet; son abdomen est jaune avec des bandes et deux points bruns à la base; anus jaune, pattes jaunes, tarses antérieurs noirs, les intermédiaires et les postérieurs jaunes avec les deux derniers articles noirs. 
Ce Chlorops qui doit son nom à ses deux gros yeux d'un vert brillant est un diptère de la famille des muscides. M. Herpin pense qu'il est l'anologue de celui qui fit tant de ravages en France en 1812, et qu'Olivier a décrit, étudié et figuré dans les Mémoires de la Société d'agriculture, t. XVI, p. 472.

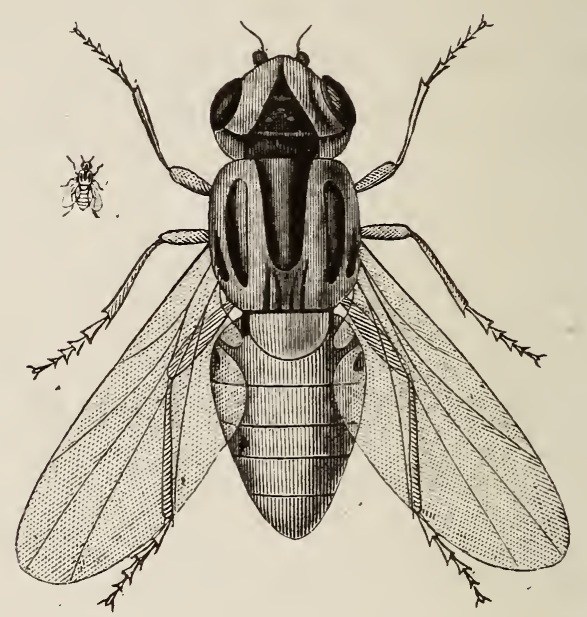

Fig. 5ั7. - Chlorops, grossi et grandeur naturelle.

Les phases les plus intéressantes de la vie de cet insecte étaient restées inconnues aux naturalistes, et les dégâts qu'il occasionne avaient été attribués par les agriculteurs, soit à une maladie de la plante, soit à quelques accidents de la végétation. On avait remarqué, en 1812, dans les blés nouvellement plantés, soit avant, soit après l'hiver, des altérations occasionnées par une larve qui, placée audessus de la racine, rongeait les feuilles du centre de la plante, la faisait jaunir et périr ensuite.

En 1859, M. le docteur Dagonet, à Chàlons-sur-Marne, 
et M. Philippar, professeur à Grignon, signalèrent de nouveau des larves qui, déterminant, au printemps, un gonflement considérable de la jeune plante de froment au-dessus du collet, détruisent les feuilles centrales et la plante elle-même.

Vers la fin du mois d'avril ou en mai, ces larves donnent naissance à une mouche à deux ailes, de couleur jaune, ayant des lignes noires sur le dos, décrite et figurée par Olivier et rapportée par ce naturaliste au genre Oscinis, par Meigen et Macquart au genre Chlorops.

L'histoire de cet insecte était restée imparfaite ; Olivier lui-même n'avait pu la compléter par ses recherches. II en ètait réduit à faire des conjectures plus ou moins vraisemblables pour expliquer comment les œufs de l'Oscine, pondus au moi de mai, peuvent se conserver et se transporter sur les jeunes plantes de froment que l'on sème seulement dans le mois d'octobre suivant.

C'est encore au docteur Herpin que nous devons d'avoir éclairci ce point important et d'aroir signalé à la science plusieurs faits nouveaux et du plus haut intérêt sur l'histoire de ce redoutable ennemi des céréales.

L'accouplement de l'Oscine sortie des jeunes plantes de seigle et de froment a lieu vers la fin de mai ou au commencement de juin.

La femelle s'occupe aussitôt à faire sa portée sur les tiges du froment qui commence alors à monter en épis ; elle dépose un ouf vers la partie inférieure de l'épi, aı fond des cannelures des feuilles. Environ quinze jours après la ponte, il sort de cet œuf une larve oblongue, jaunâtre et sans pattes, qui s'attache à la tige de la céréale, 
immédiatement au-dessous de l'épi; elle se nourrit en rongeant une partie de la surface du chamme qui est alors

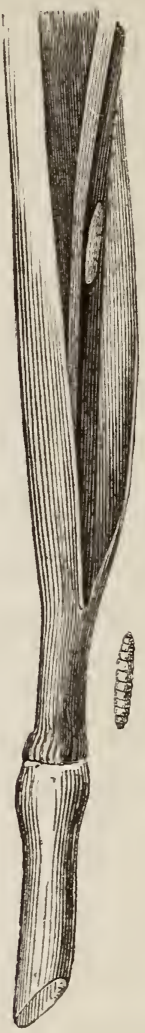

Fig. 58. - Larve du Chlorops dans son canal et Nymphe du Chlorops.

très-tendre; elle y trace et y creuse un sillon extérieur de deux millimètres environ de largeur, de un millimètre ou deux au plus de profondeur, mais qui ne pénètre jamais jusque dans le canal intérieur de la tige.

Ce sillon s'étend depuis le bas de l'épi jusqu'au premier noud supérieur, sauf quelques exceptions, lorsque, par exemple, la Jarve vient à périr ou qu'elle a pris tout son 
developpement avant d'avoir atteint le premier noud.

Arrivée à ce point, la larve a ordinairement acquis toute sa croissance ; alors elle se transforme en nymphe ou chrysalide, et se fixe le plus souvent vers la partie moyenne du sillon qu'elle a creusé à l'extérieur de la tige.

Dans le mois de septembre suivant, il en sort un diplère (mouche à deux ailes) du genre Oscine d'Olivier, ou Chlorops de MM. Meigen et Macquart, qui peut vivre pendant plusieurs semaines et ra déposer ensuite sa nouvelle ponte sur les seigles et les blés tout récemment semés.

Les tiges du froment attaquées par ces larres provenant de la deuxième ponte des Chlorops présentent des altérations tellement singulières et remarquables, qu’il est surprenant que l'on n'en ait pas jusqu'à présent reconnu la cause; ces altérations sont généralement attribuées à un vice de la végétation, occasionné par certaines intempéries des saisons.

Les tiges ainsi attaquées n'ont guère que la moitié de la hauteur des tiges de blé qui sont saines; leur maturation est retardée considérablement; elles sont encore trèsvertes lorsque les autres sont devenues james par l'effet de la maturité; l'épi n'est pas encore sorti d'entre les feuilles qui l'engraissent; il est court, peu volumineux, pell abondant en grains; ceux-ci d'ailleurs sont maigres, retraits et racornis; enfin tous les épillets situés du côté nù se trouve le sillon longitudinal creusé par la larve sont entièrement avortés et ne contiennent ancun grain.

En juillet 1840 M. Herpin a adressé à la Société royale et centrale d'agriculture, à l'administration du Muséum, ainsi quu’à plusieurs naturalistes, de enombreux échamtil- 
lons de froment attaqué par le Chlorops, ainsi que ces insectes vivants à l'état de nymphe et à l'état parfait.

Ce savant a évalué alors à un soixante-dixième de la récolte du froment le nombre des épis attaqués par le Chlorops dans les champs. Si l'on ajoute à ces ravages de la deuxième ponte le nombre considérable des jeunes plantes qui ont péri par suite des attaques du Chlorops avant ou après l'hiver, on sera convaincu que cet insecte est un fléau très-redoutable pour l'agriculture.

\section{MOYENS DE DESTRUCTION}

Dans les années où le Chlorops existe en grande quantité, le moyen de le détruire consiste à faire arracher, enlever et brûler les plantes qui en sont attaquées, tant à la première ponte qu'à la deuxième.

La première opération peut se faire lors du sarclage ou de l'échardonnage du blé; les jeunes plantes, gonflées et jaunies, sont assez facilement reconnaissables.

La seconde opération doit se faire quinze jours ou trois semaines avant l'époque de la moisson; elle est d'autant plus facile à exécuter, que les tiges attaquées par les Chlorops sont très-faciles à distinguer, même de loin, à cause de la plus petite taille, du volume plus considérable et de la couleur verte foncée de la tête, enfin parce que l'épi reste toujours engainé et enveloppé par de larges feuilles.

D'une autre part, ces plantes ainsi altérées se trouvent presque toujours situées aux bas-còtés des planches ou des sillons, de sorte qu'en passant entre deux planches on peut 
facilement les atteindre avec la main d'un côté et de l'autre, sans causer aucun dommage au blé.

Un autre moyen des plus certains, des plus économiques et des plus avantageux, dont on puisse en général faire usage pour la destruction des insectes nuisibles à nos récoltes, c'est de varier et d'alterner les cultures.

C'est de faire succéder à une céréale des plantes sarclées ou fourragères et vice versa, il en résulte que les larves nuisibles déposées dans les champs, ne trouvant pas, au moment de l'éclosion, la nourriture qui convient à leur organisation, ne peuvent subsister et përissent infailliblement.

Il est reconnu en agriculture que quand on cultive plusieurs fois de suite ou pendant longtemps la même plante dans le mème terrain, elle finit par n'y plus prospérer et même par n’y plus venir du tout, tandis cependant que d'autres végétaux y croissent admirablement. On dit alor's que la terre est fatiguée, épuisée, ce qui est complétement démenti par la brillante végétation de toutes les plantes qui y croissent spontanément. Ne serait-ce pas autant à la présence et à la propagation excessive de certains insectes nuisibles qu'à la fatigue et à l'épuisement de la terre qu'il faut attribuer ce fait, qui a forcé tous les bons cultivateurs de tous les pays à varier leurs cultures et alterner leurs assolements.

Ainsi, les rotations et les changements de culture, quand bien même ils ne seraient pas motivés par' d'autres raisons puissantes, devraient encore être adoptés et mis en pratique pour empêcher et prévenir la trop grande multiplication le certaines espèces d'insectes nuisibles. 
(Alysia Oliverii.)

Les dommages causés par le Chlorops lineata sont souvent diminués par un Ichneumon étudié par Olivier et recueilli par M. Herpin. Nous reproduisons ici la figure

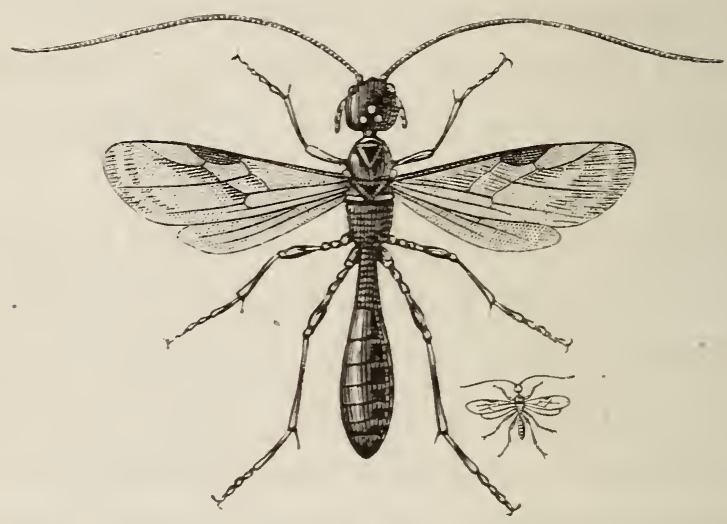

Fig. 39. - Alyse dolivier, grossie et grandeur naturelle.

donnée par Guérin-Méneville qui, contrairement à Olivier, a montré que l'Alỵsia n'est pas entièrement noire. Les pattes antérieures de cet insecte sont faures; les pattes intermédiaires et les postérieures noires arec une faible portion de la base des cuisses et des jambes seulement d'un jaune farve. M. Guérin-Ylénerille a donné une excellente description de cet insecte, dans laquelle il dit qu'un grand nombre d'individus de cette espèce étaient parfaitement identiques pour la forme, pour le stigma et les nervures des ailes, et n'offraient qu'une Jègère différence dans 
la coloration des jambes intermédiaires et postéricures qui varient du noir au brun un peu fauve.

La larve du parasite croit et grandit avec son sujet, elle se nourrit de la substance graisseuse de celui-ci; mais, chose admirable! jamais le parasite n'attaque aucun des organes essentiels à la vie du Chlorops, car, si celui-ci venait à périr, le parasite mourrait infailliblement arec lui.

Après que le Chlorops malade s'est mitamorphosé en chrysalide, le parasite finit par le détruire entièrement, et l'on voit avec surprise sortir de la chrysalide d'un Chlorops, non point la mouche destructive du froment, mais bien un ichneumonide, qui, à son tour, va persécuter la progéniture des Chlorops destructeurs du blé.

Les deux pontes du Chlorops sont également atteintes par l'Ichneumon parasite, qui éclôt ordinairement plusieurs jours avant le Chlorops; quelquefois le nombre des parasites est presque aussi considérable que celui des Chlorops.

\section{CHLOROPS DE L'ORGE}

(Chlorops Herpinii.)

L'insecte qu'on décrit sous le nom de Chlorops de l'orge pourrait être comparé à l'espèce à laquelle Neigen a domné le nom de Chlorops glabra, et à celle que Geoffroy a décrite sous celui de Mouche jaune à bandes noires (t. II, p. 508). Néanmoins elle en diffère tellement, qu'elle constitue réellement une espèce à part. Aussi M. Guérin-Méneville la croit tout a fait nouvelle. Nous l'aurions nommée, 
dit-il, Chlorops de l'orge, si nous avions été certain qu'elle est exclusivement propre à cette espèce de graminée, et si l'orge ne nourrissait pas d'autres Chlorops dans ses tiges ou dans quelques autres parties de la plante. Mais comme Olivier a obtenu des tiges de l'orge un Chlorops noir, qu'il a appelé Tephritis hordei, pour éviter toute confusion et aussi pour faire un acte de justice, il a donné au Chlorops de l'orge, le nom de Chlorops d'Herpin, en l'honneur de l'habile agriculteur qui l'a découvert.

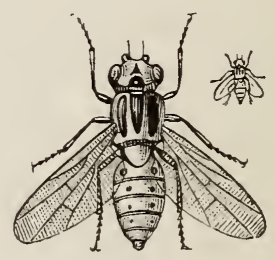

Fig. 60. - Chlorops de l'orge, grossi et grandeur naturelle.

II. Herpin a découvert cette muscide dont les larves attaquent seulement les épis de l'orge. M. Guérin-Méneville et I. Goureau ont décrit cette sorte de mouche qui a 5 millimètres de longueur. Elle est jaunâtre; la tête est jaune et marquée de deux taches noires triangulaires, placées l'une devant l'autre; les antennes sont noires ou jaunes avec le bord supérieur ainsi que la soie noire; le corselet est ovalaire avec trois larges raies noires sur le dos; l'écusson est jaune et le sous-écusson est noir'; les flancs et la poitrine présentent quatre taches noires; l'abdomen est ovoïde, terminé en pointe, de la longueur de la tête et du thorax, de la largeur de celui-ci, jaune; le premier segment porte une tache brune de chaque cité, quelquefois réunies par une bande obscure ; les pre- 
mier, deuxième et troisième segments ont lemr hord poslérieur brun, plus ou moins olsscur, avec une faible tache de chaque côté, entre les bandes; l'anus est noil' ; les pattes sont jaunes et les tarses noirâtres; ailes liyalines.

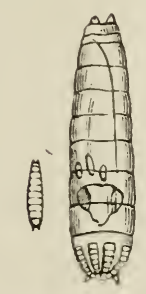

Fig. 61. - Nymphe grossie.

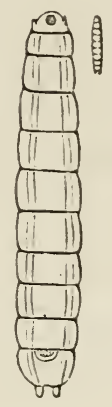

Fig. 62. - Larve grossie.

La larve est longue de quatre millimètres et demi. Blanche, allongée, presque cylindrique, atténuée du côté de la tête qui renferme un crochet buccal noir ; les stigmates antérieurs sont saillants, terminés par une couronne de petits tubercules; le dernier segment porte en dessous un tubercule mamelonné, et en arrière deux petits tubes qui forment les stigmates postérieurs.

La pupe est brune, un peu moins longue que la larve, arrondie, un peu plus étroite à l'extrémité postérieure qu'à l'antérieure qui est ridée, avec deux petites pointes à cette extrémité, et deux autres presque inperceptibles au bout antérieur.

Ce Chlorops est atteint par les mèmes parasites que les précédents, c'est-i-dire par l'Alysia Olivieri et le Pteromalus micans. 


\section{CHLOROPS DE GOUREAT}

(Chlorops vittata.)

Les mouches appelées Chlorops sont très-nombreuses dans les abris où elles se cachent pour passer l'hiver. On peut les compter par milliers, soit au plafond d'appartements inhabités, dans les campagnes, soit dans les lierres des vieilles maisons. Ce n'est que le 18 juin 1856 que II. Guérin-Véneville a trouvé dans un épis de blé déformé, dans la case d'un épillet, vide de grain, un pupe de diptère qui lui a donné un Chlorops le 17 juillet suivant.

Ce Chlorops a une longueur de 4 millimètres. Jaune, antennes jaunes, à troisième article au-rlessus et en dehor's; yeux verts ; tête jaune, à points noirs sur le vertex; thorax jaune, marqué de trois larges raies noires sur le dos, celle du milieu s'étendant sur l'écusson; sous-écusson noir ; abdomen jaune ayant les premier, deuxième, troisième et quatrième segments marqués de trois taches noirâtres; dessous jatine, avec un point noir de chaque côtẻ du prothorax, un autre sur les côtés du mésothorax, un troisième à la base des hanches postérieures; ailes hyalines, de la longueur de l'abdomen, pattes jaunes avec les crochets res tarses noirs.

On ne connait pas de moyen préservatif contre ces petites mouches ni contre leurs larves dont la présence ne se décèle que quand le mal qu'elles ont produit est irremédiahle. 


\section{CHLOROPS DU NAIN OI DI SEIGLE}

En 1859, M. Andouin appela l'attention de la Société entomologique sur une larve de diptère très-nuisible anx récoltes. Flle se tient à la base de la tige des seigles, près du collet, et c'est là qu'elle subit ses métamorphoses. Des agriculteurs de Grignon remarquèrent arec étonmement an mois de mars que les tiges du seigle qn'ils araient semé pendant l'automne de l'année précédente devenaient monstrueuses à leur base, et que ce déreloppement exces. sif avait arrêté la croissance des parties supérieures.

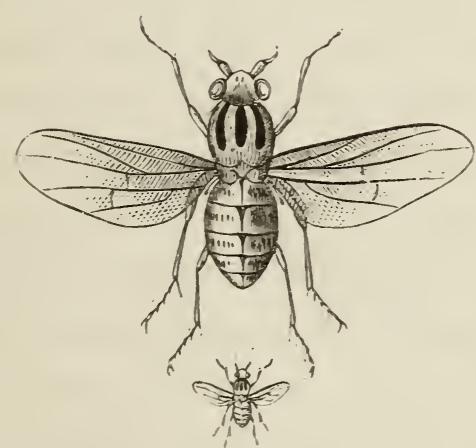

Fig. 6.5. - Chlorops du seigle, grossi et grandeur naturelle.

Audouin ayant été averti par II. Boyer, professeur d'agriculture à la ferme modèle de Grignon, reconnut bientôt la larve dont on a parlé, laquelle se transforme en un petit diptère désigné sous le nom de Musca pumilionis, et dont il présenta des indivirlıs à la Société, ainsi que la pupe ol sa larve et la plante dont cette dernière se nomrit. 
Cette petite mouche, dit M. Goureau, a été observée pour la première fois par Birkander, entomologiste suédois, qui en parle ainsi :

Au mois de mai de chaque amnée, j’aperçus parmi les seigles des chanvres nains d'un à trois pouces de longueur ; en les examinant, on reconnaissait qu'à leur première articulation il y avait intérieurement un petit ver, cause de cette-singulière croissance. Ce ver est blanc, d'ume longueur de deux lignes; il a dix anneaux; la tête pointue, noire à son extrémité, et ayant la forme d'un V. 11 commence vers le 25 mai à se changer en chrysalide. La pupe est jaune et brillante et a un peu plus d'une ligne de longueur; elle est plate et annelée. Ces pupes commencent à produire des mouches vers le 12 juin.

L'insecte parfait a un peu plus d'une ligne de longueur; sa tête est jaune et ses yeux noirs; il porte à la nuque un triangle noir; les antennes, noires, sont un peu noueuses, et il en sort quelques poils; le corselet est noir sur le dos et marqué de deux petites lignes jaunes dans le sens de la longueur ; au bas, près de l'ablomen, est une tache jaune en forme de croissant; le corselet est jaune en dessous; les pieds de devant portent deux taches noires; l'abdomen est noir en dessus, jaune en dessous et composé de quatre anneaux; les balanciers sont blancs; les ailes brillent de rouge et de rert et dépassent peu le corps; la partie des pieds voisine du corps est grisâtre et l'extrémité noire.

On pourrait, selon M. Goureau, appeler cette mouche, Musca pumilionis (la mouche du nain). On ignore encore si ces œufs sont déposés dans la tige du seigle. Le 23 avril, 
les vers étaient encore petits, ot ils avaient acquis tout leur développement le 25 mai.

Birkander donne le conseil d'arracher les pieds de seigle attaqués et de les brûler; c'est aussi ce qu'Audouin arait recommandé aux agı iculteurs de Grignon ; par ce moyeur, on diminue le nombre des nouches de la génération prochaine, et l'on peut diminuer un ṕeu les dégâts à venir.

\section{L'AGROIIYZE PIED-NOIR}

\section{(Agromyza nigripes.)}

Un insecte diptère de la famille des musciens, appartenant ausssi au groupe des oscinites, a reçu le nom générique d'Ágromyze.

Au mois d'aoùt, lorsqu'on parcourt un champ de luzerne, il arrive, dans certaines années, qu'on remarque un grand nombre de feuilles tachées de blanc; la tache ëst irrégulière et occupe la moitié plus ou moins de la feuille; si l'on examine avec attention, dit M. Goureau, on apercoit une petite raie blanche qui aboutit à la tache, et en présentant la feuille au jour on distingue une petite larve, logée entre les deux membranes très-minces qui la fórment, occupée à manger la substance renfermée entre elles et a agrandir la tache blanche. C'est cette petite larve qui a fait la raie blanche, en partant de son extrémité dès le moment de son éclosion, pour' s'avancer jusqu'au point où commence la tache, et en rongeant ensuite autour d'elle pour se construire un vaste logement. Selon le 
moment, on pourra remarquer un grand nombre de feuilles minées; renfermant une larve dans chaque tache, ou n'en renfermant, que dans quelques-unes. Ces larves croissent rapidement car elles mangent presque sans interruption et mettent peu de jours à prendre toute leur taille. Étant arrivées à ce point, elles sortent de leur habitation en perçant l'une des deux membranes et se laissent tomber à terre dans laquelle elles s'enfoncent un peu; elles se changent bientôt en pupes et les mouches s'envolent environ trois semaines après.

La petite larve mineuse, parvenue à toute sa croissance, a deux millimètres et demi de longueur, elle est blanche, molle, glabre, apode, terminée en pointe du côté de la tète qui renferme une double soie noire écailleuse, courbée en crochet à son extrémité. L'animal fait sortir à sa volonté le crochet de sa bouche et l'y fait rentrer, et s'en sert comme d'une pioche pour détacher sa nourriture et la porter dans sa bouche. La pupe a presque deux millimètres de longueur. Elle est d'un brun jaunâtre, cylindriIue, un peu arquée, arec des segments peu distincts sur le corps, et deux petites pointes à chaque bout.

L ${ }^{3}$ insecte parfait est noir luisant; la tète, le thorax et l'abdomen, sont entièrement noirs; les antennes noirs; les yeux d'un brun rougeâtre. Il a quelques poils sur le sommet de la tète, le dos et le thor'ax, L'abdomen est ovoïde, de la longueur du crochet; les pattes sont noires, les ailes hyalines, à nervures noires, dépassent beaucoup l'abdomell.

La femelle est pourvue d'une petite queue cornée avec laquelle elle perce la membrane supérieure de la feuille 
de luzerne et elle pond un auf dans la plaie, juis elle passe à une autre feuille où elle fait la même opération, continuant ainsi jusqu'à ce qu'elle ait achevé sa ponte. lie sont ces œufs qui domnent naissance aux petites larves noueuses, et comme il ne faut qu'un mois environ pour l'évolution de l'insecte, il en résulte qu'il y a probablement plusieurs générations pendant l'été. Lorsqu’il est trèsnombreux, il gâte les luzernes qui ne domnent qu'un fourrage peu nourrissant.

On ne comnait pas de moyen efficace pour s'opposer aux ravages de cette petite mouche. On peut couper la luzerne dès que les taches commencent à se montrer et la faire manger avant qu'elle soit détériorée.

\section{PARASITE DE L'AGROMY'ZE}

La larve de cette mouche est atteinte dans son gite par un petit Ichneumon qui sait la découvrir dans la feuille de luzerne, qu'elle mine et qui pond un œuf dans son corps. II sort de cet œuf une larve qui ronge les entrailles de la larve de la mouche et qui ensuite se transforme en un petit ichneumonien de la sous-tribu des Braconites et du genre Alysia, lequel a paru à M. Goureau se rapporter à l'Alysia tristis, gemre Dacnusa.

Il est long de 2 millimètres; noir luisant; antenties noires, filiformes, un peu plus longues que le corps : la tête et le thorax sont noirs, de mème largeur; l'abdomen est noir, de la longueur et de la largeur du thorax, aminci en pédicule à la base, arrondi à l'extrémité; les pattes sont noirâtres; les ailes hyalines à nervures et stigma noir's; elles sont couchées suir le dos et dépassent l'abdomen. 


\section{MOUCHE DES BETTERAVES}

(Pégomyie de jusquiame. - Pégomyia hyoscyami, lacq,)

La mouche de la betterare, connue en entomologie sous le nom de Pégomye de la jusquiame, parce qu'elle a été observée pour la première fois sur cette plante, a été depuis quelque temps trouvée sur la betterave et l'arroche.

On reconnait aisément la présence du ver dans les feuilles àux plaques blanchàtres qui couvrent leur surface. En y regardaint de près, on voit bien vite que le parenchỵme a 'disparu et que les deux membranes seulement sont demeurées intactes. L'œil le moins exercé pent distinguer ensuite sur la ligne de démarcation, entre la partie attaquée et la portion saine, des larves de 7 millimètres de lon'gueur au plus blanches, molles, au nombre de douze ou quinze; elles mangent avec une gloutonnerie qui dépasse la mesure de leur taille et font brèche dans la substance veite du parenchỵme. Ces larves commencent à paraître dans le commencement de juin et continuent à se montrer pendant tout l'èté Flles croissent rapidement et lés plus précoces ont atteint le terme de leur taille ver's' le 15 du mème mois. Elles sortent alors des feuilles dans les'quelles elles ont vécu et vont se cacher dans la terrè à peu de distance de la racine de la plante où elles se transforment en pupes ou nymphes au bout de peu de temps.

La Nouche de la betterave à l'ètat parfait a cinq milli'mètres de longueur. Sa couleur est d'un gris cendré clair ; la face et les côtés du front sont blancs; la bande frontale 
est d'un faure brun; les palpes sont fauves à extrémité noire; les deux premiers articles des antennes sont fauves ef le troisieme noir. L'abrlomen est d'un gris rougeâtre, arec une ligne dorsale de taches noires peu marquées; les pattes sont rougeàtres et les tarses noirs; les ailes hyalines dépassent l'abdomen. Cette espèce ne diffère sans doute pas de la suirante.

\section{HYLEMYIE DES BETTERAVES}

(Hylemyia coarctata.)

Les Ifylémyyies se distinguent de toutes les autres mouches parce que: $1^{\circ}$ leurs antennes descendent presque jusqu'a l'épistome, c'est-à-dire à la partie supérieure de l'ouverture buccale, et $2^{\circ}$ leur style inséré à la base du demier article est ordinairement plumeux, c'est-à-dire garni de poils serrés; $z^{0}$ leurs ailerons sont très-petits ; $4^{0}$ leur abdomen assezlong presque cylindrique surtout chez les mâles. Nous devons à M. Émile Blanchard un mémoire fort intéressant sur cet insecte et qui a été inseré dans les Mémoires de la Société d'Agriculture, année 1850 , 2e partie, page 489. Nous en extrayons la description suivante.

L'Hylémyie des betterares est longue de 6 à 7 millimètres; plus petite et plus grêle que notre mouche domestique. T'out son corps revêtu d'un duret très-court et très-serré, est d'un gris cendré. La tête est assez large grisâtre, arec la face d'un ton plus roux. Les antennes sont noires surtout 
le dernier article et le style. Les yeux sont d'un brum rougeàtre. Le thorax est d'un brun cendré, ayant souvent quelques marques plus noires sur les côtés; il présente aussi un certain nombre de poils roides également noirs. Les ailes toujours irisées, ont une nuance jaunâtre bien marquée. L'écusson est de la même couleur que le thorax. L'abdomen est également d'un gris cendré, mais chez le mâle, il devient noiràtre sur les côtés et à l'extrémité : chez la femelle, il conserve, au contraire, une nuance plus grise dans toute son étendue. Les pattes sont d'un jaune faure, arec les tarses noirs et la plus grande partic des cuisses de cette couleur; la base et l'extrémité de celle-ci restent seules de la nuance jaune générale.

La larve de l'Ilỵlém y̧ie est longue d'environ 8 millimètres et peut être 8 à 10 quand elle s'allonge pour marcher; son épaisseur n'est guère de plus de 2 millimètres. Les ammeaux de son corps sont très-apparents et les deux petits ('rochets dont sa bouche est armée se distinguent aisément par leur couleur noire. Tout l'animal est d'un blanc jaunàtre sale, arec une loque irrégulière médiane, plus obscure, produit par le canal digestif qu'on aperçoit un peu au travers du tégument.

Lorsque celte larve a pris tout son accroissement, elle se ramasse un peu sur elle-mène; comme chez toutes les larves desmouches, ses téguments se durcissent, prement une couleur d'un brun inarron et constituent la coque de la nymphe. Dans l'Hylémyie, cette nymphe est oblongue arec les ammulatures très-apparentes et les deux extrémités terminées par deux petites pointes ubtuses.

L'Iylémyie de la betterave se montre à l'état de larve 
depuis la fin de mai jusqu'an commencement de juillet, et à cette dernière époque elle se transforme en nymphe ou chrysalide et quinze ou vingt jours plıs tard apparaît l'insecte adulte. C'est au moins pendant cette période que le savant naturaliste l'a observée. A cette ípoque il ne pouvait dire si cette mouche ne fomrnit qu'mme génération par an. Il ne savait pas non plus sous quelle forme l'animal passait l'hiver. Espérons que le patient olsservateur comblera bientôt ces lacunes.

Toujours est-il que pendant le mois de juin on rencontre l'Hylémyie de la betterave à l'ètat de larve. Le genre de vie de cet insecte est alors fort singulier. Le petit ver est contenu dans l'épaisseur des feuilles; il laisse des deux côtés l'épiderme intact et ronge ainsi le parenchyme sans jamais se montrer au dehors. Cependant, si l'on vient à examiner les betteraves, la présence des petits vers se récèle facilement; les feuilles présentent des boursouflures longitudinales produites par les larves de l'Ilylémyie. Les vers sont quelquefois très-rapprochés les uns des autres et dans une feuille on peut en compter huit, dix, douze, peut-être davantage. Il est à peine nécessaire de dire que le nombre est tout à fait variable. Si dans certaines feuilles on rencontre jusqu’à dix ou douze larves, dans d'autres, on n'en trouve qu'nne seule; à cet égard, il y a des différences coïncidant avec l'abondance de l'insecte, suivant les localités, suivant les années.

Ce diptère n'est nuisible que pendant son premier état; les feuilles attaquées se desséchent au moment où les ver's ront se transformer en chrysalides, c'est-i-dire pendant la fin de juin et le commencement rle juillet. Si les IIỵlémỵics 
sont abondantes, naturellement beaucoup de feuilles se flétrissent, et il en résulte pour les betterares, dont le développement est loin d'être acheré, un dommage qui pent ètre considérable, mais dont il m'est impossible de préciser l'étendue.

Quand les larves de l'Hylémyie ont pris tout leur accroissement, quand elles ront subir leur métamorphoses, les feuilles se sont déjà fanées, jaunies ou même desséchées. Les petits vers se transforment dans la loge pratiquée dans l'épaisseur de la feuille, à l'endroit mème où ils ont vécu et pris leur nourriture. Lorsque l'insecte parfait sort de son enveloppe de nymphe, il déchire l'épiderme encore intact de la feuille et s'envole.

II. Blanchard suppose que les femelles passent l'hiver et se réfugient dans des endroits abrités pour déposer leurs œufs seulemıent au printemps.

\section{MOYENS DE DESTRUCTION}

Atteindre les insectes adultes, est chose impossible. Atteindre les larves ou les nymphes parait très-praticable.

Les feuilles attaquées se flétrissent comme on sait avant l'éclosion des mouches. En arrachant alors toutes ces feuilles flétries, on est certain d'emporter en même temps les Hylémyies qui les ont rongées. En les détruisant aussitôt par le feu, l'année suivante les champs de betteraves devront être épargnés, si partout la récolte des feuilles atteintes a èté faite arec soin. 


\section{ORTHOPTERES}

\section{CRIQUETS OU SAUTERELLES VOYAGEUSES}

(Acridium ou Locusta.)

Dans les pays bien cultivés, les Criquets que l'on confond avec les Sauterelles ne causent pas de grands dommages aux récoltes, mais dans l'Europe méridionale, en Orient et en Afrique, ils se montrent en légions innombrables et viennent s'abattre sur les moissons, les dévorent, ravagent les prés, les pâturages, détruisent les plantes potagères, les arbres fruitiers et amènent ainsi la disette dans les pays où elles se trouvent apportées en si grand nombre. Après leur mort, leur cadavres tombant en putréfaction, empoisonnent l'atmosphère, et donnent naissance à des maladies contagieuses qui déciment les hommes et les bestiaux. Orose rapporte qu'en l'an dı monde $\mathbf{3 8 0 0}$, il yeut une si grande quantité de sauterelles d'Afrique, qu'elles mangè- 
rent toutes les herbes, puis elles se noyèrent dans la mer d'où elles répandirent une odeur si infecte qu'en peu de temps trois cents mille hommes moururent.

Les sauterelles d'Égypte, dont il est mention dans l'Exode, surpassaient toutes les autres espèces en grandeur. Pline, en parlant des sauterelles des Indes, qui sont aussi grosses, dit quion se sert de leurs pattes desséchées au lieu de scies. Il y a certainement de l'exagération dans ce fait. Toujours est-il que les païens ont fait des rœux et des sacrifices à leurs dieux pour être délivrés des sauterelles.

En 1690, les sauterelles se répandirent en telle quantité dans la Pologne et dans la Lithuanie que l'air en était tout obscurci et la terre toute courerte comme d'un drap noir. Il s'en troura, en certains endroits où elles étaient mortes, les unes sur les autres et leurs cadarres amoncelés jusqu'à quatre pieds d'épaisseur' celles qui étaient virantes se perchaient sur les arbres, faisaient plier les branches jusqu'ì terre tant elles étaient nombreuses. Le peuple crut qu’il y arait des espèces de lettres hébraïques sur leurs ailes; un rabin prétendit y lire les mots qui signifient en français : colère de Dieu. Ce fut, suirant l'abbé rle G. Ussans, auteur de ce rapport, un présage funeste, car les pluies faisant mourir ces insectes, ils infectèrent l'air et les bœufs et autres bestiaux qui en manģeaient mouraient aussitôt.

Mézerai, après avoir exposé les tristes effets d'une tempête extraordinaire qui, sous Louis XIII, s'était fait sentir au mois de janvier 1615 , dit que le dommage ne fut rien en comparaison de celui causé par les Sauterelles dans la campagne d'Arles, en Provence, vers le mois de mai; il s'engendra une si grande quantité de ces insectes dạns ce pays 
(qu'en moins de sept ou huit heures elles rongèrent jusqu'i la racine des herbes ou des grains dans l'espace de plus de 15,000 arpents de terre; elles pénétrèrent jusque dans les greniers et dans les granges et dérorèrent tous les grains qui s'y trouraient. Quand les Sauterelles s'attroupaient et s'enlevaient en l'air, ces armées formidables, portées par les vents, formaient une espèce de nuage qui dérobait l'éclat du soleil. Dès qu'elles eurent ravagé tout le territoire voisin d'Arles, elles passèrent le Rhòne et vinrent à Tarascon, à Beaucaire, et ne trouvant plus de blé sur pied, elles ravagèreut les herbes potagères ef les luzernes qu'on avait semées.

De là elles allèrent à Bourbon, à Valabergues, à Vonfrin, à Aramon, où elles firent le même dégàt ; enfin elles furent mangées par les étourneaux; celles qui échappèrent formèrent en terre et principalement dans les lieux sablonneux une espèce de tuyau semblable à un étui rempli d'unc si grrande quantité d'œuls que tout le pays en aurait été désolé si on les eut laissé éclore; mais par les bons ordres que domnèrent les consuls des villes d'Arles, de Beancaire et de Tarascon, on en fut délivré en peu de temps. On en ramassa plus de trois mille quintaux qui furent enterris ou jetés dans le Rhône; on les cherchait le fer ef le fen it la main.

On supputa ensuite le nombre de brigands que ces $\alpha u f s$ auraient produits, ct en en comptant seulement vingt-cing par tuyau, on troura qu'il y en avait un million sept cent cinquante mille au quintal. Ce qui pourait domner au total cing cent cinquante mille millions de Santerelles qui anraient éclos l'année suivante. 
Un historien de Charles XII, roi de Suède, rapporte que ce prince, voyageant en Bessarabie, fut très-tourmentè par les Sauterelles.

" Ces insectes venaient, dit l'historien, fondre sur nous " comme un orage, se jetaient sur la même plaine où nous " étions, et sans crainte d'être foulés aux pieds des che" vaux, ils s'élevaient de terre et couvraient le corps et le " visage à ne pas voir devant nous jusqu'à ce que nous eus" sions passé l'endroit où elles s'arrêtaient. Partout où ces "Sauterelles se reposaient, elles y faisaient un dégât affreux " en broutant l'herbe jusqu'à la racine; en sorte qu'au lieu " de cette belle verdure dont la campagne était auparavant " couverte, on n'y voyait qu'une terre aride et sablon" neuse.")

La Hongrie, la Bohême et l'Allemagne, déjà infestées et ravagées en 1542 , le furent de nouveau en 1747 et 1748 . En 1755, on a vu tomber en quelques endroits du Portugal des nuées de Sauterelles qui ont ravagé les campagnes. I. le comte C. de Gourcy, dans un de ses voyages agronomiques, a vu en 1852, dans une partie de la Hongrie, les champs dévastés, les populations réduites à la plus cruelle disette par les ravages des Sauterelles; puis les innombrables cadavres de ces insectes, tombant en putréfaction, empoisomnaient l'atmosphère de leurs exhalaisons infectes; des maladies contagieuses en étaient la suite inévitable; elles décimaient en même temps les hommes et les bestiaux.

Cet historique sur les Sauterelles prouve surabondamment la nécessité de se garantir contre ces insectes qu'il est important d'étudier. En 1823, 1824 et 1825, le midi de 
la France eut aussi à souffrir de leurs ravages et l'administration paya 50 centimes le kilogramme d'œufs de ces insectes et 25 centimes le même poids d'insectes parfaits. Varseille paya ainsi 20,000 francs et Arles 25,000.

Le nom de Sauterelle signifie évidemment sauter, de saltare, en italien Saltarella. La Sauterelle se nomme aussi en Italie Cavalletta (petite cavale). En latin, la grande Sauterelle est appelée Locusta, d'où le nom de Loguste qu'on lui donne également. En certaines provinces, la petite Sauterelle est connue sous le nom de Sauterau, par corruption Sauteriau. Ailleurs on l'appelle Aoutrou, Aoutrelle, parce - qu'elle paraît au mois d'août.

Les entomologistes rangent les Sauterelles parmi les insectes orthoptères, c'est-à-dire à ailes droites. Les caractères distinctifs sont un corps allongé, une tête grande et verticale, deux yeux petits, saillants et arrondis, peu apparents, un corselet comprimé sur les côtés et sans écusson ; des élytres inclinées recouvrant des ailes, des pattes dont les antérieures paraissent prendre naissance sur la tête et dont les postérieures sont très-grandes. Ajoutons à cette description quelques signes distinctifs donnés par les anciens auteurs. La tête de la sauterelle, dit Valmont de Bomare, a quelque ressemblance avec celle d'un cheval; la bouche est recouverte d'une espèce de bouclier écailleux, rond, saillant et mobile. Il y a près des mâchoires une moustache verdâtre composée de deux antennules à la mâchoire supérieure qui se plient par le moyen de trois articulations; celle de la mâchoire inférieure n'a que deux antennules et deux articulations. L'extrémité de ces antennules est formée d'espèces de houppes à nervures qui 
servent à goùter d'avance ce qui convient à l'animal.

Le corselet est élevé, étroit, armé en dessus et en rlessous de deux épines dentelées.

Le dos est recouvert d'un bouclier oblong auquel sont fortement attachés les muscles des pattes de devant.

Le tube digestif est très-remarquable; il possède trois estomacs qui forment trois rentricules, dont le second est sillonné et dentelé.

Le ventre est très-développé, formé de huit anneaux el terminé par deux petites queues.

La femelle se distingue du mâle par une queue tranchante, placée à l'extrémité de l'abdomen, composée de deux lames accolées l'une à l'autre et vulgairement appelées sabre.

Quant aux ailes, la première paire assez semblable à des élytres est d'une consistance presque cornée.

La seconde paire, dans l'état de repos, est repliée le long du corps de l'animal et disposée comme les plis d'un éventail ferrné. Quand l'insecte les déploie, ces ailes offrent un bord parfaitement droit. Malgré cette double paire d'ailes les Sauterelles ne volent pas toujours facilement. Les ailes leur servent surtout de parachutes. Dans les pays où naissent les grandes Sauterelles voyageuses, il règne, à l'époque où ces insectes parviennent à toute leur croissance, des rents violents qui les emportent par millions, sans qu'il soit possible aux Sauterelles de se diriger à leur gré; elles ne le pourraient mêrne pas dans une atmosphère tranquille; leurs ailes ne font absolument que les soutenir en l'air pour aller où les vents veulent les porter. Dans ces longues et rapides migrations les Sauterelles perdraient 
hien vite haleine el périraient sulfoquées si elles n’étaient pourvoes d'un appareil de respiration supplémentaire. Sont-elles a l'état de repos ou seulenent dans leur étal d'activité ordinaire, cet appareil de réserv ne fonctionme pass.

\section{METTAMORPIIOSES DES SAUTERELLES}

Peu de temps après que les Sauterelles ont les ailes assez développées elles s'accouplent; et vers la fin de l'antomme la femelle cherehe dans la plaine a se délivrer de ses ceufs: elle les dépose dans les féntes du sol, à l'aide de son oriseapte. Les ouf's glissent entre les deux lames dont il est formé et s'enfoncent en terre; après quoi la pondeuse se dessèche et péril; les màles, à ce qu'il parail, ne survivent guere aux femelles. Ces oeuf's demeurent cachés en terre jusqu'au retour du printemps où la chaleur les fait éclore. Ils sont plus long's que gros et à peu près de la grosseur d'un grain d'anis et d'une consistance de corne, et sont blanchàtres. Quand ils ont été assez échauffés, il en nail vers la fin d'avril des larves qui ne sont pas plus grosses qu'une puce.

Jusqu’ici, on pensail que les larves qui naissent de ces oufs ne différaient de l'insecte parlait que par l'absence des ailes et des élytres.

Déjả, cependant, un médecin qui s’étail vouéa l'anatonnic des insectes, Swammerdan, avait dit "que les ailes de la Sauterelle sont couchées et étendues le long de son corps, an lieu que dans l'ètat de nymphes elles sont renfermées en quatre boutons dans lesquels elles sont plices et entor- 
tillées ensemble ; c'est ce qui a fait dire à plusieurs naturalistes que les vers dout se forment les Sauterelles étaient des Sauterelles sans ailes, et c'est ce qui leur a fait domner le nom d'attelabus, lorsque leurs ailes commençaient à pousser; et celui d'asellus, quand le corps, surtout celui de la femelle, prenait plus d'accroissement; " c'est ainsi, ajoute Valmont de Bomare, que quand on ne connaît pas bien exactement toutes les formes qu'un même insecte prend successivement, il est très-aisé de confondre et de faire deux ou plusieurs insectes d'un seul et même animal. " - " La nymphe de la Sauterelle, ajoute-t-il, au bout de vingt-quatre à vingt-cinq jours plus ou moins, songe à quitter sa robe, et pour s'y disposer elle commence par cesser de manger, puis elle ra chercher. un lieu commode, c'est-à-dire pour l'ordinaire une épine ou un chardon auquel elle s'attache. D'abord elle agite et gonfle sa tête jusqu'à ce que la peau dont elle est enveloppée, se déchire audessus du cou. La tête sort la première par cette déchir'ure avec quelque difficulté, ensuite la nymphe faisant de nouveaux efforts sort tout entière et laisse sa dépouille at:tachée à l'épine ou au chardon. " Voilà l'insecte sous unẹ nouvelle forme; il est parfait. I. Ysabeau pense qu'on nẹ doit pas dommer le nom de larves à de petites Sauterelles qui naissent de l'œuf aussi parfaites que la mère, sauf la taille et les ailes. Ces larres, dit-il, puisqu'on reut les nommer ainsi, changent trois fois de peau, devenant, à chaque peau renouvelée, un peu plus grandes que précédemment, du reste ne variant d'aspect sous aucun autre rapport. Après le quatrième changement de peau, les ailes commencent à pousser ; on dit alors que l'insecte est passé à l'ètat 
de nymphe. M. Tout le monde remarque que les nymphes des autres insectes sont bloquées dans une enveloppe ou elles ne bougent ni ne mangent en achevant de se transformer, tandis que celles de la Sauterelle mangent et vont a leurs affaires absolument comme père et nière, et ne font nullement l'effet d'être ni des larves ni des nymphes.

Dans les pays incultes, oủ rien ne gène leur nultiplication, les Sauterelles naissent ensemble, presque le même jour, à la même heure, par légions innombrables; elles subissent ensemble leurs phases de développement; elles prennent ensemble leurs ailes. Chaque ponte ètant formée d'un paquet d'œufs disposés dans une capsule que la Sauterelle femelle a déposée dans la terre, et les jeunes Sauterelles sont forcées de rester près du lieu natal tant que leurs ailes ne sont pas encore poussées. Leur nombre est fort grand. Il n'est pas rare de roir en France, dans les cantons où la petite Sauterelle est la plus commune, le sol criblé de trous où les femelles ont pondu. M. Ysabeau a souvent compté plus de ว̃ 0 de ces trous sur un espace d'un mètre carré ; c'était sur le pied de plus de 500,000 trous par hectare, soit à raison de 150 a 200 oufs par trou, en moyemne 175; environ 87,500,000 Sauterelles écloses par hectare.

Dans les steppes ou prairies désertes de l'Orient, de l'Europe, à plus forte raison, dans les parties incultes de l'A sie et de l'Afrique centrale, des centaines de millier's d'hectares sont aussi criblés de trous pleins d'œul's de Sauterelles. On renonce a calculer le chiffre d'insectes auxquels ils peuvent domer naissance.

M. Gobin prétend que les oufs sont déposés par les fé- 
melles sur les tiges des graminées et enduits comme ceux des cercopes d'une matière visqueuse qui se durcit en séchant, mais c'est là une erreur. Il ajoute que, quand on les troure dans la terre, ils sont à une profondeur de deux ou trois pouces, entassés dans un nid qui communique arec l'air extérieur au moyen d'un tube formé de terre agrglutinée.

\section{VOYAGE DES SAUTERELLES}

Ces insectes sont généralement enlerés par les rents violents d'est et de sud-est, emportés à travers l'atmosphère, où, comme nous l'arons dit, leurs ailes leur servent de parachute, sans leur permettre toujours de se diriger vers un but quelconque. Sourent des nuées de Sauterelles s'élèrent des steppes du sud-est de la Russie, entre le cours du Don et celui du Dnieper ou Borysthène. Le rent d'est les pousse rer's les parties plus ou moins cultivées et civilisées de l'Europe orientale. En suivant par terre leur itinéraire, il y aura sur tout le trajet une pluie de Sauterelles; mais tant que la nuée ne passera ni sur une forèt ni sur un pays cultivé, tant qu'elle sera emportée au-dessus d'un pays nu et désert, couvert seulement d'une maigre et rare régétation, de plantes saurages, on ne ramassera pas une seule Sauterelle qui soit descendue à terre volontairement; celles qui joncheront le sol seront les mortes ou les malades incapables de suirre le gros de la troupe et forcées par épuisement de se laisser tomber. Mais quand la nuée de Sauterelles passe au-dessus d'une for'èt, aussitòt des millier's de 
ces insectes, repliant a demi et tris-rolontantement leurs paraclutes, se laissent tomber et s'accrochent it toutes les feuilles pour les dévorer. Toutes ne sont pas cependant en état de résister à l'impétuosité dı courant aérien qui les entraine; le nuage amoindri, mais non dissipé, poursuit sa route. Partout sur leur passage, où les Sauterelles voient des bois et des champs cultivés, elle: laissent en arrière les plus fatiguées, les plus affamées, les plus pressées de prendre terre jusqu’à ce qu'enfin la masse entic̀re vienne s'abattre sur les plaines de la Ilongrie, ou les vents d'est et de sud-est, qui ont apporté les Sauterelles, sont refoulés par l'immense contre-fort des monts Carpathes ou Krapachs.

Les Sauterelles qui font ces grandes migrations sont les grandes Sauterelles connues sous le nom d'Acridie. La petite du centre de l'Europe est appelíe Locuste ou Criquet.

\section{MOYENS DE DESTRUCTION}

Si l'on en croit les anciens auteurs, il existait autrefois en Chypre une loi qui obligeait de faire chaque année la guerre aux Sauterelles : $1^{\circ}$ en cassant leur's œufs; $2^{\circ}$ en tuant leurs petits ; $5^{\circ}$ en faisant mourir ces insectes.

Aux époques de foi, on avait peu confiance dans les diver's procédés conseillés pour détruire les Sauterelles. Aldrovande, ce grand naturaliste, avoue que trop souvent les ressources de l'esprit humain n' y servent de rien et que l'unique moyen d'exterminer ces insectes est de recourir à Dieu par des prières publiques.

Ln moyen de détruire les Sauterelles, e'est de les man- 
ger. Tout le monde sait que saint Jean-Baptiste a mangé des Sauterelles dans le désert. Les peuples de l'Orient s'en régalèrent pendant longtemps et s'en régalent quelquefois encore. Les acridophages, pour prendre les Sauterelles, faisaient dans des endroits profonds des feux qui produisaient beaucoup de fumée, et aux époques de leur passage ces insectes étaient asphyxiẻs par cette fumée et tombaient sur le sol. C'était autrefois la coutume à Athènes de porter régulièrement des Sauterelles au marché. Aristophane dit qu'on les vendait comme l'on vend les oiseaux chez nous.

Les Sauterelles doivent aussi avoir été une nourriture dans la Judèe, puisque Mö̈se avait permis aux Juifs d'en manger de quatre sortes qui sont spécifiées dans le Lévilique.

La méthode de destruction employée près de Szohlnock, en Hongrie, a èté rapportée par M. de Gourcy. On sait que les plaines immenses comprises entre le cours du Danube et celui de la Huiss, qui coule parallèlement au grand fleuve longtemps avaut de se réunir à lui, sont en grande partic livrées à la culture de la pomme de terre. Les cultivateurs font sécher ef conserver en meules dans les champs les tiges ou fanes de la plante à l'époque de la récolte. S’il se présente des nuées de Sauterelles l'èté suivant et qu'elles ne passent pas à une trop grande hauteur au-dessus du sol, on allume de distance en distance des feux de branchages et de tourbes qu'on alimente avec les fanes de la pomme de terre; le principe narcotique contenu dans ces fanes, analogue au principe enivrant du tabac, asphyxie les Sauterelles et les fait tomber par millions sur le sol. On se hâte alor's de donner un labour pro- 
fond en sacrifiant la récolte. et de deux maux on en évite au moins un, celui de l'épidémie pour les gens et de l'èpizootie pour le bétail. Cette opération rend, en outre, un signalé service aux cantons du voisinage que les Sauterelles auraient ravagés; mais ce moyen, on le conçoil, n'est pas applicable partout et les circonstances ne lui permettent pas toujours de réussir.

Les Criquets ne causent pas chez nous des ravages aussi redoutables que ceux produits par les grandes espèces de l'Orient. Il est vrai qu'elle pond autant d'œufs et consomme individuellement à peu près autant de matière végètalc fraîche. Nais ces œufs, déposés en terre seulement à 5011 6 centimètres de la surface, sont toujours atteints par le soc de la charrue. Ou bien, comme le fait observer II. Ysabeau, le labour les écrase, ou bien il les enfonce à une profondeur telle que les jeunes Sauterelles, quand elles viennent à éclore, meurent faute de pouvoir sortir de terre; ou bien, enfin, et c'est ce qui a lieu le plus sonvent, le soc, en retournant la terre, ramène les oufs de sauterelle à la surface, où ils deviennent la proie des oiseaux insectivores et surtout des corbeaux. Il suffit même que les plaines qu'on ne lahoure pas soient livrées anx parcours des bestiaux, pour que les Sauterelles y soient en presque totalité écrasées sous les pieds des troupeaux, avant d'avoir acquis des ailes qui leur permettent de prendre à leur approche une fuite précipitée par bonds d'une certaine portée; car si leurs ailes ne leur servent pas à voler, elles les ouvrent au moment oì elles premnent leur élan pour sauter, ce qui les aide à franchir à chaque hond ın plus grand espace. 
On a conseillé à la suite du labour, quand le sol est retourné, de conduire en automne des troupeaux de dindons a jeun dans les champs pour y dérorer les œufs des Sauteterelles. Cependant il ne fant pas abuser du moven. Cette nourriture communique, dit-on, aux œufs une couleur noire et un goût désagréable et peut produire la dyssenterie suivie de morichez les volatiles qui en mangent une certaine quantitè. Le meilleur moỵen est le labour profond à la charrue, qui enfonce les cufs des Sauterelles à une profondenr assez grande pour que les petits soient étouffés des leur naissance.

\section{TIIPE-GRILLON OU GOURTILLIERE.}

(Gryllotalpa vulgaris, Latreille.)

Le Taupe-grillon a certainement $u n$ air de parenté arec le Grillon. Sa tìte est ronde comme la sienne; des ailes membraneuses et droites se moulent également sur le corps. Mais il en diffère par un abrlomen beaucoup plus allongè.

Quant à sa ressemblance avec la Taupe, elle réside surtout dans les deux mains antérieures et dont le Taupegrillon se sert pour creuser des galeries souterraines. II est vrai que la comparaison ne saurait ètre poussée plus loin; car si la Taupe chemine ainsi à la recherche des larres des insectes nuisibles à l'agriculture, la Courtillière mange les racines qu'elle rencontre et arrète par là même le déreloppenient de la plante. 
Les mœur's de cet insecte sont des plus intéressantes à itudier. La femelle montre la plus vive sollicitude pour ses œufs. Elle creuse à portée de sa galerie une chambre de forme ovale, bien lissée et communiquant avec le dehors par un couloir sinueux et dont l'ourerture est hermétiquement close. Elle pond daus cet espace, long de 50 millimètres et large de 26 millimètres, trois ou quatre cents

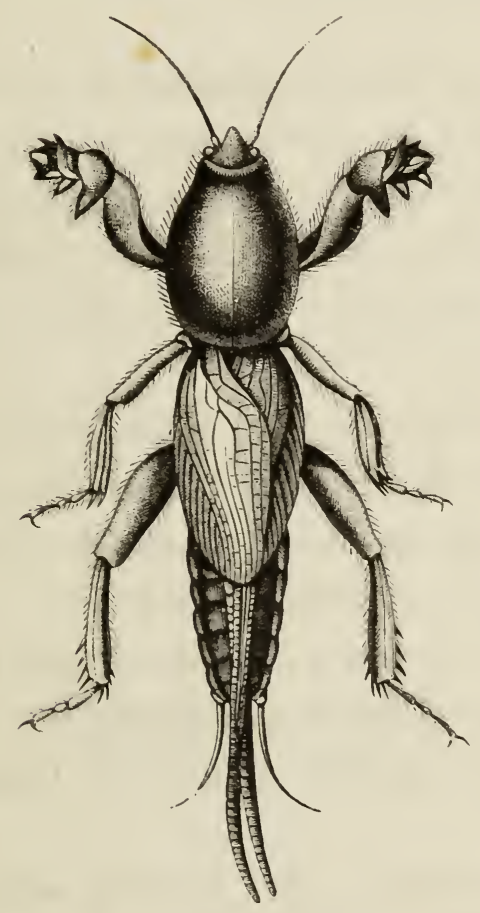

Fig. 64. - Taupe-grillon, grandeur naturelle.

œufs qui ont la grosseur d'une graine de turneps et sont d'un jame brun. Ils sont ainsi protegés contre un petit scarabée qui en est très-friand. 
La ponte a lieu en juin, et les jeunes insectes éclosent un mois après, en juin et en août. Ils commencent immédiatement à manger les racines tendres des plantes environnantes, soit blé, gazon ou autres végétaux, et lorsqu'ils n'en trouvent plus, ils vont chercher ailleurs leur nourriture. Mais aussitôt après leur première mue, ils se dispersent pour vivre isolément.

Leur présence se reconnaît aux places jaunes et flètries qui gâtent les prairies et par un semblable désordre dans les jardins.

Voici le moyen de s'en débarrasser. On mouille légèrement les couches de terrain pour les attirer pendant la grande ardeur du soleil, car ces insectes aiment beaucoup l'eau et l'humidité; ce sont pour ainsi dire des animaux amphibies. Ils accourent à la superficie et on les attend pour les détruire.

On peut avoir recours à cet autre autre moyen : verser dans les galeries de l'huile et de l'eau de savon mélangées. Les stigmates des insectes ètant bouchés, la respiration ne se fait plus et les Courtillières meurent.

A Berlin, on en prend cent mille chaque année en enfoncant à cinq centimètres au-dessous du sol des pots à fleur avec trente gouttes d'huile de térébenthine dans chacun.

En juin et en juillet, enfin, les œufs sont facilement dètruits. Il suffit d'un coup de bêche qui ouvre la chambre dans laquelle ils sont renfermés. 


\section{LE PERCE-OREILIE}

Il suffit de nommer le Perce-oreille pour que tout le monde reconnaisse l'animal dont il s'agit. C'est un insecte de couleur brune, qui a une pince à l'extrémité de l'abdomen, d'où vient le mot par lequel on le désigne. Il appartient à l'ordre des Orthoptères; il tient ses ailes cachées sous des élytres fort courtes pendant le jour, mais il les déploie dans la nuit et vole avec une grande activité. Le Perce-oreille ne subit pas à proprement parler de métamorphoses. Depuis sa sortie de l'œuf, il change plusieurs fois de peau en grandissant, et au bout de quelques mues il acquiert enfin des ailes.

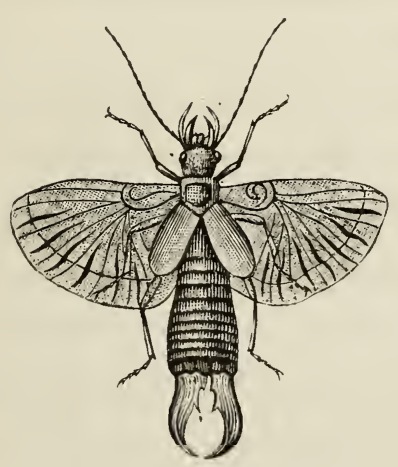

Fig. 6̈. - Perce-oreille.

Chez le Hanneton, chez le Papillon, la femelle ne tardo pas à périr après la ponte des œufs. Elle les place dans des conditions telles que les larves puissent trouver 
à leur portée des moyens de subsistance; puis c'est tout. Chez le Perce-oreille, la femelle qui survit à la ponte la garde avec le plus grand soin, et si elle croit ce gage d'une postérité menacé, elle l'emporte et cherche à le soustraire au danger en lui procurant une retraite plus sûre. Mais là paraît se borner sa sollicitude maternelle; les jeunes Perce-oreille une fois nés, sont en état de pourvoir à tous leurs besoins et la mère ne paraît plus s'en occuper.

Ces larves sont presque blanches, pourvues de deux mandibules et munies de six pattes; elles sont agiles et vont à la recherche de leur nourriture qui consiste en matière végètale tendre, comme les premières feuilles des plantes herbacées.

Le Perce-oreille aime passionnément les fruits mûrs, et si l'on ne prend soin de lui donner la chasse, il dévore les pêches et les abricots venus sur les arbres en espaliers même avant que ces fruits soient assez mûrs pour être livrés à la consommation.

Il n'y a qu'un moyen de se défendre et le voici : on suspend des sabots de moutons de distance en distance aux branches des arbres en espaliers chargés de fruits à peu près mûrs. Tous les soirs, les Perce-oreille, ailés ou non, s'y domment rendez-vous pour y passer la nuit. Le matin de bome heure, on les surprend aisément encore endormis, et on en détruit ainsi la plus grande partie. 


\section{LEPIDOPTERES}

\section{L'ALUCITE OU TEIGNE DES GRAINS}

Après le Charançon, l'Alucite est un des insectes qui causent les plus grands dommages aux blés. On fut long-

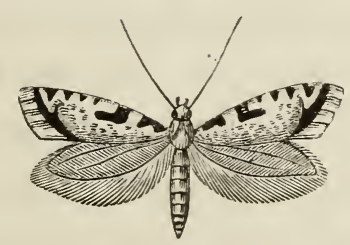

Fig. 66. - Alucite des grains.

temps avant de se douter des ravages produits par ce petit papillon, assez semblable aux Teignes de nos appartements, dont la chenille dévorant les blés, les orges, les seigles, s'est multipliée d'autant plus aisément qu'on le connaissait moins. Importée en France ou observée pour la première fois vers l'amnée 1750 dans la Charente-Infé- 
rieure, l'Alucite ne tarda pas à se répandre dans les provinces voisines, l'Aunis et la Saintonge. Vers 1780, elle commençait à paraître dans le Limousin. En 1807 ou 1808 , elle apparut dans le département de l'Indre. En 1826, elle pénétrait dans la partie méridionale du Cher.

Le Limousin, le Berry, le Nivernais, la Touraine, le Blaisois, la Sologne, etc., qui n'ètaient point affligés par l'Alucite à l'époque où Duhamel et Tillet furent chargès d'une mission spéciale par l'Académie des sciences (1760), en sont envahis; on compte 14 départements complètement ravagés par l'Alucite, qui déjà se répand vers la Beauce, malgré l'obstacle bien réel que la Loire opposait au passage ou à la migration de cet insecte. Tel était l'envahissement de l'Alucite lorsque le docteur Herpin, de Metz, qui a consacré sa vie et sa science à des questions de première utilité, adressa à la Société royale et centrale d'agriculture un mémoire des plus pressants sur ce sujet. Il constatait que dans douze ou quinze de nos départements du centre et dı midi, où la culture des céréales est à peu près la seule qui soit pratiquée, le froment, le seigle, sont attaqués sur pied, et avant leur maturité, par des myriades de teignes dont les larves, logées dans l'intérieur du grain de blè, en dévorent la substance farineuse, qũ'ils remplacent par leurs excréments ; que ces insectes subissent sous l'enveloppe protectrice du grain leurs différentes mètamorphoses; qu'à l'époque de la moisson, un quart, un tiers et quelquefois plus, des épis, sont déjà dévorés ; que la plupart des autres grains, qui paraissent sains et intacts, renferment néanmoins dans leur intérieur le giron de l'insecte destructeur; que ces larves sont quelquefois si nom- 
breuses qu'en serrant avec la main une poignée de blé ou d'épis alucités, on en exprime un fluide blanchâtre, visqueux qui est la substance même du corps des insectes écrasés; que les grains plus ou moins vidés et aplatis par la pression de la main restent adhérents et agglomérés comme serait du son mouillé; enfin que les ravages de l'Alucite se continuent dans les greniers, dans les granges, à tel point que si le battage ou la mouture sont retardés de quelques mois, les trois quarts ou les sept huitièmes des récoltes sont perdues.

Le pain qui provient des blés attaqués par l'Alucite, et surtout lorsque la farine n'a pas été convenablement blutée, contient des débris de cadavres et d'excréments des insectes : il a un goût désagréable, rebutant et qui prend à la gorge; il manque de liaison et se laisse aller dans l'eau comme le ferait un morceau de terre.

On attribue même à l'usage de cette nourriture insalubre un mal de gorge très-dangereux qui règne depuis quelques années d'une manière épidémique dans les contrées affligées par l'Alucite. Cette maladie se manifeste par des ulcérations gangréneuses qui se forment dans l'arrièrebouche, et les malades succombent en peu d'heures, avant mème qu'on ait pu leur administrer des secours.

Suivant les contrées, l'Alucite se nomme Papillon, T'eigne, Pou volant ou encore, par corruption, Alucite. Elle a èté souvent confondue arec un autre enıemi des céréales, la T'eigne des blés, dont l'aspect et les mœurs sont, comme nous le verrons, différents.

L'Alucite n'a èté classée par les naturalistes qu'en 1789 dans l'Encyclopédie méthodique; elle fut désignée sous 
le nom d'Alucite des céréales. C'est un insecte lépidoptère nocturne, ou papillon de nuit, de la tribu des tinéites; il a $0^{\mathrm{m}} 006$ à $0^{\mathrm{m}} 007$ de long. A l'état de repos, il porte ses ailes repliées le long du corps, de façon à former au dos de l'animal un toit arrondi presque plat. La tête est dégarnie de poils et pourvue d'antennes filiformes; on y voit en dessous une petite trompe bien apparente. Entre les deux antennes se distinguent comme deux petites cornes relevées en haut et facilement reconnaissables. La couleur générale de ce petit animal est d'un gris couleur du café au lait. Les deux paires d'ailes sont garnies, à leur bord postérieur et à leur extrémité, d'une frange touffue. Nous insistons sur ces caractères, parce qu'ils servent à distinguer l'Alucite de la Teigne des blés. Son nom vient du mot latin alluceo, briller, sans doute à cause du reflet métallique des ailes.

Supposons une Alucite à l'ètat de papillon ; voyons comment elle se multiplie. Dès qu'une femelle est fécondée, elle va voltigeant antour des épis du froment ou de l'orge; elle s'adresse de préférence au froment, soit sur pied ou dans les greniers, dépose ses œufs à la surface du grain et particulièrement dans l'intérieur de la raintre. Les œufs sont rouges, longs de $2 / 3$ de millimètre.

Au bout de huit à dix jours, on en voit sortir une chenille ou petit ver blanc, long de $0^{\mathrm{m}} 006$ à $0^{\mathrm{m}} 007$ sur $0^{\mathrm{m}} 00 \mathrm{I}$ de large à peine née; cette jeune larve, qui est armée de fortes mandibules ou mâchoires, pratique une ouverture presque imperceptible dans l'écorce du grain, dans la rainure même, pénètre et s'ètablit dans l'intérieur, qu'elle dévore peu à peu, de telle sorte qu'après quelques semaines seulement, il ne reste plus dı blé qu'ıne vessie creuse 
formée par le son ou l'enveloppe corticale dı grain.

L'insecte protégé, garanti par l'écorce elle-même contre l'action de la plupart des corps extérieurs, exerce ses ravages avec d'autant plus de sécurité qu'aucun signe apparent ne vient avertir le cultivateur de la présence de re redoutable ennemi, si ce n'est toutefois la chaleur extraordinaire qui se développe spontanément dans les tas de blé alucité et la diminution progressive du poids du grain.

En effet, ce blé qui, à l'époque de la récolte, pesait 75 à 80 kilogrammes l'hectolitre, a perdu 10, 20, même 50 pour 100 et plus de son poids; la substance farineuse qu'il contenait a disparu plus ou moins, elle est remplacée par les excréments, la peau et les débris des insectes; les grains sont plus ou moins vides, quelquefois il n'en reste plus que la coque. L'Alucite reste à l'état de chenille, larve ou ver', pendant vingt ou vingt-cing jours. A ce moment, la larve se change en nymphe, elle conmence un travail intérieur très-analogue à celui de la formation du poulet dans l'œuf ; son corselet, son abdomen, ses pattes, ses ailes, tous les organes fort compliqués nécessaires à son existence parfaite, se forment successivement. Ce travail d'achèvement d'insecte parfait dure de huit à dix jours; alors l'Alucite brise sa prison et en sort à l'état de papillon. Souvent, à l'époque de la moisson, on voit déjà sortir des gerbes un grand nombre de papillons d'Alucites. Cette génération est produite en grande partie par les insectes qui étaient contenus dans le blé employé pour la semence, qui passent l'hiver dans la terre et en sortent vers la mi-juin, pour pondre sur les jeunes épis. Cette première génération a 
déjà parcouru toutes les phases de son développement avant que la récolte soit rentrée.

Ces papillons s'accouplent peu de temps après être éclos, et la ponte des femelles a lieu immédiatement après. Chaque femelle dépose un œuf sur chaque grain, elle recommence la même opération jusqu'à ce qu'elle ait achevé toute sa ponte, qui est d'une centaine d'œufs. Comme elle ne mange pas pendant sa période de papillon, sa ponte acherée, elle meurt : c'est l'affaire de deux ou trois jours. Souvent éclose le matin, elle pond dans le courant de la journée et meurt de vieillesse le lendemain ; l'existence du mâle est encore plus courte que celle de la femelle. Eh bien, pendant cette vie éphémère à l'état parfait, l'Alucite. comme le fait observer arec raison M. Ysabeau, enlève à l'agriculture des millions.

On a calculé qu'un seul couple d'Alucites, faisant clıque année deux pontes de quatre-vingts œufs, chaque ponte pouvait donner naissance à plus de cent mille individus en moins de trois ans ; chiffre véritablement effrayant, surtout en songeant à la facilité arec laquelle l'Alucite se répand et se propage de proche en proche, soit par la migration des papillons, qui, quoique faibles et débiles, peurent cependant se transporter et surtout être transportés par les vents à la distance de plusieurs centaines de mètres ; mais surtout par le commerce des blés attaqués, qui porte au loin et sans qu'on s'en aperçoive l'insecte renfermé et caché dans l'intérieur du grain, et les germes de l'insecte, c'està-dire ses œufs, qui sont déposés dans la rainure du blé, auquel ils adhèrent fortement à l'aide d'une matière glıtineuse particulière, de telle sorte que les nettoyages, les 
pelletages, le crible, le tarare ordinaire, les atteignent peu ou même pas du tout.

\section{Caractères essentiels qui peuvent faire reconnaitre}

le blé alucité. - Le cultivateur sera averti par la présence des papillons de l'Alucite, par l'existence des grains piqués, et s'il prend une certaine quantité de grains et qu'il les jette dans un sceau d'eau, tous iront au fond si le blè est sain; si, au contraire, les grains sont alucités, ils surnageront tous: cela tient à ce que le blé alucité diminue de poids à mesure que sa farine est dévorée. Les animaux domestiques refusent absolument de toucher à ces grains, dont la farine impure, grise et terreuse, est infectèe d'un goût de vermine intolérable.

Parmilles moyens indiqués pour détruire l'Alucite, nous indiquerons d'abord la chaleur qui est, selon les remarques du docteur IIerpin, l'un des moyens les plus avantageux qui ont été indiqués jusqu'à ce jour pour détruire l'Alucite et les autres insectes du blé.

Les expériences faites par Duhamel dans les fours et les étuves, celle de la Société d'agriculture du Cher faite avec le moulin de M. Verrasse-Desbillons et le brûloir de M. Cadet de Vaux, celles qui ont eu lieu au moyen des appareils à vapeur de MM. Robin et d'Haranguier de Quincerot, établissent d'une manière évidente et péremptoire les avantages de cet agent. Cependant l'emploi du calorique présente quelques difficultés, exige certaines précautions pour régler la température, pour empècher qu'une partie du grain ne soit brûlée ou chauffèe trop fortement, tandis qu'une autre ne le serait pas assez.

I'un autre còté, la dessiccation fait subir au grain une 
certaine diminution de volume, ce qui cause nue perte pour le cultivateur qui vend à la mesure.

Néanmoins, malgré ces légers inconvénients, le calorique peut être appliqué et utilisé très-arantageusement.

Loin de nuire su blé, la dessiccation en farorise beaucoup la conservation, même pendant plusieurs années.

L'expérience a démontré que les œufs, les chenilles et les chrysalides de l'Alucite, ainsi que les Charançons, sont détruits dans l'intérieur même du blé par une chaleur de כ0 degrés centigrades uniformément soutenue. Mais il ne faut pas dépasser 60 degrés; car, à partir de 6 à 70 degrés, il commence à perdre ses qualités germinatives et n’est plus bon pour les semences. Au-dessus de 70 degrés, la farine ou plutôt le gluten éprouve déjà une certaine altération, et le grain perd de ses qualités. Le degré de température convenable est כ̆ degrés; on pourra, sans le thermomètre, juger cette température à la main. A ce degré, le blé est un peu humide, et c'est à peine si l'on peut y tenir la main. L'application du calorique à la destruction des insectes du blé, Alucites et Charançons, peut aroir lieu de plusieurs manières : par le chauffage direct à feu nu, par le chauffage dans le four, les étures, etc., le chauffage à la vapeur ou air chaud. C'est ce que nous examinerons prochainement.

\section{MOYENS DE DESTRUCTION}

L'application dı calorique à la destruction des insectes dı blé, Alucites et Charançons, peut avoir lieu, avonsnous dit, de plusieurs manières. 
D’abord par le chanffage direct ou à feu nu lorsqu'on soumet le grain directement à l'action du feu dans des vaisseaux appropriés.

Le brüloir de II. Cadet de Vaux consiste en un cylindre en tôle, tourmant horizontalement sur son axe, au-rlessus d'un fourneau incandescent. C'est un appareil en tous points semblable à celui dont se servent les épicier's pour griller le café. Mais la grande dépense de charbon, l'inconvénient auquel on est exposé de brûler le blé ont fait abandonner cet appareil.

I. Herpin, de Metz, a disposé dlans 1 In fournean de forme oblongue un canon de fusil, ouvert par les deux bouts, et mieux un tube en tôle, méplat, de ò centimètres de largeur, dans une position inclinée à l'horizon, d'environ 40 centimètres pour 1 mitre de longueur du tube. Celui-ci communique par sa partie supérieure aver unc trémie contenant le grain qui s'échappe par une onverture munie d'un tiroir, pour s'écouler en descendant par l'intérieur dı tube chaud dont il est question.

Iu sortir du tube convenablement échauffé, le grain avait acquis une augmentation de température d'environ 12 degrés centigrades. En faisant repasser à trois reprises successives le même blé par l'intérieur du tube échauffí modérément, la température du grain s'est élevée promptement à 5 degrés. Comme le grain est toujours en mouvement en passant dans l'intérieur du tube chauffeur, comme il n'acquiert dans ce parcours qu'une augmentation de 12 à 15 degrés, et comme il est, par conséquent, nécessaire de le repasser plusieur's fois dans le tube pour l'amener au degré de chaleur' voulu, r'est-à-dire à 5: de- 
grés centigrades, on ne court donc aucun risque de brûler le blè.

Ce procédé simple et économique pourrait être avantageusement employé par les petits cultivateurs qui, tout en se chauffant pendant les soirées d'hiver, voudraient, sans une augmentation notable de dépenses, assainir leurs blés et les purger d'insectes.

Il suffirait de disposer pour cela le tuyau de conduite de la fumée d'un poêle ordinaire ; on placera dans l'intérieur de ce tuyau un ou deux autres tubes, en tôle méplats de 1 mètre 50 centimètres de longueur, 5 centimètres de largeur et 2 centimètres de hauteur. Ces tubes devront sortir d'environ 20 centimètres à chaque bout du tuyau de conduite de la fumée; celui-ci, au lieu d'être droit et vertical, devra être coudé et incliné de bas en haut d'environ 50 à 60 centimètres par mètre pour la lon goueur des tubes. La partie supérieure du tube chauffeur est en communication avec une trémie munie d'une trappe pour régler la sortie du grain qui devra entrer dans l'intérieur des tubes; au-dessous de l'extrémité inférieure de ceux-ci on placera une corbeille pour recueillir le grain.

Vers la partie du coude inférieur, les tubes ou canons devront être recouverts d'une enveloppe de tôle pour les préserver de l'action trop vive de la flamme. On peut obtenir facilement et d'une manière exacte la température de ว5 à 60 degrés centigrades que le grain doit atteindre pour que la destruction des insectes qu'il contient ait lieu d'une manière certaine.

En ouvrant ou en fermant la porte du foyer du poêle et la clef pour accélérer ou ralentir la combustion, en faisant 
varier de quelques centimètres l'inclinaison du tuyau, ce quiaccélère ou ralentit un peu la descente du grain dans les tubes chauffeurs, on n'est jamais arrêté dans sa marche par un ofostacle quelconque. Il faut aussi se rappeler que plus on fait passer de grain à la fois, moins il s'échauffe pendant son parcour's dans le tube. Enfin il faut repasser immédiatement et successivement deux, trois et nême quatre fois le grain sortant des tubes chauffeurs, jusqu'à ce qu'il ait atteint la température voulue, 5ૅ degrés centigrades.

On conserve pendant plusieurs heures la chaleur dı blé en le mettant en tas et le couvrant avec des couvertures de laine pour achever la destruction des insectes qui auraient pu échapper à l'opération.

Chaufournage. - Un autre moyen à employer, c'est le chaufournage. Les habitants des campagnes, dit Duhamel, pourront se contenter de passer leurs blés dans des fours assez échauffés pour tuer leur insectes et leurs oul's.

On a fait, ajoute-il, bien des objections contre cette pratique, parce qu'elle a été également mal exécutée, et au lieu de chercher à remédier aux inconvénients, on a dit que le four gâtait le blé, tandis que c'est le contraire qui a lieı, car le blè prend de la qualité lorsque l'opération a été bien faite. Pour cela, il faut, selon la méthode Herpin, enfourner le blé dans des caisses en planches de bois blanc de la contenance d'un hectolitre environ, ayant de 1 mètre à 1 mètre 20 centimètres de longueur, 50 à 50 centimètres de largeur, et 20 à 50 centimètres de hauteur, ouvertes en dessus.

Le fond de ces caisses, au lieu d'être en bois, est en 
toile métallique assez forte; il est cintré par-dessus, de manière à former une voùte très-surbaissée.

Ces caisses sont supportées par des galets ou roulettes en fonte ou en faience qui permettent de placer et de ranger commodément les caisses dans l'intérieur du four, de les en retirer à l'aide de poignées en bois ou en cordes et de crochets, pour remuer le blé qu'elles contiennent.

Au moyen de ces caisses fort peu coûteuses, le bléne se trouve plus en contact immédiat avec l'àtre ou les parois du four, et par conséquent il n'est plus exposé à être surpris ou brùlé par la chaleur; il n'est plus sali par les cendres. On peut changer les caisses de place, les retirer pour remuer le grain, et vérifier exactement le degré de température auquel il est arrivé.

Un four de grandeur ordinaire peut contenir cinc ou six caisses de la dimension indiquée, c'est-à-dire que l'on peut dessécher et assainir de cette manière, et sans aucune dépense, cinq à six hectolitres de grain en quelques heures, sans autre soin que de s'assurer de temps en temps du degré de température du grain.

Chauffage par la vapeur. - Les appareils à vapeur qu'on a construits jusqu'à présent pour l'assainissement des blés alucités, tels que ceux de M. Robin, de Châteauroux, de M. d'Haranguier de Quincerot, de Bourges, n'ont pas répondu complétement aux espérances que l'on avait conçues d'un moyen aussi puissant d'application du calorique, arec lequel on peut obtenir facilement, écononiquement et régulièrement, toute température dont on peut avoir besoin, et surtout la régler d'une manière exacte et précise. 
La manière la plus convenable d'utiliser le chanlfage à la vapeur serait de mettre le grain dans une boite cylindrique en métal, bien fermée, de la contenance d'un hectolitre environ, tournant horizontalement sur son axe, semblable au brùloir à café.

Ce cylindre serait renfermé dans une caisse métallique remplic de vapeur d'eau et munie d'une soupape de sùreté.

II suffirait de tourner le cylindre deux ou trois fois pendant la durée de l'opération pour répartir la chaleur d'une manière uniforme dans la masse du grain.

Avec une chaudière de la contenance de 8 a 10 litres et une dépense de quelques centimes de coke ou de charbon de terre, on pourrait au moyen de cet appareil assainir quelques liectolitres de blé par heure.

Moyens mécaniques. - La comıpression peut enfin ètre employée avec quelque succès pour la destruction de l'Alucite. Et c'est encore à M. Ilerpin de Metz, qui a parfaitement ètudié les moyens de destruction exposés ci-dessus, que nous devons d'avoir le premier imaginé le procédé mécanique de détruire l'Alucite au moyen d'un seconeur mécanique analogue aux tarares, muni d'ailettes de bois ou de fer, marchant avec une très-grande vitesse. Les sccousses et les chocs que reçoit le blé en passant par cette machine sont si violents que les œufs sont brisés, que l’insecte est meurtri, assommé dans l'intérieur mème du grain. Cette machine, appelée par son inventeur tarare brise-insectes, et que l'on désigne aussi sous le nom de tue-teignes, se compose essentiellement d'un cylindre batteur à jour semblable aux cylindres batteur's des machines à battre, tournant horizontalement avec une grande 
vitesse, 500 à 700 tours par minute ou 1,000 à 2,000 mètres à la circonférence, d'un diamètre et d'une longueur qui peuvent varier de 50 centimètres à 1 mètre, tourıant dans l'intérieur d’un tambour en tôle; au-dessus et sur le côté du cylindre batteur est une trémie ayant une ouverture longitudinale parallèle au cylindre batteur, disposée de manière à ce que le grain, en sortant de la trémie, tombe juste sur les aubes ou battes remontantes du batteur. Et comme ce cylindre tourne avec une très-grande vitesse, le grain en tombant sur les aubes est frappé avec violence, projeté vivement contre les parois du tambour de tôle; enfin il est lancé au dehors par la force centrifuge, et il se trie de lui-même en diflérentes qualités suivant son poids. Le plus pesant est projeté au loin, les grains vides et attaqués restent près de la machine.

Les œufs de l'Alucite, qui sont fortement adhérents à l'écorce du grain, ne se détachent pas toujours facilement par l'effet du choc. C'est pourquoi M. Herpin a adapté au-dessous de la trémie une brosse circulaire qui exerce sur le grain une friction capable de détacher ou briser les œufs qui pourraient y être adhérents. Comme la roue à aubes qui constitue la partie essentielle de ce tarare tueteignes, n'est autre chose que le cylindre à jour ou le tambour batteur des machines à battre, ces machines peuvent très-bien servir pour le nettoyage des blés alucités; il suffit pour cela d'adapter une trémie à rainure longitudinale au-dessus du côté remontant du cylindre batteur, de manière à ce que le grain tombant de la trémie (comme cela a lieu dans le crible à plan incliné) soit frappé par les battes du tambour en remontant, c'est-à-dire de bas en 
haut; on supprimera les secoueurs de la paille et les picces de nettoyage qui seraient inutiles ; on domnera au cylindre batteur une très-grande vitesse.

Le blé, projeté au loin par la force de la machine, est trié ou séparé en plusieur's qualités, comme cela a lieu quand on le jette à la roue. Au moyen du tarare à percussion ou tue-teignes de M. Herpin, non-seulement on peut purger le blé des Charançons el des Alucites adultes qui sont mélangés avec le grain, mais encore des larves et des chrysalides que celui-ci renferme dans son intérieur.

\section{FAUSSE TEIGNE DES BLES}

(Papillon ou Ver des blés).

Réaumur appelait Teignes tous les papillons nocturnes dont les chenilles glabres, de couleur jaune-blanchàtre, vivent et se métamorphosent dans des fourreaux fusiformes, fixes ou portatifs, de la couleur des substances dont elles se nourrissent. Quand l'étui n'est pas fixe et que la chenille l'emporte avec elle, l'insecte se nomme OEcophore, qui veut dire porte-maison. Quand les étuis des Teignes sont fixes, Réaumur les appelle Fausses Teignes. Cette dinonination est mauvaise, en ce qu'elle renferme certaines espèces de pyrales et d'aglosses qui s'éloignent complètement du genre Teigne.

La Fausse T'eigne appartient à la même famille que l'Alucite ou T'eigne; on les a longtemps confondues. Les déno- 
minations différentes domnées à ces deux insectes ont igalement contribué à jeter de la confusion dans les descriptions. Puisqu'on a souvent appelé l'Alucite Teigne des grains, nous conserverons le nom de Fausse Teigne à l'insecte qui n'est pas l'Alucite. En cela, du reste, nous sommes d'accord avec le grand naturaliste Réaumur. A l'état de chenille, la Fausse Teigne marque sa présence dans les tas de froment, en liant entre eux deux ou trois grains par une espèce de coque soyeuse, autour de laquelle on trouve des points ronds blanchâtres, qui sont les excréments de l'insecte.

C'est aussi quand le blé est au grenier qu'il est attaqué par la Fausse T'eigne, dans la première quinzaine d'aoùt. Elle se tient à la surface des tas de blé, cachée entre les deux ou trois grains dont elle s'est formé III fourreau. Elle sort en partie de son habitation pour attaquer le grain le plus à sa portée, qu'elle lie aussi à son fourreau; elle le perce à un bout et en mange la farine, elle y pénètre de plus en plus profondément et en consomme la substance. Si elle n'est pas rassasiée, elle entame un autre grain. Il n'est pas rare, dit M. Goureau, de voir presque tous les grains situés à la surface d'un tas de blé liés les uns aux autres et former un tapis d'un ou deux centimètres d'épaisseur, qu'on peut lever d'une seule pièce ou en plusieurs lambeaux.

Cette petite chenille parvient à toute sa taille dans la deuxième quinzaine d'aoùt. Elle a alors six millimètres de long: elle est cylindrique, blanchàtre; sa tète est d'un fauve marron, avec les mâchoires noiràtres; le premier segment porte en dessus une grande tache d'un fauve pâle 
et les autres des points verruqueux de chacum desquels sort un poil ; elle est pourvue de seize pattes.

Quand on sépare, dit M. Iluzard, les grains attachés entre eux, on voit qu'ils sont entamés en partie, et on trouve souvent dans l'un d'eux la petite chenille.

Quand elle a vécu un certain temps, elle doit se changer en chrysalide; mais, pour cette métamorphose, elle abandonne les grains, quitte sa coque, et se retire le long des murs du grenier, le long des poutres et des parties en planches préférablement, s'y suspend par la partie postérieure de son corps, et se transforme en chrysalide, comme on le voit faire à un grand nombre d'autres chenilles.

A cette époque, le nombre des chenilles sur les tas de blé, sur les murs et sur les parties en bois, est plus ou moins considérable; et comme elles ressemblent assez à de petits vers, on leur a donné le nom de vers des blés. On dit alors, dans les greniers où il s'en trouve ordinairement, que le ver monte; bientôt les chenilles se changent en chrysalides, et un papillon ne tarde pas à en sortir.

Les auteurs ne sont pas d'accord sur le lieu que choisi la Fausse Teigne pour se métamorphoser : selon les uns, elle se retire dans son fourreau et y subit son changement; selon d'autres, elle reste dans le grain qu'elle a vidé. M. Charles Goureau dit avoir trouvé quelques chenilles dans les grains de blé qu'elles avaient rongés cn attendant leur métamorphose. Quoi qu'il en soit, elles passent l'hiver à l'état de chrysalide, et le papillon s'envole dans le mois de juin ou le mois de juillet suivant.

Une fois transformée en chrysalide, la Fausse Teigne ne mange plus : elle ne fait done plus aucun ravage dans les 
grains, et sa présence nuit seulement parce que les papillons y déposent des œufs pour une nouvelle génération. Ces papillons ne cherchent point à sortir des greniers; ils s'y cachent ordinairement, pendant le jour, dans les endroits les plus sombres.

Comment distingue-t-on l'Alucite de la Fausse Teigne. - Nous emprunterons aux Mémoires de la Société d'agriculture, année 1851, les caractères différentiels suivants établis avec soin par M. Huzard fils et dont nous avons vu les expériences relatives au Charançon, à l'Alucite el à la Fausse Teigne.

La grandeur des deux insectes est la même.

La couleur des ailes de l'Alucite est plus claire que celle des ailes de la Fausse Teigne, elle approche plus de celle du café au lait; on n'y remarque point de taches.

La couleur des ailes de la Fausse Teigne est plus foncée, plus grise, et l'on remarque sur le fond, à la vue simple, des taches brunes transversales bien marquées.

Les ailes de l'Alucite forment aussi une table plane sur le dos ou très-légèrement bombée, tandis que les ailes de la Fausse Teigne, à leur bord interne et à la partie postérieure seulement, se relèvent et forment entre elles $11 n$ angle ou une espèce de toit incliné de chaque côté.

Entre les antennes de l'Alucite, il y a deux barbes qui s’élèvent au-dessus de la tête, en sorte que cette tête parait porter deux petites cornes.

Entre les antennes de la Fausse 'T'eigne, il n'y a pas de petites cornes.

La chenille de l'Alucite est complétement cachée dans le grain, sous l'écorce duquel elle s'introduit quand elle 
sort de l'œuf, époque où elle n'est pas encore visible à l'œil. Elle n'en sort pas, comme celle de la Fausse Teigne, quand on remue ce grain.

La chenille de l'Alucite ne sort pas non plus du grain pour se transformer en chrysalide; ce n'est qu’à l'état de papillon qu'elle s'en échappe.

En sorte que dans un grain attaqué par l'Alucite on! trouve ou la chenille, ou la chrysalide, ou la dépouille de celle-ci, et enfin la peau, plus petite encore, de la chenille.

\section{Caractères différentiels tirés de l'aspect du grain.-} On ne s'aperçoit que les grains sont attaqués par l'Alucite, arant l'apparition des papillons sur les tas de grains, qu'au poids spécifique moindre, et ensuite, quand ces insectes sont en grand nombre, à une chaleur intense qui s'y développe souvent en très-peu de temps et qui précède de quelques jours la sortie des papillons.

Les grains ne sont pas liés entre eux par des espèces de coques soyeuses, comme ils le sont quand e'est la Fausse Teigne qui les attaque.

Les excréments de la chenille de l'Alucite ne se voient pas à l'extérieur, parce que ces excréments, quand ils sont jetés hors du grain, ce qui n'a lieu au reste que pour un petit nombre, ne restent point attachés à celui-ci. Il en résulte que le grain attaqué ne présente rien de remarquable à l'œil nu ; rependant, à la loupe et au microscope, on y remarque un petit point formé par une espece de lame de soie. Dans l'intérieur, le grain est divisé en deux chambres : dans l'une est la chenille, semblable ì la vue à celle de la Vausse Teigne el enfermée dans une 
espèce de coque soyeuse; dans l'autre partie, sont les excréments de cette chenille.

Les papillons de l'Alucite ne restent point dans les greniers comme ceux de la Fausse Teigne, à moins que la température de l'air ne soit très-basse; ils sortent et se répandent dans la campagne.

Quand c'est à la fin du printemps qu'ils naissent, ils ront se répandre sur les champs de céréales, principalement sur ceux de froment, et, à la chute du jour, on les retrouve sur les épis, occupés à pondre.

A l'état de chrysalide et de papillon, l'Alucite et la Fausse Teigne ne mangent plus, ce qui les différencie des Charançons, qui mangent pendant deux périodes de la vie ef causent par cela même plus de dégâts.

\section{MOYENS DE DESTRUCTION}

Les ravages de la Fausse Teigne sont assez faciles à arrêter ou au moins à diminuer par les manipulations qu'om donne au blé dans les magasins; en remuant le grain fortement, on détache l'un de l'autre ceux que la chenille a liés entre eux. Cette chenille se trouve à découvert, elle est froissée entre les grains remués et elle périt. C'est ce qui lui arrive encore quand elle a creusé un des grains assez pour s'y loger entièrement; elle en sort pour subir la même destinée. Enfin, quand elle est à l'époque de se transformer en chrysalide, et quand elle abandonne les grains pour monter le long des murs et des planches du grenier, pour s'y changer en chrysalide, quand le ver 
monte, comme l'on dit, même quand il est changé: en papillon, on peut en détruire beaucoup en les écrasant.

Un autre procédé consiste à renfermer dans les greniers quelques petits oiseaux du genre bergeronnette, en ayant soin de fermer les fenêtres avec un châssis en canevas. Ces oiseaux ont une adresse infinie pour saisir la Fausse Teigne dans les tas de grains, et en quelques jours ils peuvent en détruire des quantités considérables. On conseille surtout, et c'est le plus sûr, d'enroyer le grain au moulin dès qu'on s'aperçoit de la présence de la chenille, nettoyer scrupuleusement le grenier et n'y pas laisser m seul grain; si cela est possible, balayer les murs et n'y pas emmagasiner de blé ou de seigle pendant au moins une année.

\section{TEIGNE DU COLZA}

(Ypsolophus xylostei, Fabric.)

La Teigne du colza a été décrite par M. Focillon; c'est une petite chenille longue de 9 millimètres à son dernier àge, d'une couleur générale vert pâle, avec une tête écailleuse noire; le corps est hérissé de poils également noirs et présente, outre ses trois paires de pattes écailleuses, quatre paires de fausses pattes abdominales et unc paire de fausses pattes postérieures, toutes munies de cro(hets. Sa bouche est munie de mâchoires assez développées, et de mandibules très-fortes terminées par cinq dents crochues et acérées. Ce sont là les instruments de 
ces dégâts. M. Focillon a vu cette chenille à peu près à tous les âges de sa vie; elle a d'abord à peine 1 millim. 5 de longueur; sa tête est grosse, son corps très-velu et d'un vert très-pâle sous ses longs poils noirs; ses caractères, d'ailleurs, varient peu dans le cours de son développement. C'est pendant cette période qu'elle ravage les graines de colza. Elle s'introduit sans doute dans une silique

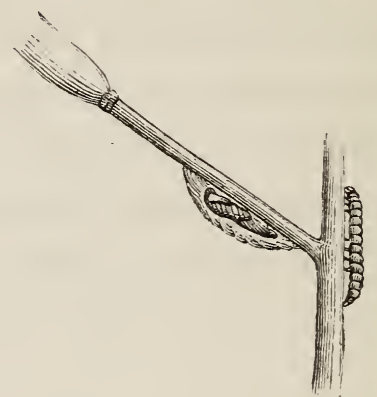

Fig. 67. - Chenille et chrysalide du colza.

encore jeune par un de ces trous si fins, qu'il faut, pour les constater, trouver l'animal occupé à les percer, et qui disparaissent souvent par le travail de la végétation. Une fois parvenue dans l'intérieur du fruit, elle y attaque une graine et ronge la substance intérieure dont les débris, encore adhérents à la coque de la graine, s'offrent sous l'aspect d'une pulpe verdâtre très-humide dans l'ètat frais. Quand son développement est achevé, la chenille fait un petit trou rond qui ne correspond pas toujours exactement au point où elle a vécu. Comme la chenille a les moyens de se mouroir, elle va souvent percer son orifice de sortie à quelque distance des grains mangés, et quelquefois même en perforant la cloison mé- 
diane qui sépare les deux loges. Du reste, la chenille ne se nourrit pas de la substance de la silique elle accumule intérieurement autour du trou les débris qu'elle fait en le perçant. Enfin ce trou la conduit au dehors, elle se promène quelque temps sur les siliques et sur les rameaux qui les portent pour choisir le lieu où elle subira ses métamorphoses, et quand elle est décidée, elle file, en le collant soit à une silique, soit à un rameaı, un cocon blanc à mailles lâches et qui semblent une sorte de tulle fin. Ce cocon est d'ailleurs ouvert aux deux extrémités. A travers cette espèce de filet blanc, on continue do voir tout ce qui arrive de la chenille; bientôt la partie antérieure brunit, enfin la mue a lieu et l'on aperçoit la chrysalide. Tous ces changements se font assez lentement, comme les dates suivantes en feront juger : le 14 juillet, une de ces chenilles, sortie d'une silique depuis la veille, commença à filer son cocon; le 16 au matin il était terminé, et on la voyait immobile au milieı; le 19, M. Focillon la trouva à l'état de chrysalide. L'écl sion du papillon eut lieu le 28. La chrysalide est longue de 7 millimètres, d'une couleur blonde, et sa dépouille, après la sortie de l'animal, est complétement transparente.

Le papillon qui en sort a un corps de 6 millimètres de longueur; mais, avec les ailes, il atteint de 8 millim. à 8 millımètres 5. On le reconnait immédiatement pour un de ces lépidoptères de la famille des Teignes, dont l'histoire est encore si obscure. Il a la tête et le dessus du dos café au lait. Cette couleur est limitée sur chacune des ailes par une ligne blanche en zigzag, et le bord externe de 
ehacune d'elles est d'un brun foncé, qui devient plus gènéral sur l'extrémité des ailes. L'animal en ouvrant ces ailes laisse voir les postérieures qui sont entières, d'un gris ardoise à reflets métalliques, et régulièrement bordées de poils. L'abdomen est amnelé de blanc et de brum ainsi que les pattes et les antennes. Dans l'ètat de repos, les ailes enveloppent le corps, et se relèvent légèrement en arrière en manière de queue de coq. Ces papillons éclosent en gè-

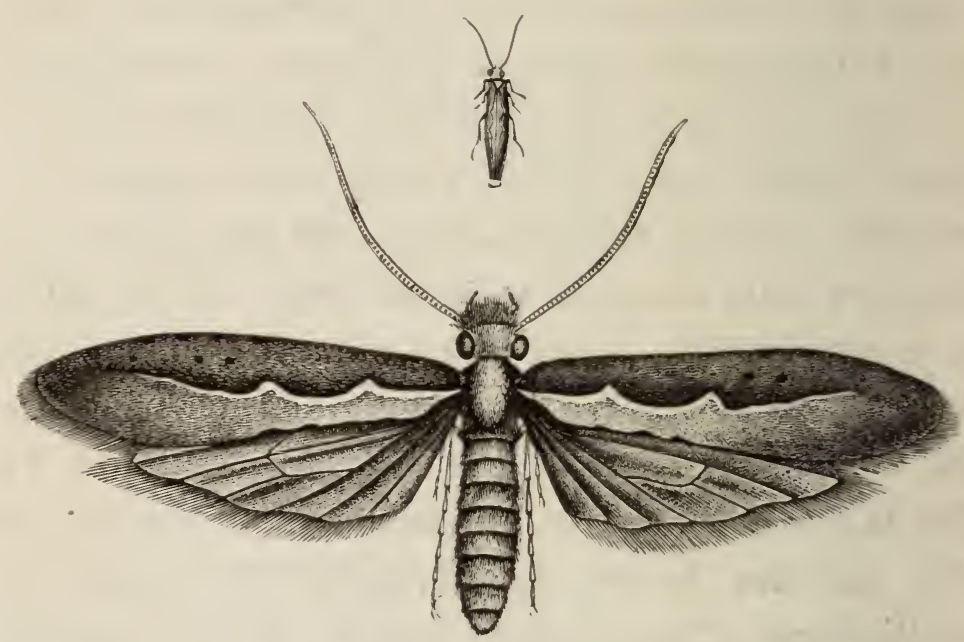

Fig. 69. - Teigne du colza grossie et grandeur naturelle.

néral vers le milieu de juin ou à la fin de ce mois. En juillet, on ne trouve plus que les retardataires; et les chenilles, trop jeunes pour se métamorphoser dans ce mois, atteignant le moment où la silique mûrie et est moissomnée se dessèche, n’y restent pas et s'en échappent, quelle que soit leur taille, par un trou qui naturellement est proportionnel à leur diamètre. Ces chenilles, d'ailleurs pen nombreuses, errent quelque temps sur les siliques 
et ne tardent pas à périr. Vu le petit nombre d'individus que la saison trop avancée a permis de farre éclore, 11. Focillon n’a pu réussir à les faire accoupler et pondre.

Les dégats commis par la chenille de ce petit lépidoplère sont très-analogues a cenx que M. Focillon a décrits comme provenant de la larve d'un coléoptère. Cependant un certain nombre de caractires lui permettent de faire une distinction. I'abord, et c'est antant qu'il a pu l'observer dans les circonstances défavorables où il se tronvait le caractere le plus tranché, la chenille ne produit pas cette coloration noire de l’intérieur de la silique qui lui a paru caractériser la présence de l'autre larve. De sorte qu'aulour dı trou mème par où elle s’échappe, et autour des graines dévorées, les parties intérieures dı fruit conservent leur couleur blanchâtre. Puis la manière dont les ğraius sont mangés n’est pas exactement la mème. La larve précédente laisse ordinairement des débris anmulaires de la pean de la graine, la chenille au contraire ronge tout mu côté, de facon à laisser un fragment ouvert de la périphérie du grain. La matière verte dont M. Focillon indique l'existence dans les débris laissés par la chenille est tonjours plus éloignée du point où elle a vécu et a commis ses dégàts; ce qui lient à ce que la chenille a des organes de monrement trés-développés, tandis que l'autre larve en est complétement dépourvue.

lo plus anples observations modifieront peut-ètre ces caractères: nais, quant à présent, ils ont toute li précision que le savant naturaliste a pu leur domier. Ces degaits ainsi caractérisés, et en raison mêue de lemr grande analogie, dojent ètre appréciés conme ceux de la larve 
précédente; ils sont restreints comme les siens, mais comme eux ils peuvent se répéter sur la mème silique. Ils ont d'ailleurs paru un peu moins fréquents.

M. Focillon a reconnu que ce petit lépidoptère est la Phalæna (tinea) xylostella de Linné, la Teigne à bandelette blanche de Geoffroy, Ypsolophus xylostei de Fabricius. La description de Geoffroy est la plus facile et la plus précise: "Sa longueur est de 5 lignes; sa couleur cendrée; ses ailes sont aplaties l'une contre l'autre vers le bout et se relèvent à cet endroit. Le bord intérieur de celles de dessus est blanc, ce qui forme, par la réunion des deux ailes, une bande longitudinale blanche qui se resserre et s'élargit alternativement par endroits. Les antennes sont entrecoupées d'anneaux blancs et cendrés, et l'insecte les porte droites devant lui. ") Cette Teigne n'est uullement spéciale au colza; elle vit sur les giroflées, sur les crucifères en génèral, et ses mołurs paraissent changer suivant le végétal sur lequel elle se développe. Le Journal de la Société angluise d'agriculture (vol. III, p. 68-72), signale le même lépidoptère sous le nom de Cerostoma xylostella, comme un emnemi du turneps; mais ici ses dégâts portent sur les feuilles qui parfois sont courertes de ces chenilles, dont la description est parfaitement conforme à celle que $\mathrm{M}$. Focillon a observée lui-mème.

\section{PARASITES DES CIIENILLES DU COL $Z$ A}

Ce mème journal signale, comme emnemi des chenilles, un ichneumon noir qu'il nomme Campoplex puniscus. M. Focillon ne l'a pas rencontré, mais il a 
trouvé un autre ennemi de la T'eigne du colza. C'est un petit ichneumonide appartenant au grand genre Chalcis de Fabricius, qui lui a paru très-roisin du genre Pteromalus de Latreille, et dont il figure la larve, la chrysalide et l'insecte parfait. La larve, qui a environ 5 millimètres et demi de longueur, vit dans le corps de la chenille et finit par en remplir une grande partie. I. Focillon l'a trourée contenue dans la peau de cette chenille qu'elle occupait entièrement et dont elle détermine la rupture par ses mourements assez brusques. Après cette rupture, elle séjourne quelque temps dans les siliques où on la trouve assez souvent, elle finit par' s'y transformer, pour s'échapper par le trou que la chenille, qui lui a servi de berceau, a percé avant de mourir. D'autres fois, sans doute, la chenille a le temps de se métamorphoser en chrysalide; car on a vu sortir de chrysalides desséchées ce petit Chalcidite, d'un beau vert cuivré. II. Focillon n'insiste pas autrement sur cet ennemi de la Teigne du colza ; peut-être, s'il en comnaissait l'utilité, l'ètudierait-il plus soigneusement; mais, il ne peut s'empêcher de l'arouerici, il est bien loin d'attacher aux parasites des espèces nuisibles l'importance qu'on a cherché à leur domner. On s'est fait, il lui semble, bien des illusions sur les services qu'ils peuvent rendre.

Qu'espère-t-on, dit-il, des parasites? qu'ils modéreront le dévẻloppement des espèces nuisibles. A quelles conditions un tel but peut-il être atteint? Ou bien faudra-t-il que l'homme puisse favoriser le déreloppement de ces paras:tes, ou bien il faudra que ce déreloppement soit naturellement proportionnel à celui des espèces nuisibles. Or, N. Focillon croit que ni l'une ni l'autre de ces conditions 
ne se réalise. Notre pouvoir sur la multiplication des parasites est nul, nous ne partageons pas cette idée. D’un autre côté, il est évidemment faux que ces mêmes ennemis se développent en raison des espèces nuisibles; d'abord ils n'ont pu les modérer assez pour les empêcher' de devenir des fléaux. Ensuite quand ces fléaux existent le nombre de parasites que l'on rencontre au milieu des myriades d'animaux qu'on observe est prodigieusement restreint. Il est donc bon, suivant M. Focillon, de signaler les parasites aux agriculteurs pour qu'ils sachent ce que font cesanimaux au milieu de leurs récoltes; mais les espérances qu'ils peuvent fonder sur eux sont très-illusoires.

\section{VER BLANC DU COLZA}

L'un des ennemis les plus redoutables du colza est un petit Ver blanc découvert par M. Focillon. En ouvrant des siliques, dit ce savant zoologiste, on voit une quantité de petites larves longues de 2 millimètres dans leur plus grande extension, blanche avant la maturité du colza et qui à cette époque passent au jaune orangé clair. Leur corps est aplati, arrondi en arrière, terminé antérieurement par une tête pointue, très-rétractile. Les anneaux sont nettcment marqués par de profonds plis transversaux, chacun d'eux porte une rangée de poils au milieu; une trainée verdâtre suivant la ligne médiane et la trace du canal digestif vu par transparence. Il donne d'ailleurs de 
cette larve une figure hes-grossie et yui fera bien commaitre sa conformation.

Quelque obscure que soil pour II. Focillon la nature de cette larve, les dégâts qu'elle occasionne lui sont parfaitement connus.

Les siliques attaquces par cette petite larve, que, pour plus de facilité, il désignera provisonrement sous le nom de petit ver blanc, présentent d'habitude d'autres lésions qui, par leur constance, semblent favoriser le développement de ce nouvel ennemi. La plus granile partie offre les traces de la chenille de la teigne ou de la larre du coléoptère. II. Focillon en a trouvé une fois deux remplies de petits vers blancs et exemptes des traces dont il parle; mais elles offraient des piqûres si nombreuses du Charançon qu'elles en étaient complétement rabougries. Il croit denc pouvoir établir que généralement les siliques où se deve. loppent les petits Vers blanes sont déjà malades dans quelqu'un de leurs points. Nous retrouverons ce fait plus tard dans l'histoire de cette larve. Quoi qu'il en soit, les siliques qu'elle dévaste se reconnaissent à l'extérieur, parce qu'elles sont souvent déformées et plus ou moins contournées et surtout parce qu'à l'époque de la maturité, au lieu d'offrì' l'aspect jaunissant des siliques qui vont s'ouvrir, elles se dessèchent totalement ou par fraction, en affectant une teinte d'un gris sale qui va en noircissant de plus en plus; les valves de la silique se contournent en se fendant irrégulièrement le long de leurs sutures; enfin tous les signes de la moisissure apparaissent à la surface de la silique, dont la déhiscence ne s'effectue pas normalement et se borne à un bâillement irrégulier rles bords des valves ma- 
lades. Quelquefois la silique n'est attaquée que dans une de ses moitiés, mais l'autre semble toujours avoir souffert de ce voisinage. L'intérieur du fruit malade offre des traces bien plus évidentes : avant la maturité, en ouvrant une des siliques ainsi attaquées, on y aperçoit d'abord vingt à vingtcinq ou quelquefois moins de ces petites larves; les points où elles habitent offrent à toute la face interne du fruit une altération profonde. La membrane interne ou l'endocarpe a perdu l'aspect blanc argenté qui lui est naturel ; elle olfre ume teinte roux verdâtre sale et suinte une liqueur sanieuse roussâtre. Les funicules des graines sont flétris et desséchés et les graines offrent le même aspect; elles perdent de leur volume, se ramassent en plissant leur surface et preunent, au lieu de la coloration brun violet des graines mûres, une teinte J)run rouge clair. Quelques-unes semblent entièrement vidées et sont aplaties comme s'il ne leur restait que leur enveloppe extérieure. Plus tard, à mesure que les bords des valves s'entr'ouvrent, les larves s'échappent et abandonnent les graines malades; parmi ces graines, les unes se détachent et tombent, les autres moisissent dans l'interieur de la silique et s'y attachent plus ou moins complétement. Tels sont les dégâts qu'entraine la présence de ces petites larves, dont M. Focillon n'a pu parvenir à connaitre l'insecte parfait.

Comment agissent-elles pour déterminer ces lésions? c’est là un point assez difficile à bien éclaircir. M. Focillon va dire son opinion actuelle, toute réserve faite de ce que pourront lui apprendre des études ultérieures. Ses obserrations ont eu pour premier objet la cemposition de la bouche de cette larve. Le savant zoologiste donne la figure 
de toute sa tête; il y a vu un cône rétractile divisé transversalement par des plis qui séparent les parties destinées à rentrer les unes après les autres lors de la rétraction. Ce cône charnu se termine par deux petites antennes entre lesquelles se dessine une espèce de bec triangulaire, soutenu à sa base par une charpente cornée, mais dépourvue de toute partie dure propre à la mastication. Une pièce cornée, aplatie et située à la face ventrale du premier anneau du corps semble destinée à limiter les mouvements de ce bec protractile et rétractile. Cette bouche, molle et douée de mouvements énergiques ne lui a paru propre qu'à la succion. M. Focillon pense donc que ces larves, se trouvant toujours dans des siliques malades, y vivent des sucs échappés des blessures des ovules ou des graines; que bientôt leur présence, leurs mouvements, l'état morbide qu'elles entretiennent dans les graines où elles prennent leur nourriture irritent la membrane interne du fruit et déterminent une maladie dont le changement de coloration est un symptôme et qui exsude à l'intérieur de la silique un suc purulent dont la larve continue à se nourrir. Ce suc exsudé est souvent si abondant que l'humidité qu'il répand dans la silique fait germer les graines à peine mùres dans les siliques encore complétement closes. Telle est l'opinion qui résulte pour M. Focillon des faits qu'il a observés et que ses études pourront mettre à sa juste valeur.

M. Focillon n'est pas sans désirer connaitre l'insecte parfait de cette petite larve; mais tous ses efforts ne lui ont jusqu’à présent donné aucune solution, et il s'est vu contraint, par la mort de toutes celles qu'il a voulu élever, de renvoyer cette question à une autre 
épcque. Dans le cours de ses tentatires, M. Focillon s'esı vil trompé par un fait assez curieux. lans un tube où il conservait une cinquantaine de ses larres, il aperçut un jour sept ou huit cocons très-semblables à des pupes, et tels que celui qui a figuré planche 111 , figure 51. Il crut, et la forme, l'organisation de la larve admettaient une pareille hypothèse, il crut avoir la pupe d'un diptère. Après avoir longtemps attendu l'éclosion, il en ourrit une et reconmut qu'elle contenait un hyménoptère noir, parasite de la larve, qui arait récu dans son corps, puis l'ayant fait périr, arait, à l'abri de la peau desséchée en une sorte de coque, subi toutes ses métamorphoses. Le sarant zoologiste se contente de donner la figure de la fausse pupe de ce parasite, fort peu abondant d'ailleur's et qu'il croit sans grande importance.

Quant à l'insecte parfait du petit Ver blanc, M. Focillon rroit inutile de former des conjectures sur ce qu'il peut itre, et il attend l'observation directe dans des circonstances suffisamment farorables. 11 a trouré ces larves en juin et les a conservées vivantes jusqu'en octobre dans des siliques desséchées sur des pieds qu'il avait apportés au laboratoire de l'lustitut agronomique ou dans des tubes et des bocaux nù il a cherché à les élever. 


\section{NOCTUELLES}

La tribu la plus nombreuse de tout l'ordre des lépidoptères est, sans contredit, celle des Noctuéliens.

Les chenilles de ces papillons sont en général glabres ou peu velues, plus ou moins cylindriques et allongées ordinairement munies de dix pattes membraneuses.

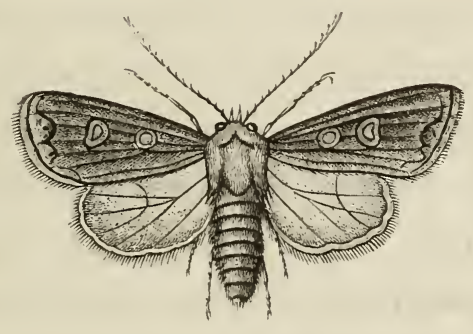

Fig. 69. - Noctuelle.

Elles vivent le plus ordinairement sur des plantes basses. Les unes pour se transformer en chrysalides se filent une coque soyeuse sur les tiges de la plante qui leur a servi de nourriture, ou dans quelque endroit voisin; d'autres, et c'est le plus grand nombre, s'enfoncent en terre pour s'y métamorphoser. Et ce sont celles-là qui décorent les plantes et sont nuisibles at l'agriculture, elles se cachent pendant le jour d'où leur nom de Noctuelles.

Les papillons de ces chenilles sont en général de taille médiocre, de couleur sombre volant peu ou rarement pendant le jour. 
Le groupe des Noctuites se distingue par des antennes sétacées. Palpes peu redressés ; le thorax plan, les ailes antérieures étroites.

\section{NOCTUELLE DES MOISSONS}

(Noctua segetum.)

La Noctuelle des moissons Noctua segetum attaque de préference les betteraves. Néanmoins comme elle n’èpargne pas non plus le blé, nous en parlerons comme insecte nuisible aux céréales. Aux approches de la moisson dit M. Herpin, j'ai trouvé une assez grande quantité de tiges de froment qui renfermaient auprès de l'épi, entre les feuilles, une grosse chenille de 2 centimètres environ de longueur, d'un jaune grisâtre, rayée sur le dos et qui a paru à ce savant observateur être la larve d'une Noctuelle. Cette chenille, ajoute-t-il, qu'on retrouve encore dans les granges plusieurs mois après la récolte, ronge et dévore l'intérieur des grains de blé encore adhérents à l'èpi et laisse entre les feuilles de gros excréments de couleur blanchâtre. M. Herpin déclare n’avoir pu élever cette chenille qui, dit-il, se cache probablement en terre pour se métamorphoser. M. Goureau a constaté que c'était à l'époque de la floraison des blés c'est-à-dire vers le commencement de juillet que la N'octuelle attaquait le blé, elle continue à le ronger jusqu’à l'époque de la moisson. Elle entame le grain dans le sil- 
lon et y perce un trou pour atteindre la substance intérieure dont elle fait sa nourriture. Cette substance ayant la consistance du lait, puis ensuite celle de la bouillie, lui convient dans son premier àge, plus tard à l'approche de la moisson elle ronge la farine dans la graine devenue dure. Les graines attaquées ne conservent quelquefois que la peau; d'autrefois il y reste de la farine mêlée à dles excréments. Cette chenille ne se contente pas d'un seul grain, qui serait insuffisant pour sa nourriture, elle en entame plusieurs, soit du même épillet, soit des épillets roisins.

Voici les transformations diverses que subissent ces chenilles. Elles attendent, pour éclore et sortir des terres, où leur mère a, l'année précédente, déposé ses œufs que les plantes, les betterares surtout deriennent succulentes. Alors des myriades de Vers gris, c'est ainsi que les cultivateurs les dėsignent, mesurant 4 centimètres, au corps lisse, luisant, d'un rert sale, et portant sur chaque anneau de ce corps un point rerruqueux, sortent de la terre, où ils se tiennent enfouis, sans se montrer à la surface. Dès que la nuit viont protéger leurs déprédations, ils se glissent jusqu'à la plante, objet de leur convoitise, en envahissent le collet, et, de leur tête noire, armée de mandibules tranchantes, ils se mettent à la dépecer avec un formidable acharnement. Une fois attaquée par eux, la pauvre plante est perdı, et cependant on ne le soupconnerait pas en la vayant conserver intactes la verdeur et l'intégrité de ses feuilles presque toujours respectées. Les vers gris ne grimpent gaère sur ces feuilles que le soir on la nuil, el n'y touchen que rarement et par caprice. 
Un mois après, les Vers gris, ne laissent derrière ou plutôt au-dessus d'eux que ruine et que mort. Dès ce moment, ils s'enfoncent dans le sol à une profondeur de quelques centimètres, s'y creusent une loge en forme d'œuf et la revêtent à l'intérieur d'une tenture de soie assez solide pour résister aux petits éboulements qui pourraient en compromettre l'architecture. Ils se transforment en chrysalides dans ce nid confortable, et y attendent le printemps de l'année suivante pour subir leur dernière transformation, devenir des papillons, s'accoupler el pondre.

Chaque année le nombre des Vers gris augmente considérablement, et l'on ne saurait prévoir où s'arrêtera l'accroissement de cette maudite engeance.

Dans lenord de la France, où la culture de la betterave a acquis une prodigieuse importance, cette culture se trouve depuis plusieurs années exposée aux ravages du Ver gris. En 1865 la chenille dévastatrice s'est montrée en si prodigieuse quantité, que ses dégâts ont été exercés dans des proportions effrayantes. L'agriculture du Nord a èté gravement atteinte, l'industrie qui amène une partie de la richesse du pays s'est vue menacée. Des personnes éclairées de l'arrondissement de Valenciennes, agriculteurs et industriels ont compris qu'il y avait une question à étudier. C'est alors que le ministre de l'agriculture a chrgé un membre de l'Institut, II. Emile Blanchard, d'aller poursuivre les recherches nécessaires pour être el mesure d'empêcher le retour d'un pareil fléaı. Nous re saurions mieux faire que de relater ici l'intéressant aricle que le savant professeur a ịnséré dans la Revue des ours scienti: 
fiques, le 16 septembre 1865. "Les naturalistes, dit M. Blanchard, sachant le mieux jusqu'à quel point peuvent semultiplier certaines espèces qui trouvent partout autour d'elles une nourriture abondante et les conditions les plus favorables à leur développement, auraient été encore fort surpris en voyant, au mois de juillet de cette année (1865), l'abondance des chenilles de la Noctuelle des moissons (Noctua segetum) dans presque tous les champs de betteraves de l'arrondissement de Valenciennes, et nous savons que cette abondance était à peu près la même dans les arrondissements de Cambrai, de Douai et ailleurs encore. Au collet de chaque betterave, sans aucune exception, on était assuré de trouver une quantité considérable de chenilles : en grattant un peu la terre entre les lignes de betteraves on en mettait à découvert sur tous les points. En certains endroits, il a été possible d'en recueillir plus d'une centaine dans l'espace d'un centimètre carré, et c'est dans une semblable proportion que ces chenilles se trouvaient répandues sur la superficie entière du plus grand nombre des champs.

" Mais dans les environs de Denain, le désastre était poussè à la dernière limite possible. Là, un des grands propriètaires de la localité, M. Crépin-Deslinsel, nous a fait parcourir des étendues considérables de terrain, où, absolument toutes les betteraves avaient été détruites. Il était nécessaire d'observer avec attention pour reconnaitre à la présence de quelques détritus, que la plantation des betteraves avait èté effectuée partout de la manière la plus régulière et la plus complète.

"C'ètait un spectacle affligeant que celui de ces champs 
dévastés. A leur aspect, il devenait facile de se douter des pertes énormes que subiraient plusieurs grands propriétaires, de la situation douloureuse dans laquelle pourraient se trouver les petits cultivateurs, et enfin de la diminution de la quantité de matière première qui serait livrée aux fabriques de sucre, comme de l'anıoindrissement des substances alimentaires destinées aux bestiaux.

"Sur le territoire de Blanc-Misseron, où l'on cultive principalement la chicorée, j’ai vu plusieurs pièces de terre en grande partie dépouillées de leur végétation. Les chicorées avaient été ravagées au collet exactement comme l'ètaient ailleurs les betteraves.

"La Noctuelle des moissons (Noctua segetum) adulte est un papillon d'un brun rougeâtre, dont les ailes présentent une envergure d'environ 4 centimètres. Les ailes supérieures, dont la teinte générale brune ou fauve, un peu variable suivant les individus, ont à leur base une double ligne ondulée, suivie d'une tache brune; au centre, deux autres taches, l'une ronde bordée de noir, l'autre réni-

1 « Lorsque je vis les premières chenilles,j'avais d'abor'd été persuadé qu'elles étaient de l'espèce appelée Noctua segetum; cependant divers entomologistes les ayant examinées pensèrent qu'elles appartenaient à l'espèce voisine connue sous le nom de Noctua exclamationis. Aujourd'luui que nous avons vu l'éclosion de nombreux papillons, toute incertitude possible a disparu. Les différences qui existent entres les Noctua segetum et exclamationis à l'ètat de papillons sautent aux yeux et aucune confusion n'est possible. A l'état de chenilles, au contraire, ces deux espèces qui vivent dans les mêmes conditions et sourent réunies se ressemblent à tel point que les personnes les plus exercées peurent s'y méprendre. Ces deux espèces sont classées par plusieurs entomologistes dans un genre particulier portant le nom d'Agrotis; c'est un démembrement du grand genre Noctuella (Noctua), , 
forme au-dessous des lignes ondulées, et enfin, au bord, une série de taches noires en forme de lumules. Les ailes postérieures sont d'un blanc opalin.

"Cette espèce parait à l'état de chenille dans la première quinzaine du mois de juin, ce qui a été constaté de nouveau cette année par plusieurs des agriculteurs de l'arrondissement de Valenciennes, mais il faut toujours remarquer que cette apparition qui s'effectue pendant la durée de deux ou trois semaines, doit être un peu avancée ou un peu retardée suivant que la température printanière a été plus ou moins élevée.

"Cette chenille, connue dans beaucoup de localités sous le nom de Ver gris, acquiert toute sa croissance dans l'espace de cinq à six semaines. Parvenue à sa plus grande dimension, elle a alors environ 4 centimètres à 4 centimètres et demi de longueur. Tout son corps lisse, luisant, et d'un gris verdâtre assez sombre, porte sur chaque anneau deux rangées transversales de points verruqueux d'un noir brillant, surmontés d'un poil; sa tête est noire avec quelques impressions sur le sommet et les parties de la bouche d'une teinte brunâtre.

"Les chenilles de la Noctuelle des moissons demeurent presque constamment cachées en terre, autour du collet de la racine qu'elles rongent; elles voyagent même bealicoup, pour se porter d'une plante à une autre sans se montrer à la surface, surtout pendant le jour ; en général, c'est seulement après le coucher du soleil que ces chenilles sortent de leur retraite et grimpent sur les feuilles, auxquelles elles ne font pas d'ordinaire de graves atteintes. Ces habitudes expliquent comment plusieurs agriculteurs 
avaient pu demeurer dans la confiance que leurs champs de betterares étaient dans d'excellentes conditions, lorsqu'ils ètaient au contraire dansune situation extrèmement fàcheuse. Si les betterares ètaient déjà volumineuses, malgré l'altération profonde des racines, le feuillage restait néanmoins d'une fort belle apparence. Des betteraves rlont la partie supérieure était fort endommagée avaient poussé une multitude de radicelles, unc sorte de cherelu, qui permettait à la plante de puiser les sucs destinés à la nourrir.

"Dans le courant du mois de juillet les chenilles de la Yoctuelle des moissons, arrivées au terme de leur accroissement, s'enfoncent dans la terre à une profondeur de quelques centimètres, se creusent une loge de forme ovalaire dont elles enduisent les parois arec une sécrétion analogue à la matière soyeuse, et propre à retenir les particules terreuses. Elles ne tardent pas à se transformer en chrrssalides. Dans le mois d'août on a ru éclore des papillons en assez grand nombre. Mais l'éclosion n'a certainement pas été générale, ainsi que j’ai pu m'en convaincre; car, à l'aris, sur une assez grande quantité de chrysalides prorenant de chenilles que j'ai rapportées de Valenciennes, je n'ai obtenu au mois d'août qu'un nombre de papillons relativement assez restreint ; les éclosions se sont arrêtées: les autres n'auront lieu qu'au printemps de l'anmée prochaine. Il est donc probable que, dans les ètés dont la température n'est pas très-chaude, on ne voit paraitre aucun papillon pendant le mois d'août; ce qui explique comment des entomologistes citent la Noctua segetum comme n'ayant qu'une génération par an, et comment d'autres af̣fipmenent qu'elle en a deux, 
( M. Nariage, maire de Thiant, qui s'est occupé avec mI grand zèle et une grande intelligence de la question relative à l'insecte destructeur des betteraves, a fait une observation intéressante au moment des éclosions du mois d'août dernier. Parmi les chrysalides dont il a vu sortir un insecte adulte, il a compté qu'un cinquième d'entre elles lui arait donné un Ichneumon, l'Ichneumon de Panzer (Icheumon Panzeri, - sous-genre Amblyte'es de Gravenhorst), dont tout le corps est noir, avec les deux premier's anneaux à la suite du pédicule de l'abdomen d'un rouge ferrugineux. Ainsi, dans le cas où la proportion serait à peu près la même pour toutes les chrysalides, les quatre cinquièmes encore donneraient des papillons dont la fécondité est connue, c'est-à-dire qu'en l'absence d'efforts combinés on rerrait encore, malgré l'Ichneumon, la dévastation se renouveler l'année prochaine sur une très-grande échelle.

"La Noctua segetum vit à l'état de chenille sur des plantes fort diverses; le fait est depuis longtemps bien connu des entomologistes; c'est un motif pour ne pas attendre ici l'heureux résultat que l'on obtient pour d'autres espèces nuisibles de l'alternance des cultures. Cependant si la Noctua segetum est préjudiciable à plusieurs sortes de cultures, elle ne les attaque pas toutes indifféremment.

( J'ai dû ainsi m'assurer avec le plus grand soin de la présence ou de l'absence de l'insecte qui a été si funeste aux betteraves et aux chicorées, dans presque tout le nord de la France.

„Voici les principales observations que j’ai faites àce sujet dans ḷ'arrondịsement de Valencienṇes, Aux portes mêmẹs 
de Valenciennes, sur l'exploitation de M. Maurice, les champs de betteraves étaient ravagés, dans toute leur ètendue; les pièces de terre qui y confinaient plantées en trèfles et en sainfoin dans une excellente condition; il fut impossible d'y découvrir une seule chenille.

«Sur le territoire d'Urtebize les betteraves étaient partout atteintes, tandis que les champs de blé voisins étaient intacts, et j'ai pris soin de les examiner sur la lisière pour m'assurer que rien n'était endommagé.

"A I)enain, de semblables constatations ont èté faites sur les terres ensemencées en céréales, blé ou avoine.

"A Artres, un habile agronome, excellent observateur, II. d'Haussy, me fit remarquer un champ de blé de la plus belle apparence. L'année dernière, le terrain planté successivement en betteraves, en carottes, etc., avait été entièrement dérasté. Désirant ne croire à l'absence de la chenille, de la Noctua segetum, qu'après un examen complet, le propriétaire m'invita à pousser mon investigation aussi loin qu'il le faudrait sans craindre de perdre quelque peı de blé. Je trouvai toutes les racines examinées parfaitement intactes, aucune chenille ne put être rencontrée dans le sol.

"Quelques personnes m'avaient affirmé que la chenille des betterares n'épargnait rien, pas plu sles céréales que les autres cultures. On pouvait, en effet, en fournir des exemples, mais voici dans quelles conditions je les ai observés.

"Des terres avaient èté plantées en betteraves ou en chicorées dès le commencement du printemps; ces betteraves et ces chicorées avaient été détruites rapidement par les chenilles de la Noctuelle des moissons. Alors, sur ces terres infestées de chenilles qui étaient bien loin du terme de leur 
croissance, avaient été plantés, par exemple, des choux; les choux et les autres crucifères exposés aux ravages de plusieurs espèces de chenilles différentes (Pieris brassicæx, Mamestra brassicæ, Hadena oleracæa) ne sont pas attaqués dans les conditions ordinaires par la Noctua segetum; mais dans des terres remplies de chenilles de cette espèce qui se trouvaient fort affamées, ils avaient été promptement détruits. A Marly, MI. Giraud-Cuvelier m'ont fait examiner une pièce de terre ensemencée en avoine, sur laquelle des betteraves avaient déjà poussé au printemps pour être bientôt détruites; l'avoine, exposée aux atteintes des chenilles qui n'avaient pas d'autre nourriture à leur portée, était rongée aux racines, et alors complétement perdue.

"Dans des conditions semblables, les mêmes faits pouvaient être observés sur un grand nombre d'exploitations.

"Dès le moment oủ les agriculteurs avaient reconnu leur ennemi, plusieurs d'entre eux avaient songé à le détruire. Il était d'un grand intérêt pour la suite de mes études, d'apprendre ce qu'ils avaient déjà essayé, et quels résultats ils avaient obtenu de leurs essais.

"Le lendemain de mon arrivée à Valenciennes, lorsque j'ai en l'honneur de recevoir les personnes qui s'étaient préoccupées des ravages subis par les betteraves, j'ai cru pouvoir leur déclarer en toute assurance que je ne pouvais attendre ancun résultat sérieux dè substances que l'on viendrait à répandre sur les terres. La chenille dévastatrice s'enfonce plus ou moins dans la terre, se loge facilement dans la racine, et échappe ainsi au contact de ces substances. A cela, il faut ajouter que les substances qui ne sont pas nuisibles à la végétation doivent en général demeurer 
inoffensives pour la chenille. Les tentatives déjà faites que me signalèrent plusieurs des personnes qui assistaient à la réunion, vinrent confirmer mon opinion, fondée sur la comnaissance de l'organisation et des conditions d'existence des insectes qu’il s'agissait de combattre. Néanmoins, afin de ne conserver aucun doute relativement à une question aussi importante, j'ai tenu à constater moi-même sur les lieux la situation des champs où les expériences avaient ité faites.

"Sur une exploitation située aux portes de Valenciennes, j’ai visité en compagnie de II. le docteur Abel Stiévenart denx pièces de betterares extrèmement raragées. Dans l'me, d'me conlenance de 2 hectares, on avait, sur une grande étendue, couvert le collet de chaque betterave de plâtre imprégné d'acide chlorhỵdrique. En levant les plàtras, on trourait en abondance les chenilles, qui semblaient aroir trouré des abris à leur convenance. Le proprictaire constata arec nous que l'effet était absolument nul. La mème obserration eut lieu dans les endroits où l'on avait répandu en abonrlance des résidus infects do chair et d'os bouillis.

"Le 10 juillet, M. Stiérenart et moi, nous nous sommes rendus à Artres, oủ M. d'Haussy s'est empressé de nous faire roir, sur sa magnifique exploitation, combien araient été sans effet les diverses matières répandues sur les terres, dans le but de faire périr les chenilles. Un champ de betterares avait été courert de suie, et les betterares n'étaient pas moins ravagées qu'ailleurs. Sur d'autres terres, on avait répandu de la vinasse de distillerie, ou du purin, toujours sans résultat. 
"A Denain, chez M. Crépin-Deslinsel, on avait fait aussi usage, en plusieurs endroits et sans aucum avantage, du purin, de la chaux, de cendres pyriteuses.

"Des citations semblables pourraient ètre fort multipliées. Qu'il me suffise de rappeler qu'un agriculteur de l'arrondissement de Cambrai, M. Ed. Boulanger, maire de Doignies, a employé, sans plus de succès, les décoctions d'aloès et de feuilles de nover. (Impartial de Cambrai, 12 juillet 1865.)

"On m’a cité des cultivateurs qui, après avoir observé que la chenille de la Noctua segetum rongeait principalement le collet de la betterave, avait eu l'idée de faire $\mathrm{m}$ petit monticule de terre sur chaque pied. Ils avaient éti bientôt amenés à renoncer à cette pratique. Les betteraves ne pouvaient, en effet, se trouver préservées par les monticules de terre, les chenilles de la Noctua segetum se tiennent presque constamment cachées, et elles circulent dans la terre meuble arec la plus grande facilité, ce qui n'a pas échappé à l'attention de plusieurs des observateurs de l'arrondissement de Valenciennes.

“ En supposant inévitable la présence de la chenille de la Noctua segetum dans les champs de betterares, il est à présent reconnu que le préjudice qu'elle cause peut être plus ou moins grand; que les betteraves plantées les premières souffrent moins que celles qui ont été semées les dernières. Il a èté recomnu que le fait était général.

( En poursuivant mes investigations, j’ai été bientôt frappé en effet de la différence que présentaient, sous le rapport de la dévastation, divers champs de betteraves infestés par un nombre de chenilles à peu près égal. 
"Ainsi chez II.M. Giraud-Cuvelier, à Marly, nous avons visité une pièce de 4 hectares, ensemencée le 6 avril, qui avait médiocrement souffert, tandis que les pertes étaient beaucoup plus considérables dans une autre pièce de 12 hectares, qui n'avait été ensemencée que le 28 avril.

"Sur l'exploitation de M. Maurice, à Valenciemnes, une différence analogue a èté remarquée entre deux pièces de terre ensemencées, l'une le 8 avril, l'autre le 25 du mème mois.

"Chez M. d'Haussy, à Artres, les betteraves plantées dans les premiers jours d'avril, étaient égalemeut dans de moins mauvaises conditions que celles dont la plantation arait été faite du 22 au 24 , et dans un champ replanté vers le 15 mai, les betterares ètaient presque entièrement détruites. De semblables constatations ont eu lieu dans d'autres localités, et notamment, à Denain; sur les terres de MII. Deslinsel, Gouvion-Deroy, etc. Déjà plusieurs agriculteurs, par leur propre observation, en étaient venus à ne plus douter que les betteraves plantées de bonne heure résistaient mieux que les autres. Ils m'en avaient fait la remarque. Je puis citer MI. Crépin-Deslinsel et Baillet, à Denain ; M. A. Brabant, à Onnaing; M. Delobel, à Famars; M. Mocq, à Haulchin; M. Bénard, fabricant de sucre à Solemmes, etc., etc. la raison de cette différence devait leur échapper, mais l'explication était facile à trourer pour un naturaliste, et il importait qu'elle füt connue de tous les cultivateurs pour empêcher certains d'entre eux d'attribuer à des circonstances fortuites la différence dans l'ètendue des ravages.

"Les papillons éclosent vers la fin de mai, ou dans les 
premiers jours de juin, un peu plus tôt ou un peu plus tard, suivant la température. Les œufs sont pondus bientot après la naissance des papillons, et les jeunes chenilles paraissent cinsuite au bout de huit ou neuf jours. Les betteraves plantées tard sont encore très-petites lorsque les chenilles conmencent à les attaquer, elles se trouvent détruites dans un très-court espace de temps ; les betteraves plantées au commencement d'avril étant déjà grosses dans le mois de juin, les chenilles qui les rongent, les altèrent plus ou moins, mais ne les détruisent pas.

"Ce sera donc toujours une bonne mesure à prendre que de semer les betteraves aussitôt que le permettront les exigences des exploitations agricoles.

"Il est un autre palliatif, déjà mis en pratique sur quelques points par des agronomes de l'arrondissement de Valenciennes, dont il importe de tenir compte. Les chenilles de la Noctua segetum se déplacent beaucoup, surtout lorsque la nourriture vient à leur faire défaut. On les voit alors se porter à de grandes listances. Abandomnant des terres où elles ont à peu près détruit toute la régétation, elles émigrent pour atteindre des champs moins dérastés. A Denain, II. Crépin-Deslinsel avait fait pratiquer des rigoles larges d'environ 50 centimètres, profondes d'environ 1 mètre, à parois bien perpendiculaires; dans ces rigoles, des millions de chenilles étaient venues tomber et s'entasser les unes sur les autres. Incapables de remonter le long des parois des rigoles; elles s'entre-dèvoraient, s'écrasaient par leur propre poids, et périssaient, comme le témoignaient les exhalaisons répandues par leurs corps en putréfaction. 
(IIII. Hamnette frères, à Monchoux, m’ont déclaré de leur côté, qu'ayant établi un ruisseau pour empècher les chenilles de passer d'un champ dans un autre, ils en araient récolté de 50 à 50 litres par jour.

"Je dois m'occuper encore de la valeur de quelques moyens qui ont été mis en pratique ou proposés pour la destruction de l'espèce nuisib'e.

" L'idèe de faire recueillir les chenilles ne pouvait manquer de se produire. A Denain, M. Gouvion-I)eroy et III. Baillet frères, ont entrepris de faire ramasser les chenilles à deux ou trois reprises différentes. Le moyen de destruction est infaillible pour les individus que l'on parvient à saisir. Mais il y aurait déjà à examiner si beaucoup de cultivateurs seraient disposés à supporter les frais d'uu échenillage à la main, qui doit ètre assez dispendieux, mème dans le cas où un champ pourrait être entièrement débarrassé de ses hôtes malfaisants. Or, la connaissance des habitudes de l'insecte derait éloigner de moi toute pensée de recommander l'échenillage. Les larves de li Noctuelle se tenant presque constamment en terre et parfois à une distance assez grande de la plante, il était évident que le plus grand nombre des chenilles devait échapper à une recherche mème minutieuse. En effet, à Denain, MII. Stiẻvenart, Nariage, Crépin-Deslinsel, Baillet et quelques autres personnes ont constaté avec moi que les chamıs les mieux échenillés, pour ètre un peu moins malades que les autres, restaient encore infestés sur tous les points par une foule de chenilles.

"Je troure aussi dans $\mathbf{m}$ article de $\mathrm{N}$. Ed. Boulanger, maire de Doignies, inséré dans l'Impartial de Cambrai, 
que " la chasse à la main fatigue trop les hommes et coute "trop cher."

"Je crois avoir à peine besoin de rappeler les tentatives faites avec les poulaillers ambulants. $\Lambda$ mon arrive à Valenciennes, j’ai trouvé tout le monde à peu près fixé a cet égard; les volailles dévorent les feuilles de betteraves en mème temps que les chenilles. Celles qui ont mangé do trop grandes quantités de chenilles sont rendues malades et souvent ne tardent pas à périr.

«En présence de difficultés probablenıent insurmontables pour opérer la destruction des chenilles, plusieurs persomnes ont été d'avis qu'il fallait songer à détruire l'espèce lorsqu'elle est à l'état de papillon. M. Stiévenart (deuxième' séance de la commission instituée à Valenciennes pour l'étude. de l'espèce nuisible aux betteraves) estime que l'on atteindrait le but en allumant dans les champs, et d'une manière générale, des feux. On sait en effet que la lumière attire la plupart des insectes nocturnes. Un autre membre de la commission (troisième séance, 17 aoùt) a rappelé à l'appui de l'avis émis par M. Stiévenart, la recommandation faite par Roberjot, d'allumer de grands feux clairs et élevés pour détruire la Pyrale de la vigne ${ }^{1}$. Certes, si des personnes de l'arrondissement de Valenciemmes veulent renouveler l'expérience pour la Noctua segetum, on en tirera cet avantage que tout le monde pourra être bientôt complétement fixé sur la valeur du procédé qu'on recommande aujourd'hui. Mais, dès à présent, je crois pouvon'

1 Roberjot (l'abbé), Sur un moyen propre à détruire les chenilles qui ravagent la vigne. - Némoires de la Société royale d'agriculture de Paris; annéc 1787, trimestre du printenps, p. 193. 
déjà dire que j’ai lieu de ne pas fonder de grandes espérances de ce côté. On a essayé en effet de l'emploi des feux pour la destruction de la Pyrale. En 1857, par exemple, les vignobles du Màconnais étaient ravagés dans des proportions formidables; on se souvint de la recommandation de Roberjot, et aussitôt se manifesta l'espérance qu'en généralisant l'emploi des feux on arriverait à une prompte destruction de la Pyrale. Feux de bois, feux de paille furent allumés le soir; on ne tarda pas à reconnaitre qu'avec de larges lampions, les papillons se noyant dans l'huile ou la graisse fondue, étaient détruits en plus grand nombre. Mais bientôt la dépense parut considérable, et parut immense le travail nécessaire pour disposer, allumer, entretenir les feux. La durée de l'éclosion des insectes sous leur forme dernière, étant d'environ trois semaines, la nécessité d'allumer une grande quantité de lumières sur d’immenses étendues, les plus décidés parmi les propriétaires de vignobles sentirent faiblir leur résolution de tout exterminer à l'aide d'un semblable moyen. M. Victor Audouin, chargé par le ministre de l'agriculture d'étudier la Pyrale de la vigne, avait suivi les expériences avec le plus grand soin; il en arriva promptement à conclure que l'emploi des feux offrait une foule de difficultés et la probabilité d'un succès fort incomplet ${ }^{1}$. En effet, s'il est vrai que beaucoup de papillons nocturnes viemnent se brûler aux lumières, il est incontestable que tous n'y sont pas pris. Parmi les papillons détruits par ce moyen, on oublie

1 Victor Audouin, Histoire des insectes misibles à la vigne el particulièrement de la Pyrale, p. 242 et suivantes. Paris, in- $4^{\circ}, 18$ ' 2. 
ensuite que la plus grande part est détruite sans profit pour la culture. Les femelles, particulièrement, lorsqu'elles naissent étant alourdies par leurs œufs, volent peu; on prend donc, surtout à l'aide des feux, des insectes qui ont déposé leur ponte, des individus, en un mot, dont l'existence près de son terme est désormais indifférente.

"Si des observations suivies sur la Pyrale de la rigne ont conduit à considérer l'emploi des feux comme un moyen presque impraticable sur une grande échelle et dans tous les cas d'une efficacité assez faible, que doit-on penser de ce moyen pour la destruction de la Noctuelle préjudiciable aux betterares. Les lumières attirent beaucoup plus les Pyrales et les Phalénes que les Noctuelles. Celles-ci ayant des ailes moins amples que les premières, relatirement au volume de leur corps, leur vol est moins fréquent, moins rapide, ce qui nous proure d'arance que les Noctuelles, attirées par les feux, seront en quantité assez médiocre, comparativement au nombre des individus répaurlus dans les champs.

"Après avoir rappelé les diverses tentatives faites pour détruire la Noctua segetum, après avoir supputé ce que l'on doit attendre des moyens proposés pour la destruction de l'insecte, soit à l'état de papillon, soit à l'état de chenille, et avoir reconnu l'insuffisance de ces moyens, il importe au plus haut degré de nous préoccuper de la manière d'arriver sûrement à préserver la culture des rarages de l'insecte.

" Est-il possible de parrenir au but par des moyeus vraiment pratiques? C'est avec assurance que je répondrai oui. Seulement, ce qui est absolument nécessaire, c'est de 
comnaitre les moindres détails de la vie de l'animal sous toutes ses formes. Déjả sous ce rapport nous sommes très-avancés, mais il reste néanmoins quelques faits à observer, peut-ètre quelques expériences à poursuive et arec les connaissances actuellement acquises, il sera facile de compléter les observations, et d'expérimenter arec de grandes chances d'obtenir d'heureux résultats. Ainsi nnns sarons que les jeunes chenilles se montrent dans les premier's jours de juin, qu'elles arrivent an terme de leur croissance vers le milieu de juillet, qu'elles se transforment alors en chrvsalides et que des papillons paraissent dans le mois d'aoùt; mais suivant toute apparence la plupart des papillons ne doirent éclore que l'année suivante dans le courant du mois de mai, un peu plus tòt ou un peu plus tard, suivant le degré de la température du printemps.

(Les papillons éclos au mois d'aoùt domnent nécessairement lieu à une seconde génération de chenilles destinées à se transformer en chrysalides vers la fin de septembre. Seulement ces chenilles, à cause de leur nombre moindre qu'au printemps, doirent, surtout en l'ètat des cultures, ìtre moins dangereuses que celles de la première génération.

"La destruction directe des chenilles nous semble hors de toute possibilité; la destruction à l'état de papillons parait tout à fait impraticable.

"Enprésence de cette situation, il devient à peu près érident qu'il faut songer à la chrrssalide, à l'éclosion des papillons et aux œufs.

" Je ne puis affirmer encore d'une manière absolue arec 
quel degré d'efficacité il sera possible d'agir pour détruire l'insecte lorsqu'il est à l'état de chrysalide. Cependant j'entrevois déjà une grande probabilité de succès si des efforts combinés sont obtenus de la part des agriculteurs.

"Lorsque aumois d'octobre commencent les labourages, il deriendra sans doute assez facile de mettre à décourert les chrysalides et de les faire enlever par des enfants. Ce serait dans tous les cas une opération beaucoup plus efficace que celle de l'enlèvement des chenilles. Néanmoins, j'aurai besoin besoin de me rendre sur les lieux au moment oủ les terres nues derront être remuées, pour apprécier exactement les opérations auxquelles on pourra se livrer arec le plus d'arantage, ne me dissimulant pas ici la possibilité de certaines difficultés. Il est une expérience que j'ai le plus grand désir de tenter, car, si l'expériènce était couronnée de succès, le résultat serait complet. Nous savons, et aujourd'hui plusieurs personnes de l'arrondissement de Valenciennes l'ont constaté, que les chrysalides de la Noctua regetum sont enfoncées dans la terre à une profondeur de quelques centimètres seulement. Pour que les papillons à peine éclos, puissent traverser la couche de terre qui les sépare de la surface, il faut que cette terre soit très-meuble. 0 si un tassement superficiel de la terre peut être opéré sans de grands embarras pour la culture, les papillons, incapables de percer un sol résistant, devront périr sans aroir réussi à se montrer au dehors. J'ai demandé à divers agriculteurs s'ils croyaient à la possibilité le faire exécuter sans grand inconvénient un tassement superficiel du sol, en leur exposant l'arantage immense 
que j’ètais fondé à espérer de cette opération. Plusieurs agriculteurs, à la vérité, au premier abord, ont cru voir des difficultés pratiques de nature à faire renoncer de suite à une semblable opération, mais l'idèe a été accueillie par quelques-uns et je me trouve ainsi assuré de pouroir constater les fruits que l'on doit en attendre. Dans le raffermissement de la couche superficielle du sol on trouverait encore un autre avantage que celui d'empêcher la sortie des papillons. Lorsqu'il y aurait des chenilles, ces chenilles qui ne peuvent vivre à découvert pendant la chaleur du jour, parviendraient difficilement à s'abriter et à circuler dans un sol trop ferme et de la sorte beaucoup d'entre elles viendraient à périr.

"Maintenant, si tous les moyens ayant pour but de détruire les chrysalides et d'empêcher la sortie des papillons ne réussissaient que d'une manière imparfaite, il nous resterait encore un moyen absolument sûr pour nous débarrasser de l'insecte nuisible; ce serait de recueillir les pontes au printemps avant l'éclosion des chenilles. Quelques observations préalables seront seules nécessaires. Il suffira de bien reconnaitre l'endroit où les pontes sont déposées. Les enlever restera une opération fort simple, comparativement à l'échenillage et d'une efficacité absolue.

"Les papillons déposent leurs œufs en paquets sur les plantes, c'est seulement dans des circonstances tout à fait accidentelles qu'ils les laissent tomber au hasard, A la fin de mai, et dans les premiers jours de juin, comme les feuilles de betteraves ne sont pas encore très-développées, on est assuré de pouroir faire aisément 
les observations préliminaires et entreprendre aussitôt le travail capable de mettre les champs de betteraves à l'abri du fléau dont ils ont tant souffert cette année.

"C'est ainsi que je dirai, avec une confiance entière, aux agriculteurs et aux industriels du Nord : Avec votre concours qui, je le sais, ne me fera point défaut, le but que vous poursuivez sera atteint, la calamité qui vous a affligés ne se renouvellera pas, tant que votre vigilance ne viendra point à s'endormir.»

\section{OCHSENHEIMERIE}

(Ochsenheimeria taurella).

Un insecte qui a une certaine analogie avec la Noctuelle des blès, a èté décrit cette année dans La vie des champs, sous la dénomination d'Ochsenheimeria taurella, nom d'un célebre entomologiste lequel a observé le premier les dégâts causès par cet insecte aux environs de Vienne.

Dès le mois de mai vous voyez parfois dans les champs de blé et de seigle, au milieu des innombrables épis bien verts, qui se balancent au gré du vent, des épis qui out subitement blanchi. Vous interrogez les gens du pays sur la cause de la présence de ces épis blancs et vides. Ils vous répondent: Nous n’en savons rien! Ou bien: C'est l'hiver qui a fait cela.

L'homme instruit, l'observateur, l'agronome ne se contentent pas de ces réponses. Ils examinent et ils trouvent que res épis blanes se retirent très-facilement de 
leur gaine. Ils examinent le point où la rupture s'est faite ct ils roient que la tige a été entièrement, ou en partie coupée à peu de distance au-dessus du nœud supérieur. On derine que c'est un insecte perfide qui a fait ces dégàts. Mais où s'est-il caché? On troure bien parfois, au fond de la gaine ses excréments desséchés !... Mais l'auteur de tout cela a disparu. Après aroir attentivement examiné vingt à trente de ces épis blancs, ou plutôt l'intérieur de leur tige jusqu'au point où elle a été coupée, rous finissez par décourrir un petit rert mort, long de 6 à 8 millimètres.

I)'autres fois rous êtes plus heureux et rous trourez l'ennemi rivant occupé à rogner la tige. Ce petit ver ou plutôt chenille, car elle a seize pattes et donne naissance à un papillon, porte le nom que nous renons d'écrire. Elle arait échappé jusqu’à présent aux recherches des naturalistes. Elle n'est pas née dans ce point de la tige de la céréale. C'est un hôte qui arrice du dehor's pour faire ses repas dérastateurs. Elle est jaune paille, garnie de petits poils fins. Sa tète est petite, noiràtre. Une petite tache grise et luisante se roit sur son onzième anneau, et deux lignes noires règnent sur ses flancs.

Ce petit ètre arrice du sol; il monte le long de la tige. I.'épi atteint, il se glisse entre la tige et sa gaine et descend jusquau noud supérieur. Là il troure la tige trèstendre, et tout à fait de son gêt. Il la ronge, passe quelque temps en abondants festins. Puis, lorsqu'il n'y a plus rien qui lui convienne, il quitte la tige par le mème chemin qui l'a amené, et il ra risiter une autre tige.

Cependant tout n'est pas bonheur dans son existence. l'endant ses fréquents voyages, la petite chenịlle est fré- 
quemment surprise par un autre insecte du gemre guêpes, par les Ichneumons, qui lui percent le rentre pour déposer leurs œufs, d'où sortent de petits êtres qui se nourrissent de sa substance, après l'avoir fait périr. Voilà pourquoi on troure parfois ces chenilles mortes au milieu de leurs festins.

C'est grâce à ces mêmes intrépides Ichmeumons que nos champs de choux sont débarrassés des 19/20 des chenilles qui, sans ces vigilants bienfaiteurs de nos cultures, les dévoreraient tous les ans par légions innombrables. Si notre petite chenille échappe heureusement it son ennemie, elle se réfugie, au commencement de juin, dans la gaine supérieure près rle l'épi. La elle s'entoure d'un tissu solide et soyeux, pour se transformer en peu de jours en chrysalyde de 6 à 8 millmètres de longueur, très-agile, quand on la touche, de couleur jaune paille, avec la tête brunàtre. De cette chrysalide sort un petit papillon au bout de quatre semaines. Celui-ci a 5 millimetres de longueur, les ailes étant déployées. Se tête est courerte de longs poils jamâtres, à pointes noires. Ses ailes antérieures sont grises, les postérieures blanches, bordées de noir. Ailes et dos sont couverts d'écailles, l'abdomen est gris nciritre.

Ce papillon voltige pendant plusieurs mois dans les champs ; il attend les semailles d'automme et la levée des premières céréales. Alors la femelle dépose $u$ o'uf daus chague jeune tige de blé, de seigle et probablement d'autres graminées qu'elle visite. Il sort de cet œuf une petite chenille verte comme la jeune plante qu'elle habite et dont elle ronge le cœur, c’est-à-dire la partie la plus tendre. Cela étant fait, elle descend à terre, va chercher une autre. 
plante et lui en fait autant. Elle continue ainsi ses royages et fait périr toutes les plantes qu'elle visite. Enfin l'hiver arrive; la neige, les gelées s'opposent à ses voyages et à ses dégâts. Alors elle va se cacher au fond de la tige, tout près du collet de la plante, et passe la froide saison tranquillement blotlie dans cette retraite.

Dès qu'arrive le printemps et que les tiges commencent à s'allonger, le petit prisonnier quitte sa demeure, grimpe au haut de la tige et va ronger la partie tendre de la tige qui se trouve au-dessus du nœud supérieur. Lorsqu'il n'y a plus rien de son goût à manger, elle descend la tige et va en trouver une autre. Ses dégâts se répartissent donc sur deux saisons : pendant l'automne elle attaque et fait périr un grand nombre de jeunes plants des céréales; au printemps et pendant un partie de l’été, elle coupe en deux un grand nombre de tiges qui dès lors sont perdues pour le cultivaleur. Enfin, au mois de juin, elle se transforme en chrysalide d'où sort un papillon au mois de juillet, ainsi que nous l'avons déjà dit. Telle est la vie de ce petit ennemi de nos céréales. Comment l'empêcher de faire ses dégàts?... Ici commence l'embarras et nous sentons toute l'impuissance de nos moyens de défense. Pendant l'automne il voyage de jeune plante en jeune plante. Pouvons-nous le saisir dans ses excursions? Non, nous ne le pouvons pas et nous n'arons qu'un parti à prendre : celui de le livrer à ses ennemis naturels, aux petits oiseaux, à l'alouette en particulier. Tout l'hiver il est caché dans le cœur de la plante. Impossible encore de l'atteindre. Le printemps et l'été il recommence ses voyages de tige à tige. 
Le mieux serait, il nous semble, de rouler énergiquement les jeunes céréales au printemps, lorsqu'elles commencent à s'élever. On raffermirait en même temps le sol déchaussé par les gelées de l'hiver ; on plomberait la terre, ce qui est reconnu comme une excellente pratique, et l'on aurait la chance d'écraser par le rouleau un certain nombre de ces petits malfaiteurs.

\section{NOCTUELLE GLYPIIQUE}

Joigneaux a décrit cette Noctuelle qui, appartenant à la division des nocturnes, vole en abondance pendant le jour sur les champs de trèfle, de luzerne où a vécu sa chenille. La Noctuelle glyphique a 30 millimètres d'envergure; le fond de ses ailes est d'un gris brun, avec deux taches irrégulières cerclées d'un cordon gris clair sur les ailes supérieures et de taches d'un jaune très-pâle sur les inférieures.

La chenille est jaune, avec des lignes longitudinales obscures. Elle apparait deux fois dans l'année, d'abord dans le courant de juillet puis en septembre. Les chenilles de la seconde génération passent l'hiver à l'état de chrysalides pour se transformer en papillons au mois de mai de l'année suivante. 


\section{BOMBYX DE LA LUZERNE}

(Bombyx trifolii.)

Le Bombyx de la luzerne est un papillon de nuit, et par conséquent ayant tous les caractères particuliers à cette tribu des lépidoptères: ailes abaissées au repos, antemnes massives et barbelées. Il porte, commesigne distinctif, une bande à la base des ailes supérieures et une raie transversale obscure sur les ailes inférieures.

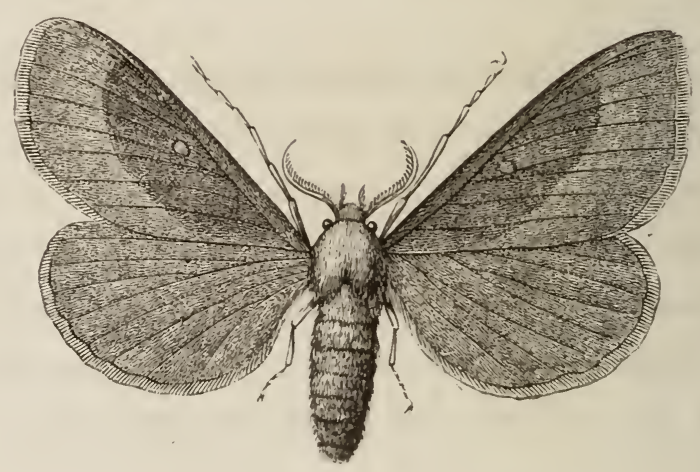

Fig. 70. - Rombyx de la luzerne.

La chenille sort d'un óuf pondu isolément par la femelle, et elle est hérissée de poils noirs. On la rencontre au mois de juin, et elle continue à vivre sur la luzerne jusqu'au commencement de juillet.

Parvenue alors à toute sa croissance, elle se file un cccon d'une toile de soie lâche au milieu des feuilles sèches ou des fragments d'herbe répandus sur le sol. Ou bien elle s'enfonce dans la terre à 15 centimètres de profon- 
deur et se change en chrysalide dans un cocon solide, ovale, couleur d'ocre brun, ou elle passe l'hiver. du printemps suivant, l'insecte parfait brise sa prison et prend la clef des champs.

L'unique inoyen d'arrèter les dégàts, lorsqu'ils deviennent par trop graves, c'est de suspendre la culture de la luzerne.

\section{BOMBYX DU TREFLE}

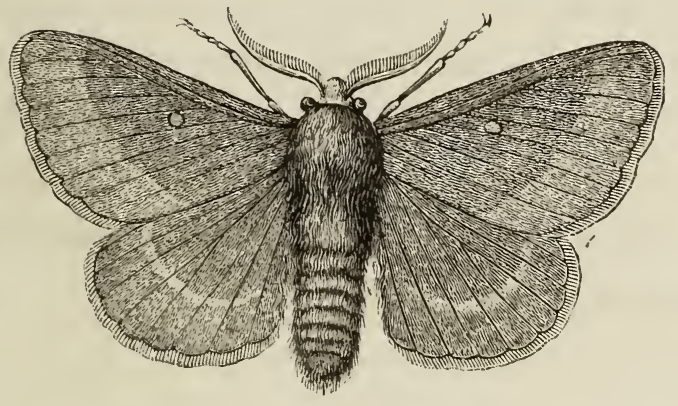

Fig. 7ı. - Bombyx du tréfle.

L'analogie avec le Bombyx de la luzerne est telle qu'il n'en forme qu'une variété. Et ce qui est vrai de l'un est vrai de l'autre.

\section{PSYGIE STOMOXELLE}

La l'syché stomoxelle appartient à la classe des papillons nocturnes et y forme une tribu des psychides; elle n'attaque ni les arbres ni les fruits, mais elle cause dans 
les prairies des ravages dont on a longtemps ignoré la cause. Depuis 1858, M. Melibet, secrétaire de la Socièté d'agriculture du Puy, l'a signalé comme très-nuisible aux prairies de ce pays.

La femelle est aptère et le mâle seul, dit Vilne Edwards, a la faculté de se déplacer par le vol. Il en résulte que les œufs pondus par cet insecte destructeur doivent se trouver dans les lieux mêmes où ils viennent d'exercer leurs ravages. Par conséquent, si on brûlait sur place des herbes dans les endroits ravagés, on pourrait espérer détruire la source du mal.

Cet insecte a les antennes plumeuses ou pictinées, le corps très-relu, les ailes chargées de peu d'écailles et souvent diaphanes. La Chenille aptère est vermiforme, et ne sort de son fourreau ni pour s'accoupler ni pour pondre; elle est glabre décolorée; les trois premiers anneaux de son corps sont ornés, le reste mou.

\section{PIERIDE DU CHOU}

(Papillon blanc du chou. - Pieris brassicæ.)

L'homme, en développant les plantes fourragères et potagères, a multipliè plusieurs espèces d'insectes nuisibles de la famille des Piérides, qui constituent un gemre nombreux de la tribu des papilioniens et très-communs dans notre pays. Le genre Pieris se distingue par des antennes assez longues, à massue comprimée, un peu coniques. 
Palpes assez longs un pen écartés, très-herissés; ce dernier article fort grèle. Ailes arrondies.

Il yen a trois espéces qu'il est facile de discerner i jremière rue ; le grand, le petit et le blanc veiné de vert. Ce I'est pas du reste le chou seul qui souffre de leurs déprédations; le turneps, le cresson, la rave et les navets, les carottes ne sont pas à l'abri de leur atteinte.

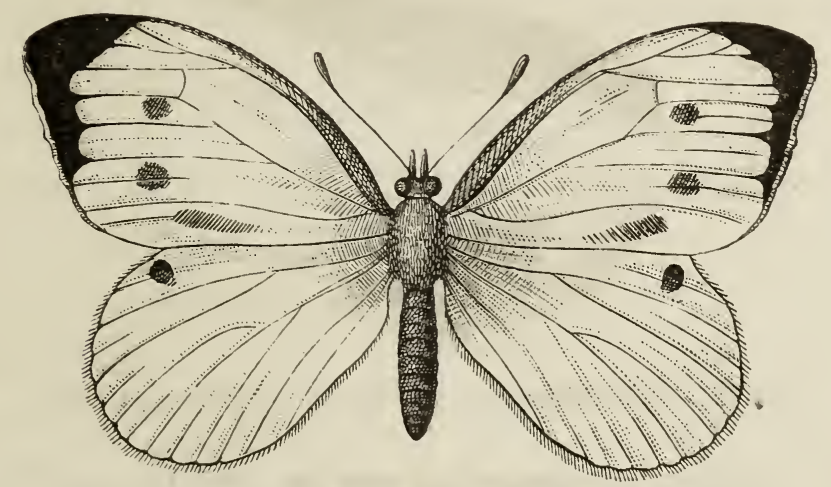

Fìn. 72. - Piéride du chou.

Le grand et le petitpapillon blanc se ressemblent a tous les points de vue, sauf la taille. II est inutile de s'etendre sur les différences légères qui les séparent, puisqu’ils sont l'un et l'autre fort communs et très-connus : le grand papillon a les ailes blanches et le corps noir; le petit a l'extrémité des ailes supérieures noires.

Dans les trois espèces dont il s'agit ici, la femelle dépose ses cufs sur le revers de la feuille de chou. Ils sont longs, jaunâtres, de la forme d'un pain de sucre, cannelés et striés transversalement et plautés debout. L’analogie jusque-là sauteaux yeux, mais elle finit quand le moment de 
l'éclosion est venu. La chenille du grand papillon est d'une couleur cendrée bleuàtre; celle du petit est d'une teinte vert sombre et celle du blanc veiné porte une nuance d'un vert délicat.

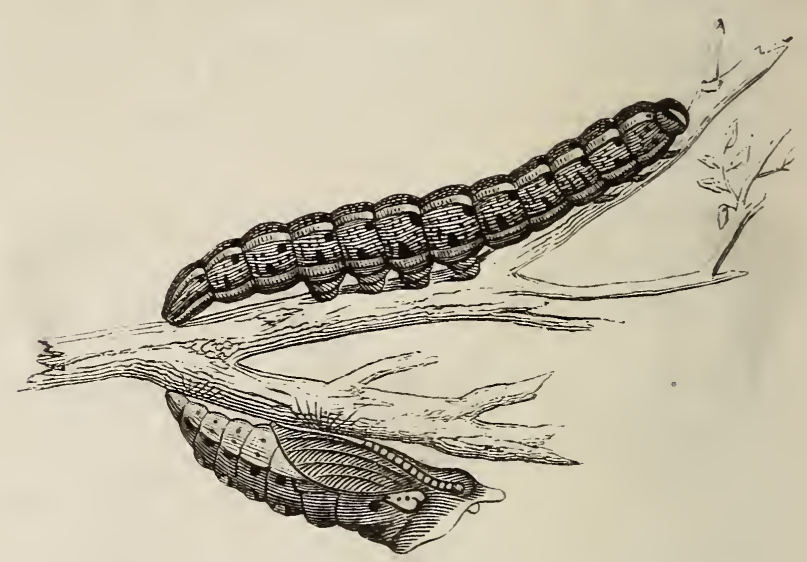

Fig. 75. - Cilienille et chrysalide de la Piéride du clıu.

Cies chenilles se répandent sur les feuilles sans s'écalter beaucoup les unes des autres; elles les rongent, les percent et en consomment une notable quantité, car elles sont très-roraces et en mangent chaque jour environ le double de leur poids. Elles subissent ensuite leurs transformations; ne se filent aucune espèce de cocon, agissant en cela du reste comme toute la famille des papillons diurnes, et se contentent de s'attacher à mi-corps par. un fil sur un rameau ou sur une feuille.

Pour l'horticulteur, ces insectes ne sont plus à craindre ni sous forme de chrysalide ni sous forme de papillon, puisqu'ils ne mangent pas dans le premier cas, et qu'ils vivent du suc des fleurs dans le second. Reste à poursuivre néanmoins la recherche de la chrysalide qui se niche 
derrière les treillages, au-dessous des corniches, atin de prévenir la multiplication. On fait la chasse également aux œufs plaqués sur le revers des feuilles.

La chenille a pour ennemis de petits lchneumons qui se logent dans son corps, s'y développent et sortent de là insectes parfaits.

$1^{\circ}$ Le Microgastre aggloméré. On doit bien se garder de tuer cet utile auxiliaire et on fera bien au contraire de te multiplier dans son jardin en y transportant les masses de cocons agglomérés que l'on rencontre fréquemment daus la campagne fixés contre les murs, les pierres et les plantes, et qui devront donner l'Ichnemmon microgastre.

$2^{\circ}$ Le Pimpla dont la femelle dépose les oufs sur les côtés de la chrysalide; elle en pond de 200 a 300 . Les petites larves entrent dans le corps de la chrysalide, se nourrissent de sa substance, et éclosent insectes parfaits au bout de quinze jours en été.

Résumant les moyens de garer les plantations contre les tribus voraces du papillon blanc, nous dirons qu'il faut écraser les œufs, rechercher les chenilles, prendre le papillon au filet, s'aider surtout, autant que possible, des précieux auxiliaires que la nature nous offre dans les Ichneumons

\section{PAPILLON MACHAON}

(Papilio machaon.)

Le papillon Machaon est un lépidoptère de la f́anille des papilionides qui comprend le gemre papillon propre= 
ment dit (papilio), dont les espèces connues s'élèvent déjà à plus de deux cent cinquante. Tous les insectes de ce genre ont une grande taille.

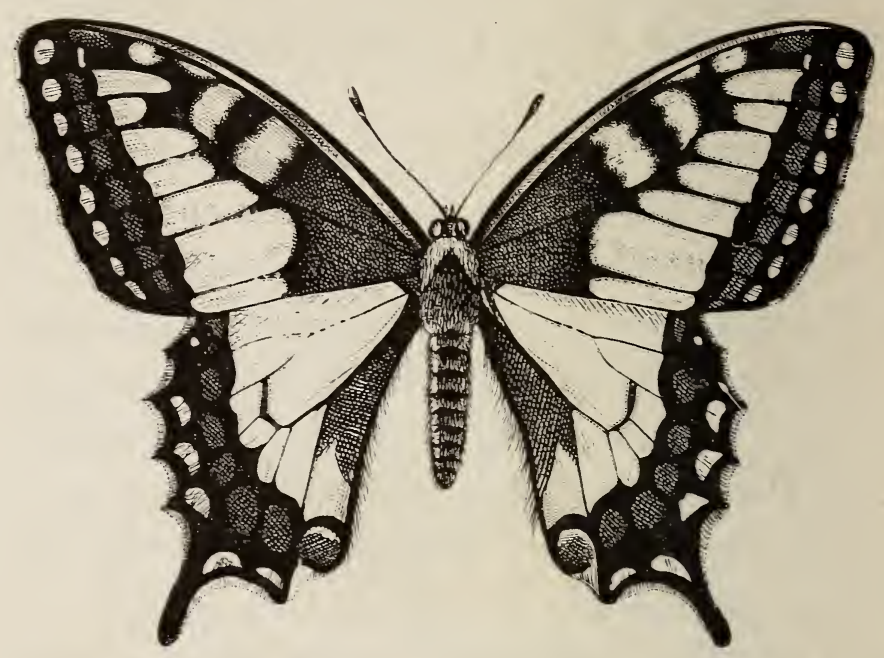

Fig. 74. - Papillon machaon.

l'endant la grande chaleur, on rencontre assez sourent ce beau papillon, aux ailes bizarrement decoupées et aux couleurs royantes, appartenant à la famille des diurnes; il. provient d'une chenille d'un beau vert, arec des anneaux noirs, ponctués de rouge, qu'on rencontre assez sourent sur les ombellifères et principalement sur la carotte et le fenouil. Elle est de la grosseur du petit doigt et répand une odeur pénétrante et désagréable, comme presque toutes les chenilles du gemre papillon proprement dit. L'anneau le plus rapproché de la tète porte une paire de cornes fanves a base commune.

L'insecte parfait a environ quatre pouces d'envergure, le dessus des ailes jame, bordé d'une large bande noire divi- 
sée sur les ailes supérieures par une série de huit points marginaux jaunes et sur les inférieures par une rangée marginale de six lunules de la même couleur, précédées d'une tache bleue; à leur angle interne se trouve une tache rouge surmontée d'un croissant bleu. La partie jaune des deux paires d'ailes est divisée par des veinures noires; le corps est jaune, arec une bande dorsale et les antennes noires.

On le regarde comme un destructeur de carottes à l'état de chenille.

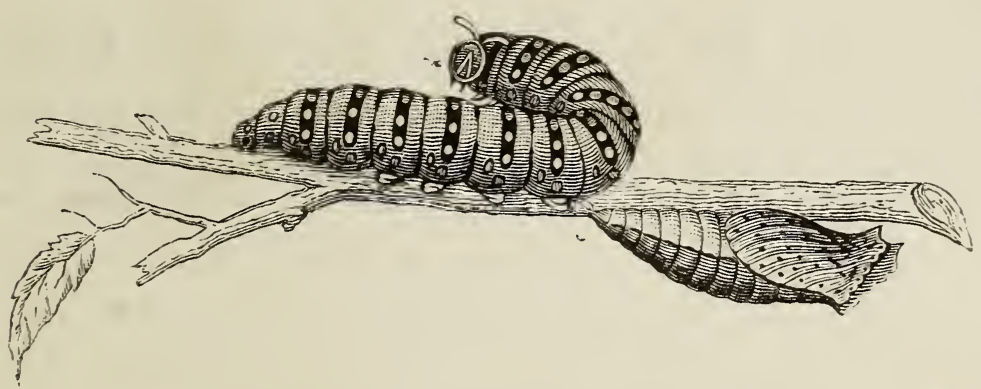

Fig. 7ö. - Chenille et chrvsalide du papillon Nachaon.

Voici la description qu'en donne Buniva dans ses observations et expériences faites pour reconnaitre les genres d'insectes nuisibles dans la contrée basse alpine :

"Papilionis Machaon larva tardigrada, pilis neutiquam hirsuta ; vix ruditer attacta cornua duo flavi coloris exerit illico caput inter ac primum annulum sita, longitudinis duarum circiter linearum, figuræ litteram \% referentis intolerabilemque exhalantia fetorem. Fieri tamen potuit ut alterutro modo noxiam efficaciam explicare possit, animalculum quod quidem tunc definiri poterit, cum microscopio spectata pars affecta pilos, intus et in cute infixos esse' 
vel abesse rleclarantur. Cieterum tumor erysipelaceus ab hoe animalculo plerumque gignitur ubi nuda super integumenta vim suam noxiam evolvit. »

Tous les insectes de ce genre ont une grande taille; le prolongement qui existe ordinairement à leurs ailes postérieures les a fait nommer les Porte-queues.

Limné les appelle les Chevaliers. Leurs chenilles supportent sur le premier anneau du corps deux tentacules rétractiles.

La nourriture de ces chenilles rarie beaucoup suivant les espèces.

On trouve assez communément chez nous le papillon Vachaou, jaune, avec des taches noiles, et sur ses ailes postérieures une rangée de taches ncellées hlenatres.

\section{MITE DES GOLZAS}

On connait assez bien aujourd'hui la famille des acarides dont les insectes en général de petite taille quelquefois même microscopiques qui pullulent prodigieusement et dont les mœurs varient à l'infini. Les uns habitent sous les pierres, les autres se rencontrent dans la collection d'insectes qu'elles ravagent, d'autres dans des substances organiques altérées comme le fromage. Certains virent en parasites sur les animaux, sur les plantes ou sur les graines. I. Focillon a signalé un acarien qui rit dans les tas de graine colza, conservé dans les greniers. Il en a 
donné le croquis que nous reproduisons ici. Cet insecte vit des débris pulvérulents que donnent dans les tas de colza les graines malades. Il en a nourri pendant un mois uniquement avec ces poussières, qu'il avait recueillis isolément.

ll a constaté au contraire que si l'on choisit des graines saines et si l'on place des Mites au milieu d'elles, ces acariens s'en échappent bientôt, ou y périssent s'ils ne le peurent. Aussi M. Focillon est-il porté à penser que la Mite vit dans les colzas de mauvaise qualité, et que le meilleur moyen de nettoyage des graines sera le meilleur aussi pour chasser ces animaux. D'ailleurs la Mite dont il s'agit ne fait, comme on voit, aucun mal au colza, et n'a d'inconvénient que de salir la graine et d'y annoncer la présence de débris malades qui altèrent la qualité du colza.

\section{NIELLE DU BLE}

Dans une des conférences de la Sorbonne que nous avons reproduites dans notre mourement scientifique. I. Pasteur a exposé l'histoire fort intéressante d'un de ces petits êtres dont il avait été si longtemps impossible à la science de surprendre le mode de reproduction.

La Nielle, cette maladie du blé, est produite par la présence dans les grains malades de petits vers microscopiques, les Anguillules.

Ces Anguillules, M. Pasteur nous les montre d'abord en- 
dormies d'un sommeil léthargique dans le grain de blé desséché où elles sont logées, puis retrouvant la vie lorsqu'un peu d'humidité a été rendue au grain, et s'agitant alors, frétillant avec une vivacité régulière.

Ces Anguillules n'ont absolument aucun organe de génération. Il ny y a parmi elles ni mâles ni femelles. Donc ce sont, a-t-on dit, des générations spontanées.

Eh bien, roici à cet égard la vérité. Que, parmi les grains de blé confiés par le laboureur aux sillons, il s'en trouve un qui soit niellé, ce grain s'imprégnera de l'humidité du sol, et tandis que cette humidité apportera la vie aux grains bien portants, les fera germer, se développer, le grain niellé au contraire se pourrira.

L'humidité pénétrera jusqu'aux Anguillules. Alors, se réveillant de leur long sommeil, elles ressusciteront pour ainsi dire, et perforant l'enveloppe pourrie qui les enferme, elles iront chercher les grains bien portants, y pénétreront, et, s'établissant dans l'intervalle des feuilles naissantes, suivront peu à peu tout le mourement de la jeune plante.

Elles arriveront ainsi aux feuilles qui renferment le jeune épi, et finiront par pénétrer dans ces grains encore mous et laiteux. Une fois là, elles deviennent adultes; les unes prennent des organes de génération mâles, d'autres des organes femelles.

Les femelles, fécondées par les mâles, pondent des œufs.

De chacun de ces œufs sort une petite Anguillule. Le père et la mère alors périssent; les débris de leurs corps se résolvent entièrement, et, quand l'épi niellé est mûr, il 
n’y a plus dans le grain que les petiles Inguillules dont nous parlions tout à l'heure, et qui demeurent sans mourement si l'épi est sec. Ces anguillules sont des jeunes qui n'ont pas encore d'organes de génération visibles, qui ne les ont qu'en puissance.

Les cultivateurs, a fail observer dans l'Union agricole d'Eure-et-Loire, notre ami II. le docteur Girouad fils, ne peurent plus dire que c'est l'humidité qui est la cause de la nielle, mais ils sauront que cette maladie du grain de blé est occasionnée par un petit ver qui reste dans la sommeil pendant tout le temps que la graine est sèche et qui retrouve la vie dans les temps humides.

Il nous est maintenant facile de comprendre que le chaulage ou le cuivrage des blés soit sans action sur le non-développement de la maladie.

Il faudrait, pour que ces moyens fussent utiles, qu'ils vinssent à détruire les petits êtres (Anguillules) après avoir traversé l'enveloppe.

Le moyen qui me parait a priori le plus utile et le plus commode, serait de faire chauffer les grains à une température assez élevée pour faire mourir les animalcules.

Il s'agirait aussi de savoir si cette température ne serait pas nuisible à la germination. C'est l'expérience qui nous l'apprendra. 


\section{LLS CHENILLES DANS LES AVOINES}

Des Chenilles, moins redoutables ou inconnues à ce qu’il parait dans la plupart des autres départements de la France, exercent de temps en temps des ravages dans les avoines des répartements d'Eure-et-Loir et du Loiret. Iepuis 175 ذ Jusqu'en 1770 environ, elles désolèrent le pays pendant ringt-cing années consécutives; leurs dégâts depuis n'a raient pas été bien remarquables jusqu'en l'an VII.

Les Chenilles attaquent les avoines vers l'époque où les premières feuilles qui recourrent la tige ont atteint à peu près deux décimètres de hauteur. Chaque. Chenille perce le brin d'aroine près de terre, le plus ordinairement audessous du nœud qui est seul développé alors. Elle y fait un trou par où elle introduit la tête, ronge le rouleau intérieur composé de feuilles et de la tige très-tendres, elle se loge entièrement dans ce fourreau, et rend ses excréments dans l'espace qu'en montant elle laisse vide au-dessous d'elle.

Pendant qu'elle fourrage de la sorte, le brin d'avoine jaunit peu à peu, se dessèche, et, en le tirant par le haut, il se degaine. Si on l'ouvre vers le commencement de juin, on y aperçoit une Chenilic rerte, longue environ d'un centimètre et demi, et grosse assez pour remplir complètement le rouleau formé par les feuilles du brin d'avoine. Quelques brins ainsi james ne contiennent plus la Che- 
nille; alors, il y a un trou à un décimètre au-dessus du premier, par où l'insecte est sarti.

Dans les années où les Chenilles sont très-multipliées, si on va le soir dans les champs, ou entend le bruit singulier qu'elles font en rongeant.

On n’a point calculé quelle est la voracité de ces insectes; mais le peu d'avoine dont on put profiter en l'an VIII ne mérite point d'être appelé récolte. On n'en voyait que des brins çà et là, qui, ne valant pas la peine du fauchage, furent presque généralement abandonnés aux moutons.

Suivant un mémoire de M. des Essarts, rapporté par Tessier (d'Angerville), quand la tige dont les Chenilles se sont nourries est tombée, elles attaquent peu les feuilles; elles s'enfoncent en terre après la mi-juin ou se placent sous l'herbe des tiges qui restent; là, elles se métamorphosent en petites chrysalides d'un brun foncé pour produire, vers la fin de juillet, le papillon destiné à fournir une autre génération ${ }^{1}$.

Les cultivateurs disent que dans l'année où il y a beancoup de Chenilles, on remarque, pendant la moisson, une grande quantité de papillons blanchâtres.

Le papillon qui, suivant le même mémoire, produit la Chenille, est très-petit, giris argenté ou bleu cendré; le mâle porte sur les ailes des taches noires presque imperceptibles; on le voit, depuis la fin de juillet jusqu’à la mi-septembre, voltiger dans les champs.

Il dépose ses oufs principalement sur le chaume des froments qu'on vient de couper et sur les branches des

1 Voir le mémoire de Wichel Fromage, 1802. 
plantes qui bordent les champs et les chemins, et qui, par leur dureté, sont à l'abri de la dent du mouton : telles que la chicorée sauvage, le chardon étoilé, le chardon roland, l'arrête-bœuí; les œufs y sont attachés avec une forte glu.

Un seul papillon pond plus de trois cents oufs; ils ne paraissent à la vue que comme de fortes taches noires que font les mouches. On les distingue bien à une loupe. surtout an mois de mai; on les voit éclore vers la fin de ce mois.

L'ın autre côté, quelques habitants du paỳs ont, dit-on, remarqué de petits oufs rouges dans les tuỵaux des chanmes ảu froment; ils y grouillent au-dessus du nœud ourert à l'air, et l'on pense que c'est là le comvain on mo réunion d'œufs de Chenilles.

On ne voit des Chenilles que dans les aroines qui succèdent aux blès; celles qui sont faites après les seigles en paraissent exemptes.

Il n'y en point non plus, selon Tessier, dans les champs d'avoines qui succèdent à un défrichement de sainfoin, de lızerne ou de trèfle.

Rarement les orges en sont attaquées; cependant, on dit qu'en l'an VIll on a vu du blé de mars et de l'orge mangés par les Chenilles, à Chalou-Moulineux, près d'Étampes. I)ans les pays secs, les Chenilles sont plus communes. I'AWlis à Chartres et à Janville, de Chartres à Orléans, de Janville à Valesherbes, elles ont tout ravagé en l'an VII et en I'an VIII. Aux environs de Dourdan et de Rambouillet, on n'en a jamais vu, sans doute parce qu'il y a des bois et plus d'humidité.

Les terres bien foulées, bien battues, arant ou après les 
semailles des avoines, ont moins de Chenilles, puisqu'il n'y en n'a pas autant quand les chaumes de blé ont èté trépignés par les troupeaux, et qu'on en voit moins aussi aux aboutissants des pièces où les laboureurs des deux champs roisins font tourner les chevaux et la charrue.

Les vignerons d'Orléans, dit Tessier, achètent sur pied le chaume des cantons voisins de la ville; ils l'arrachent et l'emportent pour faire de la litière it leurs vaches, et dans ces cantons on ne voit point de Chenilles. 11 en est de mème si au lieu de labourer simplement les chaumes en mars, on les laboure d'abord en novembre. Il en est encore de mônie si on les laboure par un temps humide.

si la pluie est réunie au trépignement, les effets son! doublement arantageux. Un habitant des environs d'Ecrouailles passa vers la fin d'avril avec six à sept chevaux sur un champ d'avoine, dans un moment où la terre était fortement trempée. Attaqué pour ce délit par le propriétaire, il s'obligea de payer, à l'époque de la moisson, le dégât qu'il avait causé. Il arriva, au contraire, que la partie du champ où araient passé les chevaux eut son avoinc intacte, tandis que les Chenilles avaient ravagé le reste.

On doit aussi conclure de ce fait, que les Chenilles me parcourent que de très-petits espaces, si elles passent d'un brin d'avoine à un autre.

Tant que ces insectes sont à l'état de Chenilles, les pluies abondantes en font sûrement périr une grande quantité, soit qu'elles rampent sur terre, soit qu'elles aient déjà pénétré dans les fourreaux des avoines; elles ont sans doute á redouter les animaux conmus pour faire leur proie des insectes de cette espèce. 
Les oiseaux à long bec, la fourmi, les araignées, les mouches ichneumones.

On demandera, pourquoi les Chenilles attaquent plutôt les aroines que les autres plantes. C'est que : $1^{0}$ chaque plante étant exposée à être mangée par un insecte particulier, cette Chenille est l'insecte qui préfère l'aroine romme aliment; $2^{\circ}$ à l'époque où le papillon produit fait sa ponte, il ne troure que les chaumes de froment où il puisse placer ses œufs, les terres en jachères et destinées au froment pour l'automne suirant étant nues alors; $5^{\circ}$ en supposant que, dans les environs, il trouvât des plantes propres à recevoir les œufs, lorsqu'ils éclosent, la tige du blé est trop dure pour que les Chenilles la percent.

Il parait que le terrain sec et sablomeux est farorable aux Chenilles, ainsi que la chaleur et la sécheresse. Ces insectes prospèrent d'autant mieux dans ces conditions qu'on laisse aux papillons de longs chaumes pour la ponte et qu'on ne détruit pas les aufs.

Des circonstances contraires en font périr une quantité proportionnée au nombre et à la force des contre-temps. "

\section{MOYENS DE DESTRUCTION}

La chrysalide existe dans les grains vers la fin de juin, et il est érident qu'on ne peut tenter alors aucum moyen de l'atteindre, à moins qu'on n'ait à espérer aucune récolte d'aroine.

Les papillons ne peuvent, selon toute apparence, être 
attaqués que par l'humidité vers la fin de juin on de juillet, mais souvent l'eau produit alors des dommages qui empêchent de la désirer.

Restent done a rombattre les Chenilles et les oufs. La Chenille étant dans les fomreanx des avoines, la snic en poudre et d'autres moyens analngues, qui réussissent coutre d'autres insectes, n'atteindraient pas ceux-ci et seraient des procédés minutieux. Mais quand il y a peu deChenilles, on pourrait les detruire en parcourant un champ s illon par sillon. Quand l'avoine est hante d'un à deux décimètres, on distingue aisément les brins qui ont jammi, on saisi avec la main le haut des feuilles de la tige attaquée. Le plus sourent la Chenille est dedans.

L.e hrin d'avoine ainsi déganné se déposerait dans un panier, qu'on porterait an bras et qu'on viderait an bout du chanip dans un sac, jusqu'i ce qu'on en eùt un tas auquel on mettrait le feu. II n’en échapperait que très-peu de cette manière. On ôte bien les chardons et autres plantes une à unc. Ce procédé pour les Chenilles n’est ni plus ient ni p!us dispendieux; il pourrait être exécuté par des enfants, et, si on l'employait aussitôt que l'avoine est attaquée, pent-être le pied offensé pousserait-il une nouvelle lige dont l’épi parviendıait à maturité.

Mais il faut surtout attaquer les oufs. Il y a deux manières, en les supposant dans les chaumes des blés. Le premier moyen est de ne pas lem laisser cette retraite. Pour cela on pent, yuand il s'agit d'une pièce d'un pen d'étendue, arracher le blé au lieu de le couper ; mais il fau que la terre soit un peu humectẻe, autrement les tiges se casseraient. La récolte par arrachement se fait aussi quel- 
quefois dans la Beauce, afin que la terre qui s'enlève avec la racine décrasse, lors du battage, les grains affectès du charbon ou de la carie. On arrache aussi le blé dans les endroits où les brins sont tombés, déracinés en partie; les scier alors serait plus difficile; on peut aussi couper les blés très-bas, ce qui laisse peu de place eux oufs et les expose à l'humidité de la terre.

l.e second moyen est de détruire les øufs dans les chaumes. Il faut, pour cela :

$1^{0}$ Nettre les troupeaux dans les chaumes des blés, peı de temps après la moisson, et même les y faire parquer aussi longtemps que la saison le permetțra;

$2^{\circ}$ Renverser et rompre les chaumes par la herse et lo rouleau;

$3^{0}$ Les labourer vers la fin de novembre ou même avant ; $4^{\circ}$ Labourer profondément;

כั Prendre autant qu'on le pourra, pour ces opérations, In temps humide ou pluvieux;

$6^{\circ}$ Couper très-bas ou arracher les chaumes; on pourrait en faire de la litière et en mettre le fumier dans une fosse à part, afin de ne l'employer sur les terres qu'une année après, de crainte que les œufs n'eussent pas èté détruits par İa première fermentation. Tessier a fait arracher en 1787 le chaume d'une pièce de terre, et il a fait couper le reste : “Les résultats de cette comparaison lui ont prouvé qu’il valait mieux l'arracher. "

Il semble prudent aussi de se garder de couvrir des bàtiments avec ces chaumes, parce que, peut-être, les Che- 
nilles n'en écloraient pas moins, et qu'elles pourraient se développer, si elles tombaient dans des circonstances favorables.

Tessier, à qui la Reauce doit tant d'études sur les maladies des céréales comme sur celles des bestiaux, Tessier dit qu'il serait utile aussi que les fermiers fissent arracher, brûler ou couper en hiver les grosses plantes qui croissent le long des chemins et qui conservent des œufs propres a perpétuer les Chenilles dans les champs roisins.

$7^{\circ}$ Enfin, ne pas mettre le feu aux chaumes de blésur pied par un temps sec et dans le sens dı vent. 



\section{TABLE IDES MATILRES}

\section{BLÉ}

diguillonier. . . . . . . . . . . . . . . . . . 109

Alucite . . . . . . . . . . . . . 175

Charançon................ . 1 à 50

Cèphe pygmée.. . . . . . . . . . . . . . 156

Cécydomie.. . . . . . . . . . . . . 145

Chlorops linéolé. . . . . . . . . . . . . . . 152

Chlorops de Goureau.. . . . . . . . . . . . . 162

Chrysomèle. . . . . . . . . . . . . . . . . . . . . . . . 89

Hanneton (larve) . . . . . . . . . . . . . . . . . . 62

Jasse dérastateur. . . . . . . . . . . . . . . . . . 127

Yoctuelle. . . . . . . . . . . . . . . 224

Nielle.. . . . . . . . . . . . . . . 2 259

Ochsenheimerie. . . . . . . . . . . . . 245

Puceron.. . . . . . . . . . . . . . . . 118

Sauterelle.. . . . . . . . . . . . 175

Teigne (fausse) . . . . . . . . . . . . . 205

Taupin. . . . . . . . . . . . . 74

Ver blanc. . . . . . . . . . . . . 218

Zabre bossu . . . . . . . . . . . . . . . . . . . 85 


\section{ORGE}

Chlorops. . . . . . . . . . . . . 159

Criocėre. . . . . . . . . . . . . 9 91

Jasse dévastateur. . . . . . . . . . . . . . . 127

Taupin. . . . . . . . . . . . 74

\section{SEIGLE}

Cèphe prgmée. . . . . . . . . . . . . . . . 136

Chlorops. . . . . . . . . . . . . . 165

Taupin. . . . . . . . . . . . . 74 à 78

\section{SARRAZIN}

Chrusomèle. . . . . . . . . . . . . . . 89

\section{AVOINE}

Chenille.. . . . . . . . . . . . 262

Jasse dévastateur. . . . . . . . . . . . . . . 127

\section{COLZA}

Altise. . . . . . . . . . . . . 96

Charançon. . . . . . . . . . . . 4 40

Yite.. . . . . . . . . . . . . . . . . . . . 259

Puceron.. . . . . . . . . . . . . 111

Teigne. . . . . . . . . . . . . . 211

\section{TRÈ F LE}

Bombyx . . . . . . . . . . . . . . 251

Charancon.. . . . . . . . . . . . 30

Cnccinelle. . . . . . . . . . . . . 107 


\section{SAINFOIN}

P'uceron.... . . . . . . . . . 125

\section{LUZERNE}

Agronyze. . . . . . . . . . . . . . 165

Bombyx.. . . . . . . . . . . . . . . . 20,

Coccinelle. . . . . . . . . . . . . . 107

Colapsis.. . . . . . . . . . . . . . . $10^{\prime}$

llanneton (rer blanc). . . . . . . . . . . . . . 6ะ

Noctuelle. . . . . . . . . . . . . . . 249

I'syché Stomoxelle. . . . . . . . . . . . . . 2.1

Taupe-grillon. . . . . . . . . . . . . . . . 188

\section{BET TERA VE}

Casside. . . . . . . . . . . . . . 102

Hylémyie. . . . . . . . . . . . . . . 168

Mouche. . . . . . . . . . . . . 168

Nitidule.. . . . . . . . . . . . . 116

Noctuelle. . . . . . . . . . . . . . 227

Silphe. . . . . . . . . . . . . . 113

CHOUX

Altise.. . . . . . . . . . . . . . . . . . . 98

Piéride... . . . . . . . . . . . . 252

N A VETS

Charançon.. . . . . . . . . . . . . is

CAROTTE

Papillon Machaon (chenille!.. . . . . . . . . . . 257 


\section{POIS}

Bruche. . . . . . . . . . . . . . ј j

\section{LENTILLE}

Bruche. . . . . . . . . . . . . . . 55

\section{VESCE}

Bruche. . . . . . . . . . . . . . . 55

Coccinelle. . . . . . . . . . . . . . 107 


\section{ERRATA}

Page 37, tig. 10: pione lise pionus

- 37, ligne 15: Nẻes d'Essembeck lise: Nees d'Essenbeck

PARIS, - IMP. SINON HACON ET COMP. RUE DERFLATH, I. 




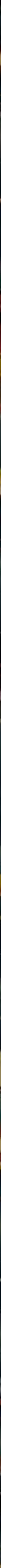




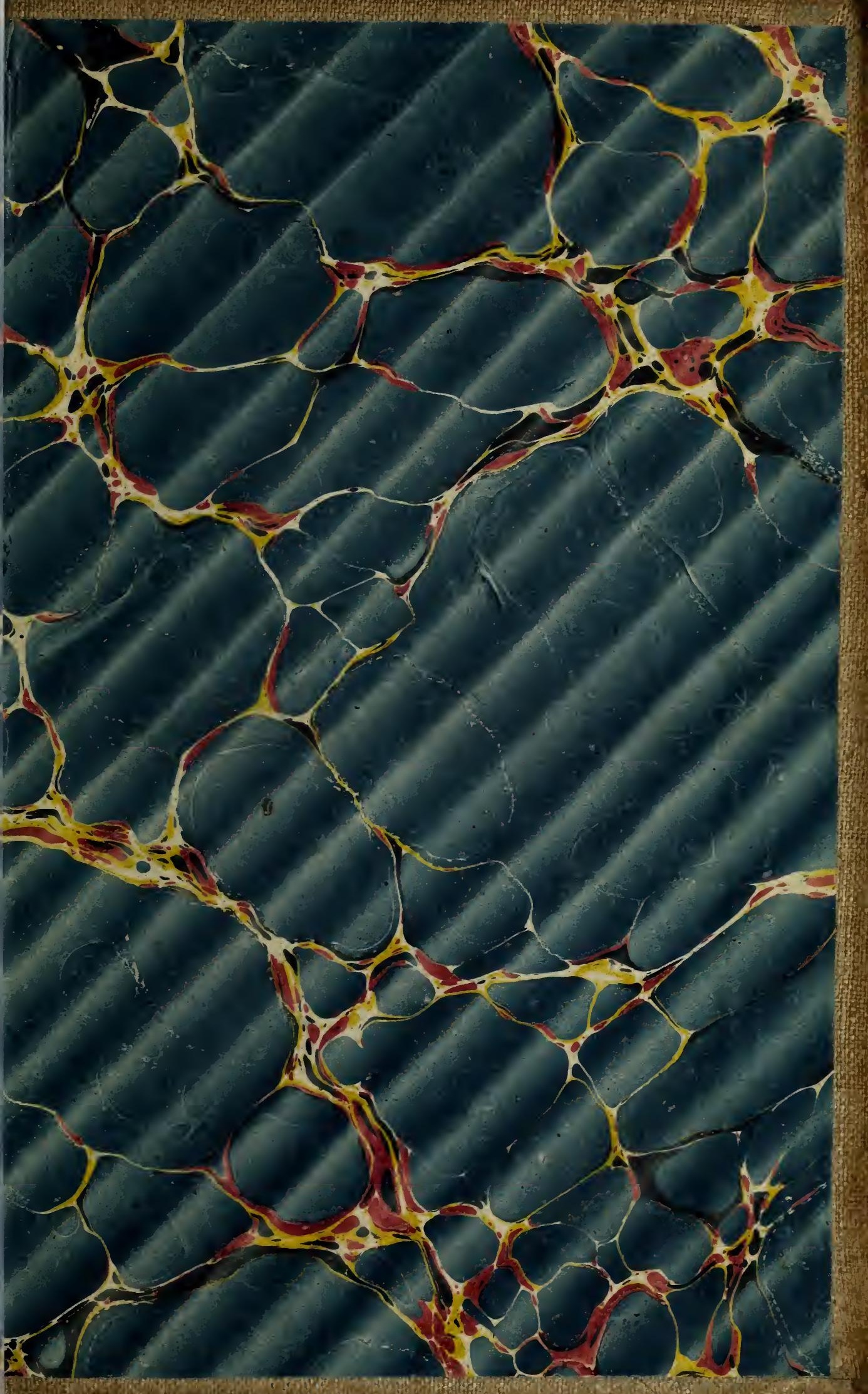




\section{LIBRARY OF CONGRESS}

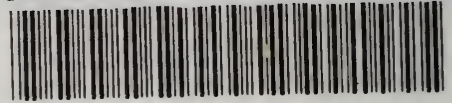

\section{$0000884186 \mathrm{~A}$}

